Manuscript Number: APEN-D-19-01207R1

Title: Assessment of construction cost reduction of nearly zero energy dwellings in a life cycle perspective

Article Type: VSI:ICAE2018

Keywords: nearly zero energy buildings; building energy technologies; construction cost; life cycle cost

Corresponding Author: Mr. Michele Zinzi, Ph.D.

Corresponding Author's Institution:

First Author: Michele Zinzi, Ph.D.

Order of Authors: Michele Zinzi, Ph.D.; Benedetta Mattoni

Manuscript Region of Origin:

Abstract: Concerning Nearly Zero Energy Buildings, it is important to guarantee energy efficiency, thermal comfort and indoor environmental quality, while keeping construction and operational costs low. In this framework, this paper explores the efficacy of applying different scenarios, for reducing construction costs of new nearly zero energy multi-family houses in a life cycle perspective. Conversely to the standard cost-optimal approach, a real Italian case study building was chosen. Alternative and unconventional combinations of solutions for envelope and technical systems were adopted. Calculations were performed in two Italian cities (Rome and Turin). Three types of analysis were developed thermal comfort, energy performance and financial calculation. Results of the thermal analysis show that the installation of active cooling to prevent summer overheating can be avoided by applying low-cost passive strategies. All the proposed low-cost scenarios (4 alternative scenarios in Rome and 5 in Turin) reached the highest grade of energy performance, with a reduction of the non-renewable primary energy consumption up to 46\% compared to the base case in Rome and 18\% in Turin. From the economic perspective, all the scenarios in the two climate zones allow both reductions in the construction costs, up to $26 \%$ in Rome and 15\% in Turin, and a Net Present Value after 50 years up to $163 € / \mathrm{m} 2$ in Rome and $158 € / \mathrm{m} 2$ in Turin. 
Dear Prof. Yan,

Please find attached the revised version of the paper: Assessment of construction cost reduction of Italian nearly zero energy buildings in a life cycle perspective, whose first title was changed, according to editors' suggestion.

We upgraded the paper following the comments provided by the reviewers and the editors, as inferred from the attached files. We also included a flowchart of the methodology to be used as graphical abstract.

We hope that the paper is suitable for publication at this stage and we look forward your answer to step forward the review process according to the Editors evaluation

Best regards,

Michele Zinzi

ENEA-DTE-SEN

F51 SP104

Via Anguillarese 301, 00123 Rome (IT)

Tel. +390630486256

Skype: michele.zinzi 
- Identification of solution sets to reduce construction costs in nearly zero energy houses

- $15 \%$ maximum reduction of energy related construction cost in Continental Italy

- $26 \%$ maximum reduction of energy related construction cost in Mediterranean Italy

- Net present values up to $163 € / \mathrm{m}^{2}$ after 50 years building lifetime 


\section{Detailed Response to Reviewers}

\section{Reviewer \#1:}

Lifecycle performance of nzEB is important for promoting its practical applications which will lead to substantial benefits of energy conservation and environmental protections. In the study, a comparative study has been conducted to explore the efficacy of combining alternative and unconventional solution sets for reducing construction costs of nZEBs in a life cycle perspective. A real case building was standardized and adapted to the minimum nzEB requirements of the two reference climatic zones. Three types of performance have been considered and systematically analyzed by the authors in terms of thermal comfort, energy performance and financial calculation. The study results showed significant performance differences as alternative solutions were implemented. They are helpful for the future nzEB planning, design and system operation. The study is well organized it is of significant scientific contributions. To further improve the quality of the study, the following minor revisions are provided for the consideration of the authors.

First, energy performance may also significantly influence the financial calculation. The impacts and dependence between these two performance may need some elaboration.

We are not sure we got the point raised by the reviewer, apologies. However we try to explain the framework we moved, for what concerns the NZEB fulfillment and the associated costs.

The Italian NZEB is not based on energy performances, but on the compliance with prescriptive requirements (e.g. U-values of envelope, heating system efficiency, share of renewable energies etc.); this implies that NZEB configurations for a specific building might have quite significantly different energy performances. In this sense the raised question is difficult to be addressed. Moreover, in our case the main target it minimize the costs once the NZEB requirements are respected and the relation between cost and performance is not crucial. In any case these aspects are also included in the revised text.

Second, energy performance could change in building lifecycle due to system performance degradation and building aging. Have the author considered the impacts of system degradation on the building energy use? Or, the authors assumed the well maintenance could keep the system efficiency at a good/unchanged level.

This is an important issue e the suggested reference are well included in the text, however we followed the current procedures in Italy (and in Europe), where aging of energy related product in not taken into account. To be noted that also the while we included the cost for a proper and timely maintenance, which reduce risks of energy depauperation with aging.

Third, the following studies could be considered to be included in the introduction part since they are closely related to the study. "A robust design of nearly zero energy building systems considering performance degradation and maintenance"" Uncertainty-based life-cycle analysis of near-zero energy buildings for performance improvements".

Very relevant, thanks. They are included now.

Fourth, the authors could present some limitations of the study in their future work stated in the conclusion part.

Done

Last, Figure-7 and -8 should use the same $x$-scale. Done 


\section{Reviewer \#2:}

Revision of APEN-D-19-01207, titled "Identification and assessment of solutions to reduce construction cost of Italian nearly zero energy building in a life cycle perspective", submitted for consideration on Applied Energy Journal, Issue VSI : ICAE 2018 .

The papers concern strategies for reducing initial costs of zero energy buildings, with reference to two Italian climates, and thus the northern climate of Turin (near Alpes) and the central Italian climate of Rome quite close to the Italian coastline). The paper is fully within aims and scope of the Journal. The written English is very readable, the contents are worthy of investigations and the outcomes are relevant. According to me, the paper is almost ready for publication and I recommend MINOR REVISION. Indeed, I have to evidence only minor possible improvements. Finally, my opinion is quite favourable.

* Highlights are not provided.

Highlights were included

* Some elements of nomenclature require units, and thus COP (Wth/Wel), ACH (h1), $\operatorname{EP}(\mathrm{kWh} / \mathrm{m} 2 \mathrm{y})$ and so on. Please, check it.

Done

* In the abstract, when you cite cost savings of $163 € / \mathrm{m} 2$ in Rome and $158 € / \mathrm{m} 2$ in Turin, specify also that these savings are the $\mathrm{X} \%$ and $\mathrm{Y} \%$ of the construction costs of the base case. In this way, you can show, immediately, also the percentage saving.

In the abstract it was specified that these two values are not costs savings by they represent the NPV over the 50 years life time of the building. According to this they were not expressed in terms of percentage difference.

* I suggest you to avoid multiple citations, and thus [8] [9] [10] in the same sentence. Please, describe each paper singularly; this is more useful for the reader. About this sentence, I agree strongly about the fact that too high insulation can worsening the summer comfort performance of the building! Multiple citations were avoided.

* Avoid multiple citations also for references [12][13][14] and for [18] [19] [20].

Multiple citations were avoided.

* First line page 5 of the pdf. Please, after methodology, ad a comma ",". In general, revise the punctuation even if the written English is readable and pleasant, a further re-reading can provide a further improvement.

Done

* Split multiple citations also at page 5 ([27][28][29][30][31]).

Done

* Line 48, page 5. It is not clear what happens starting from 01/01/2018 (in Europe, the key dates are 01/01/2019 and 01/01/2021).

Done

* The section 2, Objective and method, provides a very good summary of contents. If possible, you can use the same criterion for a flow chart, that could be the graphical abstract of the paper.

Done

* Page 8 (two times) and rest of paper. Please, correct $\mathrm{KW}$ in kW (also line 20 of page 9).

Done 
* Page 8, please, replace ${ }^{\circ}$ with ${ }^{\circ} \mathrm{C}$. These are temperatures' values. Please, be careful in correcting these typos.

Done

* Page 8, check the sentence "They were selected being large cities...". Please, revise.

Done

* It is not clear why MVHR was installed in Turin and not in Rome.

It was clarified in section 3.2 .2

* Section 4: several strategies and alternatives concerning building envelope and active energy systems are proposed. I suggest a Table for summarizing it. It could be very helpful for the readers. For example, move here Tables 4 and 5 . Tables 4 and 5 were moved from section 5 to section 4.

* Page 12, line 42. Please, specify that the relevant standard is the EN 15251. Done

* Page 12, line 52, consider to replace "handicapped" with "persons with disabilities".

Done

* Page 13. It is not clear for which scopes you have used TRNSYS (transient energy simulation) and for which scopes you have used EDILCLIMA (steady state energy simulation). Please, clarify better.

This was clarified better in the paper.

* In Tables 4 and 5, add U values of building components and peak power of PV. It could be very helpful for the readers.

Done

* Results are very interesting, mainly for what concerns the discomfort in hyper insulated buildings and the improvements due to night ventilation and shadings? Please, again, specify properly when you have used TRNSYS and when EDILCLIMA. Done

* Line 52 of page 16 and Table 9. Unit of Natural gas should be $€ / m 3$ (not $€ / \mathrm{Smc})$. (mettere $\mathrm{Sm}^{3}$ )

Done

* Line 15 of page 19 and caption of figure 5. Add a blank space before "for heating" .

Done

* Figures 7 and 8, very clear and well-done. What happens around year 15? (an accentuated cash flow saving occur). I have understood that this is due to differences compared to the base case, but, please, specify better.

It was clarified better in section 6.3

* Finally, why you have calculated NPV and not the global costs, as required by Delegated regulation 244/2012?

We are aware of the mentioned EU document, however we opted for NPV for a several reason: 1) NPV was used for LCC and LCA analysis in H2020 CoNZEBs Project, which provide the framework for the present study; 2) NPV still remain one of the most used financial indicator for energy related issues in buildings, 2) since the objective of the study is the reduction of construction costs hence savings; we chose a LCC indicator focused on gains (coming from savings) instead of costs. If considered necessary, however, the results might also presented in terms of total costs.

As said, my opinion is favorable. Indeed, I have underlined several things, but these are minor advices. The paper is exhaustive, comprehensive, and it is a 
relevant presentation of nZEB effectiveness under the point of view of costs. MINOR REVISION.

\section{Editors:}

In addition to the comments from the above reviewers, please also pay attention to some of the following aspects while improving the quality of your manuscript:

- The relevance to Applied Energy should be enhanced with the considerations of scope and readership of the Journal.

The relevance to the Journal is made more explicit in Chapter 2 objective and method

- A proof reading by a native English speaker should be conducted to improve both language and organization quality.

The text was reviewed and edited by a native English speaker

Please avoid using abbreviations in the TITLE, HIGHLIGHTS, ABSTRACT and CONCLUSION if possible.

Abbreviations were avoided.

Please also avoid "lump sum references", such as $ᄀ$ XXXXX [1-5]; all references should be cited with detailed and specific description. In the references, all authors should be included, avoiding using "et. al.";

Lump sum references were avoided and all authors have been included.

Please use 'Highlights' in the file name and include 3 to 5 bullet points (maximum 85 characters, including spaces, per bullet point).

Identification of solution sets to reduce construction costs in nearly zero energy houses

15\% maximum reduction of energy related construction cost in Continental Italy 26\% maximum reduction of energy related construction cost in Mediterranean Italy Net present values up to $163 € / \mathrm{m}^{2}$ after 50 years building lifetime

TITLE: It normally consists of about 12-15 keywords which shall not be too general or too narrow.

It was changed in : Assessment of construction cost reduction of nearly zero energy dwellings in a life cycle perspective

ABSTRACT: It should be about 150-250 words with concise text in a single paragraph. Answer the questions: What problem did you study and why is it important? What methods did you use? What were your main results? And what conclusions can you draw from your results? Please make your abstract with more specific and quantitative results while it suits broader audiences. Abstract stands alone, no references, figures, tables or equations are cited. The abstract was changed according to the suggestions

CAPTIONS: Captions for figures and tables should be presented with more specific description rather than a general sentence like "Results of the experiments ...", "A studied system...."

Captions were described in a more detailed way.

- The originality of the paper needs to be further clarified. It is of importance to have sufficient results to justify the novelty of a high quality journal paper.

The originality was made more explicit in chapter 2 objective and method, stressing the novelty elements introduced by our study

- An updated and complete literature review should be conducted to present the 
state-of-the-art and knowledge gaps of the research with strong relevance to the topic of the paper.

The literature review was extended and the gaps of the research were highlighted

- The results should be further elaborated to show how they could be used for the real applications. Modeling results should be validated by experiments. We would point out that this is not a merely calculation study. In fact, the data we started from for the analysis come from a real building, which is built in Italy, whose energy performances are proved by the Energy Performance Certificate and costs by the capitolato, made available by the building designer and owner. Of course experiments, as we normally intend, are not possible here, since this would have meant to rebuild the same building in different localities and with several different technologies.

- The paper should be written from the international perspective rather than focusing on the issues of one country.

In chapter two we also state that the implemented methodology is of general validity but the application is, in this case, tailored to a specific country (namely Italy), because the multiple boundary conditions (climate, legislation, costs, building technologies) make almost impossible to approach the problem in a wider geographical framework. 
Assessment of construction cost reduction of Italian-nearly zero energy dwellingsbutildings in a life cycle perspective Identifieation and assessment of solutions to reduce construetion cost of Italian nearly zero energy building in a life cycle perspective ${ }^{1}$

$$
\begin{gathered}
\text { Michele Zinzi }^{\text {a*}} \text {, Benedetta Mattoni } \\
\text { ab-ENEA, Via Anguillarese 301, } 00123 \text { Rome, Italy }
\end{gathered}
$$

b-SAPIENZA University of Rome, Department of Astronautical, Electrical and Energy Engineering, Via Eudossiana 18-00184 Rome, Italy

\section{Nomenclature and abbreviations}

EPBD: Energy Performance of Buildings Directive

NZEB: Nearly Zero Energy Building

EEM: $\quad$ Energy Efficiency Measures

MFH: Multi-Family Houses

ETICS: External Thermal Insulation Composite Systems

XPS: $\quad$ Extruded polystyrene

EPS: $\quad$ Expanded polystyrene

DHW: Domestic How Water

| COP: Coefficient of Performance $\left(\mathrm{W}_{\mathrm{th}} / \mathrm{W}_{\mathrm{e} 1}\right)$

PV: $\quad$ Photovoltaic

MVHR: Mechanical Ventilation with Heat Recovery

MEV: Mechanical Extract Ventilation

ACH: Air change per hour $\left(\mathrm{h}^{-1}\right)$

NPV: $\quad$ Net Present Value $\underline{\left(€ / \mathrm{m}^{2}\right)}$

EP: Indicator of Primary Energy consumption Indicator $\left(\mathrm{kWh} / \mathrm{m}^{2}\right.$ year $)$

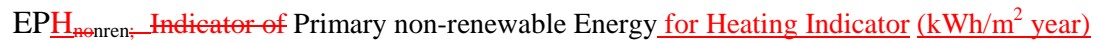

$\underline{E P W}_{\text {nen; }}$ Primary non-renewable Energy for DHW Indicator $\left(\mathrm{kWh} / \mathrm{m}^{2}\right.$ year)

$\underline{E P V}_{\text {nren; }} \underline{\text { Primary non-renewable Energy for Ventilation Indicator }\left(\mathrm{kWh} / \mathrm{m}^{2} \text { year) }\right.}$

EPgl ${ }_{\text {menrengl }}$ Indicator of Global Primary non-renewable Energy $\left(\mathrm{kWh} / \mathrm{m}^{2}\right.$ year $)$

\section{Abstract}

Concerning Nearly Zero Energy Buildings, the most important issue is to guarantee it is important to guarantee energy efficiency, thermal comfort for users-and indoor environmental quality, while keeping low construction and operational costs low. The cost optimality target, defined in the EPBD Energy Performance of Buildings Directive as "the energy performance level which leads to the lowest cost during the estimated economic lifecycle", is therefore a a key issue for public and private housing sectors, which the economic aspect is quite relevant for. In this framework, this paper explores the efficacy of applyingcombining alternative and unconventionaldifferent solution setsscenarios, -for reducing construction costs of new nearly zero energy multi-family houses in a life cycle perspective. Conversely to the standard cost-optimal approach, - - real Italian case study building,-located in the centre of Italy, was chosen. Alternative and unconventional combinations of solutions for envelope and technical systems were adopted. -Calculations were performed in two Italian cities (Rome and Turin). Three types of analysis were developed $\div$-thermal comfort, energy performance and financial calculation.-Results of the thermal analysis show that the installation of active cooling to prevent summer overheating can be avoided by applying low-cost passive strategies. All the proposed low-cost scenarios (4 alternative scenarios in Rome and 5 in Turin) reached the

\footnotetext{
${ }^{1}$ The short version of the paper was presented at ICAE2018, Aug 22-25, Honk Kong, China. This paper is a substantial extension of the short version of the conference paper.
}

Formatted: Italian (Italy)

Formatted: Subscript

Formatted: Subscript

Formatted: Superscript

Formatted: Superscript

Formatted: Font: $10 \mathrm{pt}$, Not Superscript/ Subscript 
highest grade of energy performance, with a reduction of the non-renewable primary energy consumption up to $46 \%$ compared to the base case in Rome and $18 \%$ in Turin. From the economic perspective, all the scenarios in the two climate zones allow both reductions in the construction costs, up to $26 \%$ in Rome and $15 \%$ in Turin, and savings over the 50 year life time of the buildinga Net Present Value after 50 years; up to $163 € / \mathrm{m}^{2}$ in Rome and $158 € / \mathrm{m}^{2}$ in Turin.

Keywords: nearly zero energy buildings, building energy technologies, construction cost, life cycle cost

\section{Introduction}

After the target of Horizon 2020 set in 2007 The target reduction of primary energy and emissions by buildings and consequent increase of renewable energy production set in the Horizon 2020 Program [1], was updated in the new 2030 Climate \& Energy framework. [1], regarding the reduction of buildings primary energy and emissions and the increase of renewable energy production, in the 2030 Climate \& Energy framework new goals have been introduced $[2][2]$. According to this package, the aims are to reduce the greenhouse gas emissions by $40 \%$ from 1990 levels, to increase the production from renewable energy up to $27 \%$ and to improve energy efficiency of buildings up to $27 \%$. In a long-term perspective, in 2050 gas emissions are expected to be reduced by at least $80 \%$ compared to 1990 levels [3][3]. In this framework, building sector plays a relevant role, accounting for the largest part of energy consumption and gas emissions at local and global level and representing, on the other side, a huge potential for energy savings $\{1\}[4\}[1][4]$. European Standard defined the requirements for achieving high savings in buildings: according to the Energy performance of Buildings Directive (EPBD) Directive, requires that new public buildings from 01/01/2019 and new private constructions from 01/01/2021, have to comply with Nearly zero energy buildings (NZEB) targets $[5][5]$. The definition on NZEBs provided in the Directive is quite general and is not technical. This responsibility: the characterization of NZEBs is delegated to each European Member State which that has to define what an NZEB represents at national level and to set the specific targets for buildings to be in compliance with European description. What is common to all the Member states is that NZEBs do have to certify a "very high energy performance", covering "a very significant extent" of building energy needs with renewable energy sources, partially produced on site or nearby the building [5][5]. Being the common guidelines provided by the European Standards so general, there are still ambiguities in the implementation phase of NZEBs in European member states due to the different interpretations of the definition.

Furthermore, misalignments among countries are emphasized due to the climatic, social, technological and economic differences_Ł6][6]. According to this, it is difficult to propose a minimum common threshold for energy efficiency for all the Member States. Different climatic conditions between Southern and Northern European countries lead to the highest differences in the definition of NZEB parameters $\therefore$ The former can easily meet low energy needs thresholds for heating compared to the latter_ $\{7\}[7]_{-} \div$but ${ }_{2}-$ on the other side, they cannot comply with the same limits for cooling demand due to high outdoor ambient temperature, high solar radiation and heat island effect in cities. Several studies have been developed in literature about potential overheating in southern and north-western countries due to the increase of thermal insulation, which can lead to an increase in consumption for air-conditioning, [8][8][8] [8][9] [10], -but it was also stated that passive strategies for reducing cooling needs can be successfully applied to overcome this problem. [9], $97[9]$, like solar shading and ventilation, [10], 10][10]. As an example, in [11][11]_an analysis on three different NZEB building types (single-family house, apartment block and office building) in two different Italian climatic locations (Milan and Palermo) was developed to assess the imbalance of energy needs for heating and cooling when $\mathrm{U}$-values of the building envelope are gradually reduced. It was found that, by reducing transmittance values, cooling need increases up to 5-6\% in all the analysed cases but it can be effectively reduced by using high performing shading devices.

Formatted: Font: (Default) Times New Roman, Font color: Auto

Formatted: Font: (Default) Times New Roman, Font color: Auto

Formatted: Font: (Default) Times New Roman, Font color: Auto

Formatted: Not Highlight

Formatted: Not Highlight

Formatted: Not Highlight

Formatted: Not Highlight

Formatted: Not Highlight

Formatted: Not Highlight

Formatted: Not Highlight

Formatted: Font: (Default) Times New Roman

Formatted: Font: (Default) Times New Roman

Formatted: Not Highlight

Formatted: Not Highlight 
Basing on these assumptions, NZEB should provide specific heating-cooling balance for each climatic condition [12][12][12], taking also into account-the thermal eomfortcomfort [13][13][13], and the-indoor environmental quality and building sustainability $[16],[14][14]_{\text {d }}$ during the entire building lifetimef12] 13$][14\}$. Concerning the analysis of the building in a life cycle perspective, high relevance was also attributed in $[15][15][15]$ and $[17][17],[16]$ to the effect of degradation on NZEBs performance in terms of thermal comfort, energy balance and grid independence.

Another important issue concerning NZEB development is related to construction costs. In [17] an extensive investigation on the construction cost differences between Zero Energy Buildings, Conventional Buildings and Green Buildings in United States was carried out. In this analysis, results show that the statistical difference between actual ZEB cost and modelled Conventional Buildings cost is not significant. Nevertheless, the authors highlight the limitations of the study and the need to further investigate the relations between investment costs and energy performance of buildings. In fact, ensuring: in particular how to ensure the fulfilment of NZEBs requirements and contemporary guaranteeingrequirements, guaranteeing users comfort, but also covering the involved investments and enhancing the reduction in costs are particularly relevant $[17][18][18][19]$. Although many studies and demonstration actions have demonstrated that it is possible to achieve NZEB targets, the design choices are not always proven to be cost effective both from an environmental and economic perspective Although many studies and demenstration actions have demonstrated that it is possible to achieve NZEB targets, the design choices are not always proven to be cost effective both from an environmental and economic perspective [17][18].

This economic issue was raised up in the EPBDEPBD_5]_[5]: in the Delegated Regulation No 244/2012 [19\} [20], which supplemented the EPBD regulation, a methodology framerkscheme to calculate cost-optimal levels for buildings is provided. The cost optimality is defined as "the energy performance level which leads | to the lowest cost during the estimated economic lifecycle". In the methodology ${ }_{2}$-energy efficiency measures are applied to reference buildings to contemporary reduce primary energy consumption and identify the most | economically advantageous solutions $[21][21] 20]$ [18][19][20]. Many studies in literature applied the costoptimal methodology proposed in the EPBD standard to derive cost-optimal energy efficiency measures for NZEB buildings [21][22][21][22],[22][22][23][23]and clusters of NZEB buildings [23][24], 24][24][25][25], [23][24], highlighting the need of taking into consideration the whole building life cycle.- $\mathrm{In}_{\perp}[25],[26][26]$, the comparative methodology presented in the EPBD is applied to assess the cost-optimality level of several office buildings located in a warm climate, while in [26], 27][27], the procedure is applied to multiresidential buildings in the Mediterranean Area. Results of both papers show high decrease of primary energy consumption and $\mathrm{CO}_{\Omega}^{2}$ emissions, keeping the operational and construction costs on the safe side. In [18]_[17] a simulation-based framework was applied to a residential building prototype in 14 locations across Europe in order to assess how to best assess theachieve the optimal NZEB design-configuration at the lowest cost in 14 locations across Europe. Results demonstrated that optimal solutions do strongly depend on climate condition, but a common aspect to all locations is the need ef-to integrating integrate renewables and energy efficiency measures to reach cost-effective NZEBs. Authors in [28]_27] applied a model for supporting designers in the design phase of a residential building, developing a cost optimal analysis of different scenarios to evaluate the best solution in terms ofthe balance between life cycle costs and energy performance. In [28][29] the cost-optimality and replicability on building market of different HVAC system configurations were evaluated for a residential building, taking into account the costs incurred during the whole building life-cycle. In [30], an economic analysis for developing four types of new existing residential NZEB buildings across different locations in UK was assessed. Different combinations of renewable energy technologies were evaluated. Results show that most of the analysed cases are profitable, achieving a benefit$\underline{\text { cost ratio (ratio between the costs and benefits) that ranges between }-12 \% \text { and } 53 \% \text { across different regions. }}$. What emerges from literature studies is that cost-optimal levels and packages of energy efficient measures strongly depend on national conditions[29][30] [31][32]. These differences are due to many variables such as: climatic conditions, energy, material and labour prices, available technologies and building types [27][28][29][31][32][33]. Among the different building types, high importance is given to the development
Formatted: Not Highlight

Formatted: Not Highlight

Formatted: Not Highlight

Formatted: Not Highlight

Formatted: Not Highlight

Formatted: Not Highlight

Formatted: Not Highlight

Formatted: Not Highlight

Formatted: Not Highlight

Formatted: Not Highlight

Formatted: Not Highlight

Formatted: Not Highlight

Formatted: Not Highlight

Formatted: Not Highlight

Formatted: Not Highlight

Formatted: Not Highlight

Formatted: Not Highlight

Formatted: Not Highlight

Formatted: Not Highlight

Formatted: Not Highlight

Formatted: Not Highlight

Formatted: Not Highlight

Formatted: Font: (Default) Times New Roman

Formatted: Not Highlight

Formatted: Not Highlight

Formatted: Not Highlight

Formatted: Not Highlight

Formatted: Superscript

Formatted: Not Highlight 
of residential NZEB buildings, which account for about the $75 \%$ of the total European Building stock

| [34][33]. In fact, in the residential sector the issue of cost reduction of new NZEBs is crucial, in particular for social housing multi-family houses, where the economic aspect is quite relevant, due to limited financial resources.

An extensive review was developed by the authors in [34]_[35], focused on the application of cost-optimal analysis in European literature studies, pointing out the differences among them based on several categories: methods and tools for optimization, energy efficiency measures, building type. It was found that with regard to the building typology, $68 \%$ of the reviewed reference buildings in the studies were residential and multifamily buildings represented the $34 \%$ of this share. It shows the importance of identifying the right balance between costs and energy performance in the residential sector. In [35]_34] it was also found that the most common energy efficiency measure for the envelope is to increase/decrease the thickness of insulation but this solution is not a driver for cost-optimal building design: efficiency measures on the building envelope have much lower impact on cost optimality compared to measures related to the energy systems.

This aspect makes an issue arise: the solutions proposed as energy efficiency measures (EEM) in the costoptimal framework are common and standard and the investigation of constructive alternative solutions is rarely pursued. The cost trade-off could be reached by simplifying the envelope design and the construction technologies_[35]_[36], taking advantage of issues like modularity, prefabrication and on-site assembly [32] [31] but application of these strategies in the cost-optimality studies has not been yet explored.

Regarding the national application of NZEBs in Italy, the law ascertains several requirements for new buildings, that can be reached through different strategies, technologies and operational means [37]_[36]. Starting from 01/01/2019 8 , in accordance to[37]_[38],-energy performance of minimum requirements buildings and NZEB buildings will vary only in terms of small differences in transmittance values. This implies that, from this date, very small cost differences can be expected to arise between a conventional and a nearly zero-energy building; also, reducing the costs of new nearly zero-energy multi-family houses means reducing the costs for such houses in general. Currently, according to the national document developed in $2016[39]_{2},[38]$ the extra cost in Italy for the construction of multifamily residential buildings compared to the conventional building strongly depends on the climatic region and was assessed to be about $60 € / \mathrm{m}^{2}$ on average. There is therefore ample-room for improvement, reducing this extra-cost gap. Starting from these assumptions, the target of this paper is to preliminary exploresexplore the possibility of reducing construction and life cycle costs keeping high energy target in new Italian multifamily buildingshouses, as investigated in, within the activities of the CoNZEBs (Solution sets for the cost reduction of new Nearly Zero Energy Buildings) Project [40][39]. The Project is funded by the European Union in the framework of the Horizon 2020 Program and aims at identifying and evaluating technology solution sets, leading to significant cost reductions of new Nearly Zero Energy Multi-Family Houses (MFH).

\section{Objective and method}

| This study aims at identifying solution sets for the specific sector of new nearly zero energy multi-family houses at reduced costs respect to mainstream options and assessed in a life cycle cost perspective. The cost issue in single family houses is less relevant, due to higher economic availability of potential clients for this building segment. The situation is different for multi-family houses, which is the most recurrent typology in social housing, and other public and private housing sectors, which the to whom this economic issue is more relevantfor. In this framework, the objective of the study is relevant for the construction sector in Italy and the implemented methodology could be usefully applied in other countries, with the duly boundary conditions. 
This work also introduces an innovative approach. The literature presented in the introduction proves that most of the studies are aligned to the approach The typical methodology in these studies is that implemented in EU member states for the cost optimal energy performance of buildings, as required by [5][5]: first typical

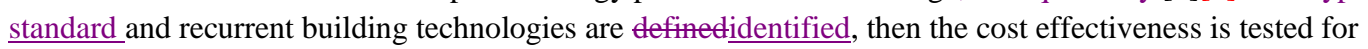
improved efficiency levels of the selected technologies [41][40]. The approach has some limitations, since it does not take into account several aspects that might be critical for cost redeutionreduction, e.g.: technical and economic trade-off between building envelope versus technical and renewable energy performances, indetificationidentification of alternative technology bundles instead of simple efficiency scaling, the role of $\underline{\text { the design in optimising the different energy uses in the buildings. The innovative contribution of the present }}$ work is to expand the technical and economic analyses of NZEB including the above cited issues, with a broader approach respect to existing studies. This method, however, does not allow to include alternative and unconventional solutions, and their combination, in the assessment.

Due to very different definitions and approaches of nearly zero energy buildings, the methodology is applied to the Italian context, defined in [37][38]. It has to be not that The NZEB requirements, as defined in the relevant Italian standard [36][37]_[37][38], are not based on energy performances but on the compliance of several prescriptions, including:

- Maximum values for defined buidlingbuilding envelope indicators;

- Minimum efficiency of the energy systems (space heating and cooling, ventilation, domestic hot water);

- $50 \%$ of energy uses provided by renewable sources.

The method allows searching different solutions sets complying with NZEB requirements without being forced to respect mandatory energy performances, opening the ground for different cost-effective solutions.

According to the above Fo overcome these limits, the methodology here developed consists of the following steps:

I. Identification of a real building, whose typology can be considered sufficiently representative of current multifamily houses in Italy. The choice of real buildings is necessary to have all the technical and economic data, needed for next analyses; as well as to have economic costs based on real market instead of on average values. This choice is also important because of the calculation and simulation analyses are framed in a real application, so that a building constructed according the given technical and economical specifications avoid the limitations -of a purely theoretical study.

II. Adjustments of the real building to selected climatic conditions and to specific NZEB requirements, for construction elements and fossil and renewable energy systems. This step allows to have standardised typical buildings, upon which it is possible to develop cost effective variants.

III.Identification of low costs solution sets for the different building envelope and energy system technologies. The solutions are developed taking into account all the energy services covered by NZEB requirements for residential buildings, fixed by national regulation.

IV. Energy and economic assessment of the building variants, in terms of construction and life cycle costs. Comparison of final and primary energy performances starting from field applications, as well as initial construction investment and Net present value at the end of the building life service are carried out.

NZEB requirements, defined in the relevant Italian standard [35][36], are not based on energy performances but on the compliance of the following prescriptions: 
Minimum efficiency of the energy systems (space heating and cooling, ventilation, domestic hot water); 50\% of energy uses provided by renewable sources.

The limit of the research relays on: the boundary conditions set in the analysis, the reference buildings and the identified low-cost solutions. Although the described methodology is tailored to the Italian reality, it can be applied to other countries once the energy, construction and economic boundary conditions are accounted for.; on the other side, it has to be noted that the methodology here defined is tailored to the Italian, however the approach might be applied in other countries once the energy, construction and economic boundary eonditions are taken into account. the relevance of the approach relays on the general validity of the methodology, which can be applied according to different boundary conditions, in Italy and elsewhere. This is an important value for designers, planners, contractors and construction companies, able to optimise costs for any construction project. Moreover, working at the intersection of: construction technologies, energy systems and economic assessment in real applications, the study is well aligned with the journal objective and scopes.

\section{The case study building}

Mihimum efficiency of the energy systems (space heating and cooling, ventilation, domestic hot wat50\% of energy uses provided by renewable sour

The San Giusto building, located in the outskirts of Prato, Tuscany, was selected after a nearly zero energy | multi-family houses screening carried out in Italy in the framework of the EU CoNZEBs project [40][39\}. The building can be considered representative of a consistent portion of the building stock. The building was commissioned by Edilizia Pubblica Pratese, a local social housing company. It is a L-shaped four-storey building with 29 apartments served by four staircases. Private cellars, a public civic centre and the utility rooms are located at the ground floor. The building is also equipped with public parking and green areas which show the multifunctional character of this project. The design plan and a picture of the building are shown in Figures 1 and 2.

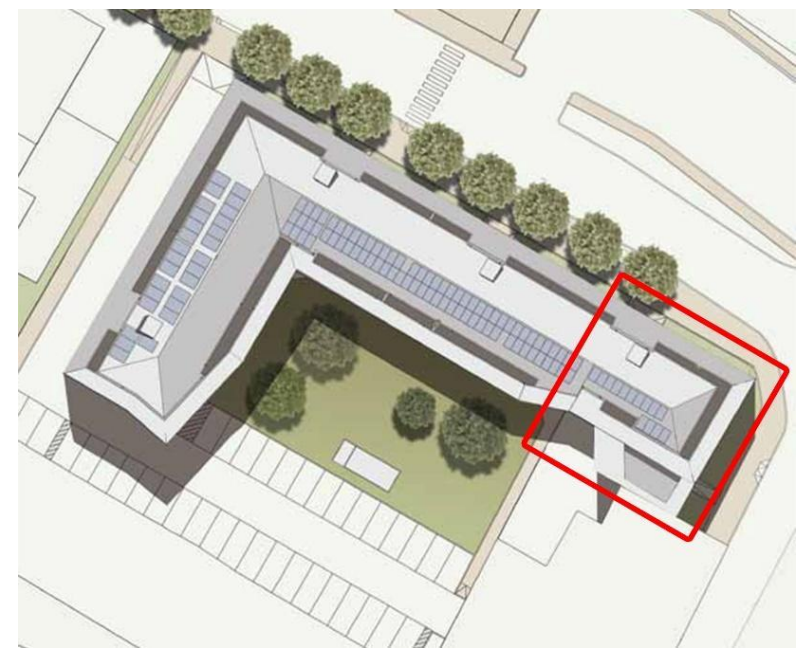

Fig. 1. Design plan of the case study building; the red square delimits the portion of building where the analysis of the thermal comfort was performed.

Formatted: Font: (Default) Times New Roman, Font color: Auto

Formatted: Not Highlight 


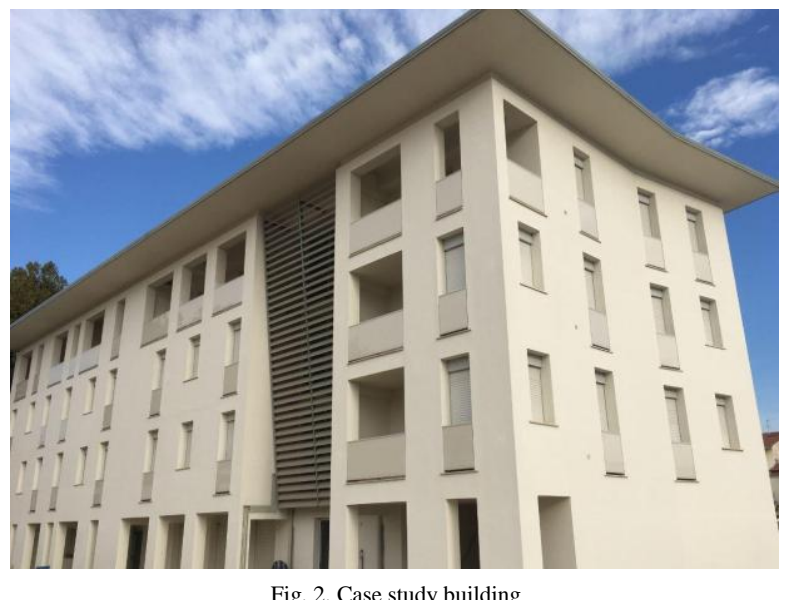

The total area of the apartments is $2207 \mathrm{~m}^{2}$ and the volume is $5960 \mathrm{~m}^{3}$, the apartments ranges betweenrange from 45 and $95 \mathrm{~m}^{2}$, with an average net area of $76 \mathrm{~m}^{2}$. The presence existence of apartments with different sizes shows the purpose of meeting the needs of the different low-income users, from couples to large families.

| The main target of the project was to realize-create a new high-performance building with low environmental impacts, and cost effective in the construction, operation and maintenance phases. The design kept this approach with the adoption of simple and low environment impact solutions. An example of this is the, as the use of recycled insulation materials from local textile companies. Bioclimatic approaches were adopted to maximise solar protection and natural ventilation in summer.

| Concerning the building structure, the external walls consist of ETICS (External Thermal Insulation Composite Systems), with $8 \mathrm{~cm}$ EPS (Expanded polystyrene) thermal insulation, a double brick layer with insulation in between ( $8 \mathrm{~cm}$ of recycled insulation in textile fibre), and internal finishing. The base floor is a masonry slab with an XPS (Extruded polystyrene) insulation layer of $8 \mathrm{~cm}$, a thermal coating in EPS of $4 \mathrm{~cm}$ and an additional insulating layer of EPS $(4 \mathrm{~cm})$ included in the floor heating system and the covering is of ceramic tiles; covering is ceramic tiles. The rooftop is a masonry tilted roof with an XPS thermal coating of $12 \mathrm{~cm}$ covered by steel plate mounted on wooden planks. Transmittances of the envelope are $0.20 \mathrm{~W} / \mathrm{m}^{2} \mathrm{~K}$ for roof and $0.17 \mathrm{~W} / \mathrm{m}^{2} \mathrm{~K}$ for walls and base floor. The continuous external insulation eliminates thermal | bridge. Argon-filled double-glazed windows with aluminium frame are installedare in place with thermal transmittance of $1.4 \mathrm{~W} / \mathrm{m}^{2} \mathrm{~K}$ and solar transmittance of 0.67 .

The Domestic Hot Water (DHW) system is fed by $43 \mathrm{~m}^{2}$ of vacuum solar thermal collectors mounted on the | south-east and south-west oriented pitches and coupled with two tanks of 2000 litres. A $94 \underline{\mathrm{k}} \underline{\mathrm{W}} \mathrm{w}$ condensing boiler is used as back of solar collectors. The heating supply is centralized, and the main heat | generator is the $171 \mathrm{kWKW}$ air water heat pump. When outdoor temperatures decrease below the working conditions of the heat pump, the condensing boiler and the solar thermal collectors work as back-up system, supporting the heat pump with keeping the seasonal coefficient of performance high. for keeping high the seasenal coefficient of performance. The Coefficient of Performance (COP) in standard conditions is 3.28. The outlet temperature of the heat pump, which supplies a room-controlled floor heating system, is $40-45_{-}^{\circ} \underline{\mathrm{C}}$ and its cut-off temperatures are $3{ }^{\circ}-45_{-}^{\circ} \underline{C}$. The system is equipped with an inertial tank of 2000 litres to cope with thermal demand peaks. Here,_, in which the heated water is sent from the heat pump and, if necessary, from the condensing boiler; within-boiler. Within the tank, when demand of domestic hot water is lower than production, high temperature fluid from solar collectors flows in a coil to additionally support heating supply. Part of the electricity needed by the heat pump is produced by a $22 \mathrm{kWp} \mathrm{PV}$ system $\left(163 \mathrm{~m}^{2}\right)$. Both

Formatted: Font: (Default) Times New Roman, Font color: Auto 
the solar thermal collectors and photovoltaic system are mounted on the tilted roof, on the south-east and south-west oriented pitches.

According to the most common construction rules in Italian buildings, especially for social housing, active cooling and mechanical ventilation systems are not installed in the case study building.

\subsection{Climatic condition}

Italy has a wide variety of climatic conditions. $\div$ Tthe national building energy codes identifyidentifiese six classes, based on the heating degree days, calculated in base $20_{-}^{\circ} \mathrm{C}$. The classes range from A (below 600 degree days) to F (above 3000 degree days). No zoning exists for the cooling season. In order to simplify the analysis, two macro-classes were identified and represented by two large cities in this study:

- Turin, 2617 degree days, representative of climatic zone E (northern and mountain zones) and F (alpine zone)

- Rome, 1440 degree days, representative of zones from A to D, with milder climatic conditions, typical of central and southern zones.

They were selected being large cities These are large cities, whose degree days are very close to average degree days of the related the climatic zones they belong to weighted with the population.

\subsection{Building's adjustments to reference climate conditions}

The characteristics of the real building are adjusted to the minimum NZEB requirements in the reference climatic zones in this section. Changes in the building envelope, energy systems and renewable sources are

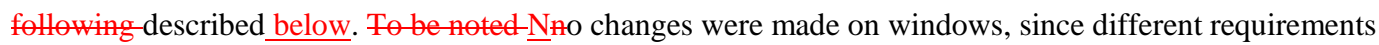
have close to negligible impact on costs.

\subsubsection{Rome climatic zone}

Envelope components insulation was brought to the standard requirements, as indicated in table 1, hence the structures were modified as follows: the external wall is covered with an $8 \mathrm{~cm}$ EPS thermal coating; the first floor between apartments and ground floor has an XPS thermal coating of $4 \mathrm{~cm}$ and an additional insulating layer of EPS $(4 \mathrm{~cm})$ included in the floor heating system; the rooftop has an XPS thermal coating of $9 \mathrm{~cm}$.

\begin{tabular}{cccc}
\multicolumn{4}{c}{ Table 1. Transmittance values of the building envelope of the reference buildings in Rome and Turin } \\
\hline City & U-roof $\left[\mathrm{W} / \mathrm{m}^{2} \mathrm{~K}\right]$ & $\mathrm{U}$-wall $\left[\mathrm{W} / \mathrm{m}^{2} \mathrm{~K}\right]$ & $\mathrm{U}$-first floor $\left[\mathrm{W} / \mathrm{m}^{2} \mathrm{~K}\right]$ \\
\hline Rome & 0.26 & 0.28 & 0.28 \\
\hline Turin & 0.21 & 0.25 & 0.24
\end{tabular}

The number of solar thermal collectors and PV panels was reduced up to exactly meet to meet the requirements of the Standard [36][37] precisely. This was done $\div$ to guarantee the $50 \%$ of DHW production from renewable sources and contemporarily to cover the $50 \%$ of total energy demand (heating, cooling and DHW) with renewable sources. According to this, solar collectors were reduced from $43 \mathrm{~m}^{2}$ to $27 \mathrm{~m}^{2}$ and the PV panels from 163 to $142 \mathrm{~m}^{2}$. This number of PV panels is also the minimum amount to meet the standard of Appendix 3 [37][38]_which requires an installed peak power of $22 \mathrm{kWKW}$ for this building. Results of the energy calculation will be shown in paragraph 6.2 to be compared with energy results of the low-cost scenarios. 


\subsubsection{Turin climatic zone}

The insulation thickness of the envelope components was brought to the NZEB requirements, as shown in Table 1. The structures were modified as follows: the external wall is a double brick walls with an EPS thermal coating of $13 \mathrm{~cm}$; the first floor between apartments and ground floor has an XPS thermal coating of $7 \mathrm{~cm}$ and an additional insulating layer of EPS $(4 \mathrm{~cm})$ included in the floor heating system. $;$ Tthe roof toprooftop is insulated with $11 \mathrm{~cm}$ of XPS.

As for the previous case, solar thermal collectors were reduced from 43 to $40 \mathrm{~m}^{2}$ and the PV panels from 163 to $142 \mathrm{~m}^{2}$. The Mechanical Ventilation with Heat recovery (MVHR) system was here-included in the reference case: one system in each apartment was provided. $\mathrm{e}, \mathrm{T}$-this is still a cutting-edge solution in Italy dwellings but recently often used in very high energy performing buildings in colder climates. According to

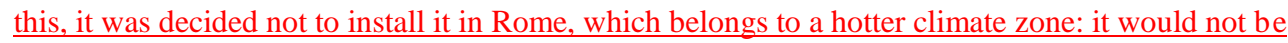
economically efficient nor crucial for obtaining low level of Primary Energy for heating. It was therefore decided to model the MHVR system in each apartment.

\subsubsection{Adjusted construction costs}

The adjusted construction costs for the two reference buildings are shown in Table 2 and $3-\underline{3}$. The costs have been taken from the bill of quantities of the real building. Cost modifications due to variation in the insulation thickness for the two reference buildings have been estimated as unitary variation $\left(€ / \mathrm{m}^{3}\right)$ of the original prices. Cost of the MVHR system used in Turin was not included in the bill of materials of the real building, but was provided by a technical company, which was asked to simulate a real offer to supply a | MHVR system for the reference building [42][41]. For the building located in Rome, overall construction cost is $€ 3^{\prime} 388^{\prime} 584$ which corresponds to $1^{\prime} 594 € / \mathrm{m}^{2}$. Table 2 shows the costs divided by categories and their percentage on the overall cost. It can be noticed that the heaviest category is Architectural components which accounts for the $46 \%$ of the overall construction costs. Overall construction costs of the building located in Turin is $€ 3^{\prime} 511^{\prime} 820$ which corresponds to $1^{\prime} 652 € / \mathrm{m}^{2}$. The incidences of each category on the overall cost are similar to ones in Rome. Differences in costs between the two buildings are mainly due to the installation of the MVHR in Turin which causes an increase in the energy systems cost of $40 € / \mathrm{m}^{2}$. More moderate differences (in the order of 5 to $15 € / \mathrm{m}^{2}$ ) are observed for the Architectural components and Renewable plants.

The cost optimal analysis of the proposed scenarios will be based only on the reduction of the "energy related costs": those costs have a direct impact on the building energy performance. In both Table 2 and 3 disaggregated energy related costs for each construction category are highlighted in grey. It can be noted that Three main aspects can be observed: the structural costs are fixed; up to the $38 \%$ of both architectural and energy systems costs is adjustable; the entire cost of renewable energy systems can be modified. In Rome the $24 \%$ of the total construction costs can be decreased by implementing more energy efficient solutions, which corresponds to $389 € / \mathrm{m}^{2-}$; in Turin it is the $27 \%$ which corresponds to $447 € / \mathrm{m}^{2-}=$

\begin{tabular}{cccccc}
\multicolumn{6}{c}{ Table 2. Total and energy related construction costs of reference building in Rome } \\
\hline & Structure & Construction components & $\begin{array}{c}\text { Technica } \\
\text { 1 Systems }\end{array}$ & Renewable sources & Total \\
\hline Costs $[€]$ & $\begin{array}{c}996^{\prime} 62 \\
4\end{array}$ & $1^{\prime}{ }^{\prime} 554^{\prime} 631$ & $782^{\prime} 027$ & $55^{\prime} 302$ & $3^{\prime} 388^{\prime} 584$ \\
\hline $\begin{array}{c}\text { Incidence on overall costs } \\
{[\%]}\end{array}$ & 29 & 46 & 23 & 2 & 100 \\
\hline Unitary costs $\left[€ / \mathrm{m}^{2}\right]$ & 469 & 731 & 368 & 26 & 1594 \\
\hline Energy related $[€]$ & 0 & $522^{\prime} 783$ & $248^{\prime} 194$ & $55^{\prime} 302$ & $826^{\prime} 279$ \\
\hline Incidence on category cost & 0 & 34 & 32 & 100 & $/$ \\
\hline
\end{tabular}




\begin{tabular}{cccccc}
\hline$[\%]$ & 246 & 117 & 26 & 389 \\
\hline $\begin{array}{c}\text { Unitary energy related costs } \\
{\left[€ / \mathrm{m}^{2}\right]}\end{array}$ & 0 & & & & \\
\hline
\end{tabular}

Table 3. Total and energy related construction costs of reference building in Turin

\begin{tabular}{|c|c|c|c|c|c|}
\hline & Structure & Construction components & $\begin{array}{r}\text { Technica } \\
1 \text { Systems }\end{array}$ & Renewable sources & Total \\
\hline Costs $[€]$ & $\begin{array}{c}9966^{\prime} 62 \\
4\end{array}$ & 1'583'195 & $867 ’ 107$ & $64 ' 894$ & 3'511'820 \\
\hline $\begin{array}{c}\text { Incidence on overall costs } \\
{[\%]}\end{array}$ & 28 & 45 & 25 & 2 & 100 \\
\hline Unitary costs $\left[€ / \mathrm{m}^{2}\right]$ & 469 & 744 & 408 & 31 & 1652 \\
\hline Energy related $[€]$ & 0 & $551 ’ 358$ & $333 ’ 306$ & $64 ' 894$ & $949 ’ 558$ \\
\hline $\begin{array}{l}\text { Incidence on total category } \\
\text { cost }[\%]\end{array}$ & 0 & 35 & 38 & 100 & l \\
\hline $\begin{array}{c}\text { Unitary energy related costs } \\
{\left[€ / \mathrm{m}^{2}\right]}\end{array}$ & 0 & 259 & 157 & 31 & 447 \\
\hline
\end{tabular}

\section{Identification of low-cost solutions}

This section describes the solutions identified to reduce the construction costs of the two reference buildings. | Each subsection describes the selected technologies and strategy, highlighting their peculiarities with respect to common trends.

\subsection{Building envelope}

Two main variations were identified. The common technique for external wall construction of NZEB in Italy consists of brickworks and ETICS; instead of following the usual approach of variation of insulation levels to reach the most performing solutions, in this paper the approach was to detect alternative construction technologies. In particular, large autoclaved concrete blocks were selected. They These are based on natural elements and reach very high insulation and lightweight properties, thanks teas a result of a specific production process which creates micro air bubbling inside the material. These blocks come in different size, so that different transmittance values can be obtained within a single construction layer. | Thanks-Due to the ad-hoc designed profiles, the blocks can be easily handled and assembled. Compared to the other solutions, this technology reduces complexity, construction time and costs.

The second proposed solution is the mono-block window. Generally, in Italy residential buildings are equipped with traditional windows which are composed as followsy: subframe, placed in the hole of the façade, the shutter box mounted above the window and the windows itself. The most time-consuming phase for windows is the preparation phase, since masonry workers have to create the hole, provide insulation for | thermal bridges and wait, waitfor wet materials to dry. After that, masonry workers install the subframe and specialised workers mount the shutter box and finally the window itself. The mono-block windows are | directly placed in the façadefacade hole and then fixed, with consequent savings in time, and material and labour costs for the subframe works.

| In both cases the performance indicator (thermal transmittance) keeps-maintains the value of the base case, but its cost change. In some Turin scenarios, the so-called super NZEB envelope was tested, where lower transmittances for walls, roof and ground floor were considered. Hence for these super NZEB scenarios the | $\mathrm{U}$ values $\left[\mathrm{W} / \mathrm{m}^{2} \mathrm{~K}\right.$ ] were adjusted as followsto : 0.105 (roof), 0.15 (wall), 0.12 (ground floor). This configuration was tested in combination with alternative energy systems, targeted to an overall cost reduction. 


\subsection{Energy systems and renewable energy}

In Italy space heating in NZEB buildings is generally provided by heat pumps coupled with floor heating while DHW is normally supplied by condensing boilers supported by solar thermal collectors.

The implementation of both systems is expeansive, therefore one of the proposed strategies is a thermal driven scenario where the condensing boiler is used for both heating and DHW services. The floor heating distribution system is then replaced by aluminium radiators. The use of condensing boilers and radiators allows to save money and reduce construction and maintenance costs. This is because $\div$ the architectural works for the construction of the floor heating system, the backbone lines of the floor heating system and the storage tank of the heat pump are eliminated. In addition, atso-maintenance costs of the condensing boilers and radiators is lower, allowing to save money in a life cycle cost (LCC) perspective. On the other sidehand, the amount of renewable sources has to be increased to respect the percentage of renewable energy production required by the Standard.

A second strategy is, conversely, an electricity-driven solution which minimize the use of gas: the air water heat pump is used both for heating and DHW production. According to this, the condensing boiler is used as a backup system for both services. Floor heating is replaced by low temperature aluminium radiators which are more expensive than conventional aluminium radiators but lower less expensive than floor heating. In this case, the minimum level of energy production from renewable sources are-is achieved only by means efthrough the use of the PV panels which feed the heat pump, so the expense forneed for solar thermal collectors is avoided.

The third strategy is at the forefront, but it is forbidden in Italy according to the current Standard. It consists $\mid$ in providing space heating with electric radiators in rooms $\_-\underline{i t}_{\text {it }}$ allows to eliminate technical system for heating production and most of electricity is provided by the PV panels. This approach does not comply with | Italian regulation, since energy from PV panels cannot be counted for the contribute ofaccounted as renewable sources if they directly feed electric systems for heating, DHW or ventilation services. The condensing boiler is only used for DHW production. For respectingTo comply with the standard requirements, the amount of solar thermal collectors and PV panels has to beis considerably increased: theincreased. The highest technical expenses in this scenario are basically due to the installation of renewable sources. Nevertheless, investment costs of technical systems for heating supply and distribution are avoided.

Another very simple solution to reduce construction costs was to decrease the number of PV panels to the minimum amount needed for self-consumption. This strategy does not comply with national standards, since the minimum peak power of photovoltaic is calculated as a function of the surface area of the building at ground level.

Common to all the strategies is to replace the floor heating with a cheaper solution; due to this, the insulation provided by the floor heating system was always replaced with an additional layer of thermal insulation of | EPS $(4 \mathrm{~cm})$ on the floors to comply withrespect the transmittance values required by the Standard. For the colder climate in Turin, in addition to the others, two proposals were tested. Firstly, the combined use of solar thermal collectors for both Heating and DHW in the thermal driven scenarios: solar thermal collectors provide pre-heated water for condensing boiler, allowing to reduce the amount of gas needed. Secondly, the replacement of the MVHR with a simple mechanical ventilation with only extraction (MEV). It is a cheaper solution, but, on the other side, the benefits of the heat recovery on heating consumption are no more guaranteed. 


\subsection{Proposed Scenarios}

$\underline{\text { In Table } 4 \text { and } 5 \text { the characteristics of the reference buildings and scenarios for the Rome and Turin are }}$ shown. The energy performance of these scenarios was simulated in steady state regime, as described in section 5.2 .

\begin{tabular}{|c|c|c|c|c|c|c|}
\hline \multirow{2}{*}{\multicolumn{2}{|c|}{$\underline{\text { Technology }}$}} & \multirow[b]{2}{*}{$\underline{\text { Reference building }}$} & Scenario 1 & Scenario 2 & Scenario 3 & Scenario 4 \\
\hline & & & $\begin{array}{l}\text { Thermal driven } \\
\text { solution }\end{array}$ & $\begin{array}{l}\text { Electricity driven } \\
\text { solution }\end{array}$ & $\begin{array}{l}\text { Electricity driven } \\
\text { solution (outlaw) }\end{array}$ & $\begin{array}{l}\text { Thermal driven } \\
\text { solution (outlaw) }\end{array}$ \\
\hline \multicolumn{2}{|r|}{$\frac{\text { Solar thermal }}{\text { collectors }}$} & $\underline{15 \text { modules; } 27 \mathrm{~m}^{2}}$ & $\frac{19 \text { modules; }}{34 \mathrm{~m}^{2}}$ & Absent & $\frac{18 \text { modules; }}{33 \mathrm{~m}^{2}}$ & $\frac{19 \text { modules; }}{34 \mathrm{~m}^{2}}$ \\
\hline \multirow{2}{*}{\multicolumn{2}{|c|}{ External wall }} & $\begin{array}{l}\frac{89 \text { modules; }}{142 \mathrm{~m}^{2}} \\
22 \mathrm{kWp}\end{array}$ & $\begin{array}{l}\frac{89 \text { modules; }}{142 \mathrm{~m}^{2}} \\
\underline{22 \mathrm{kWp}}\end{array}$ & $\begin{array}{l}\frac{89 \text { modules; }}{142 \mathrm{~m}^{2}} \\
\underline{22 \mathrm{kWp}}\end{array}$ & $\begin{array}{l}\frac{100 \text { modules; }}{163 \mathrm{~m}^{2}} \\
25 \mathrm{kWp}\end{array}$ & $\begin{array}{l}\frac{6 \text { modules; }}{9.6 \mathrm{~m}^{2}} \\
1.5 \mathrm{kWp}\end{array}$ \\
\hline & & $\begin{array}{l}\text { Two brick walls }(20 \mathrm{Cm}) \\
\text { with an EPS thermal coating } \\
(8 \mathrm{~cm}) \text { covered by plaster } \\
\text { U value: } 0.28 \mathrm{~W} / \mathrm{m}^{2} \mathrm{~K}\end{array}$ & \multicolumn{4}{|c|}{$\begin{array}{l}\text { autoclaved concrete bricks }(30 \mathrm{~cm}) \text { covered by plaster } \\
\underline{\text { U value: } 0.28 \mathrm{~W} / \mathrm{m}^{2} \mathrm{~K}}\end{array}$} \\
\hline \multicolumn{2}{|r|}{ Roof } & \multicolumn{5}{|c|}{$\begin{array}{l}\text { Masonry tilted roof with an XPS thermal coating of } 9 \mathrm{~cm} \text { covered by a steel plate mounted on wooden planks. } \\
\text { U value: } 0.26 \mathrm{~W} / \mathrm{m}^{2} \mathrm{~K}\end{array}$} \\
\hline & $\frac{\text { Floor above }}{\underline{\text { apartments }}}$ & $\begin{array}{l}\text { Masonry floor with an XPS } \\
\text { thermal coating of } 4 \mathrm{~cm} \text { and } \\
\text { an EPS layer }(4 \mathrm{~cm}) \\
\text { included in the floor heating } \\
\text { system } \\
\text { U value: } 0.28 \mathrm{~W} / \mathrm{m}^{2} \mathrm{~K}\end{array}$ & \multicolumn{4}{|c|}{$\frac{\text { Masonry floor with an XPS thermal coating of } 8 \mathrm{~cm}}{\text { U value: } 0.28 \mathrm{~W} / \mathrm{m}^{2} \mathrm{~K}}$} \\
\hline \multicolumn{2}{|r|}{$\underline{\text { Windows }}$} & $\begin{array}{l}\text { Traditional windows } \\
\text { U value: } 1.46 \mathrm{~W} / \mathrm{m}^{2} \mathrm{~K} \\
\end{array}$ & \multicolumn{4}{|c|}{$\begin{array}{l}\text { Monoblock windows } \\
\text { U value: } 1.46 \mathrm{~W} / \mathrm{m}^{2} \mathrm{~K}\end{array}$} \\
\hline \multirow{2}{*}{$\begin{array}{r}\text { Heat } \\
\text { supply }\end{array}$} & $\underline{\text { Unit }}$ & $\begin{array}{l}\text { Heat pump }+ \text { Condensing } \\
\underline{\text { boiler (back up) }}\end{array}$ & $\underline{\text { Condensing boiler }}$ & $\begin{array}{l}\text { Heat pump }+ \\
\text { Condensing boiler } \\
\text { (back up) }\end{array}$ & $\underline{\text { Absent }}$ & Condensing boiler \\
\hline & $\begin{array}{l}\text { Heating } \\
\text { System }\end{array}$ & Floor heating & $\underline{\text { Radiators }}$ & $\begin{array}{l}\text { Low-temperature } \\
\text { radiators }\end{array}$ & $\underline{\text { Electric radiators }}$ & $\underline{\text { Radiators }}$ \\
\hline$\underline{D H W}$ & $\underline{\text { Unit }}$ & $\underline{\text { Condensing boiler }}$ & $\underline{\text { Condensing boiler }}$ & $\begin{array}{l}\text { Heat pump }+ \\
\text { Condensing boiler } \\
\text { (back up) }\end{array}$ & $\underline{\text { Condensing boiler }}$ & Condensing boiler \\
\hline
\end{tabular}

Table 5. . Description of the building envelope and technical systems for the reference building and proposed low-cost scenarios in Turin

\begin{tabular}{|c|c|c|c|c|c|c|}
\hline & & Scenario 1 & Scenario 2 & Scenario 3 & Scenario 4 & Scenario 5 \\
\hline$\underline{\text { Technology }}$ & $\underline{\text { Reference building }}$ & $\begin{array}{l}\text { Thermal driven } \\
\text { solution }\end{array}$ & $\begin{array}{l}\text { Thermal driven } \\
\text { solution }\end{array}$ & $\begin{array}{l}\text { Electricity } \\
\text { driven solution }\end{array}$ & $\begin{array}{l}\text { Electricity } \\
\text { driven solution }\end{array}$ & $\begin{array}{l}\text { Electricity } \\
\text { driven solution } \\
\text { (outlaw) }\end{array}$ \\
\hline$\frac{\text { Solar thermal }}{\text { collectors }}$ & 22 modules; $40 \mathrm{~m}^{2}$ & $\frac{44 \text { modules; }}{79 \mathrm{~m}^{2}}$ & $\frac{44 \text { modules; }}{79 \mathrm{~m}^{2}}$ & $\underline{\text { Absent }}$ & $\underline{\text { Absent }}$ & $\frac{30 \text { modules; }}{54 \mathrm{~m}^{2}}$ \\
\hline$\underline{P V}$ & $\frac{89 \text { modules; }}{\frac{142 \mathrm{~m}^{2}}{22 \mathrm{kWp}}}$ & $\begin{array}{l}\frac{89 \text { modules; }}{142 \mathrm{~m}^{2}} \\
\frac{22 \mathrm{kWp}}{2}\end{array}$ & $\begin{array}{l}\frac{89 \text { modules; }}{142 \mathrm{~m}^{2}} \\
\underline{22 \mathrm{kWp}}\end{array}$ & $\begin{array}{l}\frac{89 \text { modules; }}{142 \mathrm{~m}^{2}} \\
\underline{22 \mathrm{kWp}}\end{array}$ & $\frac{89 \text { modules; }}{\frac{142 \mathrm{~m}^{2}}{22 \mathrm{kWp}}}$ & $\begin{array}{l}100 \text { modules; } \\
\frac{163 \mathrm{~m}^{2}}{25 \mathrm{kWp}}\end{array}$ \\
\hline$\underline{\text { External wall }}$ & $\begin{array}{l}\text { two brick walls }(20 \mathrm{Cm}) \\
\text { with an EPS thermal } \\
\text { coating }(13 \mathrm{~cm}) \text { covered } \\
\text { by plaster } \\
\text { U value: } 0.25 \mathrm{~W} / \mathrm{m}^{2} \mathrm{~K}\end{array}$ & 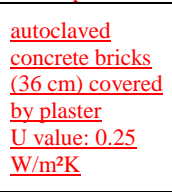 & $\begin{array}{l}\text { super NZEB } \\
\text { autoclaved } \\
\text { concrete bricks } \\
(45 \mathrm{~cm}) \text { covered } \\
\text { by plaster } \\
\text { U value: } 0.15 \\
\text { W/m } / \mathrm{m}^{2} \mathrm{~K} \\
\end{array}$ & 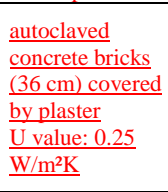 & 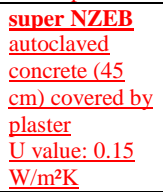 & $\begin{array}{l}\text { super NZEB } \\
\text { autoclaved } \\
\text { concrete }(45 \\
\mathrm{cm}) \text { covered by } \\
\text { plaster } \\
\text { U value: } 0.15 \\
\text { W/m² } \mathrm{K}\end{array}$ \\
\hline$\underline{\text { Roof }}$ & $\begin{array}{l}\text { Masonry tilted roof with } \\
\text { an XPS thermal coating } \\
\text { of } 11 \mathrm{~cm} \text { covered by a } \\
\text { steel plate mounted on } \\
\text { wooden planks. } \\
\text { U value: } 0.21 \mathrm{~W} / \mathrm{m}^{2} \mathrm{~K}\end{array}$ & $\begin{array}{l}\text { As reference } \\
\text { building } \\
\underline{\mathrm{U} \text { value: } 0.21} \\
\underline{\mathrm{W} / \mathrm{m}^{2} \mathrm{~K}}\end{array}$ & $\begin{array}{l}\text { super NZEB } \\
\text { Masonry tilted } \\
\text { roof with an } \\
\text { XPS thermal } \\
\text { coating of } 27 \\
\text { cm } \\
\text { U value: } 0.11 \\
\text { W/m² }\end{array}$ & $\begin{array}{l}\underline{\text { As reference }} \\
\text { building } \\
\underline{\mathrm{U} \text { value: }} 0.21 \\
\underline{\mathrm{W} / \mathrm{m}^{2} \mathrm{~K}}\end{array}$ & $\begin{array}{l}\text { Super NZEB } \\
\text { Masonry tilted } \\
\text { roof with an } \\
\text { XPS thermal } \\
\text { coating of } 27 \\
\text { cm } \\
\text { U value: } 0.11 \\
\text { W/m² }\end{array}$ & $\begin{array}{l}\text { super NZEB } \\
\text { Masonry tilted } \\
\text { roof with an } \\
\text { XPS thermal } \\
\text { coating of } 27 \\
\text { cm } \\
\text { U value: } 0.11 \\
\text { W/m² }\end{array}$ \\
\hline$\frac{\text { Floor above }}{\underline{\text { apartments }}}$ & $\begin{array}{l}\text { Masonry floor with an } \\
\text { XPS thermal coating of } 7 \\
\text { cm and an EPS layer (4 } \\
\text { cm) included in the floor } \\
\text { heating system } \\
\text { U value: } 0.24 \mathrm{~W} / \mathrm{m}^{2} \mathrm{~K}\end{array}$ & $\begin{array}{l}\text { Masonry floor } \\
\text { with an XPS } \\
\text { thermal coating } \\
\text { of } 11 \mathrm{~cm} . \\
\text { U value: } 0.24 \\
\text { W/m² }\end{array}$ & $\begin{array}{l}\text { super NZEB } \\
\text { Masonry floor } \\
\text { with an XPS } \\
\text { thermal coating } \\
\text { of } 20 \mathrm{~cm} \text {. } \\
\text { U value: } 0.12 \\
\text { W/m } / \mathrm{m}^{2}\end{array}$ & $\begin{array}{l}\frac{\text { Masonry floor }}{\text { with an XPS }} \\
\text { thermal coating } \\
\text { of } 11 \mathrm{~cm} . \\
U \mathrm{U} \text { value: } 0.24 \\
\underline{\mathrm{W} / \mathrm{m}^{2} \mathrm{~K}}\end{array}$ & $\begin{array}{l}\text { super NZEB } \\
\text { Masonry floor } \\
\text { with an XPS } \\
\text { thermal coating } \\
\text { of } 20 \mathrm{~cm} . \\
\text { U value: } 0.12 \\
\text { W/m } / \mathrm{m}^{2} \mathrm{~K}\end{array}$ & $\begin{array}{l}\text { super NZEB } \\
\text { Masonry floor } \\
\text { with an XPS } \\
\text { thermal coating } \\
\text { of } 20 \mathrm{~cm} . \\
\text { U value: } 0.12 \\
\text { W/m² }\end{array}$ \\
\hline Windows & $\begin{array}{l}\text { Traditional windows } \\
\text { U value: } 1.4 \mathrm{~W} / \mathrm{m}^{2} \mathrm{~K}\end{array}$ & \multicolumn{5}{|c|}{$\begin{array}{l}\text { Monoblock windows } \\
\text { U value: } 1.4 \mathrm{~W} / \mathrm{m}^{2} \mathrm{~K}\end{array}$} \\
\hline
\end{tabular}


In Rome, transmittances of the external walls and windows are the same as in the base case. The roof and floor above the apartments are the same as the reference building apart from the additional insulation layers which compensates the absence of floor heating in the four scenarios.

In Turin, two of the five scenarios maintain the same transmittance values of the building envelope as in the base case (scenarios 1 and 3), while the other three scenarios have a super NZEB envelope. According to this, scenario 2 has the same characteristics as scenario 1 apart from the lower transmittance values of the envelope and the Mechanical Extract Ventilation (MEV) instead of the MVHR. Similarly, scenario 4 is coupled with scenario 3. In the thermal driven scenarios 1 and 2 solar collectors provide pre-heating of water for both heating and DHW services.

As aforementioned in paragraph 4.2, it must be noticed that scenarios 3 and 4 in Rome and scenario 5 in Turin are outlaw either because of the installation of electric radiators as heating system, or because of the lower amount of PV panels respect to the Standard requirements.

\subsubsection{Passive cooling solutions}

Modern buildings may suffer of overheating respect in comparison to older ones, since well insulated envelopes obstacle the thermal discharge of the building at night. $\div$ Iin fact, active cooling systems are often installed in NZEB in Italy, as documented in the relevant chapter in [43][42]. This trendIt also depends on the calculation method used to assess the energy performance of buildings, based on steady-state method, which overestimates the cooling demand and does not allow to assess the potentialities of passive cooling | techniques to provide thermal comfort conditions. The objective is atto reach a better understanding of the thermal response of NZEBs in the cooling and season and to assess whether proper passive solutions might avoid the installation of active cooling, thus keeping lower costs for design and installation of such systems.

The mitigation of the indoor environment is pursued through two main strategies:

a) Solar protection. The application of external solar shading devices on all the windows with orientation from north-east to north-west passing through south to block direct solar radiations-

b) Night ventilation cooling. The increase of natural ventilation during the night hours, when the ambient temperature drops below the internal ones, creates favourable conditions to lower indoor air and structure temperatures. This objective can be pursued through windows opening, especially with different orientation.

Solutions other than the selected ones exist, however they have higher economic impacts, e.g. phase change materials on envelope elements and installation of heat sinks, thus were not taken into account. On the contrary, solar protection and natural ventilation are typical solution in Mediterranean dwellings, that only recently are-were replaced by mechanical cooling systems. The assessment of the impact of such solutions was carried out through a numerical analysis in transient regime, as described in section 5.1. 


\section{Calculation \\ 5.1. Thermal calculation}

| The analysis was carried out according to the relevant standard EN 15251 [43][44]_in which the thermal comfort, and consequently the overheating risk, is assessed in buildings without active cooling systems. The concept relays on the principle of the adaptive comfort, in which the subject has not fixed comfort | expectations but adapted himself to different conditions depending on internal microclimatic conditions, external weather conditions, clothing and possibility to building features to improve personal comfort.

The standard identifies two categories, which are relevant in residential buildings:

I. High level of expectation and iswhich is recommended for spaces occupied by very sensitive and fragile persons with special requirements like handicappedpeople with disabilities, sick, very young children and elderly persons

II. Normal level of expectation and shouldwhich should be used for new buildings and renovations

The focus This paper is focused is on the second category, which is relevant according to the building typology investigated in this paper. $\div$ Tthe analysis is however carried out on the first category for completeness, as well.

The relevant metric is the time evolution of the operative temperature, defined as the arithmetic average of air and mean radiant temperatures in a built environment, according to standard. The compliance with the standard requires that the number of hours in which the operative temperature exceeds the upper and lower limits to beis within $5 \%$ of the observation period (here considered in the June-August period). The acceptance band for the operative temperature is governed by the following equation for respectively category I and II:

$$
\begin{aligned}
& 0.33 \times t_{r m}+18.8-2 \leq t_{o p} \leq 0.33 \times t_{r m}+18.8+2 \\
& 0.33 \times t_{r m}+18.8-3 \leq t_{o p} \leq 0.33 \times t_{r m}+18.8+3
\end{aligned}
$$

Being:

$t_{o p}\left({ }^{\circ} \mathrm{C}\right)$ - hourly operative temperature

$t_{r m}\left({ }^{\circ} \mathrm{C}\right)$ - mean running outdoor air temperature, calculated according to-[43]_[44].

To reduce the calculation time, the operative temperature was calculated only in the apartments in the portion of the building delimited by red square in figure 1. This portion includes 8 apartments: A1-A3 on the first floor, A4-A6 on the second floor, A7 and A8 on the third floor.

The numerical analysis was carried out with TRNSYS, a well-known and calibrated software, able to model | the thermal behaviour of the building in transient state [45][444]. TRSNYS works with assembled calculation components, named types, each of them with a specific calculation tasks in the framework of the overall thermal and energy performance analysis. The project implemented in this analysis consists of the following components:

- weather data reader, for this project the climatic data of Rome were used, being more severe, and so more conservative, than Turin during the summer season;

- the solar generator which allows to build the solar irradiation dataset; 
- additional components used for specific calculation tasks (such as the calculation of the effective sky temperature and of the heat transfer through the ground);

- the building block, which is filled in with all the data building inputs;

- the output results of the calculation, in this case outdoor temperatures in all flats and the outdoor air temperature.

The time resolution for the analysis is one hour, according to the requirements in the relevant standard. The building is in free floating conditions, meaning that no active cooling systems are installed. Simulations were run first increasing the solar shading (from 0 to 0.8 ), next increasing the base $0.3 \mathrm{ACH}$ with additional night ventilation (from 0 to $1.5 \mathrm{ACH}$ ). The calculation was carried out for the base case NZEB configuration and for the configuration with increased insulation levels for the building envelope (super NZEB).

\subsection{Energy calculation}

Differently from the thermal calculation, the eEnergy ealeulation simulations were performed using EDILCLIMA, version EC700 [46][45], according to the relevant Standard.- The software is, in fact, -based on the national technical specification UNI/TS 1300 series [47][46], and on the CEN relevant standards with adaptation to the Italian context. A quasi-steady-state method is used for calculation of heating and cooling needs, with monthly heat balance and utilization factors in compliance with relevant national and EU standards. Input data (i.e. climatic condition, user behaviour) can be adapted to assess energy performance in accordance with standard or with real operating conditions. The tool allows to model any type of technical system and building components, both in graphical form and in tabular form. Envelope can be modelled using materials from the library or using the default building envelopes. The software allows calculating | thermal transmittance of opaque structures according to the UNI EN ISO 6946 [48][47]. In this analysis the annual energy is computed for the following energy services: space heating, ventilation, domestic hot water production.

In all simulations the internal gains are set to $5 \mathrm{~W} / \mathrm{m}^{2}$ for sensible heat and $2.5 \mathrm{~W} / \mathrm{m}^{2}$ for latent heat, | according to Italian standards [46]. In the building, in line with according the national building code, an air change rate of $0.3 \mathrm{~h}-1$ is considered. Artificial lighting in residential buildings is not taken into account in the energy performance scheme and certification in Italy.

In Table 4 and 5 the characteristics of the reference buildings and scenarios for the Rome and Turin are shown.

\begin{tabular}{|c|c|c|c|c|c|c|}
\hline & Technology & Reference building & $\begin{array}{l}\text { Scenario 1 } \\
\text { Thermal driven } \\
\text { solution }\end{array}$ & $\begin{array}{l}\text { Scenario } 2 \\
\text { Electricity driven } \\
\text { solution }\end{array}$ & $\begin{array}{l}\text { Scenario } 3 \\
\text { Electricity driven } \\
\text { solution (outlaw) }\end{array}$ & $\begin{array}{l}\text { Scenario } 4 \\
\text { Thermal driven } \\
\text { solution (outlaw) }\end{array}$ \\
\hline & $\begin{array}{r}\text { Solar thermal } \\
\text { eollectors }\end{array}$ & 15 modules; $27 \mathrm{~m}^{2}$ & $\begin{array}{l}19 \text { modules; } \\
34 \mathrm{~m}^{2}\end{array}$ & Absent & $\begin{array}{l}18 \text { modules; } \\
33 \mathrm{~m}^{2}\end{array}$ & $\begin{array}{l}19 \text { modules; } \\
34 \mathrm{~m}^{2}\end{array}$ \\
\hline & $P V$ & $\begin{array}{l}89 \text { modules; } \\
142 \mathrm{~m}^{2}\end{array}$ & $\begin{array}{l}89 \text { modules; } \\
142 \mathrm{~m}^{2}\end{array}$ & $\begin{array}{l}89 \text { modules; } \\
142 \mathrm{~m}^{2}\end{array}$ & $\begin{array}{l}100 \text { modules; } \\
163 \mathrm{~m}^{2}\end{array}$ & $\begin{array}{l}6 \text { modules; } \\
9.6 \mathrm{~m}^{2}\end{array}$ \\
\hline & External wall & $\begin{array}{l}\text { wo brick walls }(20 \mathrm{Cm}) \\
\text { with an EPS thermal coating } \\
(8 \mathrm{~cm}) \text { covered by plaster }\end{array}$ & \multicolumn{4}{|c|}{ autoclaved concrete bricks $(30 \mathrm{~cm})$ covered by plaster } \\
\hline & Rogf & \multicolumn{5}{|c|}{ Masonry tilted roof with an XPS thermal coating of $9 \mathrm{~cm}$ covered by a steel plate mounted on wooden planks. } \\
\hline & $\begin{array}{l}\text { Floor above } \\
\text { apartments }\end{array}$ & $\begin{array}{l}\text { Masonry floor with an XPS } \\
\text { thermal coating of } 4 \mathrm{~cm} \text { and } \\
\text { an EPS layer }(4 \mathrm{~cm}) \\
\text { included in the floor heating } \\
\text { system }\end{array}$ & \multicolumn{4}{|c|}{ Masonry floor with an XPS thermal coating of $8 \mathrm{~cm}$. } \\
\hline & Hindens & Traditionalwindows & \multicolumn{4}{|c|}{ Menoblock windows } \\
\hline \multirow{2}{*}{$\begin{array}{l}\text { Heat } \\
\text { stupply }\end{array}$} & Unit & $\begin{array}{l}\text { Heat pump + Condensing } \\
\text { boiler (back up) }\end{array}$ & Cendensing beiler & $\begin{array}{l}\text { Heat pump + } \\
\text { Eondensing boiler } \\
\text { (back up) }\end{array}$ & Absent & Cendensing boiler \\
\hline & $\begin{array}{l}\text { Heating } \\
\text { System }\end{array}$ & Floor heating & Radiaters & $\begin{array}{l}\text { Low temperature } \\
\text { radiators }\end{array}$ & Electric radiators & Radiaters \\
\hline
\end{tabular}


In Rome, transmittances of the external walls and windows are the same as in the base case. The roof and floor above the apartments are the same as the reference building apart from the additional insulation layers which compensates the absence of floor heating in the four scenarios.

In Turin, two of the five scenarios maintain the same transmittance values of the building envelope as in the base case (scenarios 1 and 3), while the other three scenarios have a super NZEB envelope. According to this, scenario 2 has the same characteristics as scenario 1 apart from the lower transmittance values of the envelope and the Mechanical Extract Ventilation (MEV) instead of the MVHR. Similarly, scenario 4 is coupled with scenario 3. In the thermal driven scenarios 1 and 2 solar collectors provide pre heating of water for both heating and DHW services.

As aforementioned in paragraph 4.2, it must be noticed that scenarios 3 and 4 in Rome and scenario 5 in Turin are outlaw either because of the installation of electric radiators as heating system, or because of the tower amount of $\mathrm{PV}$ panels respect to the Standard requirements.

\subsection{Financial calculation}

Prices of proposed low-cost solutions for the envelope (autoclaved blocks, mono-block window) and for the energy systems which were not included in the bill of quantities of the real building (Mechanical extract ventilation and MVHR) in a first stage were derived from official regional price lists, which provide unitary 
costs $\left(€ / \mathrm{m}^{2}\right)$ for materials and labour [49][48]. Lately, it was chosen to ask for costs to real construction companies since it was noticed that price lists generally overpriced values.

| For the external wall-, a company which uses both technologies [50][49] was asked to simulate a real market offer for the reference building, giving disaggregated costs in labour and material of both traditional (brickwall + thermal coating) and new solution (autoclaved blocks). It was observed that the cost of material of the blocks is $15 \%$ lower than traditional solution,; in terms ofConcerning the labour savings results are even more relevant since the impact on the construction time is a man-hours reduction of about $48 \%$. It resulted in a reduction of $16 € / \mathrm{m}^{2}$ in all the scenarios where transmittances of the external walls are the same as in the base case; a reduction of $5 € / \mathrm{m}^{2}$ did occur in the super NZEB scenarios in Turin.

Similarly, disaggregated costs for conventional windows and full mono-block windows were provided by a | construction company [51][50]. In this case it was observed that windows cost in the new solution is higher (about $38 \%$ more than conventional windows) but cost of the subframe is substantially null compared to standard solution. It leads to the overall observation that the full mono-block is cheaper by nearly $20 \%$ with about $60 \%$ time saving in the installation phase. It resulted in a reduction of $40 € / \mathrm{m}^{2}$ compared to the conventional windows.

For the Mechanical Extract ventilation system, as for MVHR, a company simulated a real economic offer to supply the MEV system for the reference building [42][41].

All the other costs of the building envelope and energy systems in the scenarios have been estimated as unitary variation $\left(€ / \mathrm{m}^{3}\right)$ of the original prices included in the bill of quantities or as price variation due to the different couplings of the installed systems.

| The LCC analysis was developed in terms ofconsidering the incremental and actualized savings compared to the base case on 50 years expected lifetime of the building. According to this, only the "Energy related costs" of the overall construction costs have been considered in accordance-agreement to the standard application of the cost-optimal methodology [52][51]. The economic analysis was carried out based on the requirements of relative European Standard [53]_52] taking into account: costs and lifetime of technical solutions implemented in the building configurations, costs for the used fuels, national economic indicators. The net present value (NPV) was selected as key performance indicator.

The maintenance costs and lifetime of the solutions are shown in Table 6. Most of these values have been | taken from the Standard [53]_52] apart from the values related to electric radiators which have been extrapolated from German guidelines VDI 2067 which deals with the calculation of the economic efficiency of building installations.

Table 6. Mmaintenance costs and lifetime of the proposed solutionssolution sets

\begin{tabular}{|c|c|c|c|}
\hline & Technology & $\begin{array}{c}\text { Life Time } \\
\text { [years] }\end{array}$ & $\begin{array}{c}\text { Maintenance } \\
\text { Costs [\%] }\end{array}$ \\
\hline \multicolumn{2}{|c|}{ Solar thermal collectors } & 20 & 0.5 \\
\hline \multirow{2}{*}{\multicolumn{2}{|c|}{$\begin{array}{r}P V \\
\text { Building envelope }\end{array}$}} & 50 & 0.5 \\
\hline & & 50 & 0.5 \\
\hline \multicolumn{2}{|c|}{ Windows } & 30 & 0.5 \\
\hline \multirow{2}{*}{$M V H R$} & Unit & 15 & 4 \\
\hline & Pipes & 30 & 1 \\
\hline \multirow{2}{*}{$M E V$} & Unit & 20 & 4 \\
\hline & Pipes & 30 & 1 \\
\hline \multirow{2}{*}{ Heat pump } & Unit & 20 & 3 \\
\hline & Pipes & 30 & 1 \\
\hline \multirow{2}{*}{ Condensing boiler } & Unit & 20 & 1.5 \\
\hline & Pipes & 30 & 1 \\
\hline \multicolumn{2}{|r|}{ Floor heating } & 50 & 2 \\
\hline \multicolumn{2}{|r|}{ Radiators } & 35 & 1.5 \\
\hline \multicolumn{2}{|c|}{ Electric Radiators } & 22 & 1 \\
\hline
\end{tabular}


Table 7 shows the national economic indicators used for the LCC analysis [54][53].These data wereThe data was extrapolated derived from a preliminary study for the new cost optimal analysis in Italy. Costs for the used fuels are the following: Gas $0.72 € / \mathrm{Sm}^{3}$ sme; Electricity (bought from the grid) $0.20 € / \mathrm{kWh}$; Electricity (sold to the grid) $0.06 € / \mathrm{kWh}$. Estimation of incomes for selling the surplus of renewable electricity to the grid is based on the Italian procedure of the net metering as prescribed in [54]_[55]. The GSE company [56][55] provides on annual basis the economic contribution (CS) for electricity sold to the grid according to this formula:

$C S=(O E: C E i))+(C U s f \times E S)$

Where:

- $O E$ is the product between the amount of energy taken from the grid and the national power exchange price

- $C E i$ is the product between the amount of energy sold to the grid and the price zone available on the Electricity Day-Ahead Market

- CUSf is the annual lump-sum contribution for energy exchange

- ES is minimum, on an annual basis, between the amount of electricity put into and taken from the grid

It was chosen to calculate only the second term of the formula for two main reasons $\div$ F First it was observed that is the heaviest part of the eontribute-contribution. Then, and secondly-the prices for estimating $O E$ and $C E i$ are daily variable so it would have been difficult to assess the precise values. Value of $C U s f$ for the year 2017 were taken from the Arera web site, the Regulatory Authority for Energy, Networks and Environment in Italy_[57] [56] and it corresponds to the price for electricity sold to the grid.

\section{6. $\quad$ Results}

\subsection{Passive cooling}

The first set of simulations carried out-with TRNSYS runs-showed that solar shading alone does not provide adequate thermal comfort with standard $0.3 \mathrm{ACH}$, with discomfort hours always above $20 \%$. The second set showed the improvement of comfort conditions upon the simultaneous application of shading devices and night ventilation cooling strategies. For brevity, Rresults are presented for the best performing configuration, consisting of external solar protection devices with shading factor 0.8 and $1.5 \mathrm{ACH}$ of night ventilation rate.

Figure 3 presents the hourly plot of the operative temperature in three reference apartments, located respectively at first, second and third (upper) floors for a week in July. It can be observed the small amplitude of the operative temperature in the apartments, $3{ }_{-}^{\circ} \mathrm{C}$ maximum in the 24 hours, versus variations up $14{ }_{-}^{\circ} \mathrm{C}$ of the external air temperature. The figure also shows the higher thermal stress in the attic flats, where the operative temperature raises up to $1_{-}^{\circ} \mathrm{C}$ respect to the lower floors. 
Under these conditions and taking into account the comfort category 2 of the relevant standard [43], the number of hours in which the operative temperature exceeds the comfort band is in the $0-1.3 \%$ range for the NZEB configuration in the observation period, while it raises to $0-1.9 \%$ range for the super NZEB configuration. In all cases the discomfort hours are by far below than $5 \%$, limit indicated by the relevant standard.T bee noted, finally, that Finally, the number of hours in the two digits range are calculated for the two flats located in the upper floor, just below the roofs, being negligible in all the other apartments.

An additional test was carried out to check the compliance with category 1 of the relevant standard, to assess if the thermal indoor environment might be significantly deteriorated respect to the requirements for weaker classes of residents. The results are presented in figure 4 and show a significant increase of discomfort hours. The discomfort hours are in the $0-4 \%$ range of the observation period for all the analysed flat but A8, where they reach $10 \%$, for the NZEB configuration, thus above the standard limits. The super NZEB configuration causes an increase of discomfort hours; in three cases (A1, A4, A7) the operative temperatures hours are above the limit in the 5-8\% of the all observation period, while for apartment A8 they reach $14 \%$.

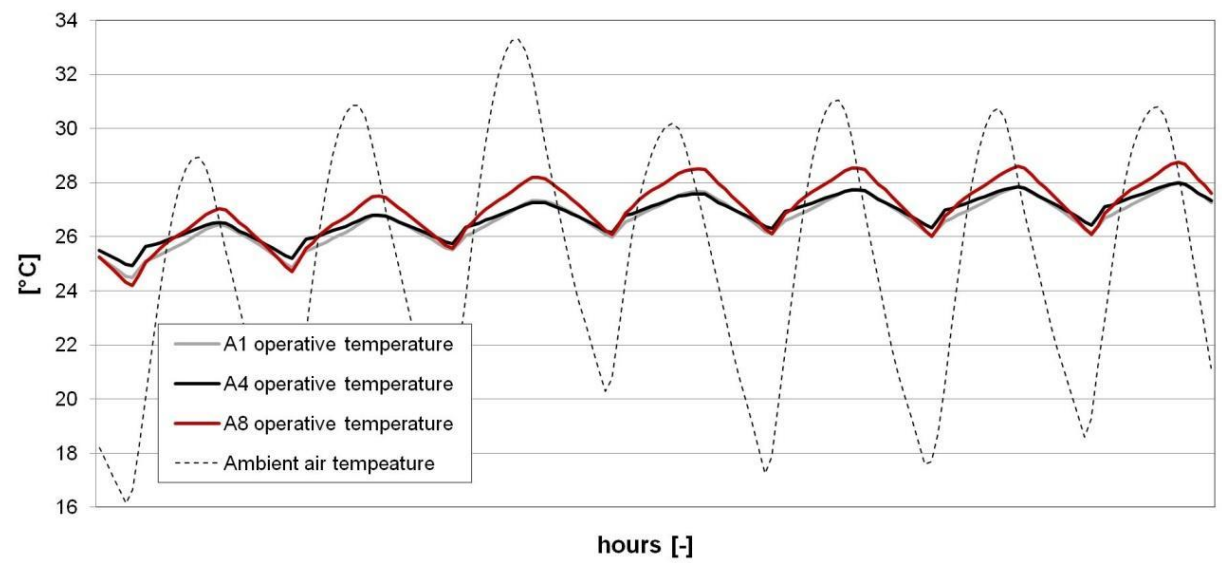

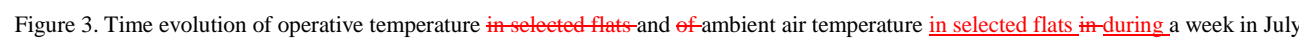

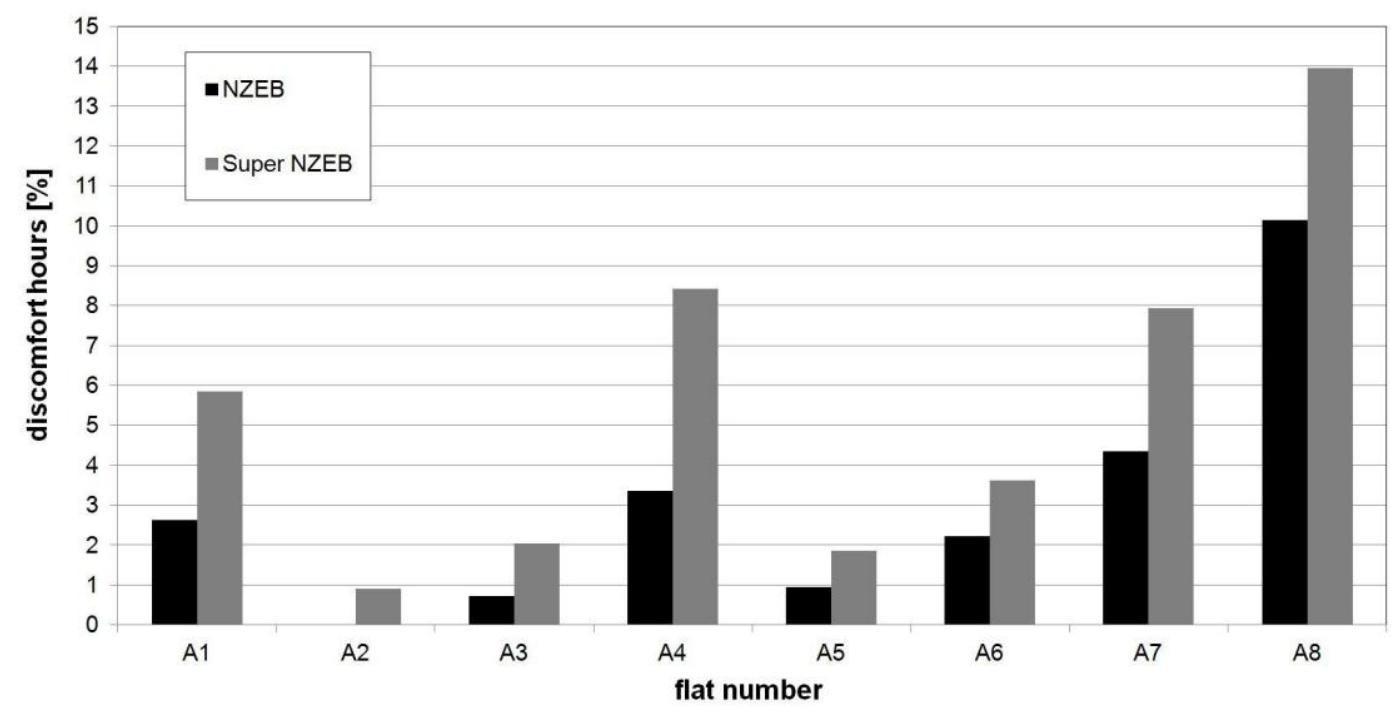

Figure 4. Relative discomfort hours in the investigated portion of the building for NZEB and super NZEB configurations in the June-August period. 
The main outcomes of the analysis are:

- Requirements set for solar protection devices can be achieved with conventional textile and technical shading systems. Air exchange rates can also be easily fulfilled with multiple opening of windows_[58], adequate planning of tay outlayout and facades_façades of the building can ensure even higher rates [59][60][57][58][59]. This implies that passive solutions can be adequately planned and installed at no extra costs.

- The passive cooling solutions generally provides acceptable thermal comfort conditions at tested latitudes, according to the category II requirements of the relevant standard; in factfact, the discomfort hours are always at very low level for category II.

- Higher deviations are calculated for category I, however very low-cost solutions can be implemented. Higher night ventilation rates and improved indoor conditions can be easily achieved by ceiling fans or simple ventilation systems, thus lowering the discomfort hours to acceptable levels. These punctual systems should be installed and switched on only where and when needed. Moreover, they might be fed by the renewable electricity produced at building level, which exceeds the energy needs in many hours during summer, thus having a close to negligible impact on the use of fossil fuels.

\subsection{Energy performance}

In all the scenarios simulated In all the energy simulations carried out with Edilclima, the building obtained the grade A4 which is the highest level of energy performance.; infact, Aatthough the indicator of primary energy (EP) is different for each scenario, it is always much lower than the EP of the reference building to whom the case study is compared. According to the Italian Standard, in each simulation a reference building is defined, which is the same as the case study building in terms ofconcerning the geometry, orientation, geographic location, energy systems, but it has predetermined thermal and energy characteristics. It This allows to calculate thee primary energy limit that must be respected by the case study building.

The final energy and primary non-renewable energy_( $\left.\mathrm{EP}_{\text {nenren }}\right)$ for heating $\left(\mathrm{EPH}_{\text {, }}{ }_{\mathrm{n} e n}\right), \mathrm{DHW}\left(\mathrm{EPW}_{\text {nren }}\right)$ and Formatted: Subscript Ventilation $\left(\mathrm{EPV}_{\text {n }}\right.$ ren $)$ of Rome and Turin are shown in Figure 5 and 6; Table 8 shows the global primary non-renewable energy (EPgl $1_{\text {nrenenrengl } 2}$ 
1

2

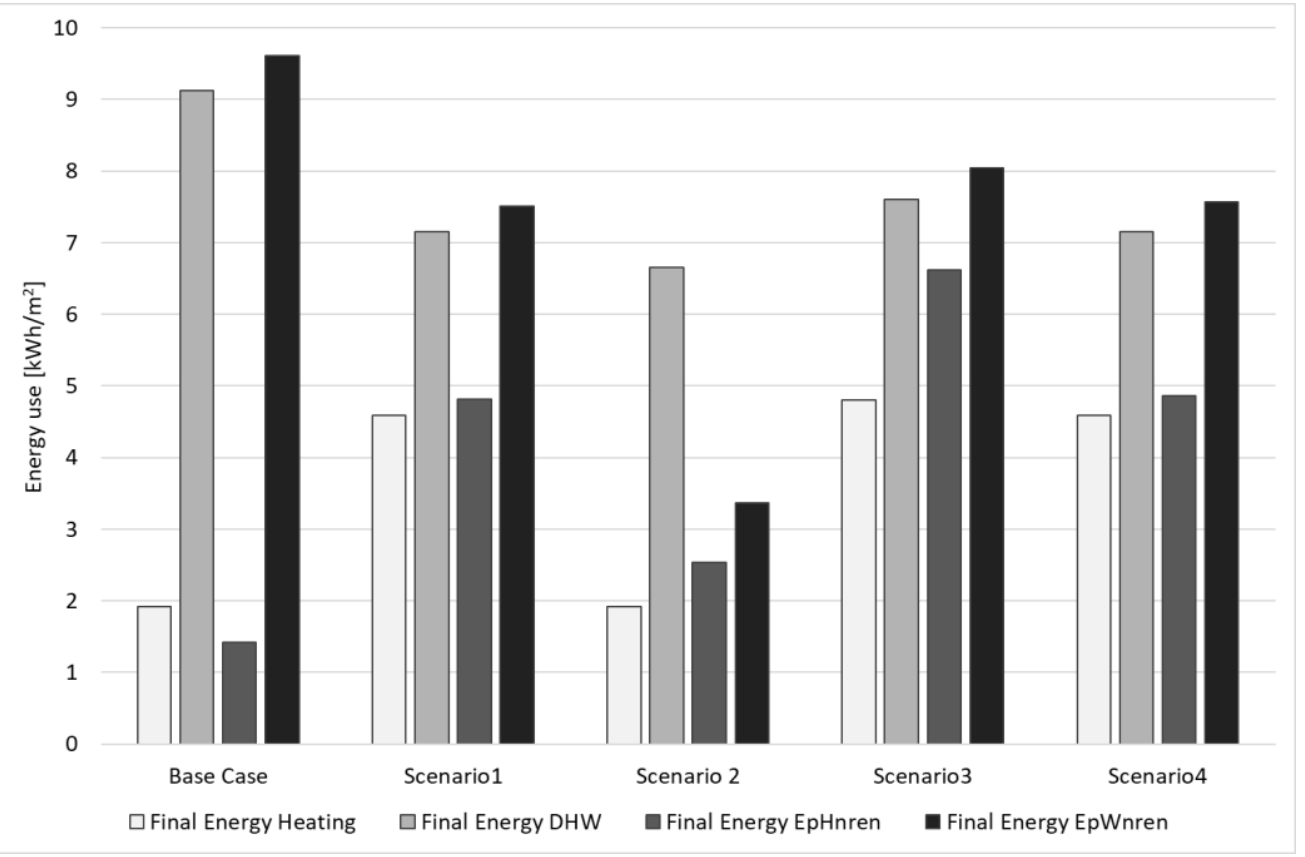

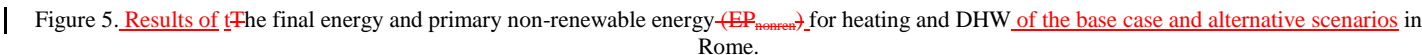

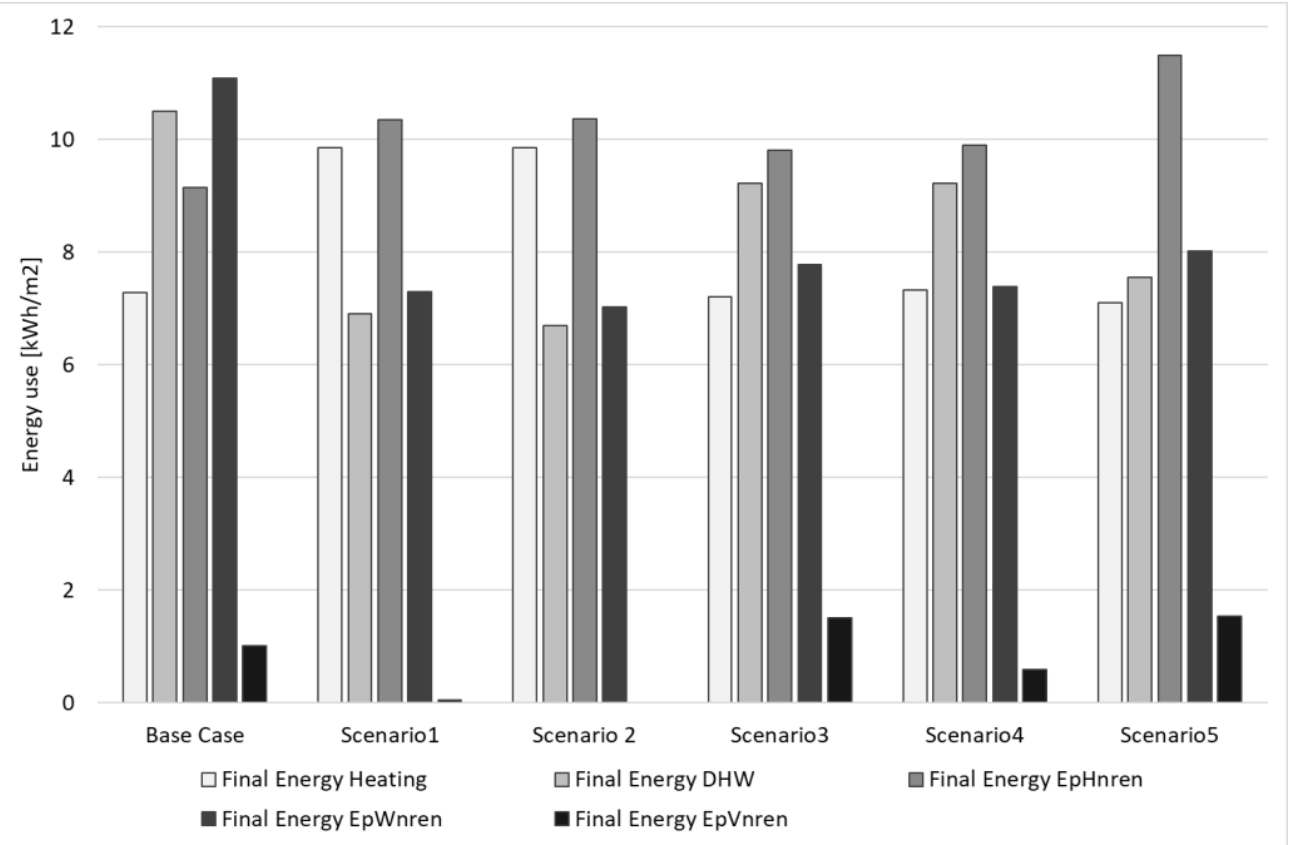

Figure 6. Results of tThe final energy and primary non-renewable energy__( $\left.\mathrm{EP}_{\text {nenren }}\right)$ for heating, DHW and Ventilation of the base case and the alternative scenarios in Turin. 
Table 8. The totalglobal primary non-renewable energy ( $\left.\mathrm{EPgl} l_{\text {nomren }}\right)$ of the base cases and the alternative scenarios in of $\mathrm{Rome}$ and Turin

\begin{tabular}{|c|c|c|c|c|c|c|c|c|c|c|c|}
\hline \multirow{3}{*}{$\begin{array}{l}\mathrm{EPg} \mathrm{l}_{\text {nenre }} \\
\text { ngl } \\
{\left[\mathrm{kWh} / \mathrm{m}^{2}\right.} \\
]\end{array}$} & \multicolumn{5}{|c|}{ Rome } & \multicolumn{6}{|c|}{ Turin } \\
\hline & $\begin{array}{l}\text { Base } \\
\text { case }\end{array}$ & Scen. 1 & Scen. 2 & Scen. 3 & Scen. 4 & $\begin{array}{l}\text { Base } \\
\text { case }\end{array}$ & Scen. 1 & Scen. 2 & Scen. 3 & Scen.4 & Scen.5 \\
\hline & 11.0 & 12.3 & 5.9 & 14.7 & 12.4 & 21.2 & 17.7 & 17.4 & 19.1 & 17.9 & 21.0 \\
\hline
\end{tabular}

In Rome, the EPgl $\underline{n n e n n e n r e n g l ~}_{\text {of }}$ all the scenarios (sum of Heating and DWH) is higher than base case, except

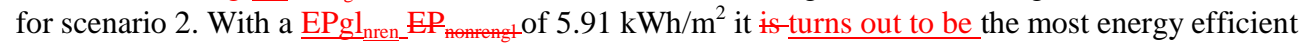
scenario: the use of the heat pump for both heating and DHW allows to exploit as much as possible the potentiality of both the heat pump and the PV panels.

In the base case scenario, there is a high difference between $\mathrm{EPW}_{\text {nenren }}$ ef $\mathrm{DHW}$-and $\mathrm{EPH}_{\text {nren }} \mathrm{Heating}_{\text {, being }}$ the first high $\left(9.6 \mathrm{kWh} / \mathrm{m}^{2}\right)$ and the second very low $\left(1.42 \mathrm{kWh} / \mathrm{m}^{2}\right)$ : two separate systems are used (heat pump and condensing boiler) and a lower amount of solar thermal collectors is installed. On the contrary, in the other scenarios, the $\mathrm{EPH}_{\text {nren }} \mathrm{EP}_{\text {nemren }}$ for heating is always higher compared to the base case thanks to the use of the condensing boiler instead of the heat pump, while a decrease in the $\underline{E P W}_{\text {nren }} \mathrm{EP}_{\text {nonren }}$ for DHW-is always obtained due to increase of solar thermal collectors and/or the optimization of the heat pump.

The worst scenario is number 3. It has the highest $\underline{E P H}_{\text {nren_ }} \mathrm{EP}_{\text {nomren }}$ for heating $\left(6.7 \mathrm{kWh} / \mathrm{m}^{2}\right)$, since, when not provided by the PV panels, energy is directly taken from the grid $\div-$ Ttherefore, firstly much more electricity is absorbed for heating supply compared to amount of electricity needed for the heat pump compressor and secondly the share of non-renewable energy in the electric grid is much higher compared to the renewable part.

Conversely, in Turin all the scenarios present a better energy performance compared to the base case, with globally lower $\mathrm{EPgl}_{\text {nren }} \mathrm{EP}_{\text {nenren. }}$ ranging between 17.38 and $21.05 \mathrm{kWh} / \mathrm{m}^{2}$.

The best scenario is number 2, where the $\underline{\mathrm{EPH}}_{\mathrm{nren}} \mathrm{EP}_{\text {nonren, }}$ for heating is slightly higher than base case (10.4 vs $9.1 \mathrm{kWh} / \mathrm{m}^{2}$.) due to the use of condensing boiler, but the EPW ${ }_{\text {nren_ }} \mathrm{EP}_{\text {nenren }}$ for DHW is much lower (7.0 vs $11.1 \mathrm{kWh} / \mathrm{m}^{2}$ ) thanks to the installation of twice as many solar thermal collectors. The EPV ventilation is null: the installed MEV requires a lower amount of electricity compared to the MVHR and so, being scenario 2 a thermal driven solution, the highest part of electricity from PV panels can be used for the mechanical ventilation system.

Results of scenario 1 are coupled with the ones of scenario $2 . ;$ similarly Similarly, also scenarios 3 and 4 couple between themselves. The $\mathrm{EP}_{\text {nenren }}$ in these two couples are aligned: differences among the values range between $1 \%$ for heating and 5\% for DHW. These differences are due to the fact that scenarios 1 and 3 have a standard NZEB envelope and a MVHR, while scenarios 2 and 4 have a super NZEB envelope and a MEV. As a matter of fact, the super NZEB envelope almost does not affect the $\underline{E P H}_{\text {nren_EP }} \mathrm{Ennen}_{\text {nor heating }}$ but it has a little influence on the $\mathrm{EPW}_{\mathrm{nren}} \mathrm{EP}_{\text {nonren }}$ for DHW. In fact, in the couple 1-2, solar thermal collectors provide pre-heats water for both heating and DHW: the lower transmittance values of the envelope in | scenario 2 allow to employ the solar collectors more for DHW than for heating, reducing the $\mathrm{EP}_{\text {nerren }}$ up to $4 \%$ compared to scenario 1 . In cases 3 and 4, DHW and heating are supplied by the heat pump; being scenario 4 a super NZEB, lower energy needs are required so a higher amount of electricity from PV panels can be provided to the heat pump for DHW, reducing the $\mathrm{EP}_{\text {nenren }}$ up to $5 \%$ compared to scenario 3 .

In scenario 3 and 5, the $\mathrm{EPV}_{\text {nren_ }} \mathrm{EP}_{\text {nemren }}$ for ventilation-is higher than base case, since more electricity from PV panels is absorbed for heating supply compared to the other scenarios.

| Table 9. Results of eEnergy consumption and energy production in Rome and Turin for the base cases and the alternative scenarios

\begin{tabular}{|l|l|l|l|l|}
\hline Scenarios & $\begin{array}{l}\text { Electricity } \\
\text { consumption } \\
{[\mathrm{kWh}]}\end{array}$ & $\begin{array}{l}\text { Electricity } \\
\text { production } \\
{[\mathrm{kWh}]}\end{array}$ & $\begin{array}{c}\text { Gas } \\
\text { consumption } \\
{\left[\mathrm{Sm}_{\mathbf{3}} \mathrm{e}\right]}\end{array}$ \\
\hline
\end{tabular}




\begin{tabular}{|c|c|c|c|c|}
\hline \multirow{4}{*}{ Rome } & Base case & 1601 & 20618 & 2324 \\
\cline { 2 - 5 } & Scenario 1 & 0 & 23060 & 2913 \\
\cline { 2 - 5 } & Scenario 2 & 7149 & 10513 & 98 \\
\cline { 2 - 5 } & Scenario 3 & 8604 & 22934 & 1890 \\
\cline { 2 - 5 } & Scenario 4 & 304 & 363 & 2913 \\
\hline \multirow{4}{*}{ Turin } & Base case & 8490 & 13277 & 3481 \\
\cline { 2 - 5 } & Scenario 1 & 78 & 13676 & 4171 \\
\cline { 2 - 5 } & Scenario 2 & 0 & 16666 & 4110 \\
\cline { 2 - 5 } & Scenario 3 & 18004 & 4086 & 1212 \\
\cline { 2 - 5 } & Scenario 4 & 16340 & 5428 & 1234 \\
\cline { 2 - 5 } & Scenario 5 & 16864 & 14068 & 1876 \\
\hline
\end{tabular}

In table 9 the energy consumption of electricity and gas and the renewable energy production are shown. Both in Rome and Turin, the thermal driven scenarios ( 1 and 4 in Rome and 1 and 2 in Turin) have almost zero electricity consumption and consume only a slightly higher amount of gas compared to the base case (up to $26 \%$ more in Rome) thanks due to the greater number of solar thermal collectors installed. Additionally, in the base case in Turin the back-up condensing boiler does often intervene instead of the heat pump for heating supply due to the lower outdoor temperature. It contributes to align the data of gas consumption between the base case and the thermal driven scenarios which only use condensing boiler for space heating.

Conversely, in electricity driven scenario 2 in Rome the use of the heat pump for both heating and DHW make the electricity consumption arise up to $346 \%$ and the gas consumption decreases up to zero; in Turin electricity and gas consumption in electricity-driven scenarios are both high.

\subsection{Economic analysis and LCC results}

Two additional scenarios, called S3b and S5b, have been introduced in the financial analysis for respectively Rome and Turin, as variations of scenarios 3 and 5. In these variants-variations of the scenarios 3 and 5, a lower investment cost for the electric radiators has been proposed. Due to the variability in the market price of these systems, it was chosen to show two representative costs in these range of prices.

In Table 10 the Net Present Values (NPV) and the energy related construction costs are shown for each scenario; these unitary NPVs $\left(€ / \mathrm{m}^{2}\right)$ are expressed in terms of actualized savings compared to the base case on 50 years expected lifetime of the building.

Table 10. Results of the Net Present Values (NPV) and the-energy related construction costs in Rome and Turin for the base cases and the alternative scenarios

\begin{tabular}{|c|c|c|c|}
\hline \multirow{4}{*}{ Scenarios } & $\begin{array}{c}\text { Energy related } \\
\text { construction costs } \\
{\left[€ / \mathrm{m}^{2}\right]}\end{array}$ & $\begin{array}{c}\mathrm{NPV} \\
{\left[€ / \mathrm{m}^{2}\right]}\end{array}$ \\
\hline \multirow{4}{*}{ Rome } & Base case & 389 & - \\
\cline { 2 - 4 } & Scenario 1 & 310 & 133 \\
\cline { 2 - 4 } & Scenario 2 & 321 & 111 \\
\cline { 2 - 4 } & Scenario 3 & 296 & 143 \\
\cline { 2 - 4 } & Scenario 4 & 295 & 150 \\
\hline \multirow{4}{*}{ Turin } & Scenario 3b & 287 & 163 \\
\hline & Base case & 447 & - \\
\cline { 2 - 4 } & Scenario 1 & 384 & 121 \\
\cline { 2 - 4 } & Scenario 2 & 385 & 158 \\
\hline
\end{tabular}




\begin{tabular}{|c|c|c|c|}
\hline \multirow{4}{*}{ Scenario 3 } & 382 & 77 \\
\cline { 2 - 4 } & Scenario 4 & 383 & 122 \\
\cline { 2 - 4 } & Scenario 5 & 391 & 105 \\
\hline & Scenario 5b & 383 & 121 \\
\hline
\end{tabular}

In graphs 7 and 8 the cash flows of the scenarios over the 50-year life time of the building for the two climate zones are shown. The occurring positive and negative variations in the trends, which make the slope | of the line vary and the savings increase or decrease rapidly, are due to the one-off replacement of the technical systems. The replacements are also expressed as costs difference between the scenarios and the | base cases. On this note, $\div$ when the scenario has lower costs, there are savings and the slope of the line increases, when the scenario has higher replacement costs compared to the base case there are expenses and the slope of the line decreases. This can be observed, for example, in figure 7 for scenarios S3b and S3 in which high savings compared to the base case do occur around year 20 since replacement of the technical systems are avoided, but similar or higher expenses, compared to the base case, are registered around year 22, which compensate for the previous savings. Similarly, in figure 8 for scenarios S2 and S4 an accentuated cash flow saving do occur for the same reasons.

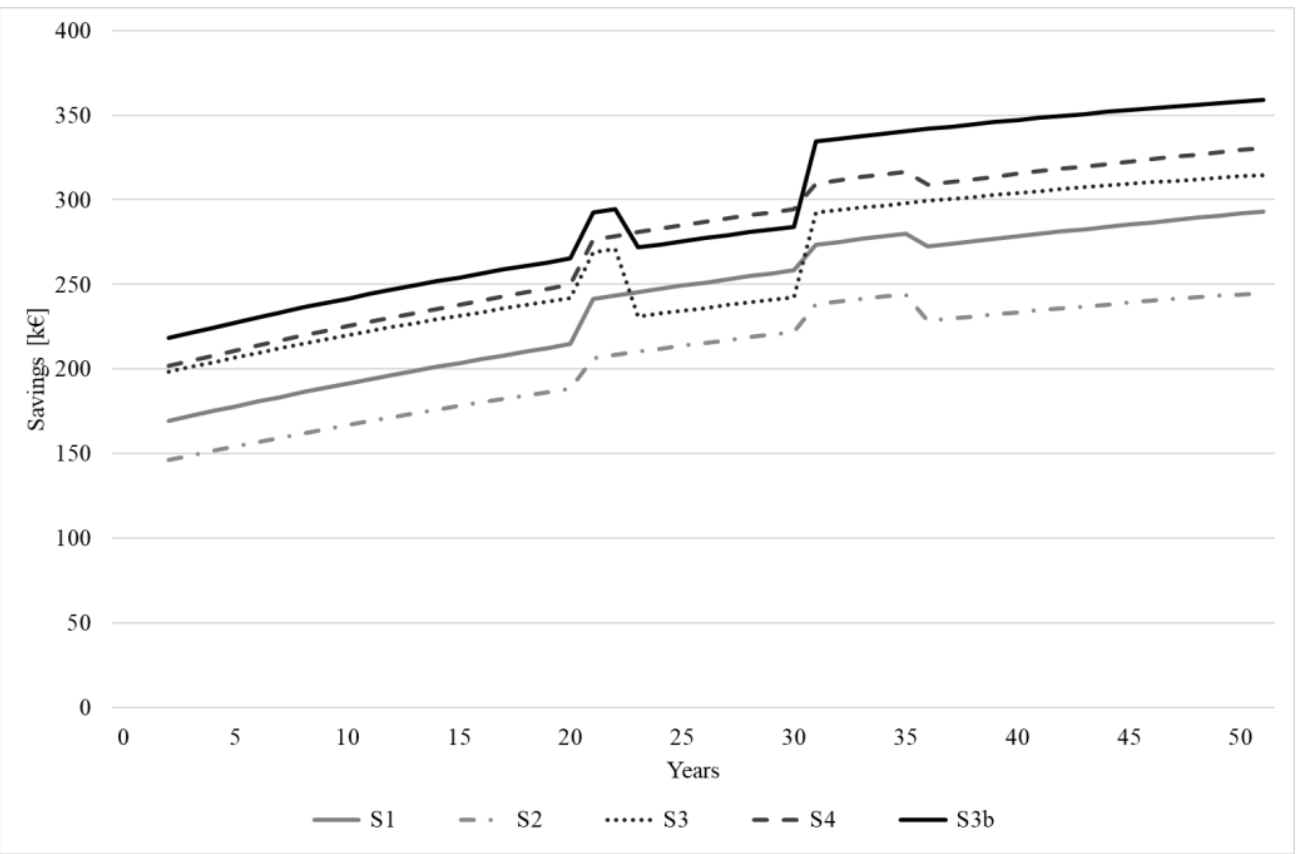

Figure 7. Results of the Life Cycle Cost (LCC)CC analysis in Rome for the alternative scenarios. Results are expressed in terms of actualized savings compared to the base case on 50 years expected lifetime of the building. 


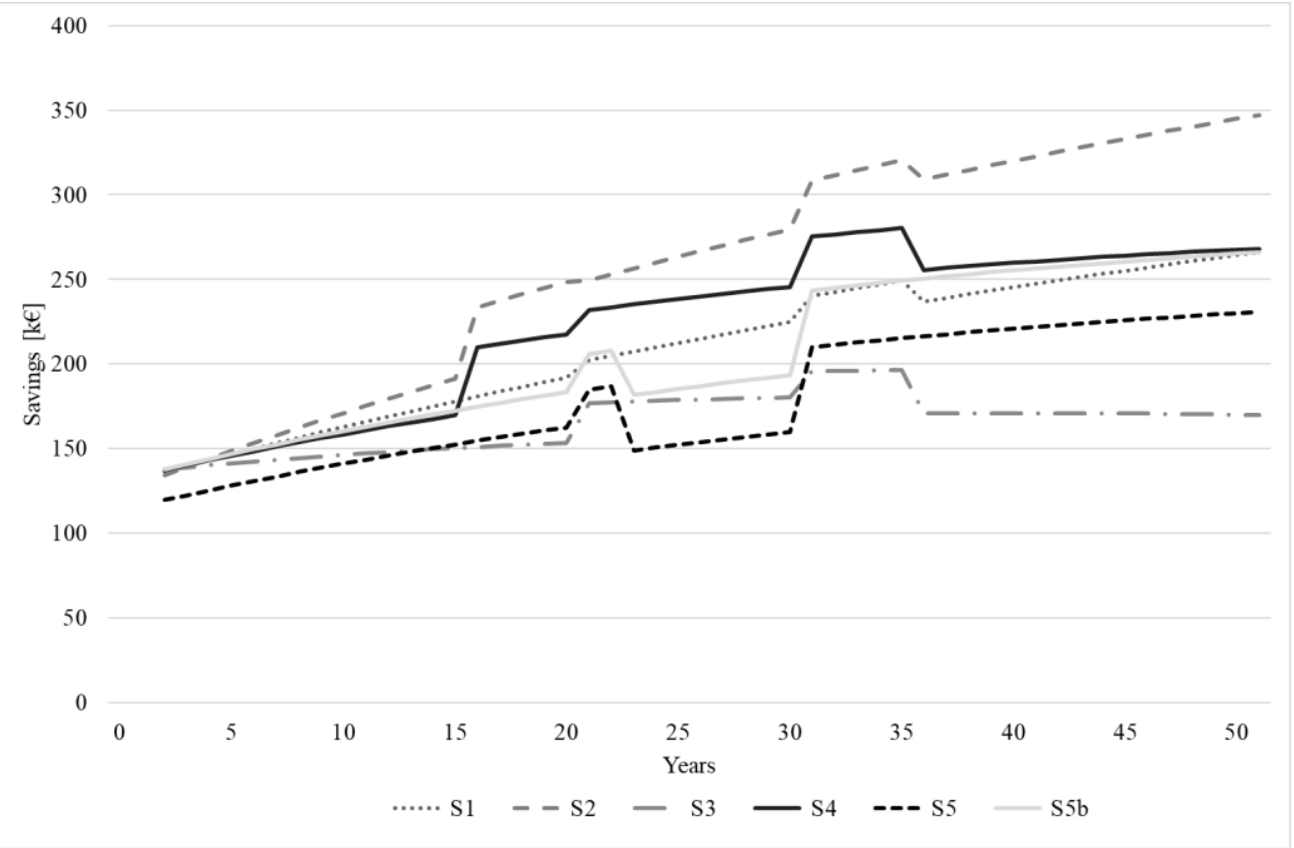

Figure 8. Results of the Life Cycle Cost (LCC)C analysis in Turin for the alternative scenarios. Results are expressed in terms of actualized savings compared to the base case on 50 years expected lifetime of the building.

\section{LCC analysis in Turin}

It can be noted that all scenarios in the two climate zones allow both reductions in the construction costs and savings in a long-term perspective. In the life cycle cost analysis three types of costs have been considered: maintenance costs of the technical systems and envelope, energy costs, and replacements costs based on the lifetime of each technology.

In Rome, the development of low-cost technical solutions in the construction phase guarantees up to $26 \%$ reduction of investment costs. All scenarios have lower annual maintenance costs for the envelope compared to the base case. The ; differences among scenarios are mainly registered in terms ofas variations of maintenance costs for the technical systems and energy costs. The best scenario is $3 \mathrm{~b}$, which shows the lowest initial construction costs $\left(287 € / \mathrm{m}^{2}\right)$ and the highest NPV $\left(163 € / \mathrm{m}^{2}\right)$. The absence of technical system for heating supply allows to considerably reduce maintenance and replacement costs: at the end of the 50 years up to $€ 329^{\prime} 000$ are saved for maintenance costs of technical system compared to the base case. It compensates for the annual energy expense, which is much higher than the base case, achieving a total actualized expense of about $€ 93^{\prime} 000$ more than the base case. High profits can be also achieved with scenarios 4 and 3 ; the main variation between scenario $3 \mathrm{~b}$ and 4 is due to the difference in savings for systems replacement, which are much higher in scenario $3 b$. It has to be observed that these three scenarios are outlaw. Considering only the scenarios compliant with legal standard, the most efficient is number 1 .

In Turin, up to $15 \%$ of savings in investment costs were obtained with scenario 3 . Construction costs of the five scenarios are very similar to each other reaching a maximum percentage difference of about $2 \%$ between | 3 and scenario 5-: Iin fact, when the expense for the envelope are higher (super NZEB) it is balanced by cheaper technical systems (MEV instead of MVHR, absence of solar thermal collectors, elimination of heat | supply system $) \div$ Aatso in this case differences among scenarios are mainly registered in termsas of variations of maintenance costs for the technical systems and energy costs.

Scenario 2 is the most efficient from a long-term perspective showing a NPV of $158 € / \mathrm{m}^{2}$ : after 50 years maintenance costs for renewable system and envelope are higher than the base case (actualized expense of 
respectively $€ 12^{\prime} 000$ more than the base case), , but Nevertheless, operational energy costs and maintenance costs for technical systems are much lower (actualized savings of about $€ 398^{\prime} 000$ for maintenance costs and $€ 106^{\prime} 000$ for energy costs). The replacement of technical system is also less expensive than base case, since the condensing boiler is used instead of the heat pump and the MEV instead of the MVHR.

Scenarios 1, 4 and 5b, despite the differences in trends, show aligned NPV at the end of the 50 years. A great impact on the trend variations among these scenarios is given by the different costs for systems replacement.

The outlaw scenario $5 \mathrm{~b}$ allows the highest savings for maintenance costs of the technical systems but on the other side it entails an increase of costs for PV panels, envelope and energy due to the high amount of electricity taken from the grid as it happens in scenarios 3 and 4. As shown in Table 9, despite the high electricity consumption, the amount of energy sold to the grid is also very high, contrary to cases 3 and 4 where the energy sold to the grid is considerably lower than the bought one. Based on the procedure of net metering, the energy payed to the building owner corresponds to the minimum between the amount of electricity sold and bought from the grid: in this case, being these two values quite aligned and very high, the annual incomes are much more than the other scenarios.

\section{Conclusion}

In this paper solution sets for reducing construction costs of new nearly zero energy multi-family houses were explored in a life cycle perspective. Conversely to the typical methodology of cost-optimal analysis, in this study alternative constructive strategies and unconventional combinations of technical solutions have been proposed; , analysing als $\theta$ the efficacy of forefront proposals, ${ }_{2}$-currently forbidden in Italy according to the relevant Standard, were also analysed. The real case study building, located in the centre of Italy, was standardized and adapted to the minimum Nearly Zero Energy Building ZEB requirements of the two reference-climatic zones chosen for the analysis (Rome and Turin). The choice of an existing building allowed to carry out a more-very realistic evaluation of the cost effectiveness of the proposed variants, duethanks-to the availability of technical and economic data based on real market instead of on average values. The LCC analysis also allowed to compare all the scenarios in a life cycle perspective, including the annual operational, maintenance and replacements costs based on the lifetime of each technology.

In a first stage of analysis, since the real building was not provided with a cooling system, a thermal | calculation was performed. This analysis was aimed to to assess whether the use of passive solutions (solar protection and night ventilation cooling) might avoid the installation of active cooling to prevent summer overheating, thus keeping lower costs for design and installation of such systems. Results demonstrated that low-cost passive strategies can be adequately planned and installed at no extra costs, providing acceptable | thermal comfort conditions at tested latitudes. $\div$ Iin the three reference apartments, located respectively at first, second and third (upper) floors, results show that the discomfort hours in summer period are by far below than $5 \%$, limit indicated by the relevant standard.

Lately, results of the energy calculation performed on the low-costs scenarios in Rome and Turin demonstrated that all the variants reached the highest grade of energy performance (level A4). Although, it was observed that in all the scenarios in Rome, except for number 2, the global primary non-renewable energy indicators $\left(\mathrm{EPg} \mathrm{l}_{\text {nrenenrengl }}\right)$ is higher than base case, with a maximum percentage difference of $34 \%$. The most energy efficient is the electricity driven scenario number 2 . In this scenario, where the use of the heat pump for both heating and Domestic Hot WaterPHW allows to exploit as much as possible the potentiality of both the heat pump and the Photovoltaic panels V panels. The $\mathrm{EPg}_{\underline{n+e n}} \mathrm{EP}_{\text {nenrengt }}$ is $46 \%$ lower than the base case.

Conversely in Turin, all the scenarios show a lower $\mathrm{EPgl}_{\text {nren }} \mathrm{EP}_{\text {nenrengl }}$ compared to the base case, with a reduction up to $18 \%$ between base case and the thermal driven scenario 2 . It is also the most efficient: electricity consumption for heating is reduced ${ }_{i} ;$ the high number of solar collectors allows to minimize thermal consumption for Domestic Hot Water DHW; and the installed Mechanical Extract VentilationEV 
requires a lower amount of electricity compared to the MVHR-Mechanical Ventilation with Heat Recovery of the base case, maximizing the contribute of Photovoltaic panels PV panels.

From the financial perspective, it was demonstrated that, compared to the base case, all the scenarios in the two climate zones allow both reductions in the construction costs, up to $26 \%$ in Rome, and savings over the 50-year life time of the building, up to $163 € / \mathrm{m}^{2}$ in Rome. Results also show the importance of an accurate | evaluation of the maintenance and replacement costs of each technology. In fact,-, since it was observed that these expenses have a key role in the assessment of the most profitable scenario, making the differences among the proposed solution sets.

In Rome, the most economically efficient is scenario $3 \mathrm{~b}$, having both the lowest investment costs $\left(287 € / \mathrm{m}^{2}\right)$ and the highest Net Present ValuePV $\left(163 € / \mathrm{m}^{2}\right)$. It This is a variant of the electricity driven scenario 3 but is; not compliant with Standard requirements, where-In this scenario the investment costs of the electric radiators are lower than scenario 3 and the absence of technical system for heating supply allows to considerably reduce maintenance and replacement costs.

In Turin, differently from Rome, the most energy efficient scenario, is number 2, is-which is also the most profitable $\div$ - it shows the highest Net Present ValueNPV $(158 € / \mathrm{m} 2)$ although it doesn't have also the lowest construction costs. Nevertheless, it can be observed that investment costs of the five scenarios in Turin are | very similar, reaching a maximum percentage difference of about $2 \%$ between 3 and scenario 5 . These results confirm that differences among the scenarios can be only assessed in a long-term perspective, highlighting the importance of developing Life Cycle CosteC analysis on buildings.

Limitations of the present study included: boundary conditions, characteristic of the reference building and the technological solution; fFuture developments of this researehwill take them into account, as well as $\underline{\underline{z}}$ more holistic approach to costs (as those related to design and preliminaries) and to would consider the inclusion of more detailed costs occurring in the building construction process, such as design and planning eosts and preliminaries factors affecting the energy performances across time (as the impact of aging of building and systems elements and the impact of climate change).- Preliminaries costs, also called indirect, include expenses not related to the building site, as commercial and alministrative costs, which cannot be directly imputed to the construction process itself, but may have a high impact on the entire process. The inclusion of these variables and the evaluation of alternative and uncenventional technologies, would improve the cost optimal analysis of the building, reaching the best compromise between energy and economic efficiency from a global perspective.

\section{AKNOWLEDGEMENTS}

The CoNZEBs project has received funding from the European Union's Horizon 2020 research and innovation programme under grant agreement no. 754046. The article reflects the authors' view. The Commission is not responsible for any use that may be made of the information it contains.

\section{References}

[1] Horizon 2020 EU Research and Innovation programme. Available at: http://ec.europa.eu/research/participants/portal/desktop/en/funding/reference_docs.html [2] Green Paper, A 2030 framework for climate and energy policies, COM (2013)169 http://ec.europa.eu/energy/consultations/20130702 green paper 2030en.htm

[3] 2050 Energy strategy. Available at: https://ec.europa.eu/energy/en/topics/energy-strategy-and-energyunion/2050-energy-strategy

[4] Eurostat. Final energy consumption by sector. 2016. Available at: http://ec.europa.eu/eurostat/en/web/products-datasets/-/T2020_34

[5] European Parliament and Council: Directive 2010/31/EU of the European Parliament and of the Council of 19 May 2010 on the energy performance of buildings. 2010. Official Journal L 153, 18.6.2010, p. 13-35. Available at http://eur-lex.europa.eu/legal-content/EN/TXT/?uri=OJ:L:2010:153:TOC.

[6] S. Attia, P. Eleftheriou, F. Xeni, R. Morlot, C. Menezo, V. Kostopoulos, M. Betsi, I. Kalaitzoglou, L. Pagliano, M. Cellura, M. Almeida, M. Ferreira, T. Baracu, V. Badescu, R. Crutescu, J.M. Hidalgo-Betanzos, 
et al. Overview and future challenges of nearly zero energy buildings (nZEB) design in Southern Europe, Energy and Buildings, 2017, vol 155, pp.439-458 [6]

[7] J. Schnieders, W. Feist, L. Rongen, Passive Houses for different climate zones, Energy and Buildings, 2015, vol. 105, pp. 71-87.

[8] A. Pathan, A. Mavrogianni, A. Summerfield, T. Oreszczyn, M. Davies, Monitoring summer indoor overheating in the London housing stock, Energy and Buildings, 2017, vol. 141, pp.361-378.

[9] S. Colcough , O. Kinnane , N. Hewitt , P. Griffiths , Investigation Of nZEB Social Housing built to the Passive House Standard, Energy \& Buildings, 2018, vol 179, pp. 344-359.

10-S. K. M. Chvatal, H. Corvacho, The impact of increasing the building envelope insulation upon the risk of overheating in summer and an increased energy consumption, Journal of Building Performance Simulation, 2009, vol. 4, pp. 267-282.

4[10] A. Pathan, A. Mavrogianni, A. Summerfield, T. Oreszczyn, M. Davies, Monitoring summer indoor overheating in the London housing stock, Energy and Buildings, 2017, vol. 141, pp.361-378.

$4[11]$ G. Murano, I. Ballarini, D.Dirutigliano, E.Primo, V. Corrado, The significant imbalance of nZEB energy need for heating and cooling in Italian climatic zones, Energy Procedia, 2017, vol. 126, pp. 258-265.

12] F. Ascione, R.F. De Masi, F. de Rossi, S. Ruggiero, G. P. Vanoli, Optimization of building envelope design for nZEBs in Mediterranean climate: Performance analysis of residential case study, Applied Energy, 2016, vol 183, pp. 938-957.

-A. Figueiredo, J. Kämpf, R. Vicente, Passive house optimization for Portugal: overheating evaluation and energy performance, Energy and Buildings, 2016, vol. 188, pp. 181-196. [13]

14\}S. Guillén-Lambea, B. Rodríguez-Soria, J.M. Marín, Comfort settings and energy demand for residential nZEB in warm climates, Applied Energy, 2017, vol. 202, pp 471-486. $47[14]$

$15]$ P.Huang, G. Huang, Y. Sun, Uncertainty-based life-cycle analysis of near-zero energy buildings for performance improvements, Applied Energy, 2018, vol. 213, pp. 486-498

16] P.Huang, G. Huang, Y. Sun, A robust design of nearly zero energy building systems considering performance degradation and maintenance, Energy, 2018, vol. 163, pp. 905-919. F. Ascione, R.F. De Masi, F. de Rossi, S. Ruggiero, G. P. Vanoli, Optimization of building envelope design for $n Z E B s$ in Mediterranean climate: Performance analysis of residential case study, Applied Energy, 2016, vol 183, pp. 938957.

$16]$

[17] M. Hu, Does Zero Energy Building Cost More? - An Empirical Comparison of the Construction Costs for Zero Energy Education Building in United States, Sustainable Cities and Society, 2019, vo. 45, pp. 324334.A. Figueiredo, J. Kämpf, R. Vicente, Passive house optimization for Portugal: overheating evaluation and energy performance, Energy and Buildings, 2016, vol. 188, pp. 181196.

[18] D. D’Agostino, D. Parker, A framework for the cost-optimal design of nearly zero energy buildings (NZEBs) in representative climates across Europe, Energy, 2018, vol. 149, pp. 814-829

[19] W. Wu, H. M. Skye, P. A. Domanski, Selecting HVAC systems to achieve comfortable and cost-effective residential net-zero energy buildings, Applied Energy 212 (2018) 577-591.

20]EU, 244/2012. Commission Delegated Regulation No 244/2012 of 16 January 2012. Supplementing Directive 2010/31/EU of the European Parliament and of the Council on the energy Performance of Buildings by Establishing a Comparative Methodology Framework for Calculating Cost-optimal Levels of Minimum Energy Performance Requirements for Buildings and Building Elements. Official Journal of the European Union.

$21]$ D. D'Agostino, L. Mazzarella, What is a Nearly zero energy building? Overview, implementation and comparison of definitions, Journal of Building Engineering, 2019, vol. 21, pp. 200-212

22] J. Kurnitskia, A. Saarib, T. Kalameesc, M. Vuolled, J. Niemeläd, T. Tarke, Cost optimal and nearly zero (nZEB) energy performance calculations for residential buildings with REHVA definition for nZEB national implementation, Energy and Buildings, 2011, vol. 43, pp. 3279-3288.

$20\}$ 23] E. Pikas, M. Thalfeldt, J. Kurnitski, R. Liias, Extra cost analyses of two apartment buildings for achieving nearly zero and low energy buildings, Energy, 2015, VOL. 84, pp. 623-633

]24] M.1 Villa-Arrietaa, A. Sumperb, Economic evaluation of Nearly Zero Energy Cities Economic evaluation of Nearly Zero Energy Cities, Applied Energy 2019, vol. 237, pp. 404-416. 
25] P. Huang, Y. Sun, A clustering-based grouping method of nearly zero energy buildings for performance improvements, Applied Energy, 2019, vol. 235, pp. 43-55. $22]_{1}$

3][26] P.M. Congedo, C. Baglivo, D. D'Agostino, I. Zacà, Cost-optimal design for nearly zero energy office buildings located in warm climates, Energy, 2015, vol. 91, pp. 967-982

D. D'Agestine, L. Mazzarella, What is a Nearly zero energy building? Overview, implementation and eomparison of definitions, Journal of Building Engineering, 2019, vol. 21, pp. 200212

24] J. Kurnitskia, A. Saarib, T. Kalameese, M. Vuolled, J. Niemeläd, T. Tarke, Cost optimal and nearly zero* (nZEB) energy performance calculations for residential buildings with REHVA definition for nZEB national implementation, Energy and Buildings, 2011, vol. 43, pp. 32793288.

25] E. Pikas, M. Thalfeldt, J. Kurnitski, R. Liias, Extra cost analyses of two apartment buildings for achieving nearly zero and low energy buildings, Energy, 2015, VOL. 84, pp. 623-633

26] M.1 Villa-Arrietaa, A. Sumperb, Economic evaluation of Nearly Zero Energy Cities Economic evaluation of Nearly Zero Energy Cities, Applied Energy 2019, vol. 237, pp. $404-416$.

[27] C. Becchio, M. C. Bottero, S. P. Corgnati, C. Ghiglione, nZEB design: challenging between energy and economic targets, Energy Procedia, 2015, vol. 78, pp. 2070 - 2075.

[28] V.M. Barthelmes, C. Becchio, S.P. Corgnati, C. Guala, M. Lequio, Replicability of nZEBs on real estate market in Mediterranean countries

[29] BPIE (Buildings Performance Institute Europe). Implementing the costoptimal methodology in EU countries. Pages 1-82. ISBN 9789491143083. http://bpie.eu/costoptimalmethodology.html

[30] F. Reda, Z. Fatima, Northern European nearly zero energy building concepts for apartment buildings using integrated solar technologies and dynamic occupancy profile: Focus on Finland and other Northern European countries, Applied Energy, 2019, vol. 237, pp. 598-617.

31] E. Annunziata, M. Frey, F. Rizzi , Towards nearly zero-energy buildings: The state of art of national regulations in Europe, Energy, 2013, vol. 57, pp. 125-133.

31] CA EPBD, Concerted action EPBD: Implementing the energy performance of buildings directive (EPBD). Information of the joint initiative of EU Member States and the European Commission, Available at: http://www.epbel ca.eu/themes/cost optimum.

[32] S. Attia, Net Zero Energy Buildings (NZEB), 1st Edition, Butterworth-Heinemann, 2018

[33] Hamdy, M., Siren, K., Attia, S., Impact of financial assumptions on the cost optimality towards nearly zero energy buildings: a case study. Energy and Buildings, 2017, vol. 153, pp. 421- 438.

[34] Buildings Performance Institute Europe (BPIE), Europe's buildings under the microscope: A country-bycountry review of the energy performance of buildings.

[35] M. Ferrara, V. Monetti, E. Fabrizio, Cost-Optimal Analysis for Nearly Zero Energy Buildings Design and Optimization: A Critical Review, Energies, 2018, vol. 11, n. 1478.

[36] B. Heymer, Sh. Pless, S. Hackel, 2016. Zero net energy building cost and feasibility. Webinar. Available from: http://www.seventhwave.org/sites/default/files/zero-energywebinar-slides-052616.pdf (accessed 20.01.18).

[37] DM 26 giugno 2015: Application of calculation methodologies for energy performance and definition of prescription and minimum requirements of buildings. 2015.

[38] Dlsg 28/2011: Implementation of Directive 2009/28/CE on the promotion of the use of energy from renewable sources and amending and subsequently repealing Directives 2001/77/EC and 2003/30/EC, 2011.

[39] PANZEB: Piano d'Azione Nazionale per incrementare gli edifici ad energia quasi zero, 2016. Available at.:

http://www.sviluppoeconomico.gov.it/images/stories/normativa/all_decreto_interministeriale_19_giugno_20 17_panzeb.pdf

[40] CoNZEBs - Solution sets for the cost reduction of new Nearly Zero-Energy Buildings, EU H2020 Funded Project, Contract number 754046 (www.conzebs.eu)

[41] V. Corrado, I. Ballarini, S. Paduos, Sviluppo della metodologia comparativa costoptimal secondo Direttiva 2010/31/UE, Ricerca di sistema elettrico, Report RdS/2013/144.

[42] C. Buttà: Personal Communication, Mydatec.

Formatted: Font: (Default) Times New Roman, Font color: Auto

Formatted: Justified, Space After: $8 \mathrm{pt}$, Line spacing: Multiple $1.08 \mathrm{II}$

Formatted: Justified, No bullets 0 numbering

Formatted: Italian (Italy)

Formatted: Italian (Italy) 
43] H. Erhorn- Kluttig, H. Erhorn, B. Utesch, K. Wittchen, K. Engelund Thomsen, O. Mørck, O. Baslev- Olsen, M. Jungshoved, M. Zinzi, B. Mattoni, M. Šijanec- Zavrl, D. Varšek, 2018, Overview of Cost Baselines for three Building Levels, Report of CoNZEBs Project, available at www.conzebs.eu.

[44] EN15251- Indoor environmental input parameters for design and assessment of energy performance of buildings addressing indoor air quality, thermal environment, lighting and acoustics, 2007.

[45] TRNSYS 17. Available online at www.trnsys.com

[46] EDILCLIMA EC700. https://www.edilclima.it/

[47] UNI/TS 11300: Parte 1 - Determinazione del fabbisogno di energia termica dell'edificio per la climatizzazione estiva ed invernale, 2014.

448] UNI EN ISO 6946:2008: Componenti ed elementi per edilizia - Resistenza termica e trasmittanza termica - Metodo di calcolo,2008.

49] Prezzi Informativi dell'edilizia, Nuove costruzioni, DEI, Febbraio 2018

[50] Miliani, A.: Personal communication, Xella Italia S.r.1.

[51] Paolini, A.: Personal communication, Giuliani S.C.

[52] J. Kurtnitskij, A. Saari, T. Kalamees, M. Vuolle, J. Niemela, T. Tark, Cost optimal and nearly zero (nZEB) energy performance calculations for residential buildings with REHVA definition for nZEB national implementation. Energy and Buildings, 2011, vol. 11, pp. 3279-3288.

[53] UNI EN 15459-1: Energy Performance of Buildings-Economic evaluation procedure for energy systems in buildings -Part 1, 2018.

[54] Riva, G.: Personal communication, 2017.

[55] Allegato A alla delibera ARG/elt 74/08 - Testo integrato delle modalità e delle condizioni tecnico economiche per lo scambio sul posto - Available at: https://www.arera.it/allegati/docs/08/074-08argall2.pdf

[56] GSE Gestore Servizi Energetici. Available at: https://www.gse.it/

[57] Valori del corrispettivo unitario di scambio forfetario per l'anno 2017, 03 aprile 2018. Available at: https://www.arera.it/it/comunicati/18/180403.htm

[58] G.Iwashita, H. Akasaka, The effects of human behavior on natural ventilation rate and indoor air environment in summer- a field study in southern Japan, Energy and Buildings, 1997, vol. 25, pp. 195-205

[59] C. Howard-Reed, L.A. Wallace, W. R. Ott, The Effect of Opening Windows on Air Change Rates in Two Homes, Journal of the Air \& Waste Management Association, 2002, vol. 52:2, pp. 147-159.

[60] P.R. Warren, Ventilation through openings on one wall only, in: International Conference Heat and Mass transfer in Buildings, Dubrovnik, Yugoslavia, 1977. 


\section{Assessment of construction cost reduction of nearly zero energy dwellings in a life cycle perspective $^{1}$}

\author{
Michele Zinzi ${ }^{\mathrm{a} *}$, Benedetta Mattoni ${ }^{\mathrm{ab}}$
}

a-ENEA, Via Anguillarese 301, 00123 Rome, Italy

b-SAPIENZA University of Rome, Department of Astronautical, Electrical and Energy Engineering, Via Eudossiana 18-00184 Rome, Italy

\title{
Nomenclature and abbreviations
}

EPBD: Energy Performance of Buildings Directive

NZEB: Nearly Zero Energy Building

EEM: $\quad$ Energy Efficiency Measures

MFH: Multi-Family Houses

ETICS: External Thermal Insulation Composite Systems

XPS: $\quad$ Extruded polystyrene

EPS: $\quad$ Expanded polystyrene

DHW: Domestic How Water

COP: Coefficient of Performance $\left(\mathrm{W}_{\mathrm{th}} / \mathrm{W}_{\mathrm{el}}\right)$

PV: $\quad$ Photovoltaic

MVHR: Mechanical Ventilation with Heat Recovery

MEV: Mechanical Extract Ventilation

ACH: $\quad$ Air change per hour $\left(\mathrm{h}^{-1}\right)$

NPV: $\quad$ Net Present Value $\left(€ / \mathrm{m}^{2}\right)$

EP: $\quad$ Primary Energy consumption Indicator $\left(\mathrm{kWh} / \mathrm{m}^{2}\right.$ year $)$

$\mathrm{EPH}_{\text {nren }}$ Primary non-renewable Energy for Heating Indicator $\left(\mathrm{kWh} / \mathrm{m}^{2}\right.$ year)

$\mathrm{EPW}_{\text {nren; }}$ Primary non-renewable Energy for DHW Indicator $\left(\mathrm{kWh} / \mathrm{m}^{2}\right.$ year)

$\mathrm{EPV}_{\text {nren; }}$ Primary non-renewable Energy for Ventilation Indicator $\left(\mathrm{kWh} / \mathrm{m}^{2}\right.$ year)

$\mathrm{EPgl}_{\text {nren }}$ Indicator of Global Primary non-renewable Energy $\left(\mathrm{kWh} / \mathrm{m}^{2}\right.$ year)

\begin{abstract}
Concerning Nearly Zero Energy Buildings, it is important to guarantee energy efficiency, thermal comfort and indoor environmental quality, while keeping construction and operational costs low. In this framework, this paper explores the efficacy of applying different scenarios, for reducing construction costs of new nearly zero energy multi-family houses in a life cycle perspective. Conversely to the standard cost-optimal approach, a real Italian case study building was chosen. Alternative and unconventional combinations of solutions for envelope and technical systems were adopted. Calculations were performed in two Italian cities (Rome and Turin). Three types of analysis were developed thermal comfort, energy performance and financial calculation. Results of the thermal analysis show that the installation of active cooling to prevent summer overheating can be avoided by applying low-cost passive strategies. All the proposed low-cost scenarios (4 alternative scenarios in Rome and 5 in Turin) reached the highest grade of energy performance, with a reduction of the non-renewable primary energy consumption up to $46 \%$ compared to the base case in Rome and $18 \%$ in Turin. From the economic perspective, all the scenarios in the two climate zones allow both reductions in the construction costs, up to $26 \%$ in Rome and $15 \%$ in Turin, and a Net Present Value after 50 years up to $163 € / \mathrm{m}^{2}$ in Rome and $158 € / \mathrm{m}^{2}$ in Turin.
\end{abstract}

\footnotetext{
${ }^{1}$ The short version of the paper was presented at ICAE2018, Aug 22-25, Honk Kong, China. This paper is a substantial extension of the short version of the conference paper.
} 
Keywords: nearly zero energy buildings, building energy technologies, construction cost, life cycle cost

\section{Introduction}

The target reduction of primary energy and emissions by buildings and consequent increase of renewable energy production set in the Horizon 2020 Program [1], was updated in the new 2030 Climate \& Energy framework. [2]. According to this package, the aims are to reduce the greenhouse gas emissions by $40 \%$ from 1990 levels, to increase the production from renewable energy up to $27 \%$ and to improve energy efficiency of buildings up to $27 \%$. In a long-term perspective, in 2050 gas emissions are expected to be reduced by at least $80 \%$ compared to 1990 levels [3]. In this framework, building sector plays a relevant role, accounting for the largest part of energy consumption and gas emissions at local and global level and representing, on the other side, a huge potential for energy savings[1][4].

European Standard defined the requirements for achieving high savings in buildings: the Energy performance of Buildings Directive (EPBD), requires that new public buildings from 01/01/2019 and new private constructions from 01/01/2021, have to comply with Nearly zero energy buildings (NZEB) targets[5]. The definition on NZEBs provided in the Directive is quite general and is not technical. This responsibility is delegated to each European Member State that has to define what an NZEB represents at national level and to set the specific targets for buildings to be in compliance with European description. What is common to all the Member states is that NZEBs do have to certify a "very high energy performance", covering "a very significant extent" of building energy needs with renewable energy sources, partially produced on site or nearby the building [5]. Being the common guidelines provided by the European Standards so general, there are still ambiguities in the implementation phase of NZEBs in European member states due to the different interpretations of the definition. Furthermore, misalignments among countries are emphasized due to the climatic, social, technological and economic differences [6]. According to this, it is difficult to propose a minimum common threshold for energy efficiency for all the Member States. Different climatic conditions between Southern and Northern European countries lead to the highest differences in the definition of NZEB parameters. The former can easily meet low energy needs thresholds for heating compared to the latter [7] but, on the other side, they cannot comply with the same limits for cooling demand due to high outdoor ambient temperature, high solar radiation and heat island effect in cities. Several studies have been developed in literature about potential overheating in southern and north-western countries due to the increase of thermal insulation, which can lead to an increase in consumption for air-conditioning [8], but it was also stated that passive strategies for reducing cooling needs can be successfully applied to overcome this problem [9], like solar shading and ventilation Error! Reference source not found.. As an example, in [11] an analysis on three different NZEB building types (single-family house, apartment block and office building) in two different Italian climatic locations (Milan and Palermo) was developed to assess the imbalance of energy needs for heating and cooling when U-values of the building envelope are gradually reduced. It was found that, by reducing transmittance values, cooling need increases up to 5-6\% in all the analysed cases but it can be effectively reduced by using high performing shading devices. Basing on these assumptions, NZEB should provide specific heating-cooling balance for each climatic condition [12], taking also into account thermal comfort [13], indoor environmental quality and building sustainability [14] during the entire building life-time. Concerning the analysis of the building in a life cycle perspective, high relevance was also attributed in [15] and [17] to the effect of degradation on NZEBs performance in terms of thermal comfort, energy balance and grid independence.

Another important issue concerning NZEB development is related to construction costs. In [17] an extensive investigation on the construction cost differences between Zero Energy Buildings, Conventional Buildings and Green Buildings in United States was carried out. In this analysis, results show that the statistical difference between actual ZEB cost and modelled Conventional Buildings cost is not significant. Nevertheless, the authors highlight the limitations of the study and the need to further investigate the 
relations between investment costs and energy performance of buildings. In fact, ensuring the fulfilment of the reduction in costs are particularly relevant [18][19]. Although many studies and demonstration actions have demonstrated that it is possible to achieve NZEB targets, the design choices are not always proven to be cost effective both from an environmental and economic perspective [18].

This economic issue was raised up in the EPBD [5]: in the Delegated Regulation No 244/2012 [20], which supplemented the EPBD regulation, a methodology scheme to calculate cost-optimal levels for buildings is provided. The cost optimality is defined as "the energy performance level which leads to the lowest cost during the estimated economic lifecycle". In the methodology, energy efficiency measures are applied to reference buildings to contemporary reduce primary energy consumption and identify the most economically advantageous solutions [21]. Many studies in literature applied the cost-optimal methodology proposed in the EPBD standard to derive cost-optimal energy efficiency measures for NZEB buildings [22][23] and clusters of NZEB buildings [24][25], highlighting the need of taking into consideration the whole building life cycle. In [26], the comparative methodology presented in the EPBD is applied to assess the costoptimality level of several office buildings located in a warm climate, while in [27] the procedure is applied to multi-residential buildings in the Mediterranean Area. Results of both papers show high decrease of primary energy consumption and $\mathrm{CO}^{2}$ emissions, keeping the operational and construction costs on the safe side. In [18] a simulation-based framework was applied to a residential building prototype in 14 locations across Europe in order to assess the optimal NZEB configuration at the lowest cost. Results demonstrated that optimal solutions do strongly depend on climate condition, but a common aspect to all locations is the need to integrate renewables and energy efficiency measures to reach cost-effective NZEBs. Authors in [28] applied a model for supporting designers in the design phase of a residential building, developing a cost optimal analysis of different scenarios to evaluate the best solution in the balance between life cycle costs and energy performance. In [29] the cost-optimality and replicability on building market of different HVAC system configurations were evaluated for a residential building, taking into account the costs incurred during the whole building life-cycle. In [30], an economic analysis for developing four types of new existing residential NZEB buildings across different locations in UK was assessed. Different combinations of renewable energy technologies were evaluated. Results show that most of the analysed cases are profitable, achieving a benefit-cost ratio (ratio between the costs and benefits) that ranges between -12\% and 53\% across different regions.

What emerges from literature studies is that cost-optimal levels and packages of energy efficient measures strongly depend on national conditions [31][32]. These differences are due to many variables such as: climatic conditions, energy, material and labour prices, available technologies and building types [33]. Among the different building types, high importance is given to the development of residential NZEB buildings, which account for about the 75\% of the total European Building stock [34]. In fact, in the residential sector the issue of cost reduction of new NZEBs is crucial, in particular for social housing multifamily houses, where the economic aspect is quite relevant, due to limited financial resources. An extensive review was developed by the authors in [35], focused on the application of cost-optimal analysis in European literature studies, pointing out the differences among them based on several categories: methods and tools for optimization, energy efficiency measures, building type. It was found that with regard to the building typology, $68 \%$ of the reviewed reference buildings in the studies were residential and multi-family buildings represented the $34 \%$ of this share. It shows the importance of identifying the right balance between costs and energy performance in the residential sector. In [35] it was also found that the most common energy efficiency measure for the envelope is to increase/decrease the thickness of insulation but this solution is not a driver for cost-optimal building design: efficiency measures on the building envelope have much lower impact on cost optimality compared to measures related to the energy systems. This aspect makes an issue arise: the solutions proposed as energy efficiency measures (EEM) in the cost-optimal framework are common and standard and the investigation of constructive alternative solutions is rarely pursued. The cost trade-off could be reached by simplifying the envelope design and the construction technologies [36], taking 
advantage of issues like modularity, prefabrication and on-site assembly [32] but application of these NZEBs in Italy, the law ascertains several requirements for new buildings, that can be reached through different strategies, technologies and operational means [37] . Starting from 01/01/2019, in accordance to [38], energy performance of minimum requirements buildings and NZEB buildings will vary only in terms of small differences in transmittance values. This implies that, from this date, very small cost differences can be expected to arise between a conventional and a nearly zero-energy building; also, reducing the costs of new nearly zero-energy multi-family houses means reducing the costs for such houses in general. Currently, according to the national document developed in 2016 [39], the extra cost in Italy for the construction of multifamily residential buildings compared to the conventional building strongly depends on the climatic region and was assessed to be about $60 € / \mathrm{m}^{2}$ on average. There is therefore room for improvement, reducing this extra-cost gap. Starting from these assumptions, the target of this paper is to explore the possibility of reducing construction and life cycle costs keeping high energy target in new Italian multifamily houses, as investigated in [40].

\section{Objective and method}

This study aims at identifying solution sets for the specific sector of new nearly zero energy multi-family houses at reduced costs respect to mainstream options and assessed in a life cycle cost perspective. The cost issue in single family houses is less relevant, due to higher economic availability of potential clients for this building segment. The situation is different for multi-family houses, which is the most recurrent typology in social housing, and other public and private housing sectors, to whom this economic issue is more relevant. In this framework, the objective of the study is relevant for the construction sector in Italy and the implemented methodology could be usefully applied in other countries, with the duly boundary conditions.

The literature presented in the introduction proves that most of the studies are aligned to the approach implemented in EU member states for the cost optimal energy performance of buildings [5]: first standard and recurrent building technologies are identified, then the cost effectiveness is tested for improved efficiency levels of the selected technologies [41]. The approach has some limitations, since it does not take into account several aspects that might be critical for cost reduction, e.g.: technical and economic trade-off between building envelope versus technical and renewable energy performances, identification of alternative technology bundles instead of simple efficiency scaling, the role of the design in optimising the different energy uses in the buildings. The innovative contribution of the present work is to expand the technical and economic analyses of NZEB including the above cited issues, with a broader approach respect to existing studies.

Due to very different definitions and approaches of nearly zero energy buildings, the methodology is applied to the Italian context, defined in [37][38]. The NZEB requirements, are not based on energy performances but on the compliance of several prescriptions, including:

- Maximum values for defined building envelope indicators;

- Minimum efficiency of the energy systems (space heating and cooling, ventilation, domestic hot water);

- $50 \%$ of energy uses provided by renewable sources.

The method allows searching different solutions sets complying with NZEB requirements without being forced to respect mandatory energy performances, opening the ground for different cost-effective solutions.

According to the above, the methodology here developed consists of the following steps:

I. Identification of a real building, whose typology can be considered sufficiently representative of current multifamily houses in Italy. The choice of real buildings is necessary to have all the technical and economic data, needed for next analyses; as well as to have economic costs based on real market instead of on average values. This choice is also important because of the calculation and simulation 
analyses are framed in a real application, so that a building constructed according the given technical and economical specifications avoid the limitations of a purely theoretical study.

II. Adjustments of the real building to selected climatic conditions and to specific NZEB requirements, for construction elements and fossil and renewable energy systems. This step allows to have standardised typical buildings, upon which it is possible to develop cost effective variants.

III.Identification of low costs solution sets for the different building envelope and energy system technologies. The solutions are developed taking into account all the energy services covered by NZEB requirements for residential buildings, fixed by national regulation.

IV. Energy and economic assessment of the building variants, in terms of construction and life cycle costs. Comparison of final and primary energy performances starting from field applications, as well as initial construction investment and Net present value at the end of the building life service are carried out.

The limit of the research relays on: the boundary conditions set in the analysis, the reference building and the identified low-cost solutions. Although the described methodology is tailored to the Italian reality, it can be applied to other countries once the energy, construction and economic boundary conditions are accounted for. This is an important value for designers, planners, contractors and construction companies, able to optimise costs for any construction project. Moreover, working at the intersection of construction technologies, energy systems and economic assessment in real applications, the study is well aligned with the journal objective and scopes.

\section{The case study building}

The San Giusto building, located in the outskirts of Prato, Tuscany, was selected after a nearly zero energy multi-family houses screening carried out in Italy in the framework of the EU CoNZEBs project [40]. The building can be considered representative of a consistent portion of the building stock. The building was commissioned by Edilizia Pubblica Pratese, a local social housing company. It is a L-shaped four-storey building with 29 apartments served by four staircases. Private cellars, a public civic centre and the utility rooms are located at the ground floor. The building is also equipped with public parking and green areas which show the multifunctional character of this project. The design plan and a picture of the building are shown in Figures 1 and 2.

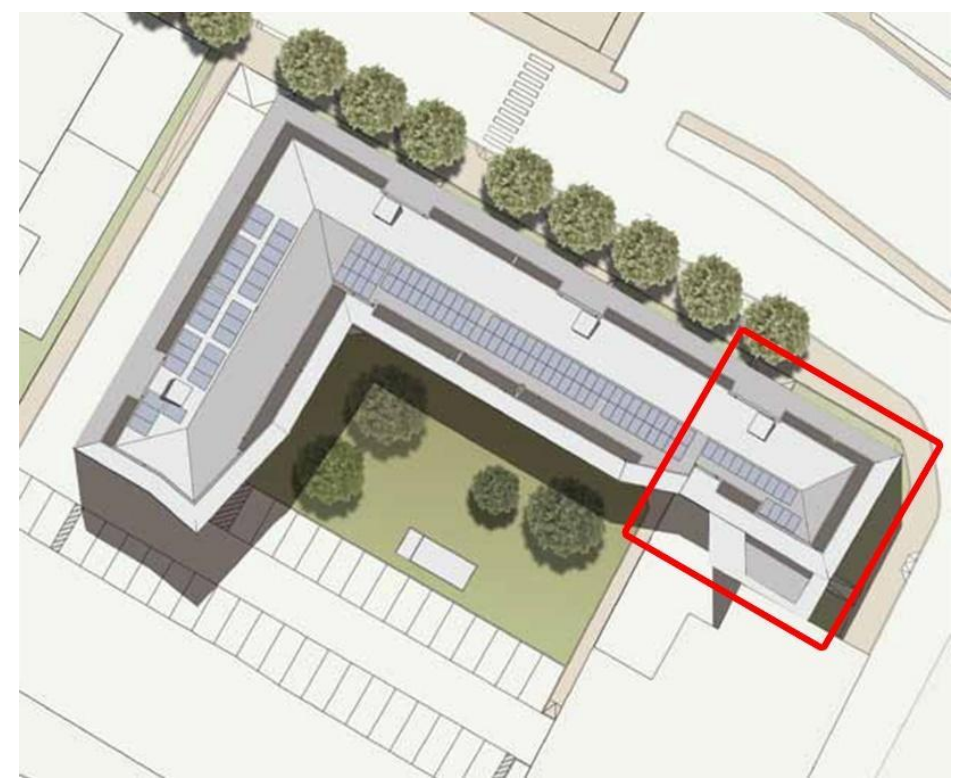


Fig. 1. Design plan of the case study building; the red square delimits the portion of building where the analysis of the thermal comfort was performed.

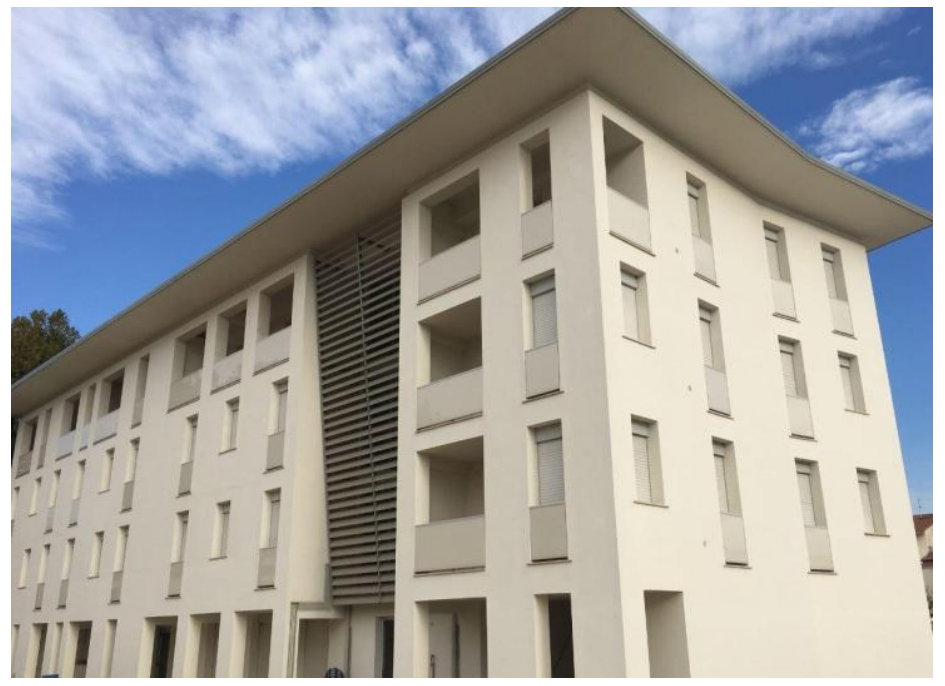

Fig. 2. Case study building

The total area of the apartments is $2207 \mathrm{~m}^{2}$ and the volume is $5960 \mathrm{~m}^{3}$, the apartments range from 45 and 95 $\mathrm{m}^{2}$, with an average net area of $76 \mathrm{~m}^{2}$. The existence of apartments with different sizes shows the purpose of meeting the needs of the different low-income users, from couples to large families.

The main target of the project was to create a new high-performance building with low environmental impacts, and cost effective in the construction, operation and maintenance phases. The design kept this approach with the adoption of simple and low environment impact solutions. An example of this is the use of recycled insulation materials from local textile companies. Bioclimatic approaches were adopted to maximise solar protection and natural ventilation in summer.

Concerning the building structure, the external walls consist of ETICS (External Thermal Insulation Composite Systems), with $8 \mathrm{~cm}$ EPS (Expanded polystyrene) thermal insulation, a double brick layer with insulation in between ( $8 \mathrm{~cm}$ of recycled insulation in textile fibre), and internal finishing. The base floor is a masonry slab with an XPS (Extruded polystyrene) insulation layer of $8 \mathrm{~cm}$, a thermal coating in EPS of $4 \mathrm{~cm}$ and an additional insulating layer of EPS $(4 \mathrm{~cm})$ included in the floor heating system and the covering is of ceramic tiles The rooftop is a masonry tilted roof with an XPS thermal coating of $12 \mathrm{~cm}$ covered by steel plate mounted on wooden planks. Transmittances of the envelope are $0.20 \mathrm{~W} / \mathrm{m}^{2} \mathrm{~K}$ for roof and $0.17 \mathrm{~W} / \mathrm{m}^{2} \mathrm{~K}$ for walls and base floor. The continuous external insulation eliminates thermal bridge. Argon-filled doubleglazed windows with aluminium frame are in place with thermal transmittance of $1.4 \mathrm{~W} / \mathrm{m}^{2} \mathrm{~K}$ and solar transmittance of 0.67 .

The Domestic Hot Water (DHW) system is fed by $43 \mathrm{~m}^{2}$ of vacuum solar thermal collectors mounted on the south-east and south-west oriented pitches and coupled with two tanks of 2000 litres. A $94 \mathrm{~kW}$ condensing boiler is used as back of solar collectors. The heating supply is centralized, and the main heat generator is the $171 \mathrm{~kW}$ air water heat pump. When outdoor temperatures decrease below the working conditions of the heat pump, the condensing boiler and the solar thermal collectors work as back-up system, supporting the heat pump with keeping the seasonal coefficient of performance high.. The Coefficient of Performance (COP) in standard conditions is 3.28 . The outlet temperature of the heat pump, which supplies a room-controlled floor heating system, is $40-45^{\circ} \mathrm{C}$ and its cut-off temperatures are $3-45^{\circ} \mathrm{C}$. The system is equipped with an inertial tank of 2000 litres to cope with thermal demand peaks. Here the heated water is sent from the heat pump and, if necessary, from the condensing boiler. Within the tank, when demand of domestic hot water is lower than production, high temperature fluid from solar collectors flows in a coil to additionally support heating 
supply. Part of the electricity needed by the heat pump is produced by a $22 \mathrm{kWp} \mathrm{PV} \mathrm{system}\left(163 \mathrm{~m}^{2}\right)$. Both south-west oriented pitches.

According to the most common construction rules in Italian buildings, especially for social housing, active cooling and mechanical ventilation systems are not installed in the case study building.

\subsection{Climatic condition}

Italy has a wide variety of climatic conditions. The national building energy codes identify six classes, based on the heating degree days, calculated in base $20^{\circ} \mathrm{C}$. The classes range from A (below 600 degree days) to $\mathrm{F}$ (above 3000 degree days). No zoning exists for the cooling season. In order to simplify the analysis, two macro-classes were identified and represented by two large cities in this study:

- Turin, 2617 degree days, representative of climatic zone $\mathrm{E}$ (northern and mountain zones) and F (alpine zone)

- Rome, 1440 degree days, representative of zones from A to D, with milder climatic conditions, typical of central and southern zones.

These are large cities, whose degree days are very close to average degree days of the climatic zones they belong to.

\subsection{Building's adjustments to reference climate conditions}

The characteristics of the real building are adjusted to the minimum NZEB requirements in the reference climatic zones in this section. Changes in the building envelope, energy systems and renewable sources are described below. No changes were made on windows, since different requirements have close to negligible impact on costs.

\subsubsection{Rome climatic zone}

Envelope components insulation was brought to the standard requirements, as indicated in table 1, hence the structures were modified as follows: the external wall is covered with an $8 \mathrm{~cm}$ EPS thermal coating; the first floor between apartments and ground floor has an XPS thermal coating of $4 \mathrm{~cm}$ and an additional insulating layer of EPS $(4 \mathrm{~cm})$ included in the floor heating system; the rooftop has an XPS thermal coating of $9 \mathrm{~cm}$.

\begin{tabular}{cccc} 
Table 1. Transmittance values of the building envelope of the reference buildings in Rome and Turin \\
\hline City & U-roof $\left[\mathrm{W} / \mathrm{m}^{2} \mathrm{~K}\right]$ & U-wall $\left[\mathrm{W} / \mathrm{m}^{2} \mathrm{~K}\right]$ & U-first floor $\left[\mathrm{W} / \mathrm{m}^{2} \mathrm{~K}\right]$ \\
\hline Rome & 0.26 & 0.28 & 0.28 \\
\hline Turin & 0.21 & 0.25 & 0.24 \\
\hline
\end{tabular}

The number of solar thermal collectors and PV panels was reduced to meet the requirements of the Standard [37] precisely. This was done to guarantee the $50 \%$ of DHW production from renewable sources and contemporarily to cover the $50 \%$ of total energy demand (heating, cooling and DHW) with renewable sources. According to this, solar collectors were reduced from $43 \mathrm{~m}^{2}$ to $27 \mathrm{~m}^{2}$ and the PV panels from 163 to $142 \mathrm{~m}^{2}$. This number of PV panels is also the minimum amount to meet the standard of Appendix 3 [38] which requires an installed peak power of $22 \mathrm{~kW}$ for this building. Results of the energy calculation will be shown in paragraph 6.2 to be compared with energy results of the low-cost scenarios. 


\subsubsection{Turin climatic zone}

The insulation thickness of the envelope components was brought to the NZEB requirements, as shown in Table 1. The structures were modified as follows: the external wall is a double brick walls with an EPS thermal coating of $13 \mathrm{~cm}$; the first floor between apartments and ground floor has an XPS thermal coating of $7 \mathrm{~cm}$ and an additional insulating layer of EPS $(4 \mathrm{~cm})$ included in the floor heating system. The rooftop is insulated with $11 \mathrm{~cm}$ of XPS. As for the previous case, solar thermal collectors were reduced from 43 to 40 $\mathrm{m}^{2}$ and the PV panels from 163 to $142 \mathrm{~m}^{2}$. The Mechanical Ventilation with Heat recovery (MVHR) system was included in the reference case: one system in each apartment was provided. This is still a cutting-edge solution in Italy dwellings but recently often used in very high energy performing buildings in colder climates. According to this, it was decided not to install it in Rome, which belongs to a hotter climate zone: it would not be economically efficient nor crucial for obtaining low level of Primary Energy for heating.

\subsubsection{Adjusted construction costs}

The adjusted construction costs for the two reference buildings are shown in Table 2 and 3 . The costs have been taken from the bill of quantities of the real building. Cost modifications due to variation in the insulation thickness for the two reference buildings have been estimated as unitary variation $\left(€ / \mathrm{m}^{3}\right)$ of the original prices. Cost of the MVHR system used in Turin was not included in the bill of materials of the real building, but was provided by a technical company, which was asked to simulate a real offer to supply a MHVR system for the reference building [42]. For the building located in Rome, overall construction cost is $€$ 3'388' 584 which corresponds to $1^{\prime} 594 € / \mathrm{m}^{2}$. Table 2 shows the costs divided by categories and their percentage on the overall cost. It can be noticed that the heaviest category is Architectural components which accounts for the $46 \%$ of the overall construction costs. Overall construction costs of the building located in Turin is $€ 3^{\prime} 511^{\prime} 820$ which corresponds to $1^{\prime} 652 € / \mathrm{m}^{2}$. The incidences of each category on the overall cost are similar to ones in Rome. Differences in costs between the two buildings are mainly due to the installation of the MVHR in Turin which causes an increase in the energy systems cost of $40 € / \mathrm{m}^{2}$. More moderate differences (in the order of 5 to $15 € / \mathrm{m}^{2}$ ) are observed for the Architectural components and Renewable plants.

The cost optimal analysis of the proposed scenarios will be based only on the reduction of the "energy related costs": those costs have a direct impact on the building energy performance. In both Table 2 and 3 disaggregated energy related costs for each construction category are highlighted in grey. Three main aspects can be observed: the structural costs are fixed; up to the $38 \%$ of both architectural and energy systems costs is adjustable; the entire cost of renewable energy systems can be modified. In Rome the $24 \%$ of the total construction costs can be decreased by implementing more energy efficient solutions, which corresponds to $389 € / \mathrm{m}^{2}$; in Turin it is the $27 \%$ which corresponds to $447 € / \mathrm{m}^{2}$.

Table 2. Total and energy related construction costs of reference building in Rome

\begin{tabular}{cccccc}
\multicolumn{5}{c}{ Table 2. Total and energy related construction costs of reference building in Rome } & Total \\
\hline & Structure & Construction components & $\begin{array}{c}\text { Technica } \\
\text { 1 Systems }\end{array}$ & Renewable sources & 3'388'584 \\
\hline Costs $[€]$ & $\begin{array}{c}996^{\prime} 62 \\
4\end{array}$ & $1^{\prime} 554^{\prime} 631$ & $782^{\prime} 027$ & $55^{\prime} 302$ & 100 \\
\hline $\begin{array}{c}\text { Incidence on overall costs } \\
{[\%]}\end{array}$ & 29 & 46 & 23 & 2 & 1594 \\
\hline $\begin{array}{c}\text { Unitary costs }\left[€ / \mathrm{m}^{2}\right] \\
\text { Energy related }[€]\end{array}$ & 469 & 731 & 368 & 26 & $826^{\prime} 279$ \\
\hline $\begin{array}{c}\text { Incidence on category cost } \\
{[\%]}\end{array}$ & 0 & $522^{\prime} 783$ & $248^{\prime} 194$ & $55^{\prime} 302$ & 1 \\
\hline $\begin{array}{c}\text { Unitary energy related costs } \\
{\left[€ / \mathrm{m}^{2}\right]}\end{array}$ & 0 & 34 & 32 & 100 & 389 \\
\hline
\end{tabular}




\begin{tabular}{|c|c|c|c|c|c|}
\hline & Structure & Construction components & $\begin{array}{l}\text { Technica } \\
1 \text { Systems }\end{array}$ & Renewable sources & Total \\
\hline Costs $[€]$ & $\begin{array}{c}996 ' 62 \\
4\end{array}$ & 1'583’195 & $867 ’ 107$ & $64 ’ 894$ & 3'511'820 \\
\hline $\begin{array}{c}\text { Incidence on overall costs } \\
{[\%]}\end{array}$ & 28 & 45 & 25 & 2 & 100 \\
\hline Unitary costs $\left[€ / \mathrm{m}^{2}\right]$ & 469 & 744 & 408 & 31 & 1652 \\
\hline Energy related $[€]$ & 0 & $551 ' 358$ & $333^{\prime} 306$ & $64 ’ 894$ & $949^{\prime} 558$ \\
\hline $\begin{array}{l}\text { Incidence on total category } \\
\text { cost }[\%]\end{array}$ & 0 & 35 & 38 & 100 & l \\
\hline $\begin{array}{c}\text { Unitary energy related costs } \\
{\left[€ / \mathrm{m}^{2}\right]}\end{array}$ & 0 & 259 & 157 & 31 & 447 \\
\hline
\end{tabular}

\section{Identification of low-cost solutions}

This section describes the solutions identified to reduce the construction costs of the two reference buildings. Each subsection describes the selected technologies and strategy, highlighting their peculiarities with respect to common trends.

\subsection{Building envelope}

Two main variations were identified. The common technique for external wall construction of NZEB in Italy consists of brickworks and ETICS; instead of following the usual approach of variation of insulation levels to reach the most performing solutions, in this paper the approach was to detect alternative construction technologies. In particular, large autoclaved concrete blocks were selected. These are based on natural elements and reach very high insulation and lightweight properties, as a result of a specific production process which creates micro air bubbling inside the material. These blocks come in different size, so that different transmittance values can be obtained within a single construction layer. Due to the ad-hoc designed profiles, the blocks can be easily handled and assembled. Compared to the other solutions, this technology reduces complexity, construction time and costs.

The second proposed solution is the mono-block window. Generally, in Italy residential buildings are equipped with traditional windows which are composed by: subframe, placed in the hole of the façade, the shutter box mounted above the window and the windows itself. The most time-consuming phase for windows is the preparation phase, since masonry workers have to create the hole, provide insulation for thermal bridges and wait for wet materials to dry. After that, masonry workers install the subframe and specialised workers mount the shutter box and finally the window itself. The mono-block windows are directly placed in the façade hole and then fixed, with consequent savings in time, and material and labour costs for the subframe works.

In both cases the performance indicator (thermal transmittance) maintains the value of the base case, but its cost change. In some Turin scenarios, the so-called super NZEB envelope was tested, where lower transmittances for walls, roof and ground floor were considered. Hence for these super NZEB scenarios the $\mathrm{U}$ values $\left[\mathrm{W} / \mathrm{m}^{2} \mathrm{~K}\right]$ were adjusted to : 0.105 (roof), 0.15 (wall), 0.12 (ground floor). This configuration was tested in combination with alternative energy systems, targeted to an overall cost reduction.

\subsection{Energy systems and renewable energy}

In Italy space heating in NZEB buildings is generally provided by heat pumps coupled with floor heating while DHW is normally supplied by condensing boilers supported by solar thermal collectors.

The implementation of both systems is expensive, therefore one of the proposed strategies is a thermal driven scenario where the condensing boiler is used for both heating and DHW services. The floor heating 
distribution system is then replaced by aluminium radiators. The use of condensing boilers and radiators for the construction of the floor heating system, the backbone lines of the floor heating system and the storage tank of the heat pump are eliminated. In addition, maintenance costs of the condensing boilers and radiators is lower, allowing to save money in a life cycle cost (LCC) perspective. On the other hand, the amount of renewable sources has to be increased to respect the percentage of renewable energy production required by the Standard.

A second strategy is, conversely, an electricity-driven solution which minimize the use of gas: the air water heat pump is used both for heating and DHW production. According to this, the condensing boiler is used as a backup system for both services. Floor heating is replaced by low temperature aluminium radiators which are more expensive than conventional aluminium radiators but less expensive than floor heating. In this case, the minimum level of energy production from renewable sources is achieved only through the use of PV panels which feed the heat pump, so the need for solar thermal collectors is avoided.

The third strategy is at the forefront, but it is forbidden in Italy according to the current Standard. It consists in providing space heating with electric radiators in rooms. It allows to eliminate technical system for heating production and most of electricity is provided by the PV panels. This approach does not comply with Italian regulation, since energy from PV panels cannot accounted as renewable sources if they directly feed electric systems for heating, DHW or ventilation services. The condensing boiler is only used for DHW production. To comply with the standard requirements, the amount of solar thermal collectors and PV panels has to be considerably increased. The highest technical expenses in this scenario are due to the installation of renewable sources. Nevertheless, investment costs of technical systems for heating supply and distribution are avoided.

Another very simple solution to reduce construction costs was to decrease the number of PV panels to the minimum amount needed for self-consumption. This strategy does not comply with national standards, since the minimum peak power of photovoltaic is calculated as a function of the surface area of the building at ground level.

Common to all the strategies is to replace the floor heating with a cheaper solution; due to this, the insulation provided by the floor heating system was always replaced with an additional layer of thermal insulation of EPS $(4 \mathrm{~cm})$ on the floors to comply with the transmittance values required by the Standard.

For the colder climate in Turin, in addition to the others, two proposals were tested. Firstly, the combined use of solar thermal collectors for both Heating and DHW in the thermal driven scenarios: solar thermal collectors provide pre-heated water for condensing boiler, allowing to reduce the amount of gas needed. Secondly, the replacement of the MVHR with a simple mechanical ventilation with only extraction (MEV). It is a cheaper solution, but, on the other side, the benefits of the heat recovery on heating consumption are no more guaranteed.

\subsection{Proposed Scenarios}

In Table 4 and 5 the characteristics of the reference buildings and scenarios for the Rome and Turin are shown. The energy performance of these scenarios was simulated in steady state regime, as described in section 5.2.

Table 4. Description of the building envelope and technical systems for the reference building and proposed low-cost scenarios in Rome

\begin{tabular}{|c|c|c|c|c|c|}
\hline \multirow[b]{2}{*}{ Technology } & \multirow[b]{2}{*}{ Reference building } & \multirow{2}{*}{$\begin{array}{l}\text { Scenario 1 } \\
\text { Thermal driven } \\
\text { solution }\end{array}$} & \multirow{2}{*}{$\begin{array}{l}\text { Scenario } 2 \\
\text { Electricity driven } \\
\text { solution }\end{array}$} & \multirow{2}{*}{$\begin{array}{l}\text { Scenario } 3 \\
\text { Electricity driven } \\
\text { solution (outlaw) }\end{array}$} & \multirow{2}{*}{$\begin{array}{l}\text { Scenario } 4 \\
\text { Thermal driven } \\
\text { solution (outlaw) }\end{array}$} \\
\hline & & & & & \\
\hline $\begin{array}{r}\text { Solar thermal } \\
\text { collectors }\end{array}$ & 15 modules; $27 \mathrm{~m}^{2}$ & $\begin{array}{l}19 \text { modules; } \\
34 \mathrm{~m}^{2}\end{array}$ & Absent & $\begin{array}{l}18 \text { modules; } \\
33 \mathrm{~m}^{2}\end{array}$ & $\begin{array}{l}19 \text { modules; } \\
34 \mathrm{~m}^{2}\end{array}$ \\
\hline$P V$ & $\begin{array}{l}89 \text { modules; } \\
142 \mathrm{~m}^{2}\end{array}$ & $\begin{array}{l}89 \text { modules; } \\
142 \mathrm{~m}^{2}\end{array}$ & $\begin{array}{l}89 \text { modules; } \\
142 \mathrm{~m}^{2}\end{array}$ & $\begin{array}{l}100 \text { modules; } \\
163 \mathrm{~m}^{2}\end{array}$ & $\begin{array}{l}6 \text { modules; } \\
9.6 \mathrm{~m}^{2}\end{array}$ \\
\hline
\end{tabular}




\begin{tabular}{|c|c|c|c|c|c|c|}
\hline \multirow{2}{*}{\multicolumn{2}{|c|}{ External wall }} & $22 \mathrm{kWp}$ & $22 \mathrm{kWp}$ & $22 \mathrm{kWp}$ & $25 \mathrm{kWp}$ & $1.5 \mathrm{kWp}$ \\
\hline & & $\begin{array}{l}\text { Two brick walls }(20 \mathrm{Cm}) \\
\text { with an EPS thermal coating } \\
(8 \mathrm{~cm}) \text { covered by plaster } \\
\text { U value: } 0.28 \mathrm{~W} / \mathrm{m}^{2} \mathrm{~K}\end{array}$ & \multicolumn{4}{|c|}{$\begin{array}{l}\text { autoclaved concrete bricks }(30 \mathrm{~cm}) \text { covered by plaster } \\
\text { U value: } 0.28 \mathrm{~W} / \mathrm{m}^{2} \mathrm{~K}\end{array}$} \\
\hline & Roof & \multicolumn{5}{|c|}{$\begin{array}{l}\text { Masonry tilted roof with an XPS thermal coating of } 9 \mathrm{~cm} \text { covered by a steel plate mounted on wooden planks. } \\
\text { U value: } 0.26 \mathrm{~W} / \mathrm{m}^{2} \mathrm{~K}\end{array}$} \\
\hline & $\begin{array}{c}\text { Floor above } \\
\text { apartments }\end{array}$ & $\begin{array}{l}\text { Masonry floor with an XPS } \\
\text { thermal coating of } 4 \mathrm{~cm} \text { and } \\
\text { an EPS layer }(4 \mathrm{~cm}) \\
\text { included in the floor heating } \\
\text { system } \\
\text { U value: } 0.28 \mathrm{~W} / \mathrm{m}^{2} \mathrm{~K}\end{array}$ & \multicolumn{4}{|c|}{$\begin{array}{l}\text { Masonry floor with an XPS thermal coating of } 8 \mathrm{~cm} \text {. } \\
\text { U value: } 0.28 \mathrm{~W} / \mathrm{m}^{2} \mathrm{~K}\end{array}$} \\
\hline & Windows & $\begin{array}{l}\text { Traditional windows } \\
\text { U value: } 1.46 \mathrm{~W} / \mathrm{m}^{2} \mathrm{~K}\end{array}$ & \multicolumn{4}{|c|}{$\begin{array}{l}\text { Monoblock windows } \\
\text { U value: } 1.46 \mathrm{~W} / \mathrm{m}^{2} \mathrm{~K}\end{array}$} \\
\hline \multirow{2}{*}{$\begin{array}{r}\text { Heat } \\
\text { supply }\end{array}$} & Unit & $\begin{array}{l}\text { Heat pump }+ \text { Condensing } \\
\text { boiler (back up) }\end{array}$ & Condensing boiler & $\begin{array}{l}\text { Heat pump }+ \\
\text { Condensing boiler } \\
\text { (back up) }\end{array}$ & Absent & Condensing boiler \\
\hline & $\begin{array}{l}\text { Heating } \\
\text { System }\end{array}$ & Floor heating & Radiators & $\begin{array}{l}\text { Low-temperature } \\
\text { radiators }\end{array}$ & Electric radiators & Radiators \\
\hline$D H W$ & Unit & Condensing boiler & Condensing boiler & $\begin{array}{l}\text { Heat pump }+ \\
\text { Condensing boiler } \\
\text { (back up) }\end{array}$ & Condensing boiler & Condensing boiler \\
\hline
\end{tabular}

Table 5. . Description of the building envelope and technical systems for the reference building and proposed low-cost scenarios in Turin

\begin{tabular}{|c|c|c|c|c|c|c|c|}
\hline \multirow{2}{*}{\multicolumn{2}{|c|}{ Technology }} & & Scenario 1 & Scenario 2 & Scenario 3 & Scenario 4 & Scenario 5 \\
\hline & & Reference building & $\begin{array}{l}\text { Thermal driven } \\
\text { solution }\end{array}$ & $\begin{array}{l}\text { Thermal driven } \\
\text { solution }\end{array}$ & $\begin{array}{l}\text { Electricity } \\
\text { driven solution }\end{array}$ & $\begin{array}{l}\text { Electricity } \\
\text { driven solution }\end{array}$ & $\begin{array}{l}\text { Electricity } \\
\text { driven solution } \\
\text { (outlaw) }\end{array}$ \\
\hline \multicolumn{2}{|c|}{$\begin{array}{r}\text { Solar thermal } \\
\text { collectors }\end{array}$} & 22 modules; $40 \mathrm{~m}^{2}$ & $\begin{array}{l}44 \text { modules; } \\
79 \mathrm{~m}^{2}\end{array}$ & $\begin{array}{l}44 \text { modules; } \\
79 \mathrm{~m}^{2}\end{array}$ & Absent & Absent & $\begin{array}{l}30 \text { modules; } \\
54 \mathrm{~m}^{2}\end{array}$ \\
\hline \multirow{2}{*}{\multicolumn{2}{|c|}{ External wall }} & $\begin{array}{l}89 \text { modules; } \\
142 \mathrm{~m}^{2} \\
22 \mathrm{kWp}\end{array}$ & $\begin{array}{l}89 \text { modules; } \\
142 \mathrm{~m}^{2} \\
22 \mathrm{kWp}\end{array}$ & $\begin{array}{l}89 \text { modules; } \\
142 \mathrm{~m}^{2} \\
22 \mathrm{kWp}\end{array}$ & $\begin{array}{l}89 \text { modules; } \\
142 \mathrm{~m}^{2} \\
22 \mathrm{kWp}\end{array}$ & $\begin{array}{l}89 \text { modules; } \\
142 \mathrm{~m}^{2} \\
22 \mathrm{kWp}\end{array}$ & $\begin{array}{l}100 \text { modules; } \\
163 \mathrm{~m}^{2} \\
25 \mathrm{kWp}\end{array}$ \\
\hline & & $\begin{array}{l}\text { two brick walls }(20 \mathrm{Cm}) \\
\text { with an } \mathrm{EPS} \text { thermal } \\
\text { coating }(13 \mathrm{~cm}) \text { covered } \\
\text { by plaster } \\
\text { U value: } 0.25 \mathrm{~W} / \mathrm{m}^{2} \mathrm{~K}\end{array}$ & $\begin{array}{l}\text { autoclaved } \\
\text { concrete bricks } \\
(36 \mathrm{~cm}) \text { covered } \\
\text { by plaster } \\
\text { U value: } 0.25 \\
\mathrm{~W} / \mathrm{m}^{2} \mathrm{~K}\end{array}$ & $\begin{array}{l}\text { super NZEB } \\
\text { autoclaved } \\
\text { concrete bricks } \\
(45 \mathrm{~cm}) \text { covered } \\
\text { by plaster } \\
\text { U value: } 0.15 \\
\text { W/m² }\end{array}$ & $\begin{array}{l}\text { autoclaved } \\
\text { concrete bricks } \\
(36 \mathrm{~cm}) \text { covered } \\
\text { by plaster } \\
\text { U value: } 0.25 \\
\mathrm{~W} / \mathrm{m}^{2} \mathrm{~K}\end{array}$ & $\begin{array}{l}\text { super NZEB } \\
\text { autoclaved } \\
\text { concrete }(45 \\
\text { cm) covered by } \\
\text { plaster } \\
\text { U value: } 0.15 \\
\text { W/m² K }\end{array}$ & $\begin{array}{l}\text { super NZEB } \\
\text { autoclaved } \\
\text { concrete }(45 \\
\text { cm) covered by } \\
\text { plaster } \\
\text { U value: } 0.15 \\
\text { W/m² } \mathrm{K}\end{array}$ \\
\hline \multirow{2}{*}{\multicolumn{2}{|c|}{$\begin{array}{r}\text { Floor above } \\
\text { apartments }\end{array}$}} & $\begin{array}{l}\text { Masonry tilted roof with } \\
\text { an XPS thermal coating } \\
\text { of } 11 \mathrm{~cm} \text { covered by a } \\
\text { steel plate mounted on } \\
\text { wooden planks. } \\
\text { U value: } 0.21 \mathrm{~W} / \mathrm{m}^{2} \mathrm{~K}\end{array}$ & $\begin{array}{l}\text { As reference } \\
\text { building } \\
\text { U value: } 0.21 \\
\mathrm{~W} / \mathrm{m}^{2} \mathrm{~K}\end{array}$ & $\begin{array}{l}\text { super NZEB } \\
\text { Masonry tilted } \\
\text { roof with an } \\
\text { XPS thermal } \\
\text { coating of } 27 \\
\mathrm{~cm} \\
\mathrm{U} \text { value: } 0.11 \\
\text { W/m² K }\end{array}$ & $\begin{array}{l}\text { As reference } \\
\text { building } \\
\text { U value: } 0.21 \\
\mathrm{~W} / \mathrm{m}^{2} \mathrm{~K}\end{array}$ & $\begin{array}{l}\text { super NZEB } \\
\text { Masonry tilted } \\
\text { roof with an } \\
\text { XPS thermal } \\
\text { coating of } 27 \\
\mathrm{~cm} \\
\mathrm{U} \text { value: } 0.11 \\
\mathrm{~W} / \mathrm{m}^{2} \mathrm{~K}\end{array}$ & $\begin{array}{l}\text { super NZEB } \\
\text { Masonry tilted } \\
\text { roof with an } \\
\text { XPS thermal } \\
\text { coating of } 27 \\
\mathrm{~cm} \\
\mathrm{U} \text { value: } 0.11 \\
\mathrm{~W} / \mathrm{m}^{2} \mathrm{~K}\end{array}$ \\
\hline & & $\begin{array}{l}\text { Masonry floor with an } \\
\text { XPS thermal coating of } 7 \\
\mathrm{~cm} \text { and an EPS layer }(4 \\
\mathrm{cm}) \text { included in the floor } \\
\text { heating system } \\
\text { U value: } 0.24 \mathrm{~W} / \mathrm{m}^{2} \mathrm{~K}\end{array}$ & $\begin{array}{l}\text { Masonry floor } \\
\text { with an XPS } \\
\text { thermal coating } \\
\text { of } 11 \mathrm{~cm} . \\
\mathrm{U} \text { value: } 0.24 \\
\mathrm{~W} / \mathrm{m}^{2} \mathrm{~K}\end{array}$ & $\begin{array}{l}\text { super NZEB } \\
\text { Masonry floor } \\
\text { with an XPS } \\
\text { thermal coating } \\
\text { of } 20 \mathrm{~cm} \text {. } \\
\mathrm{U} \text { value: } 0.12 \\
\mathrm{~W} / \mathrm{m}^{2} \mathrm{~K}\end{array}$ & $\begin{array}{l}\text { Masonry floor } \\
\text { with an XPS } \\
\text { thermal coating } \\
\text { of } 11 \mathrm{~cm} . \\
\text { U value: } 0.24 \\
W / \mathrm{m}^{2} \mathrm{~K}\end{array}$ & $\begin{array}{l}\text { super NZEB } \\
\text { Masonry floor } \\
\text { with an XPS } \\
\text { thermal coating } \\
\text { of } 20 \mathrm{~cm} \text {. } \\
\mathrm{U} \text { value: } 0.12 \\
\mathrm{~W} / \mathrm{m}^{2} \mathrm{~K}\end{array}$ & $\begin{array}{l}\text { super NZEB } \\
\text { Masonry floor } \\
\text { with an XPS } \\
\text { thermal coating } \\
\text { of } 20 \mathrm{~cm} \text {. } \\
\text { U value: } 0.12 \\
\text { W } / \mathrm{m}^{2} \mathrm{~K}\end{array}$ \\
\hline \multicolumn{2}{|r|}{ Windows } & $\begin{array}{l}\text { Traditional windows } \\
\text { U value: } 1.4 \mathrm{~W} / \mathrm{m}^{2} \mathrm{~K}\end{array}$ & \multicolumn{5}{|c|}{$\begin{array}{l}\text { Monoblock windows } \\
\text { U value: } 1.4 \mathrm{~W} / \mathrm{m}^{2} \mathrm{~K}\end{array}$} \\
\hline \multicolumn{2}{|c|}{ Ventilation } & MVHR & MVHR & MEV & MVHR & MEV & MVHR \\
\hline \multirow{2}{*}{$\begin{array}{r}\text { Heat } \\
\text { supply }\end{array}$} & Unit & $\begin{array}{l}\text { Heat pump }+ \text { Condensing } \\
\text { boiler (back up) }\end{array}$ & $\begin{array}{l}\text { Condensing } \\
\text { boiler }\end{array}$ & $\begin{array}{l}\text { Condensing } \\
\text { boiler }\end{array}$ & $\begin{array}{l}\text { Heat pump + } \\
\text { Condensing } \\
\text { boiler (back up) }\end{array}$ & $\begin{array}{l}\text { Heat pump + } \\
\text { Condensing } \\
\text { boiler (back } \\
\text { up) }\end{array}$ & Absent \\
\hline & $\begin{array}{l}\text { Heating } \\
\text { System }\end{array}$ & Floor heating & Radiators & Radiators & $\begin{array}{l}\text { Low- } \\
\text { temperature } \\
\text { radiators }\end{array}$ & $\begin{array}{l}\text { Low- } \\
\text { temperature } \\
\text { radiators }\end{array}$ & $\begin{array}{l}\text { Electric } \\
\text { Radiators }\end{array}$ \\
\hline$D H W$ & Unit & Condensing boiler & $\begin{array}{l}\text { Condensing } \\
\text { boiler }\end{array}$ & $\begin{array}{l}\text { Condensing } \\
\text { boiler }\end{array}$ & $\begin{array}{l}\text { Heat pump + } \\
\text { Condensing } \\
\text { boiler (back up) }\end{array}$ & $\begin{array}{l}\text { Heat pump + } \\
\text { Condensing } \\
\text { boiler (back } \\
\text { up) }\end{array}$ & $\begin{array}{l}\text { Condensing } \\
\text { boiler }\end{array}$ \\
\hline
\end{tabular}


In Rome, transmittances of the external walls and windows are the same as in the base case. The roof and

In Turin, two of the five scenarios maintain the same transmittance values of the building envelope as in the base case (scenarios 1 and 3), while the other three scenarios have a super NZEB envelope. According to this, scenario 2 has the same characteristics as scenario 1 apart from the lower transmittance values of the envelope and the Mechanical Extract Ventilation (MEV) instead of the MVHR. Similarly, scenario 4 is coupled with scenario 3 . In the thermal driven scenarios 1 and 2 solar collectors provide pre-heating of water for both heating and DHW services.

As aforementioned in paragraph 4.2, it must be noticed that scenarios 3 and 4 in Rome and scenario 5 in Turin are outlaw either because of the installation of electric radiators as heating system, or because of the lower amount of PV panels respect to the Standard requirements.

\subsection{Passive cooling solutions}

Modern buildings may suffer of overheating in comparison to older ones, since well insulated envelopes obstacle the thermal discharge of the building at night. In fact, active cooling systems are often installed in NZEB in Italy, as documented in the relevant chapter in [43]. It also depends on the calculation method used to assess the energy performance of buildings, based on steady-state method, which overestimates the cooling demand and does not allow to assess the potentialities of passive cooling techniques to provide thermal comfort conditions. The objective is to reach a better understanding of the thermal response of NZEBs in the cooling and season and to assess whether proper passive solutions might avoid the installation of active cooling, thus keeping lower costs for design and installation of such systems.

The mitigation of the indoor environment is pursued through two main strategies:

a) Solar protection. The application of external solar shading devices on all the windows with orientation from north-east to north-west passing through south to block direct solar radiations

b) Night ventilation cooling. The increase of natural ventilation during the night hours, when the ambient temperature drops below the internal ones, creates favourable conditions to lower indoor air and structure temperatures. This objective can be pursued through windows opening, especially with different orientation.

Solutions other than the selected ones exist, however they have higher economic impacts, e.g. phase change materials on envelope elements and installation of heat sinks, thus were not taken into account. On the contrary, solar protection and natural ventilation are typical solution in Mediterranean dwellings, that only recently were replaced by mechanical cooling systems. The assessment of the impact of such solutions was carried out through a numerical analysis in transient regime, as described in section 5.1.

\section{Calculation}

\subsection{Thermal calculation}

The analysis was carried out according to the relevant standard EN 15251 [44] in which the thermal comfort, and consequently the overheating risk, is assessed in buildings without active cooling systems. The concept relays on the principle of the adaptive comfort, in which the subject has not fixed comfort expectations but adapted himself to different conditions depending on internal microclimatic conditions, external weather conditions, clothing and possibility to building features to improve personal comfort.

The standard identifies two categories, which are relevant in residential buildings: 

investigated in this paper. The analysis is however carried out on the first category for completeness, as well.

The relevant metric is the time evolution of the operative temperature, defined as the arithmetic average of air and mean radiant temperatures in a built environment, according to standard. The compliance with the standard requires that the number of hours in which the operative temperature exceeds the upper and lower limits to be within 5\% of the observation period (here considered in the June-August period). The acceptance band for the operative temperature is governed by the following equation for respectively category I and II:

$$
\begin{aligned}
& 0.33 \times t_{r m}+18.8-2 \leq t_{o p} \leq 0.33 \times t_{r m}+18.8+2 \\
& 0.33 \times t_{r m}+18.8-3 \leq t_{o p} \leq 0.33 \times t_{r m}+18.8+3
\end{aligned}
$$

Being:

$t_{o p}\left({ }^{\circ} \mathrm{C}\right)$ - hourly operative temperature

$t_{r m}\left({ }^{\circ} \mathrm{C}\right)$ - mean running outdoor air temperature, calculated according to [44].

To reduce the calculation time, the operative temperature was calculated only in the apartments in the portion of the building delimited by red square in figure 1. This portion includes 8 apartments: A1-A3 on the first floor, A4-A6 on the second floor, A7 and A8 on the third floor.

The numerical analysis was carried out with TRNSYS, a well-known and calibrated software, able to model the thermal behaviour of the building in transient state [45]. TRSNYS works with assembled calculation components, named types, each of them with a specific calculation tasks in the framework of the overall thermal and energy performance analysis. The project implemented in this analysis consists of the following components:

- weather data reader, for this project the climatic data of Rome were used, being more severe, and so more conservative, than Turin during the summer season;

- the solar generator which allows to build the solar irradiation dataset;

- additional components used for specific calculation tasks (such as the calculation of the effective sky temperature and of the heat transfer through the ground);

- the building block, which is filled in with all the data building inputs;

- the output results of the calculation, in this case outdoor temperatures in all flats and the outdoor air temperature.

The time resolution for the analysis is one hour, according to the requirements in the relevant standard. The building is in free floating conditions, meaning that no active cooling systems are installed. Simulations were run first increasing the solar shading (from 0 to 0.8 ), next increasing the base $0.3 \mathrm{ACH}$ with additional night ventilation (from 0 to $1.5 \mathrm{ACH}$ ). The calculation was carried out for the base case NZEB configuration and for the configuration with increased insulation levels for the building envelope (super NZEB). 


\subsection{Energy calculation}

Differently from the thermal calculation, the energy simulations were performed using EDILCLIMA, version EC700 [46], according to the relevant Standard. The software is, in fact, based on the national technical specification UNI/TS 1300 series [47], and on the CEN relevant standards with adaptation to the Italian context. A quasi-steady-state method is used for calculation of heating and cooling needs, with monthly heat balance and utilization factors in compliance with relevant national and EU standards. Input data (i.e. climatic condition, user behaviour) can be adapted to assess energy performance in accordance with standard or with real operating conditions. The tool allows to model any type of technical system and building components, both in graphical form and in tabular form. Envelope can be modelled using materials from the library or using the default building envelopes. The software allows calculating thermal transmittance of opaque structures according to the UNI EN ISO 6946 [48]. In this analysis the annual energy is computed for the following energy services: space heating, ventilation, domestic hot water production.

In all simulations the internal gains are set to $5 \mathrm{~W} / \mathrm{m}^{2}$ for sensible heat and $2.5 \mathrm{~W} / \mathrm{m}^{2}$ for latent heat, according to Italian standards [46]. In the building, in line with the national building code, an air change rate of $0.3 \mathrm{~h}-1$ is considered. Artificial lighting in residential buildings is not taken into account in the energy performance scheme and certification in Italy.

\subsection{Financial calculation}

Prices of proposed low-cost solutions for the envelope (autoclaved blocks, mono-block window) and for the energy systems which were not included in the bill of quantities of the real building (Mechanical extract ventilation and MVHR) in a first stage were derived from official regional price lists, which provide unitary costs $\left(€ / \mathrm{m}^{2}\right)$ for materials and labour [49]. Lately, it was chosen to ask for costs to real construction companies since it was noticed that price lists generally overpriced values.

For the external wall, a company which uses both technologies [50] was asked to simulate a real market offer for the reference building, giving disaggregated costs in labour and material of both traditional (brick-wall + thermal coating) and new solution (autoclaved blocks). It was observed that the cost of material of the blocks is $15 \%$ lower than traditional solution. Concerning the labour savings results are even more relevant since the impact on the construction time is a man-hours reduction of about $48 \%$. It resulted in a reduction of $16 € / \mathrm{m}^{2}$ in all the scenarios where transmittances of the external walls are the same as in the base case; a reduction of $5 € / \mathrm{m}^{2}$ did occur in the super NZEB scenarios in Turin.

Similarly, disaggregated costs for conventional windows and full mono-block windows were provided by a construction company [51]. In this case it was observed that windows cost in the new solution is higher (about 38\% more than conventional windows) but cost of the subframe is substantially null compared to standard solution. It leads to the overall observation that the full mono-block is cheaper by nearly $20 \%$ with about $60 \%$ time saving in the installation phase. It resulted in a reduction of $40 € / \mathrm{m}^{2}$ compared to the conventional windows.

For the Mechanical Extract ventilation system, as for MVHR, a company simulated a real economic offer to supply the MEV system for the reference building [42].

All the other costs of the building envelope and energy systems in the scenarios have been estimated as unitary variation $\left(€ / \mathrm{m}^{3}\right)$ of the original prices included in the bill of quantities or as price variation due to the different couplings of the installed systems. 
The LCC analysis was developed considering the incremental and actualized savings compared to the base case on 50 years expected lifetime of the building. According to this, only the "Energy related costs" of the overall construction costs have been considered in agreement to the standard application of the cost-optimal methodology [52]. The economic analysis was carried out based on the requirements of relative European Standard [53] taking into account: costs and lifetime of technical solutions implemented in the building configurations, costs for the used fuels, national economic indicators. The net present value (NPV) was selected as key performance indicator.

The maintenance costs and lifetime of the solutions are shown in Table 6. Most of these values have been taken from the Standard [53] apart from the values related to electric radiators which have been extrapolated from German guidelines VDI 2067 which deals with the calculation of the economic efficiency of building installations.

Table 6. Maintenance costs and lifetime of the solution sets

\begin{tabular}{|c|c|c|c|}
\hline & Technology & $\begin{array}{l}\text { Life Time } \\
\text { [years] }\end{array}$ & $\begin{array}{c}\text { Maintenance } \\
\text { Costs [\%] }\end{array}$ \\
\hline \multicolumn{2}{|c|}{ Solar thermal collectors } & 20 & 0.5 \\
\hline \multirow{2}{*}{\multicolumn{2}{|c|}{$\begin{array}{r}P V \\
\text { Building envelope }\end{array}$}} & 50 & 0.5 \\
\hline & & 50 & 0.5 \\
\hline \multicolumn{2}{|c|}{ Windows } & 30 & 0.5 \\
\hline \multirow{2}{*}{$M V H R$} & Unit & 15 & 4 \\
\hline & Pipes & 30 & 1 \\
\hline \multirow{2}{*}{$M E V$} & Unit & 20 & 4 \\
\hline & Pipes & 30 & 1 \\
\hline \multirow{2}{*}{ Heat pump } & Unit & 20 & 3 \\
\hline & Pipes & 30 & 1 \\
\hline \multirow{2}{*}{ Condensing boiler } & Unit & 20 & 1.5 \\
\hline & Pipes & 30 & 1 \\
\hline & Floor heating & 50 & 2 \\
\hline \multirow{2}{*}{\multicolumn{2}{|c|}{$\begin{array}{r}\text { Radiators } \\
\text { Electric Radiators }\end{array}$}} & 35 & 1.5 \\
\hline & & 22 & 1 \\
\hline
\end{tabular}

Table 7. National economic indicators for the LCC analysis

\begin{tabular}{lc}
\hline Discount rate & $4 \%$ \\
\hline Tax of interest income & $26 \%$ \\
\hline $\begin{array}{l}\text { Inflation of energy } \\
\text { electricity }\end{array}$ & $3.4 \%$ \\
\hline Inflation of energy gas & $2.3 \%$ \\
\hline Inflation of maintenance & $2 \%$ \\
\hline Evolution Price Product & $2 \%$ \\
\hline
\end{tabular}

Table 7 shows the national economic indicators used for the LCC analysis [54].The data was derived from a preliminary study for the new cost optimal analysis in Italy. Costs for the used fuels are the following: Gas $0.72 € / \mathrm{Sm}^{3}$; Electricity (bought from the grid) $0.20 € / \mathrm{kWh}$; Electricity (sold to the grid) $0.06 € / \mathrm{kWh}$.

Estimation of incomes for selling the surplus of renewable electricity to the grid is based on the Italian procedure of the net metering as prescribed in [55]. The GSE company [56] provides on annual basis the economic contribution $(C S)$ for electricity sold to the grid according to this formula:

$C S=(O E: C E i))+(C U S f \times E S)$

Where: 
- $O E$ is the product between the amount of energy taken from the grid and the national power exchange price

- $C E i$ is the product between the amount of energy sold to the grid and the price zone available on the Electricity Day-Ahead Market

- CUsf is the annual lump-sum contribution for energy exchange

- $E S$ is minimum, on an annual basis, between the amount of electricity put into and taken from the grid

It was chosen to calculate only the second term of the formula for two main reasons. First it was observed that is the heaviest part of the contribution. Then, the prices for estimating $O E$ and $C E i$ are daily variable so it would have been difficult to assess the precise values. Value of CUsf for the year 2017 were taken from the Arera web site, the Regulatory Authority for Energy, Networks and Environment in Italy [57] and it corresponds to the price for electricity sold to the grid.

\section{Results \\ 6.1. Passive cooling}

The first set of simulations carried out with TRNSYS showed that solar shading alone does not provide adequate thermal comfort with standard $0.3 \mathrm{ACH}$, with discomfort hours always above $20 \%$. The second set showed improvement of comfort conditions upon the simultaneous application of shading devices and night ventilation cooling strategies. Results are presented for the best performing configuration, consisting of external solar protection devices with shading factor 0.8 and $1.5 \mathrm{ACH}$ of night ventilation rate.

Figure 3 presents the hourly plot of the operative temperature in three reference apartments, located respectively at first, second and third (upper) floors for a week in July. It can be observed the small amplitude of the operative temperature in the apartments, $3{ }^{\circ} \mathrm{C}$ maximum in the 24 hours, versus variations up $14{ }^{\circ} \mathrm{C}$ of the external air temperature. The figure also shows the higher thermal stress in the attic flats, where the operative temperature raises up to $1{ }^{\circ} \mathrm{C}$ respect to the lower floors.

Under these conditions and taking into account the comfort category 2 of the relevant standard [43], the number of hours in which the operative temperature exceeds the comfort band is in the $0-1.3 \%$ range for the NZEB configuration in the observation period, while it raises to $0-1.9 \%$ range for the super NZEB configuration. In all cases the discomfort hours are by far below than $5 \%$, limit indicated by the relevant standard. Finally, the number of hours in the two digits range are calculated for the two flats located in the upper floor, just below the roofs, being negligible in all the other apartments.

An additional test was carried out to check the compliance with category 1 of the relevant standard, to assess if the thermal indoor environment might be significantly deteriorated respect to the requirements for weaker classes of residents. The results are presented in figure 4 and show a significant increase of discomfort hours. The discomfort hours are in the $0-4 \%$ range of the observation period for all the analysed flat but A8, where they reach $10 \%$, for the NZEB configuration, thus above the standard limits. The super NZEB configuration causes an increase of discomfort hours; in three cases (A1, A4, A7) the operative temperatures hours are above the limit in the 5-8\% of the all observation period, while for apartment A8 they reach $14 \%$. 


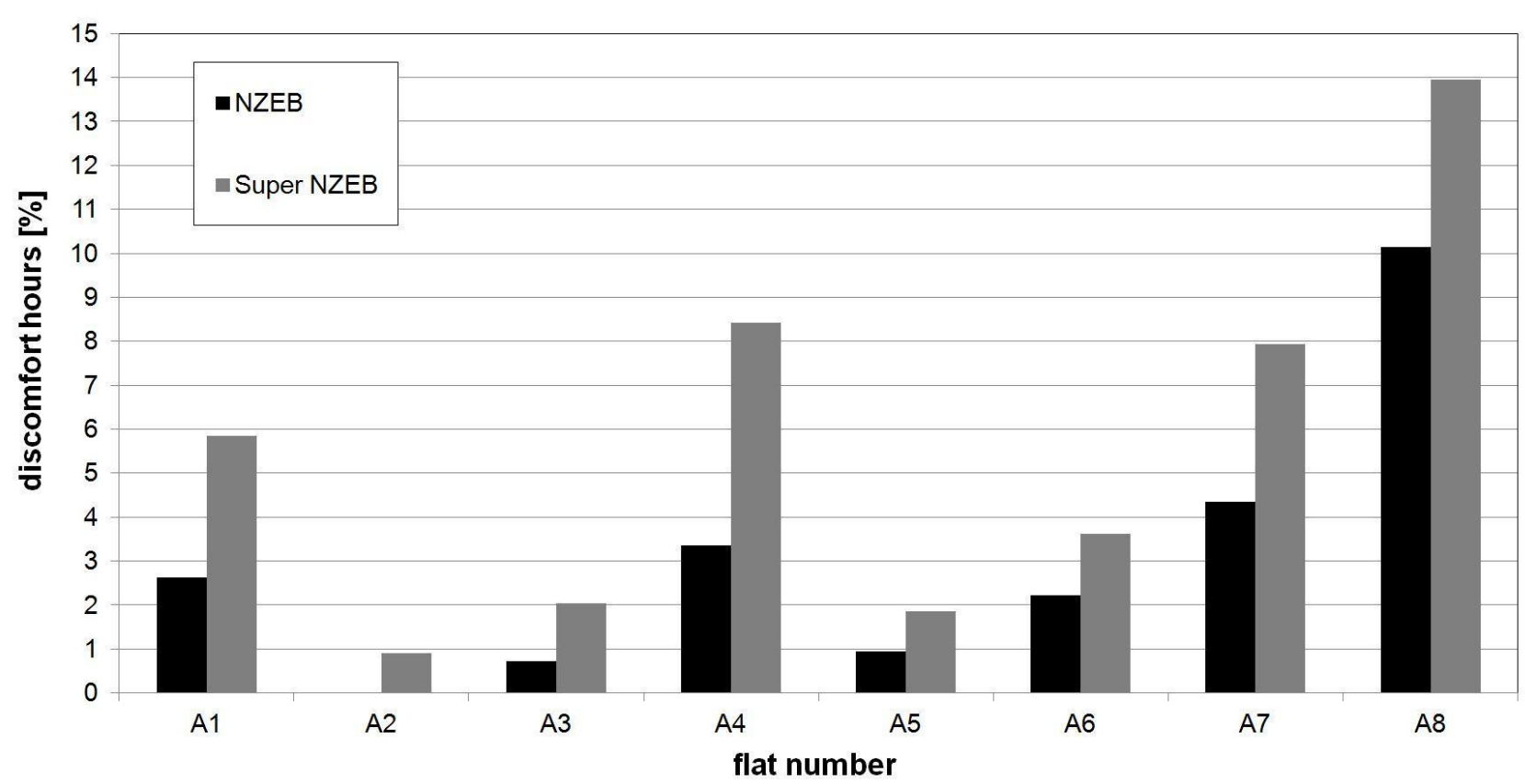

Figure 4. Relative discomfort hours in the investigated portion of the building for NZEB and super NZEB configurations in the June-August period.

The main outcomes of the analysis are:

- Requirements set for solar protection devices can be achieved with conventional textile and technical shading systems. Air exchange rates can also be easily fulfilled with multiple opening of windows [58], adequate planning of layout and façades of the building can ensure even higher rates [59][60]. This implies that passive solutions can be adequately planned and installed at no extra costs.

- The passive cooling solutions generally provides acceptable thermal comfort conditions at tested latitudes, according to the category II requirements of the relevant standard; in fact, the discomfort hours are always at very low level for category II.

- Higher deviations are calculated for category I, however very low-cost solutions can be implemented. Higher night ventilation rates and improved indoor conditions can be easily achieved by ceiling fans or simple ventilation systems, thus lowering the discomfort hours to acceptable levels. These punctual systems should be installed and switched on only where and when needed. Moreover, they might be fed by the renewable electricity produced at building level, which exceeds 


\subsection{Energy performance}

In all the energy simulations carried out with Edilclima, the building obtained the grade A4 which is the highest level of energy performance. Although the indicator of primary energy (EP) is different for each scenario, it is always much lower than the EP of the reference building to whom the case study is compared. According to the Italian Standard, in each simulation a reference building is defined, which is the same as the case study building concerning the geometry, orientation, geographic location, energy systems, but it has predetermined thermal and energy characteristics. This allows to calculate the primary energy limit that must be respected by the case study building.

The final energy and primary non-renewable energy for heating $\left(\mathrm{EPH}_{\text {,nen }}\right)$, DHW $(\mathrm{EPW}$, nren $)$ and Ventilation $\left(E P V,{ }_{\text {nren }}\right)$ of Rome and Turin are shown in Figure 5 and 6; Table 8 shows the global primary non-renewable energy $\left(\mathrm{EPgl}_{\text {nren }}\right)$

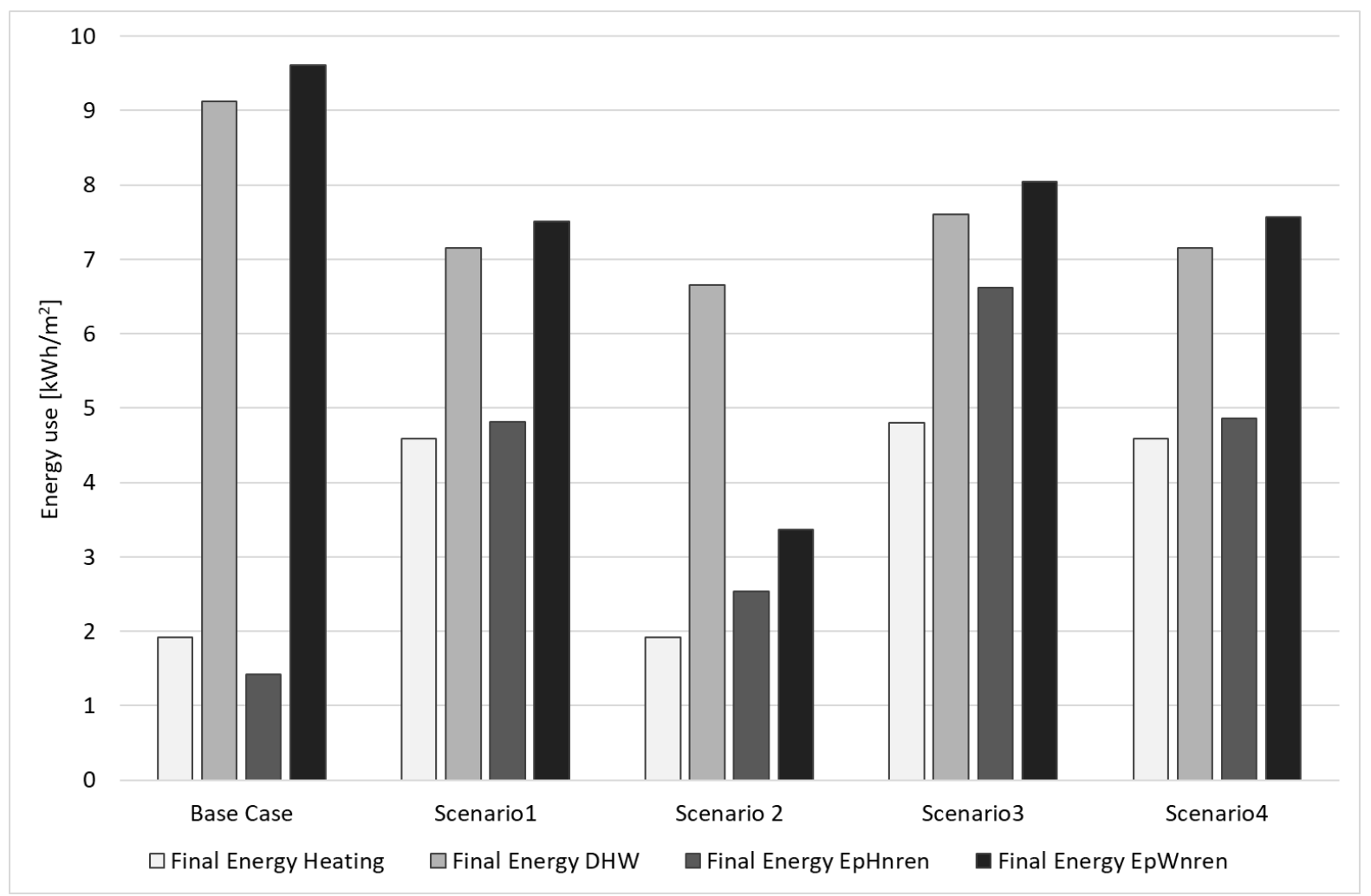

Figure 5. Results of the final energy and primary non-renewable energy for heating and DHW of the base case and alternative scenarios in Rome. 


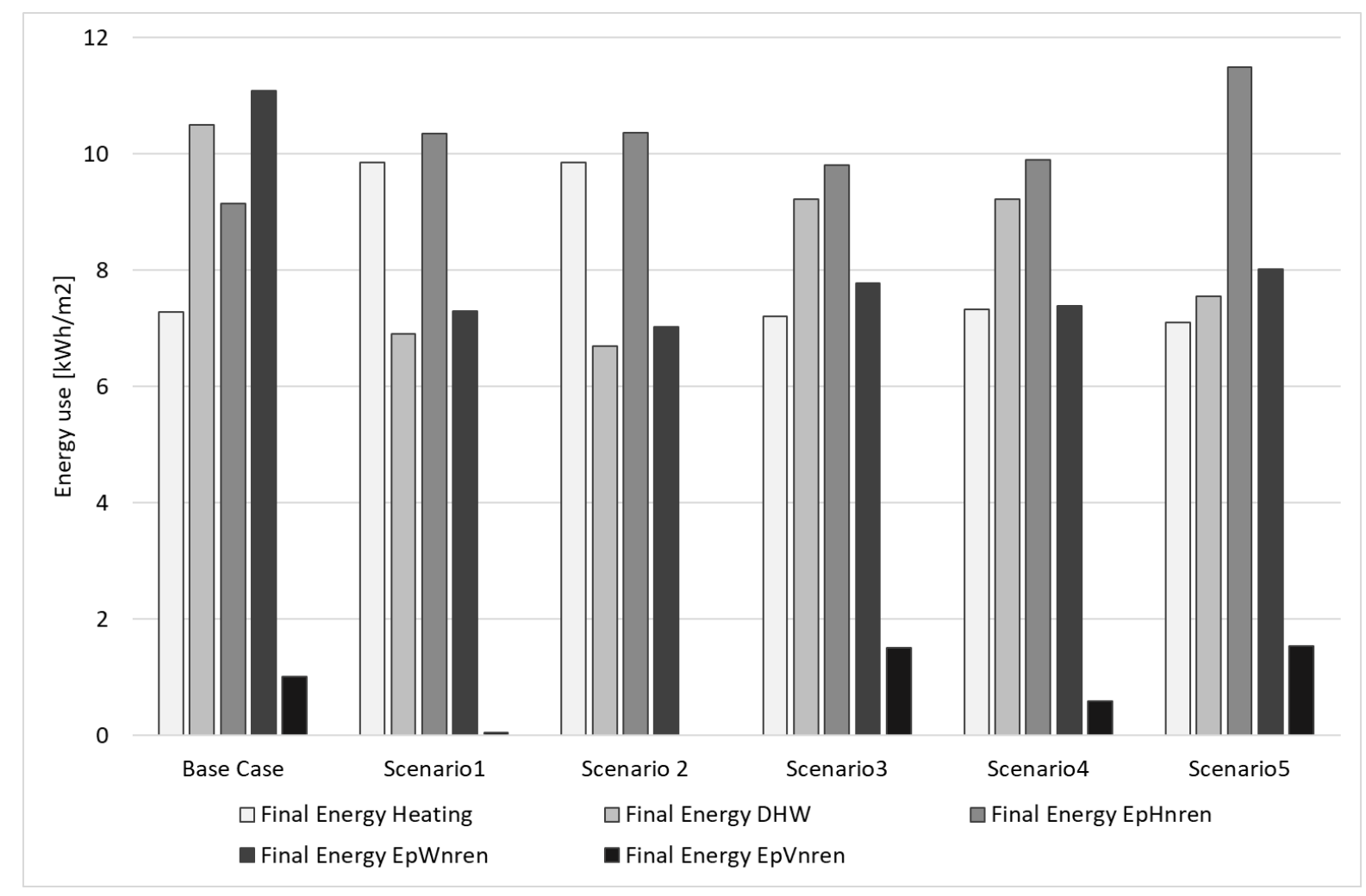

Figure 6. Results of the final energy and primary non-renewable energy for heating, DHW and Ventilation of the base case and the alternative scenarios in Turin.

Table 8. The global primary non-renewable energy $\left(\mathrm{EPgl}_{\text {nren }}\right)$ of the base cases and the alternative scenarios in Rome and Turin

\begin{tabular}{|c|c|c|c|c|c|c|c|c|c|c|c|}
\hline \multirow{3}{*}{$\begin{array}{l}\mathrm{EPgl}_{\text {nrengl }} \\
{\left[\mathrm{kWh} / \mathrm{m}^{2}\right.} \\
]\end{array}$} & \multicolumn{5}{|c|}{ Rome } & \multicolumn{6}{|c|}{ Turin } \\
\hline & $\begin{array}{l}\text { Base } \\
\text { case }\end{array}$ & Scen. 1 & Scen. 2 & Scen. 3 & Scen. 4 & $\begin{array}{l}\text { Base } \\
\text { case }\end{array}$ & Scen. 1 & Scen. 2 & Scen. 3 & Scen.4 & Scen.5 \\
\hline & 11.0 & 12.3 & 5.9 & 14.7 & 12.4 & 21.2 & 17.7 & 17.4 & 19.1 & 17.9 & 21.0 \\
\hline
\end{tabular}

In Rome, the $\mathrm{EPgl}_{\text {nren }}$ of all the scenarios (sum of Heating and DWH) is higher than base case, except for scenario 2. With a $E P g l_{\text {nren }}$ of $5.91 \mathrm{kWh} / \mathrm{m}^{2}$ it turns out to be the most energy efficient scenario: the use of the heat pump for both heating and DHW allows to exploit as much as possible the potentiality of both the heat pump and the PV panels.

In the base case scenario, there is a high difference between $\mathrm{EPW}_{\text {nren }}$ and $\mathrm{EPH}_{\text {nren }}$, being the first high $(9.6$ $\left.\mathrm{kWh} / \mathrm{m}^{2}\right)$ and the second very low $\left(1.42 \mathrm{kWh} / \mathrm{m}^{2}\right)$ : two separate systems are used (heat pump and condensing boiler) and a lower amount of solar thermal collectors is installed. On the contrary, in the other scenarios, the $\mathrm{EPH}_{\text {nren }}$ is always higher compared to the base case thanks to the use of the condensing boiler instead of the heat pump, while a decrease in the $\mathrm{EPW}_{\text {nren }}$ is always obtained due to increase of solar thermal collectors and/or the optimization of the heat pump.

The worst scenario is number 3. It has the highest $\mathrm{EPH}_{\text {nren }}\left(6.7 \mathrm{kWh} / \mathrm{m}^{2}\right)$, since, when not provided by the PV panels, energy is directly taken from the grid. Therefore, much more electricity is absorbed for heating supply compared to amount of electricity needed for the heat pump compressor and secondly the share of non-renewable energy in the electric grid is much higher compared to the renewable part.

Conversely, in Turin all the scenarios present a better energy performance compared to the base case, with globally lower $\mathrm{EPgl}_{\text {nren. }}$ ranging between 17.38 and $21.05 \mathrm{kWh} / \mathrm{m}^{2}$. 
The best scenario is number 2, where the $\mathrm{EPH}_{\text {nren }}$ is slightly higher than base case $\left(10.4 \mathrm{vs} 9.1 \mathrm{kWh} / \mathrm{m}^{2}\right.$.) due to the use of condensing boiler, but the $\mathrm{EPW}_{\text {nren }}$ is much lower $\left(7.0 \mathrm{vs} 11.1 \mathrm{kWh} / \mathrm{m}^{2}\right)$ thanks to the installation of twice as many solar thermal collectors. The $\mathrm{EPV}_{\text {nren }}$ is null: the installed MEV requires a lower amount of electricity compared to the MVHR and so, being scenario 2 a thermal driven solution, the highest part of electricity from PV panels can be used for the mechanical ventilation system.

Results of scenario 1 are coupled with the ones of scenario 2.Similarly, also scenarios 3 and 4 couple between themselves. The $\mathrm{EP}_{\text {nren }}$ in these two couples are aligned: differences among the values range between $1 \%$ for heating and 5\% for DHW. These differences are due to the fact that scenarios 1 and 3 have a standard NZEB envelope and a MVHR, while scenarios 2 and 4 have a super NZEB envelope and a MEV. As a matter of fact, the super NZEB envelope almost does not affect the $\mathrm{EPH}_{\text {nren }}$ but it has a little influence on the $\mathrm{EPW}_{\text {nren. }}$. In fact, in the couple 1-2, solar thermal collectors provide pre-heats water for both heating and DHW: the lower transmittance values of the envelope in scenario 2 allow to employ the solar collectors more for DHW than for heating, reducing the $\mathrm{EP}_{\text {nren }}$ up to $4 \%$ compared to scenario 1 . In cases 3 and 4 , DHW and heating are supplied by the heat pump; being scenario 4 a super NZEB, lower energy needs are required so a higher amount of electricity from PV panels can be provided to the heat pump for DHW, reducing the $\mathrm{EP}_{\text {nren }}$ up to $5 \%$ compared to scenario 3.

In scenario 3 and 5, the $\mathrm{EPV}_{\text {nren }}$ is higher than base case, since more electricity from PV panels is absorbed for heating supply compared to the other scenarios.

Table 9. Results of energy consumption and energy production in Rome and Turin for the base cases and the alternative scenarios

\begin{tabular}{|c|c|c|c|c|}
\hline \multirow{4}{*}{ Scenarios } & $\begin{array}{l}\text { Electricity } \\
\text { consumption } \\
{[\mathrm{kWh}]}\end{array}$ & $\begin{array}{l}\text { Electricity } \\
\text { production } \\
{[\mathrm{kWh}]}\end{array}$ & $\begin{array}{c}\text { Gas } \\
\text { consumption } \\
{\left[\mathrm{Sm}^{3}\right]}\end{array}$ \\
\hline \multirow{4}{*}{ Rome } & Base case & 1601 & 20618 & 2324 \\
\cline { 2 - 5 } & Scenario 1 & 0 & 23060 & 2913 \\
\cline { 2 - 5 } & Scenario 2 & 7149 & 10513 & 98 \\
\cline { 2 - 5 } & Scenario 3 & 8604 & 22934 & 1890 \\
\cline { 2 - 5 } & Scenario 4 & 304 & 363 & 2913 \\
\hline \multirow{5}{*}{ Turin } & Base case & 8490 & 13277 & 3481 \\
\cline { 2 - 5 } & Scenario 1 & 78 & 13676 & 4171 \\
\cline { 2 - 5 } & Scenario 2 & 0 & 16666 & 4110 \\
\cline { 2 - 5 } & Scenario 3 & 18004 & 4086 & 1212 \\
\cline { 2 - 5 } & Scenario 4 & 16340 & 5428 & 1234 \\
\cline { 2 - 5 } & Scenario 5 & 16864 & 14068 & 1876 \\
\hline
\end{tabular}

In table 9 the energy consumption of electricity and gas and the renewable energy production are shown. Both in Rome and Turin, the thermal driven scenarios ( 1 and 4 in Rome and 1 and 2 in Turin) have almost zero electricity consumption and consume only a slightly higher amount of gas compared to the base case (up to $26 \%$ more in Rome) due to the greater number of solar thermal collectors installed. Additionally, in the base case in Turin the back-up condensing boiler does often intervene instead of the heat pump for heating supply due to the lower outdoor temperature. It contributes to align the data of gas consumption between the base case and the thermal driven scenarios which only use condensing boiler for space heating.

Conversely, in electricity driven scenario 2 in Rome the use of the heat pump for both heating and DHW make the electricity consumption arise up to $346 \%$ and the gas consumption decreases up to zero; in Turin electricity and gas consumption in electricity-driven scenarios are both high. 


\subsection{Economic analysis and LCC results}

Two additional scenarios, called S3b and S5b, have been introduced in the financial analysis for respectively Rome and Turin, as variations of scenarios 3 and 5. In these variations of the scenarios 3 and 5, a lower investment cost for the electric radiators has been proposed. Due to the variability in the market price of these systems, it was chosen to show two representative costs in these range of prices.

In Table 10 the Net Present Values (NPV) and the energy related construction costs are shown for each scenario; these unitary NPVs $\left(€ / \mathrm{m}^{2}\right)$ are expressed in terms of actualized savings compared to the base case on 50 years expected lifetime of the building.

Table 10. Results of the Net Present Values (NPV) and energy related construction costs in Rome and Turin for the base cases and the alternative scenarios

\begin{tabular}{|c|c|c|c|}
\hline & Scenarios & $\begin{array}{c}\text { Energy related } \\
\text { construction costs } \\
{\left[€ / \mathrm{m}^{2}\right]}\end{array}$ & $\begin{array}{c}\mathrm{NPV} \\
{\left[€ / \mathrm{m}^{2}\right]}\end{array}$ \\
\hline \multirow{6}{*}{ Rome } & Base case & 389 & - \\
\hline & Scenario 1 & 310 & 133 \\
\hline & Scenario 2 & 321 & 111 \\
\hline & Scenario 3 & 296 & 143 \\
\hline & Scenario 4 & 295 & 150 \\
\hline & Scenario $3 b$ & 287 & 163 \\
\hline \multirow{7}{*}{ Turin } & Base case & 447 & - \\
\hline & Scenario 1 & 384 & 121 \\
\hline & Scenario 2 & 385 & 158 \\
\hline & Scenario 3 & 382 & 77 \\
\hline & Scenario 4 & 383 & 122 \\
\hline & Scenario 5 & 391 & 105 \\
\hline & Scenario $5 b$ & 383 & 121 \\
\hline
\end{tabular}

In graphs 7 and 8 the cash flows of the scenarios over the 50-year life time of the building for the two climate zones are shown. The occurring positive and negative variations in the trends, which make the slope of the line vary and the savings increase or decrease rapidly, are due to the one-off replacement of the technical systems. The replacements are also expressed as costs difference between the scenarios and the base cases. On this note, when the scenario has lower costs, there are savings and the slope of the line increases, when the scenario has higher replacement costs compared to the base case there are expenses and the slope of the line decreases. This can be observed, for example, in figure 7 for scenarios S3b and S3 in which high savings compared to the base case do occur around year 20 since replacement of the technical systems are avoided, but similar or higher expenses, compared to the base case, are registered around year 22 , which compensate for the previous savings. Similarly, in figure 8 for scenarios S2 and S4 an accentuated cash flow saving do occur for the same reasons. 


\section{0}

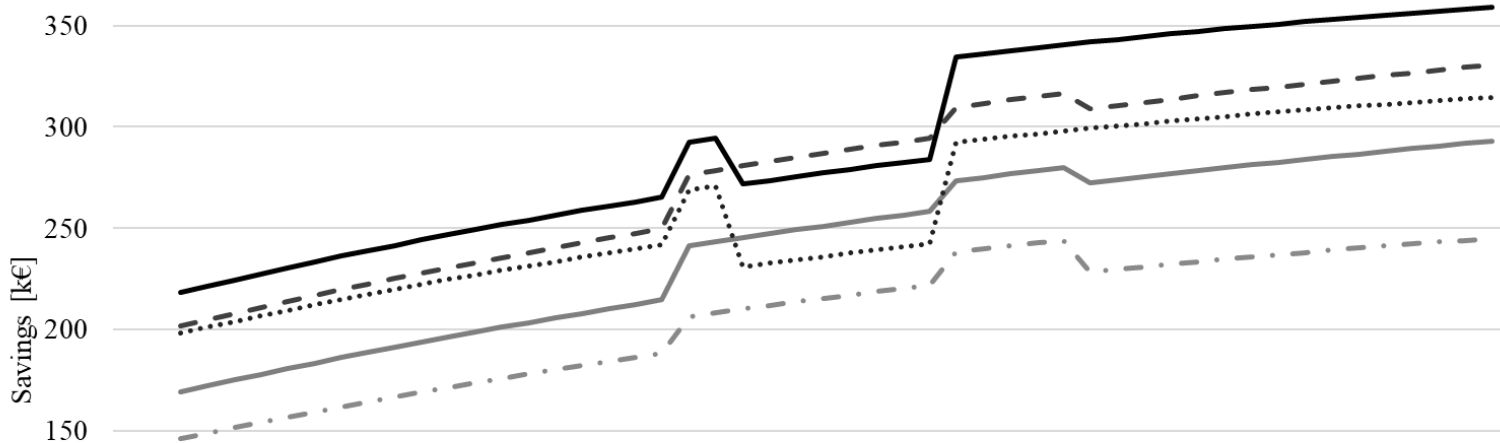

100

50

0

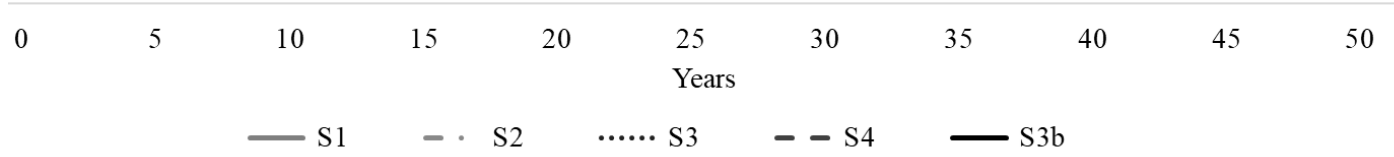

Figure 7. Results of the Life Cycle Cost (LCC)C analysis in Rome for the alternative scenarios. Results are expressed in terms of actualized savings compared to the base case on 50 years expected lifetime of the building.

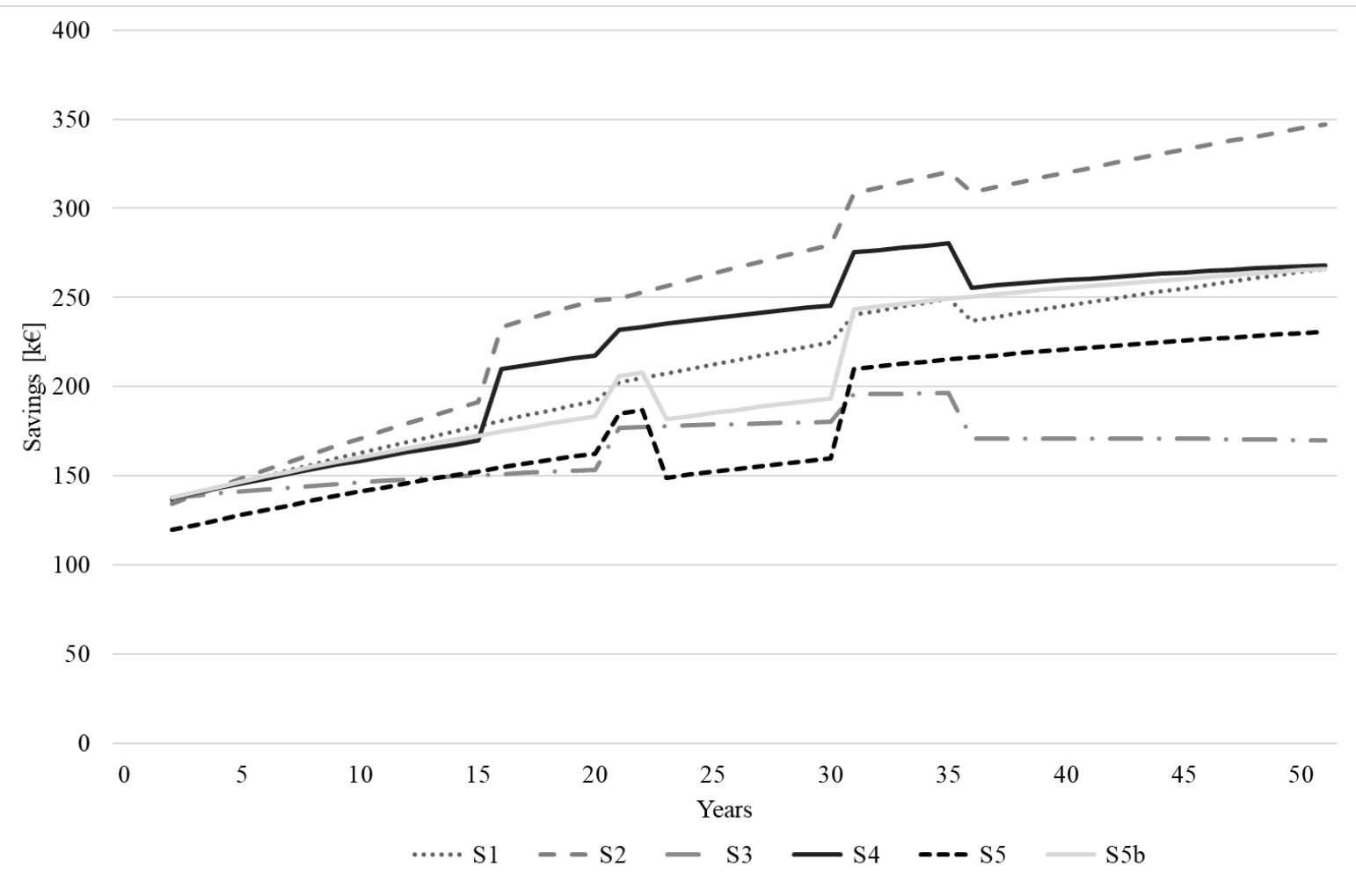

Figure 8. Results of the Life Cycle Cost (LCC)C analysis in Turin for the alternative scenarios. Results are expressed in terms of actualized savings compared to the base case on 50 years expected lifetime of the building.

It can be noted that all scenarios in the two climate zones allow both reductions in the construction costs and savings in a long-term perspective. In the life cycle cost analysis three types of costs have been considered: 
maintenance costs of the technical systems and envelope, energy costs, and replacements costs based on the reduction of investment costs. All scenarios have lower annual maintenance costs for the envelope compared to the base case. The differences among scenarios are mainly registered as variations of maintenance costs for the technical systems and energy costs. The best scenario is $3 \mathrm{~b}$, which shows the lowest initial construction costs $\left(287 € / \mathrm{m}^{2}\right)$ and the highest NPV $\left(163 € / \mathrm{m}^{2}\right)$. The absence of technical system for heating supply allows to considerably reduce maintenance and replacement costs: at the end of the 50 years up to $€$ $329^{\prime} 000$ are saved for maintenance costs of technical system compared to the base case. It compensates for the annual energy expense, which is much higher than the base case, achieving a total actualized expense of about $€ 93^{\prime} 000$ more than the base case. High profits can be also achieved with scenarios 4 and 3; the main variation between scenario $3 \mathrm{~b}$ and 4 is due to the difference in savings for systems replacement, which are much higher in scenario $3 \mathrm{~b}$. It has to be observed that these three scenarios are outlaw. Considering only the scenarios compliant with legal standard, the most efficient is number 1 .

In Turin, up to $15 \%$ of savings in investment costs were obtained with scenario 3 . Construction costs of the five scenarios are very similar to each other reaching a maximum percentage difference of about $2 \%$ between 3 and scenario 5-In fact, when the expense for the envelope are higher (super NZEB) it is balanced by cheaper technical systems (MEV instead of MVHR, absence of solar thermal collectors, elimination of heat supply system). Also in this case differences among scenarios are mainly registered as variations of maintenance costs for the technical systems and energy costs.

Scenario 2 is the most efficient from a long-term perspective showing a NPV of $158 € / \mathrm{m}^{2}$ : after 50 years maintenance costs for renewable system and envelope are higher than the base case (actualized expense of respectively $€ 12^{\prime} 000$ more than the base case).Nevertheless, operational energy costs and maintenance costs for technical systems are much lower (actualized savings of about $€ 398^{\prime} 000$ for maintenance costs and $€$ $106^{\prime} 000$ for energy costs). The replacement of technical system is also less expensive than base case, since the condensing boiler is used instead of the heat pump and the MEV instead of the MVHR.

Scenarios 1, 4 and 5b, despite the differences in trends, show aligned NPV at the end of the 50 years. A great impact on the trend variations among these scenarios is given by the different costs for systems replacement.

The outlaw scenario $5 \mathrm{~b}$ allows the highest savings for maintenance costs of the technical systems but on the other side it entails an increase of costs for PV panels, envelope and energy due to the high amount of electricity taken from the grid as it happens in scenarios 3 and 4. As shown in Table 9, despite the high electricity consumption, the amount of energy sold to the grid is also very high, contrary to cases 3 and 4 where the energy sold to the grid is considerably lower than the bought one. Based on the procedure of net metering, the energy payed to the building owner corresponds to the minimum between the amount of electricity sold and bought from the grid: in this case, being these two values quite aligned and very high, the annual incomes are much more than the other scenarios.

\section{Conclusion}

In this paper solution sets for reducing construction costs of new nearly zero energy multi-family houses were explored in a life cycle perspective. Conversely to the typical methodology of cost-optimal analysis, in this study alternative constructive strategies and unconventional combinations of technical solutions have been proposed; the efficacy of forefront proposals, currently forbidden in Italy according to the relevant Standard, were also analysed. The real case study building, located in the centre of Italy, was standardized and adapted to the minimum Nearly Zero Energy Building requirements of the two climatic zones chosen for the analysis (Rome and Turin). The choice of an existing building allowed to carry out a very realistic evaluation of the cost effectiveness of the proposed variants, dueto the availability of technical and economic data based on real market instead of on average values. The LCC analysis also allowed to compare all the 
scenarios in a life cycle perspective, including the annual operational, maintenance and replacements costs calculation was performed. This analysis was aimed to assess whether the use of passive solutions (solar protection and night ventilation cooling) might avoid the installation of active cooling to prevent summer overheating, thus keeping lower costs for design and installation of such systems. Results demonstrated that low-cost passive strategies can be adequately planned and installed at no extra costs, providing acceptable thermal comfort conditions at tested latitudes. In the three reference apartments, located respectively at first, second and third (upper) floors, results show that the discomfort hours in summer period are by far below than $5 \%$, limit indicated by the relevant standard.

Lately, results of the energy calculation performed on the low-costs scenarios in Rome and Turin demonstrated that all the variants reached the highest grade of energy performance (level A4). Although, it was observed that in all the scenarios in Rome, except for number 2, the global primary non-renewable energy indicators $\mathrm{EPgl}_{\text {nren }}$ is higher than base case, with a maximum percentage difference of $34 \%$. The most energy efficient is the electricity driven scenario number 2. In this scenario the use of the heat pump for both heating and Domestic Hot Water allows to exploit as much as possible the potentiality of both the heat pump and the Photovoltaic panels. The $\mathrm{EPgl}_{\text {nren }}$ is $46 \%$ lower than the base case. Conversely in Turin, all the scenarios show a lower $\mathrm{EPgl}_{\text {nren }}$ compared to the base case, with a reduction up to $18 \%$ between base case and the thermal driven scenario 2. It is also the most efficient: electricity consumption for heating is reduced; the high number of solar collectors allows to minimize thermal consumption for Domestic Hot Water ; the installed Mechanical Extract Ventilation requires a lower amount of electricity compared to the Mechanical Ventilation with Heat Recovery of the base case, maximizing the contribute of Photovoltaic panels.

From the financial perspective, it was demonstrated that, compared to the base case, all the scenarios in the two climate zones allow both reductions in the construction costs, up to $26 \%$ in Rome, and savings over the 50-year life time of the building, up to $163 € / \mathrm{m}^{2}$ in Rome. Results also show the importance of an accurate evaluation of the maintenance and replacement costs of each technology. In fact, it was observed that these expenses have a key role in the assessment of the most profitable scenario, making the differences among the proposed solution sets.

In Rome, the most economically efficient is scenario $3 b$, having both the lowest investment costs $\left(287 € / \mathrm{m}^{2}\right)$ and the highest Net Present Value $\left(163 € / \mathrm{m}^{2}\right)$. This is a variant of the electricity driven scenario 3 but is not compliant with Standard requirements. In this scenario the investment costs of the electric radiators are lower than scenario 3 and the absence of technical system for heating supply allows to considerably reduce maintenance and replacement costs. In Turin, differently from Rome, the most energy efficient scenario, is number 2, which is also the most profitable. It shows the highest Net Present Value $(158 € / \mathrm{m} 2)$ although it doesn't have also the lowest construction costs. Nevertheless, it can be observed that investment costs of the five scenarios in Turin are very similar, reaching a maximum percentage difference of about $2 \%$ between 3 and scenario 5. These results confirm that differences among the scenarios can be only assessed in a longterm perspective, highlighting the importance of developing Life Cycle Cost analysis on buildings.

Limitations of the present study included: boundary conditions, characteristic of the reference building and the technological solution; future developments will take them into account, as well as more holistic approach to costs (as those related to design and preliminaries) and to factors affecting the energy performances across time (as the impact of aging of building and systems elements and the impact of climate change).

\section{AKNOWLEDGEMENTS}

The CoNZEBs project has received funding from the European Union's Horizon 2020 research and innovation programme under grant agreement no. 754046. The article reflects the authors' view. The Commission is not responsible for any use that may be made of the information it contains. 


\section{References}

[1] Horizon 2020 EU Research and Innovation programme. Available at: http://ec.europa.eu/research/participants/portal/desktop/en/funding/reference docs.html

[2] Green Paper, A 2030 framework for climate and energy policies, COM (2013)169 http://ec.europa.eu/energy/consultations/20130702 green paper 2030en.htm

[3] 2050 Energy strategy. Available at: https://ec.europa.eu/energy/en/topics/energy-strategy-and-energyunion/2050-energy-strategy

[4] Eurostat. Final energy consumption by sector. 2016. Available at: http://ec.europa.eu/eurostat/en/web/products-datasets/-/T2020_34

[5] European Parliament and Council: Directive 2010/31/EU of the European Parliament and of the Council of 19 May 2010 on the energy performance of buildings. 2010. Official Journal L 153, 18.6.2010, p. 13-35. Available at http://eur-lex.europa.eu/legal-content/EN/TXT/?uri=OJ:L:2010:153:TOC.

[6] S. Attia, P. Eleftheriou, F. Xeni, R. Morlot, C. Menezo, V. Kostopoulos, M. Betsi, I. Kalaitzoglou, L. Pagliano, M. Cellura, M. Almeida, M. Ferreira, T. Baracu, V. Badescu, R. Crutescu, J.M. Hidalgo-Betanzos, Overview and future challenges of nearly zero energy buildings (nZEB) design in Southern Europe, Energy and Buildings, 2017, vol 155, pp.439-458

[7] J. Schnieders, W. Feist, L. Rongen, Passive Houses for different climate zones, Energy and Buildings, 2015, vol. 105, pp. 71-87.

[8] A. Pathan, A. Mavrogianni, A. Summerfield, T. Oreszczyn, M. Davies, Monitoring summer indoor overheating in the London housing stock, Energy and Buildings, 2017, vol. 141, pp.361-378.

[9] S. Colcough , O. Kinnane, N. Hewitt, P. Griffiths , Investigation Of nZEB Social Housing built to the Passive House Standard, Energy \& Buildings, 2018, vol 179, pp. 344-359.

[10] S. K. M. Chvatal, H. Corvacho, The impact of increasing the building envelope insulation upon the risk of overheating in summer and an increased energy consumption, Journal of Building Performance Simulation, 2009, vol. 4, pp. 267-282.

[11] G. Murano, I. Ballarini, D.Dirutigliano, E.Primo, V. Corrado, The significant imbalance of nZEB energy need for heating and cooling in Italian climatic zones, Energy Procedia, 2017, vol. 126, pp. 258-265.

[12] F. Ascione, R.F. De Masi, F. de Rossi, S. Ruggiero, G. P. Vanoli, Optimization of building envelope design for nZEBs in Mediterranean climate: Performance analysis of residential case study, Applied Energy, 2016, vol 183, pp. 938-957.

[13] A. Figueiredo, J. Kämpf, R. Vicente, Passive house optimization for Portugal: overheating evaluation and energy performance, Energy and Buildings, 2016, vol. 188, pp. 181-196.

[14] S. Guillén-Lambea, B. Rodríguez-Soria, J.M. Marín, Comfort settings and energy demand for residential nZEB in warm climates, Applied Energy, 2017, vol. 202, pp 471-486.

[15] P.Huang, G. Huang, Y. Sun, Uncertainty-based life-cycle analysis of near-zero energy buildings for performance improvements, Applied Energy, 2018, vol. 213, pp. 486-498

[16] P.Huang, G. Huang, Y. Sun, A robust design of nearly zero energy building systems considering performance degradation and maintenance, Energy, 2018, vol. 163, pp. 905-919.

[17] M. Hu, Does Zero Energy Building Cost More? - An Empirical Comparison of the Construction Costs for Zero Energy Education Building in United States, Sustainable Cities and Society, 2019, vo. 45, pp. 324-334.

[18] D. D'Agostino, D. Parker, A framework for the cost-optimal design of nearly zero energy buildings (NZEBs) in representative climates across Europe, Energy, 2018, vol. 149, pp. 814-829

[19] W. Wu, H. M. Skye, P. A. Domanski, Selecting HVAC systems to achieve comfortable and cost-effective residential net-zero energy buildings, Applied Energy 212 (2018) 577-591.

[20] EU, 244/2012. Commission Delegated Regulation No 244/2012 of 16 January 2012. Supplementing Directive 2010/31/EU of the European Parliament and of the Council on the energy Performance of Buildings by Establishing a Comparative Methodology Framework for Calculating Cost-optimal Levels of Minimum Energy Performance Requirements for Buildings and Building Elements. Official Journal of the European Union.

[21] D. D'Agostino, L. Mazzarella, What is a Nearly zero energy building? Overview, implementation and comparison of definitions, Journal of Building Engineering, 2019, vol. 21, pp. 200-212

[22] J. Kurnitskia, A. Saarib, T. Kalameesc, M. Vuolled, J. Niemeläd, T. Tarke, Cost optimal and nearly zero (nZEB) energy performance calculations for residential buildings with REHVA definition for nZEB national implementation, Energy and Buildings, 2011, vol. 43, pp. 3279-3288. 
[23] E. Pikas, M. Thalfeldt, J. Kurnitski, R. Liias, Extra cost analyses of two apartment buildings for achieving nearly zero and low energy buildings, Energy, 2015, VOL. 84, pp. 623-633

[24] M.l Villa-Arrietaa, A. Sumperb, Economic evaluation of Nearly Zero Energy Cities Economic evaluation of Nearly Zero Energy Cities, Applied Energy 2019, vol. 237, pp. 404-416.

[25] P. Huang, Y. Sun, A clustering-based grouping method of nearly zero energy buildings for performance improvements, Applied Energy, 2019, vol. 235, pp. 43-55.

[26] P.M. Congedo, C. Baglivo, D. D'Agostino, I. Zacà, Cost-optimal design for nearly zero energy office buildings located in warm climates, Energy, 2015, vol. 91, pp. 967-982

[27] C. Becchio, M. C. Bottero, S. P. Corgnati, C. Ghiglione, nZEB design: challenging between energy and economic targets, Energy Procedia, 2015, vol. 78, pp. 2070 - 2075.

[28] V.M. Barthelmes, C. Becchio, S.P. Corgnati, C. Guala, M. Lequio, Replicability of nZEBs on real estate market in Mediterranean countries

[29] BPIE (Buildings Performance Institute Europe). Implementing the costoptimal methodology in EU countries. Pages 1-82. ISBN 9789491143083. http://bpie.eu/costoptimalmethodology.html

[30] F. Reda, Z. Fatima, Northern European nearly zero energy building concepts for apartment buildings using integrated solar technologies and dynamic occupancy profile: Focus on Finland and other Northern European countries, Applied Energy, 2019, vol. 237, pp. 598-617.

[31] E. Annunziata, M. Frey, F. Rizzi , Towards nearly zero-energy buildings: The state of art of national regulations in Europe, Energy, 2013, vol. 57, pp. 125-133.

[32] S. Attia, Net Zero Energy Buildings (NZEB), 1st Edition, Butterworth-Heinemann, 2018

[33] Hamdy, M., Siren, K., Attia, S., Impact of financial assumptions on the cost optimality towards nearly zero energy buildings: a case study. Energy and Buildings, 2017, vol. 153, pp. 421- 438.

[34] Buildings Performance Institute Europe (BPIE), Europe's buildings under the microscope: A country-bycountry review of the energy performance of buildings.

[35] M. Ferrara, V. Monetti, E. Fabrizio, Cost-Optimal Analysis for Nearly Zero Energy Buildings Design and Optimization: A Critical Review, Energies, 2018, vol. 11, n. 1478.

[36] B. Heymer, Sh. Pless, S. Hackel, 2016. Zero net energy building cost and feasibility. Webinar. Available from: http://www.seventhwave.org/sites/default/files/zero-energywebinar-slides-052616.pdf (accessed 20.01.18).

[37] DM 26 giugno 2015: Application of calculation methodologies for energy performance and definition of prescription and minimum requirements of buildings. 2015.

[38] Dlsg 28/2011: Implementation of Directive 2009/28/CE on the promotion of the use of energy from renewable sources and amending and subsequently repealing Directives 2001/77/EC and 2003/30/EC, 2011.

[39] PANZEB: Piano d'Azione Nazionale per incrementare gli edifici ad energia quasi zero, 2016. Available at.:

http://www.sviluppoeconomico.gov.it/images/stories/normativa/all_decreto_interministeriale_19_giugno_20 17_panzeb.pdf

[40] CoNZEBs - Solution sets for the cost reduction of new Nearly Zero-Energy Buildings, EU H2020 Funded Project, Contract number 754046 (www.conzebs.eu)

[41] V. Corrado, I. Ballarini, S. Paduos, Sviluppo della metodologia comparativa costoptimal secondo Direttiva 2010/31/UE, Ricerca di sistema elettrico, Report RdS/2013/144.

[42] C. Buttà: Personal Communication, Mydatec.

[43] H. Erhorn- Kluttig, H. Erhorn, B. Utesch, K. Wittchen, K. Engelund Thomsen, O. Mørck, O. Baslev- Olsen, M. Jungshoved, M. Zinzi, B. Mattoni, M. Šijanec- Zavrl, D. Varšek, 2018, Overview of Cost Baselines for three Building Levels, Report of CoNZEBs Project, available at www.conzebs.eu.

[44] EN15251- Indoor environmental input parameters for design and assessment of energy performance of buildings addressing indoor air quality, thermal environment, lighting and acoustics, 2007.

[45] TRNSYS 17. Available online at www.trnsys.com

[46] EDILCLIMA EC700. https://www.edilclima.it/

[47] UNI/TS 11300: Parte 1 - Determinazione del fabbisogno di energia termica dell'edificio per la climatizzazione estiva ed invernale, 2014.

[48] UNI EN ISO 6946:2008: Componenti ed elementi per edilizia - Resistenza termica e trasmittanza termica - Metodo di calcolo,2008.

[49] Prezzi Informativi dell'edilizia, Nuove costruzioni, DEI, Febbraio 2018

[50] Miliani, A.: Personal communication, Xella Italia S.r.l. 
[51] Paolini, A.: Personal communication, Giuliani S.C.

[52] J. Kurtnitskij, A. Saari, T. Kalamees, M. Vuolle, J. Niemela, T. Tark, Cost optimal and nearly zero (nZEB) energy performance calculations for residential buildings with REHVA definition for nZEB national implementation. Energy and Buildings, 2011, vol. 11, pp. 3279-3288.

[53] UNI EN 15459-1: Energy Performance of Buildings-Economic evaluation procedure for energy systems in buildings -Part 1, 2018.

[54] Riva, G.: Personal communication, 2017.

[55] Allegato A alla delibera ARG/elt 74/08 - Testo integrato delle modalità e delle condizioni tecnico economiche per lo scambio sul posto - Available at: https://www.arera.it/allegati/docs/08/074-08argall2.pdf

[56] GSE Gestore Servizi Energetici. Available at: https://www.gse.it/

[57] Valori del corrispettivo unitario di scambio forfetario per l'anno 2017, 03 aprile 2018. Available at: https://www.arera.it/it/comunicati/18/180403.htm

[58] G.Iwashita, H. Akasaka, The effects of human behavior on natural ventilation rate and indoor air environment in summer- a field study in southern Japan, Energy and Buildings, 1997, vol. 25, pp. 195-205

[59] C. Howard-Reed , L.A. Wallace, W. R. Ott , The Effect of Opening Windows on Air Change Rates in Two Homes, Journal of the Air \& Waste Management Association, 2002, vol. 52:2, pp. 147-159.

[60] P.R. Warren, Ventilation through openings on one wall only, in: International Conference Heat and Mass transfer in Buildings, Dubrovnik, Yugoslavia, 1977. 
Table 1. Transmittance values of the building envelope of the reference buildings in Rome and Turin

\begin{tabular}{cccc}
\hline City & U-roof $\left[\mathrm{W} / \mathrm{m}^{2} \mathrm{~K}\right]$ & U-wall $\left[\mathrm{W} / \mathrm{m}^{2} \mathrm{~K}\right]$ & U-first floor $\left[\mathrm{W} / \mathrm{m}^{2} \mathrm{~K}\right]$ \\
\hline Rome & 0.26 & 0.28 & 0.28 \\
\hline Turin & 0.21 & 0.25 & 0.24 \\
\hline
\end{tabular}

Table 2. Total and energy related construction costs of reference building in Rome

\begin{tabular}{cccccc}
\hline & Structure & Construction components & $\begin{array}{c}\text { Technical } \\
\text { Systems }\end{array}$ & Renewable sources & Total \\
\hline Costs $[€]$ & $996^{\prime} 624$ & $1^{\prime} 554^{\prime} 631$ & $782^{\prime} 027$ & $55^{\prime} 302$ & $3^{\prime} 388^{\prime} 584$ \\
\hline Incidence on overall costs $[\%]$ & 29 & 46 & 23 & 2 & 100 \\
\hline Unitary costs $\left[€ / \mathrm{m}^{2}\right]$ & 469 & 731 & 368 & 26 & 1594 \\
\hline $\begin{array}{c}\text { Energy related }[€] \\
\begin{array}{c}\text { Incidence on category cost } \\
{[\%]}\end{array}\end{array}$ & 0 & $522^{\prime} 783$ & $248^{\prime} 194$ & $55^{\prime} 302$ & $826^{\prime} 279$ \\
\hline $\begin{array}{c}\text { Unitary energy related costs } \\
{\left[€ / \mathrm{m}^{2}\right]}\end{array}$ & 0 & 34 & 32 & 100 & 1 \\
\hline
\end{tabular}

Table 3. Total and energy related construction costs of reference building in Turin

\begin{tabular}{cccccc}
\hline & Structure & Construction components & $\begin{array}{c}\text { Technical } \\
\text { Systems }\end{array}$ & Renewable sources & Total \\
\hline Costs $[€]$ & $996^{\prime} 624$ & $1^{\prime} 583^{\prime} 195$ & $867^{\prime} 107$ & $64^{\prime} 894$ & $3^{\prime} 511^{\prime}, 820$ \\
\hline Incidence on overall costs [\%] & 28 & 45 & 25 & 2 & 100 \\
\hline Unitary costs $\left[€ / \mathrm{m}^{2}\right]$ & 469 & 744 & 408 & 31 & 1652 \\
\hline Energy related $[€]$ & 0 & $551^{\prime} 358$ & $333^{\prime} 306$ & $64^{\prime} 894$ & 1 \\
\hline $\begin{array}{c}\text { Incidence on total category } \\
\text { cost }[\%]\end{array}$ & 0 & 35 & 38 & 100 & 447 \\
\hline $\begin{array}{c}\text { Unitary energy related costs } \\
{\left[€ / \mathrm{m}^{2}\right]}\end{array}$ & 0 & 259 & 157 & 31 & 1 \\
\hline
\end{tabular}

Table 4. . Description of the building envelope and technical systems for the reference building and proposed low-cost scenarios in Rome

\begin{tabular}{|c|c|c|c|c|c|c|}
\hline & Technology & Reference building & $\begin{array}{l}\text { Scenario 1 } \\
\text { Thermal driven } \\
\text { solution }\end{array}$ & $\begin{array}{l}\text { Scenario } 2 \\
\text { Electricity driven } \\
\text { solution }\end{array}$ & $\begin{array}{l}\text { Scenario } 3 \\
\text { Electricity driven } \\
\text { solution (outlaw) }\end{array}$ & $\begin{array}{l}\text { Scenario } 4 \\
\text { Thermal driven } \\
\text { solution (outlaw) }\end{array}$ \\
\hline & $\begin{array}{r}\text { olar thermal } \\
\text { collectors }\end{array}$ & 15 modules; $27 \mathrm{~m}^{2}$ & $\begin{array}{l}19 \text { modules; } \\
34 \mathrm{~m}^{2}\end{array}$ & Absent & $\begin{array}{l}18 \text { modules; } \\
33 \mathrm{~m}^{2}\end{array}$ & $\begin{array}{l}19 \text { modules; } \\
34 \mathrm{~m}^{2}\end{array}$ \\
\hline & $P V$ & $\begin{array}{l}89 \text { modules; } \\
142 \mathrm{~m}^{2}\end{array}$ & $\begin{array}{l}89 \text { modules; } \\
142 \mathrm{~m}^{2}\end{array}$ & $\begin{array}{l}89 \text { modules; } \\
142 \mathrm{~m}^{2}\end{array}$ & $\begin{array}{l}100 \text { modules; } \\
163 \mathrm{~m}^{2}\end{array}$ & $\begin{array}{l}6 \text { modules; } \\
9.6 \mathrm{~m}^{2}\end{array}$ \\
\hline & External wall & $\begin{array}{l}\text { two brick walls }(20 \mathrm{Cm}) \\
\text { with an EPS thermal coating } \\
(8 \mathrm{~cm}) \text { covered by plaster }\end{array}$ & \multicolumn{4}{|c|}{ autoclaved concrete bricks $(30 \mathrm{~cm})$ covered by plaster } \\
\hline & Roof & \multicolumn{5}{|c|}{ Masonry tilted roof with an XPS thermal coating of $9 \mathrm{~cm}$ covered by a steel plate mounted on wooden planks. } \\
\hline & $\begin{array}{c}\text { Floor above } \\
\text { apartments }\end{array}$ & $\begin{array}{l}\text { Masonry floor with an XPS } \\
\text { thermal coating of } 4 \mathrm{~cm} \text { and } \\
\text { an EPS layer }(4 \mathrm{~cm}) \\
\text { included in the floor heating } \\
\text { system }\end{array}$ & \multicolumn{4}{|c|}{ Masonry floor with an XPS thermal coating of $8 \mathrm{~cm}$. } \\
\hline & Windows & Traditional windows & \multicolumn{4}{|c|}{ Monoblock windows } \\
\hline \multirow{2}{*}{$\begin{array}{r}\text { Heat } \\
\text { supply }\end{array}$} & Unit & $\begin{array}{l}\text { Heat pump + Condensing } \\
\text { boiler (back up) }\end{array}$ & Condensing boiler & $\begin{array}{l}\text { Heat pump }+ \\
\text { Condensing boiler } \\
\text { (back up) }\end{array}$ & Absent & Condensing boiler \\
\hline & $\begin{array}{l}\text { Heating } \\
\text { System }\end{array}$ & Floor heating & Radiators & $\begin{array}{l}\text { Low-temperature } \\
\text { radiators }\end{array}$ & Electric radiators & Radiators \\
\hline$D H W$ & Unit & Condensing boiler & Condensing boiler & $\begin{array}{l}\text { Heat pump }+ \\
\text { Condensing boiler } \\
\text { (back up) }\end{array}$ & Condensing boiler & Condensing boiler \\
\hline
\end{tabular}

Table 5. Description of the building envelope and technical systems for the reference building and proposed low-cost scenarios in Turin

\begin{tabular}{|c|c|c|c|c|c|c|}
\hline Technology & Reference building & $\begin{array}{l}\text { Scenario 1 } \\
\text { Thermal driven }\end{array}$ & \begin{tabular}{|l|} 
Scenario 2 \\
Thermal driven
\end{tabular} & $\begin{array}{l}\text { Scenario } 3 \\
\text { Electricity }\end{array}$ & $\begin{array}{l}\text { Scenario } 4 \\
\text { Electricity }\end{array}$ & $\begin{array}{r}\text { Scenario } 5 \\
\text { Electricity }\end{array}$ \\
\hline
\end{tabular}




\begin{tabular}{|c|c|c|c|c|c|c|c|}
\hline & & & solution & solution & driven solution & driven solution & $\begin{array}{l}\text { driven solution } \\
\text { (outlaw) }\end{array}$ \\
\hline \multicolumn{2}{|c|}{$\begin{array}{r}\text { Solar thermal } \\
\text { collectors }\end{array}$} & 22 modules; $40 \mathrm{~m}^{2}$ & $\begin{array}{l}44 \text { modules; } \\
79 \mathrm{~m}^{2}\end{array}$ & $\begin{array}{l}44 \text { modules; } \\
79 \mathrm{~m}^{2}\end{array}$ & Absent & Absent & $\begin{array}{l}30 \text { modules; } \\
54 \mathrm{~m}^{2}\end{array}$ \\
\hline \multirow{2}{*}{\multicolumn{2}{|c|}{ External wall }} & $\begin{array}{l}89 \text { modules; } \\
142 \mathrm{~m}^{2}\end{array}$ & $\begin{array}{l}89 \text { modules; } \\
142 \mathrm{~m}^{2}\end{array}$ & $\begin{array}{l}89 \text { modules; } \\
142 \mathrm{~m}^{2}\end{array}$ & $\begin{array}{l}89 \text { modules; } \\
142 \mathrm{~m}^{2}\end{array}$ & $\begin{array}{l}89 \text { modules; } \\
142 \mathrm{~m}^{2}\end{array}$ & $\begin{array}{l}100 \text { modules; } \\
163 \mathrm{~m}^{2}\end{array}$ \\
\hline & & $\begin{array}{l}\text { two brick walls }(20 \mathrm{Cm}) \\
\text { with an EPS thermal } \\
\text { coating }(13 \mathrm{~cm}) \text { covered } \\
\text { by plaster }\end{array}$ & $\begin{array}{l}\text { autoclaved } \\
\text { concrete bricks } \\
(36 \mathrm{~cm}) \text { covered } \\
\text { by plaster }\end{array}$ & $\begin{array}{l}\text { Super NZEB } \\
\text { autoclaved } \\
\text { concrete bricks } \\
(45 \mathrm{~cm}) \text { covered } \\
\text { by plaster }\end{array}$ & $\begin{array}{l}\text { autoclaved } \\
\text { concrete bricks } \\
(36 \mathrm{~cm}) \text { covered } \\
\text { by plaster }\end{array}$ & $\begin{array}{l}\text { super NZEB } \\
\text { autoclaved } \\
\text { concrete }(45 \\
\mathrm{cm}) \text { covered by } \\
\text { plaster }\end{array}$ & $\begin{array}{l}\text { Super NZEB } \\
\text { autoclaved } \\
\text { concrete }(45 \\
\mathrm{cm}) \text { covered by } \\
\text { plaster }\end{array}$ \\
\hline \multirow{2}{*}{\multicolumn{2}{|c|}{$\begin{array}{r}\text { Floor above } \\
\text { apartments }\end{array}$}} & $\begin{array}{l}\text { Masonry tilted roof with } \\
\text { an XPS thermal coating } \\
\text { of } 11 \mathrm{~cm} \text { covered by a } \\
\text { steel plate mounted on } \\
\text { wooden planks. }\end{array}$ & $\begin{array}{l}\text { As reference } \\
\text { building }\end{array}$ & $\begin{array}{l}\text { super NZEB } \\
\text { Masonry tilted } \\
\text { roof with an } \\
\text { XPS thermal } \\
\text { coating of } 27 \\
\mathrm{~cm}\end{array}$ & $\begin{array}{l}\text { As reference } \\
\text { building }\end{array}$ & $\begin{array}{l}\text { super NZEB } \\
\text { Masonry tilted } \\
\text { roof with an } \\
\text { XPS thermal } \\
\text { coating of } 27 \\
\mathrm{~cm}\end{array}$ & $\begin{array}{l}\text { Super NZEB } \\
\text { Masonry tilted } \\
\text { roof with an } \\
\text { XPS thermal } \\
\text { coating of } 27 \\
\mathrm{~cm}\end{array}$ \\
\hline & & $\begin{array}{l}\text { Masonry floor with an } \\
\text { XPS thermal coating of } 7 \\
\mathrm{~cm} \text { and an EPS layer ( } 4 \\
\mathrm{~cm} \text { ) included in the floor } \\
\text { heating system }\end{array}$ & $\begin{array}{l}\text { Masonry floor } \\
\text { with an XPS } \\
\text { thermal coating } \\
\text { of } 11 \mathrm{~cm} \text {. }\end{array}$ & $\begin{array}{l}\text { Super NZEB } \\
\text { Masonry floor } \\
\text { with an XPS } \\
\text { thermal coating } \\
\text { of } 20 \mathrm{~cm} .\end{array}$ & $\begin{array}{l}\text { Masonry floor } \\
\text { with an XPS } \\
\text { thermal coating } \\
\text { of } 11 \mathrm{~cm} \text {. }\end{array}$ & $\begin{array}{l}\text { Super NZEB } \\
\text { Masonry floor } \\
\text { with an XPS } \\
\text { thermal coating } \\
\text { of } 20 \mathrm{~cm} .\end{array}$ & $\begin{array}{l}\text { Super NZEB } \\
\text { Masonry floor } \\
\text { with an XPS } \\
\text { thermal coating } \\
\text { of } 20 \mathrm{~cm} .\end{array}$ \\
\hline \multicolumn{2}{|r|}{ Windows } & Traditional windows & \multicolumn{5}{|c|}{ Monoblock windows } \\
\hline \multicolumn{2}{|c|}{ Ventilation } & MVHR & MVHR & MEV & MVHR & MEV & MVHR \\
\hline \multirow{2}{*}{$\begin{array}{l}\text { Heat } \\
\text { supply }\end{array}$} & Unit & $\begin{array}{l}\text { Heat pump }+ \text { Condensing } \\
\text { boiler (back up) }\end{array}$ & $\begin{array}{l}\text { Condensing } \\
\text { boiler }\end{array}$ & $\begin{array}{l}\text { Condensing } \\
\text { boiler }\end{array}$ & $\begin{array}{l}\text { Heat pump + } \\
\text { Condensing } \\
\text { boiler (back up) }\end{array}$ & $\begin{array}{l}\text { Heat pump + } \\
\text { Condensing } \\
\text { boiler (back } \\
\text { up) }\end{array}$ & Absent \\
\hline & $\begin{array}{l}\text { Heating } \\
\text { System }\end{array}$ & Floor heating & Radiators & Radiators & $\begin{array}{l}\text { Low- } \\
\text { temperature } \\
\text { radiators }\end{array}$ & $\begin{array}{l}\text { Low- } \\
\text { temperature } \\
\text { radiators }\end{array}$ & $\begin{array}{l}\text { Electric } \\
\text { Radiators }\end{array}$ \\
\hline$D H W$ & Unit & Condensing boiler & $\begin{array}{l}\text { Condensing } \\
\text { boiler }\end{array}$ & $\begin{array}{l}\text { Condensing } \\
\text { boiler }\end{array}$ & $\begin{array}{l}\text { Heat pump + } \\
\text { Condensing } \\
\text { boiler (back up) }\end{array}$ & $\begin{array}{l}\text { Heat pump + } \\
\text { Condensing } \\
\text { boiler (back } \\
\text { up) }\end{array}$ & $\begin{array}{l}\text { Condensing } \\
\text { boiler }\end{array}$ \\
\hline
\end{tabular}

Table 6. Maintenance costs and lifetime of the solution sets

\begin{tabular}{|c|c|c|c|}
\hline & Technology & $\begin{array}{c}\text { Life Time } \\
\text { [years] }\end{array}$ & $\begin{array}{c}\text { Maintenance } \\
\text { Costs [\%] }\end{array}$ \\
\hline \multicolumn{2}{|c|}{ Solar thermal collectors } & 20 & 0.5 \\
\hline \multicolumn{2}{|c|}{$P V$} & 50 & 0.5 \\
\hline \multicolumn{2}{|c|}{ Building envelope } & 50 & 0.5 \\
\hline \multicolumn{2}{|c|}{ Windows } & 30 & 0.5 \\
\hline \multirow{2}{*}{$M V H R$} & Unit & 15 & 4 \\
\hline & Pipes & 30 & 1 \\
\hline \multirow{2}{*}{$M E V$} & Unit & 20 & 4 \\
\hline & Pipes & 30 & 1 \\
\hline \multirow{2}{*}{ Heat pump } & Unit & 20 & 3 \\
\hline & Pipes & 30 & 1 \\
\hline \multirow{2}{*}{ Condensing boiler } & Unit & 20 & 1.5 \\
\hline & Pipes & 30 & 1 \\
\hline \multicolumn{2}{|r|}{ Floor heating } & 50 & 2 \\
\hline \multicolumn{2}{|r|}{ Radiators } & 35 & 1.5 \\
\hline \multicolumn{2}{|c|}{ Electric Radiators } & 22 & 1 \\
\hline
\end{tabular}

Table 7. National economic indicators for the LCC analysis

\begin{tabular}{lc}
\hline Discount rate & $4 \%$ \\
\hline Tax of interest income & $26 \%$ \\
\hline $\begin{array}{l}\text { Inflation of energy } \\
\text { electricity }\end{array}$ & $3.4 \%$ \\
\hline Inflation of energy gas & $2.3 \%$ \\
\hline Inflation of maintenance & $2 \%$ \\
\hline Evolution Price Product & $2 \%$ \\
\hline
\end{tabular}




\begin{tabular}{|c|c|c|c|c|c|c|c|c|c|c|c|}
\hline \multirow{3}{*}{$\begin{array}{l}\mathrm{EP}_{\text {nonrengl }} \\
{\left[\mathrm{kWh} / \mathrm{m}^{2}\right]}\end{array}$} & \multicolumn{5}{|c|}{ Rome } & \multicolumn{6}{|c|}{ Turin } \\
\hline & Base case & Scen. 1 & Scen. 2 & Scen. 3 & Scen.4 & Base case & Scen. 1 & Scen. 2 & Scen. 3 & Scen. 4 & Scen.5 \\
\hline & 11.0 & 12.3 & 5.9 & 14.7 & 12.4 & 21.2 & 17.7 & 17.4 & 19.1 & 17.9 & 21.0 \\
\hline
\end{tabular}

Table 9. Results of energy consumption and energy production in Rome and Turin for the base cases and the alternative scenarios

\begin{tabular}{ccccc}
\hline \multirow{7}{*}{ Scenarios } & $\begin{array}{l}\text { Electricity } \\
\text { consumption } \\
{[\mathrm{kWh}]}\end{array}$ & $\begin{array}{c}\text { Electricity } \\
\text { production } \\
{[\mathrm{kWh}]}\end{array}$ & $\begin{array}{c}\text { Gas } \\
\text { consumption } \\
{[\text { Smc] }}\end{array}$ \\
\hline \multirow{4}{*}{ Rome } & Base case & 1601 & 20618 & 2324 \\
\cline { 2 - 5 } & Scenario 1 & 0 & 23060 & 2913 \\
\cline { 2 - 5 } & Scenario 2 & 7149 & 10513 & 98 \\
\cline { 2 - 5 } & Scenario 3 & 8604 & 22934 & 1890 \\
\cline { 2 - 5 } & Scenario 4 & 304 & 363 & 2913 \\
\cline { 2 - 5 } & Base case & 8490 & 13277 & 3481 \\
\cline { 2 - 5 } & Scenario 1 & 78 & 13676 & 4171 \\
\cline { 2 - 5 } & Scenario 2 & 0 & 16666 & 4110 \\
\cline { 2 - 5 } & Scenario 3 & 18004 & 4086 & 1212 \\
\cline { 2 - 5 } & Scenario 4 & 16340 & 5428 & 1234 \\
\cline { 2 - 5 } & Scenario 5 & 16864 & 14068 & 1876 \\
\hline
\end{tabular}

Table 10. Results of the Net Present Values (NPV) and energy related construction costs in Rome and Turin for the base cases and the alternative scenarios

\begin{tabular}{|c|c|c|c|}
\hline & Scenarios & $\begin{array}{c}\text { Energy related } \\
\text { construction costs } \\
{\left[€ / \mathrm{m}^{2}\right]}\end{array}$ & $\begin{array}{c}\mathrm{NPV} \\
{\left[€ / \mathrm{m}^{2}\right]}\end{array}$ \\
\hline \multirow{6}{*}{ Rome } & Base case & 389 & - \\
\hline & Scenario 1 & 310 & 133 \\
\hline & Scenario 2 & 321 & 111 \\
\hline & Scenario 3 & 296 & 143 \\
\hline & Scenario 4 & 295 & 150 \\
\hline & Scenario $3 b$ & 287 & 163 \\
\hline \multirow{7}{*}{ Turin } & Base case & 447 & - \\
\hline & Scenario 1 & 384 & 121 \\
\hline & Scenario 2 & 385 & 158 \\
\hline & Scenario 3 & 382 & 77 \\
\hline & Scenario 4 & 383 & 122 \\
\hline & Scenario 5 & 391 & 105 \\
\hline & Scenario $5 b$ & 383 & 121 \\
\hline
\end{tabular}




\title{
Identification and assessment of solutions to reduce construction cost of Italian nearly zero energy building in a life cycle perspective ${ }^{1}$
}

\author{
Michele Zinzi ${ }^{\text {a* }}$, Benedetta Mattoni ${ }^{\text {ab }}$ \\ a-ENEA, Via Anguillarese 301, 00123 Rome, Italy \\ b-SAPIENZA University of Rome, Department of Astronautical, Electrical and Energy Engineering, Via Eudossiana \\ 18-00184 Rome, Italy
}

\author{
Nomenclature \\ EPBD: Energy Performance of Buildings Directive \\ NZEB: Nearly Zero Energy Building \\ EEM: $\quad$ Energy Efficiency Measures \\ MFH: Multi-Family Houses \\ ETICS: External Thermal Insulation Composite Systems \\ XPS: $\quad$ Extruded polystyrene \\ EPS: $\quad$ Expanded polystyrene \\ DHW: Domestic How Water \\ COP: Coefficient of Performance \\ PV: Photovoltaic \\ MVHR: Mechanical Ventilation with Heat Recovery \\ MEV: Mechanical Extract Ventilation \\ ACH: Air change per hour \\ NPV: $\quad$ Net Present Value \\ EP: Indicator of Primary Energy consumption \\ $\mathrm{EP}_{\text {nonren; }}$ Indicator of Primary non-renewable Energy \\ $\mathrm{EP}_{\text {nonrengl }}$ Indicator of Global Primary non-renewable Energy
}

\begin{abstract}
Concerning Nearly Zero Energy Buildings, the most important issue is to guarantee energy efficiency, thermal comfort for users and indoor environmental quality, keeping low construction and operational costs. The cost-optimality target, defined in the EPBD as "the energy performance level which leads to the lowest cost during the estimated economic lifecycle", is a key issue for public and private housing sectors, which the economic aspect is quite relevant for. In this framework, this paper explores the efficacy of combining alternative and unconventional solution sets for reducing construction costs of new nearly zero energy multifamily houses in a life cycle perspective. The real case study building, located in the centre of Italy, was standardized and adapted to the minimum NZEB requirements of the two reference climatic zones chosen for the analysis (Rome and Turin). Three type of analysis were developed: thermal comfort, energy performance and financial calculation. Results of the thermal analysis show that the installation of active cooling to prevent summer overheating can be avoided by applying low-cost passive strategies. All the proposed lowcost scenarios (4 alternative scenarios in Rome and 5 in Turin) reached the highest grade of energy performance, with a reduction of the non-renewable primary energy consumption up to $46 \%$ compared to the base case in Rome and 18\% in Turin. From the economic perspective, all the scenarios in the two climate zones allow both reductions in the construction costs, up to $26 \%$ in Rome and $15 \%$ in Turin, and savings over the 50-year life time of the building, up to $163 € / \mathrm{m}^{2}$ in Rome and $158 € / \mathrm{m}^{2}$ in Turin.
\end{abstract}

\footnotetext{
${ }^{1}$ The short version of the paper was presented at ICAE2018, Aug 22-25, Honk Kong, China. This paper is a substantial extension of the short version of the conference paper.
} 
Keywords: nearly zero energy buildings, building energy technologies, construction cost, life cycle cost

\section{Introduction}

After the target of Horizon 2020 set in 2007 [1], regarding the reduction of buildings primary energy and emissions and the increase of renewable energy production, in the 2030 Climate \& Energy framework new goals have been introduced [2]. According to this package, the aims are to reduce the greenhouse gas emissions by $40 \%$ from 1990 levels, to increase the production from renewable energy up to $27 \%$ and improve energy efficiency of buildings up to $27 \%$. In a long-term perspective, in 2050 gas emissions are expected to be reduced by at least $80 \%$ compared to 1990 levels [3]. In this framework, building sector plays a relevant role, accounting for the largest part of energy consumption and gas emissions at local and global level and representing, on the other side, a huge potential for energy savings [1][4].

European Standard defined the requirements for achieving high savings in buildings: according to the EPBD Directive, new public buildings from 01/01/2019 and new private constructions from 01/01/2021, have to comply with Nearly zero energy buildings (NZEB) targets [5]. The definition on NZEBs provided in the Directive is quite general and is not technical: the characterization of NZEBs is delegated to each European Member State which has to define what an NZEB represents at national level and to set the specific targets for buildings to be in compliance with European description. What is common to all the Member states is that NZEBs do have to certify a "very high energy performance", covering "a very significant extent" of building energy needs with renewable energy sources, partially produced on site or nearby the building [5]. Being the common guidelines provided by the European Standards so general, there are still ambiguities in the implementation phase of NZEBs in European member states due to the different interpretations of the definition. Furthermore, misalignments among countries are emphasized due to the climatic, social, technological and economic differences [6]. According to this, it is difficult to propose a minimum common threshold for energy efficiency for all the Member States. Different climatic conditions between Southern and Northern European countries lead to the highest differences in the definition of NZEB parameters: the former can easily meet low energy needs thresholds for heating compared to the latter [7]; but on the other side, they cannot comply with the same limits for cooling demand due to high outdoor ambient temperature, high solar radiation and heat island effect in cities. Several studies have been developed in literature about potential overheating in southern and north-western countries due to the increase of thermal insulation, which can lead to an increase in consumption for air-conditioning [8] [9] [10] but it was also stated that passive strategies for reducing cooling needs can be successfully applied to overcome this problem. As an example, in [11] an analysis on three different NZEB building types (single-family house, apartment block and office building) in two different Italian climatic locations (Milan and Palermo) was developed to assess the imbalance of energy needs for heating and cooling when U-values of the building envelope are gradually reduced. It was found that, by reducing transmittance values, cooling need increases up to 5-6\% in all the analysed cases but it can be effectively reduced by using high performing shading devices.

Basing on these assumptions, NZEB should provide specific heating-cooling balance for each climatic condition, taking also into account the thermal comfort and the indoor environmental quality [12][13][14]. Another important issue concerning NZEB development is related to construction costs: in particular how to ensure the fulfilment of NZEBs requirements and contemporary guaranteeing comfort, covering the involved investments and enhancing the reduction in costs [15][16]. Although many studies and demonstration actions have demonstrated that it is possible to achieve NZEB targets, the design choices are not always proven to be cost effective both from an environmental and economic perspective [15].

This economic issue was raised up in the EPBD [5]: in the Delegated Regulation No 244/2012 [17], which supplemented the EPBD regulation, a methodology framework to calculate cost-optimal levels for buildings is provided. The cost optimality is defined as "the energy performance level which leads to the lowest cost 
during the estimated economic lifecycle". In the methodology energy efficiency measures are applied to Many studies in literature applied the cost-optimal methodology proposed in the EPBD standard to derive cost-optimal energy efficiency measures for NZEB buildings [21][22] and clusters of NZEB buildings [23][24], highlighting the need of taking into consideration the whole building life cycle. In [15] a simulation-based framework was applied to a residential building prototype in order to assess how to best achieve the NZEB design at the lowest cost in 14 locations across Europe. Results demonstrated that optimal solutions do strongly depend on climate condition, but a common aspect to all locations is the need of integrating renewables and energy efficiency measures to reach cost-effective NZEBs. Authors in [25] applied a model for supporting designers in the design phase of a residential building, developing a cost optimal analysis of different scenarios to evaluate the best solution in terms of balance between life cycle costs and energy performance. In [26] the cost-optimality and replicability on building market of different HVAC system configurations were evaluated for a residential building, taking into account the costs incurred during the whole building life-cycle.

What emerges from literature studies is that cost-optimal levels and packages of energy efficient measures strongly depend on national conditions. These differences are due to many variables such as: climatic conditions, energy, material and labour prices, available technologies and building types [27][28][29][30][31]. Among the different building types, high importance is given to the development of residential NZEB buildings, which account for about the $75 \%$ of the total European Building stock [32]. In fact, in the residential sector the issue of cost reduction of new NZEBs is crucial, in particular for social housing multi-family houses, where the economic aspect is quite relevant, due to limited financial resources.

An extensive review was developed by the authors in [33], focused on the application of cost-optimal analysis in European literature studies, pointing out the differences among them based on several categories: methods and tools for optimization, energy efficiency measures, building type. It was found that with regard to the building typology, $68 \%$ of the reviewed reference buildings in the studies were residential and multifamily buildings represented the $34 \%$ of this share. It shows the importance of identifying the right balance between costs and energy performance in the residential sector. In [33] it was also found that the most common energy efficiency measure for the envelope is to increase/decrease the thickness of insulation but this solution is not a driver for cost-optimal building design: efficiency measures on the building envelope have much lower impact on cost optimality compared to measures related to the energy systems. This aspect makes an issue arise: the solutions proposed as energy efficiency measures (EEM) in the costoptimal framework are common and standard and the investigation of constructive alternative solutions is rarely pursued. The cost trade-off could be reached by simplifying the envelope design and the construction technologies [34], taking advantage of issues like modularity, prefabrication and on-site assembly [30] but application of these strategies in the cost-optimality studies has not been yet explored.

Regarding national application of NZEBs in Italy, law fixes several requirements for new buildings, that can be reached through different strategies, technologies and operational means [35]. Starting from 01/01/2018, in accordance to [36], energy performance of minimum requirements buildings and NZEB buildings will vary only in terms of small differences in transmittance values. This implies that, from this date, very small cost differences can be expected to arise between a conventional and a nearly zero-energy building; also, reducing the costs of new nearly zero-energy multi-family houses means reducing the costs for such houses in general. Currently, according to the national document developed in 2016, [37] the extra cost in Italy for the construction of multifamily residential buildings compared to the conventional building strongly depends on the climatic region and was assessed to be about $60 € / \mathrm{m}^{2}$ on average. There is therefore ample room for improvement, reducing this extra-cost gap. Starting from these assumptions, the target of this paper is to preliminary explores the possibility of reducing construction and life cycle costs keeping high energy target in new Italian multifamily buildings, within the activities of the CoNZEBs (Solution sets for the cost 
reduction of new Nearly Zero-Energy Buildings) Project [38]. The Project is funded by the European Union sets, leading to significant cost reductions of new Nearly Zero-Energy Multi-Family Houses (MFH).

\section{Objective and method}

This study aims at identifying solution sets for new nearly zero energy multi-family houses at reduced costs respect to mainstream options and assessed in a life cycle cost perspective. The cost issue in single family houses is less relevant, due to higher economic availability of potential clients for this building segment. The situation is different for multi-family houses, which is the most recurrent typology in social housing, and other public and private housing sectors, which the economic issue is more relevant for. In this framework, the objective of the study is relevant for the construction sector in Italy and the implemented methodology could be usefully applied in other countries, with the duly boundary conditions.

This work also introduces an innovative approach. The typical methodology in these studies is that implemented in EU member states for the cost optimal energy performance of buildings, as required by [5]: first typical and recurrent building technologies are defined, then the cost effectiveness is tested for improved efficiency levels of the selected technologies [39]. This method, however, does not allow to include alternative and unconventional solutions, and their combination, in the assessment.

To overcome these limits, the methodology here developed consists of the following steps:

I. Identification of a real building, whose typology can be considered sufficiently representative of current multifamily houses in Italy. The choice of real buildings is necessary to have all the technical and economic data, needed for next analyses; as well as to have economic costs based on real market instead of on average values.

II. Adjustments of the real building to selected climatic conditions and to specific NZEB requirements. This step allows to have standardised typical buildings, upon which it is possible to develop cost effective variants.

III.Identification of low costs solution sets for the different building envelope and energy system technologies. The solutions are developed taking into account all the energy services covered by NZEB requirements for residential buildings, fixed by national regulation.

IV. Energy and economic assessment of the building variants, in terms of construction and life cycle costs. Comparison of final and primary energy performances, as well as initial construction investment and Net present value at the end of the building life service are carried out.

The limit of the research relays on: the boundary conditions set in the analysis, the reference buildings and the identified low-cost solutions; on the other side, the relevance of the approach relays on the general validity of the methodology, which can be applied according to different boundary conditions, in Italy and elsewhere. This is an important value for designers, planners, contractors and construction companies, able to optimise costs for any construction project.

\section{The case study building}

NZEB requirements, defined in the relevant Italian standard [35][36], are not based on energy performances but on the compliance of the following prescriptions:

- Maximum thermal transmittance, including thermal bridges, of the envelope components;

- Minimum efficiency of the energy systems (space heating and cooling, ventilation, domestic hot water);

- $50 \%$ of energy uses provided by renewable sources.

The San Giusto building, located in the outskirts of Prato, Tuscany, was selected after a nearly zero energy multi-family houses screening carried out in Italy in the framework of the EU CoNZEBs project [38]. The 
building can be considered representative of a consistent portion of the building stock. The building was commissioned by Edilizia Pubblica Pratese, a local social housing company. It is a L-shaped four-storey building with 29 apartments served by four staircases. Private cellars, a public civic centre and the utility rooms are located at the ground floor. The building is also equipped with public parking and green areas which show the multifunctional character of this project. The design plan and a picture of the building are shown in Figures 1 and 2.

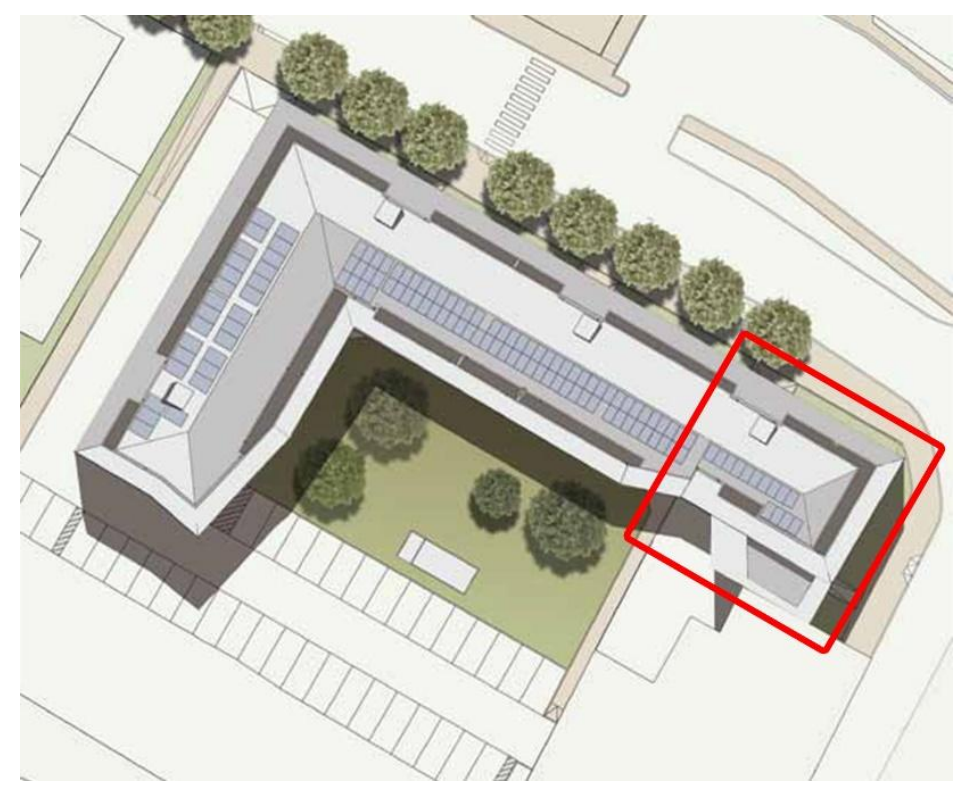

Fig. 1. Design plan of the building

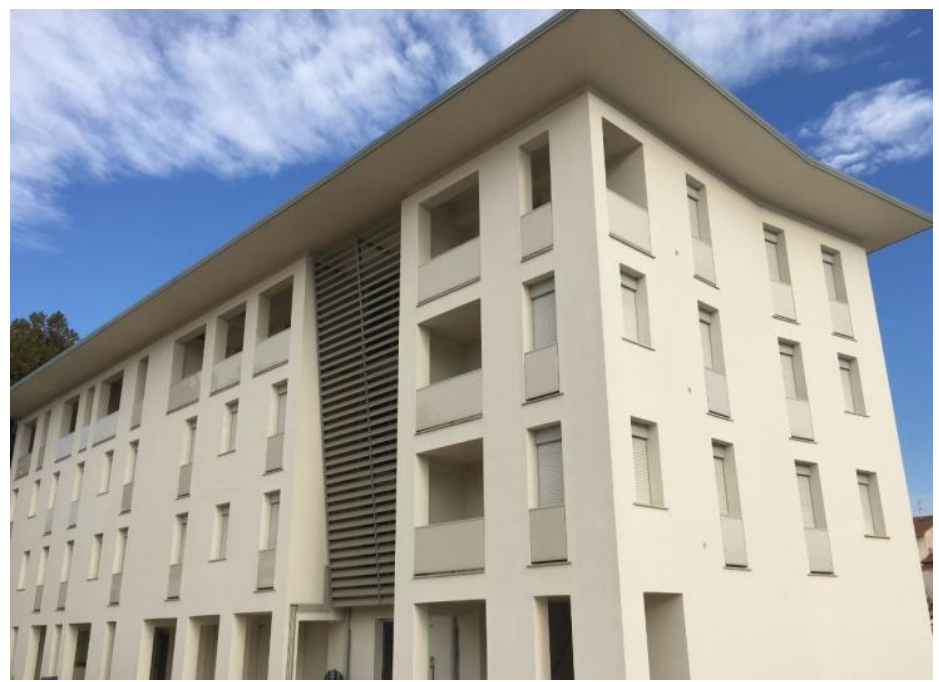

Fig. 2. Case study building

The total area of the apartments is $2207 \mathrm{~m}^{2}$ and the volume is $5960 \mathrm{~m}^{3}$, the apartments ranges between 45 and $95 \mathrm{~m}^{2}$, with an average net area of $76 \mathrm{~m}^{2}$. The presence of apartments with different sizes shows the purpose of meeting needs of different low-income users, from couples to large families.

The main target of the project was to realize a new high-performance building with low environmental impacts, and cost effective in the construction, operation and maintenance phases. The design kept this approach with the adoption of simple and low environment impact solutions, as the use of recycled insulation materials from local textile companies. Bioclimatic approaches were adopted to maximise solar protection and natural ventilation in summer. 
Concerning the building structure, external walls consist of ETICS (External Thermal Insulation Composite Systems), with $8 \mathrm{~cm}$ EPS (Expanded polystyrene) thermal insulation, a double brick layer with insulation in between ( $8 \mathrm{~cm}$ of recycled insulation in textile fibre), and internal finishing. The base floor is a masonry slab with an XPS (Extruded polystyrene) insulation layer of $8 \mathrm{~cm}$, a thermal coating in EPS of $4 \mathrm{~cm}$ and an additional insulating layer of EPS $(4 \mathrm{~cm})$ included in the floor heating system; covering is ceramic tiles. The rooftop is a masonry tilted roof with an XPS thermal coating of $12 \mathrm{~cm}$ covered by steel plate mounted on wooden planks. Transmittances of the envelope are $0.20 \mathrm{~W} / \mathrm{m}^{2} \mathrm{~K}$ for roof and $0.17 \mathrm{~W} / \mathrm{m}^{2} \mathrm{~K}$ for walls and base floor. The continuous external insulation eliminates thermal bridge. Argon-filled double-glazed windows with aluminium frame are installed with thermal transmittance of $1.4 \mathrm{~W} / \mathrm{m}^{2} \mathrm{~K}$ and solar transmittance of 0.67.

The Domestic Hot Water (DHW) system is fed by $43 \mathrm{~m}^{2}$ of vacuum solar thermal collectors mounted on the south-east and south-west oriented pitches and coupled with two tanks of 2000 litres. A 94Kw condensing boiler is used as back of solar collectors. The heating supply is centralized, and the main heat generator is the $171 \mathrm{Kw}$ air water heat pump. When outdoor temperatures decrease below the working conditions of the heat pump, the condensing boiler and the solar thermal collectors work as back-up system, supporting the heat pump for keeping high the seasonal coefficient of performance. The Coefficient of Performance (COP) in standard conditions is 3.28. The outlet temperature of the heat pump, which supplies a room-controlled floor heating system, is $40-45^{\circ}$ and its cut-off temperatures are $3^{\circ}-45^{\circ}$. The system is equipped with an inertial tank of 2000 litres to cope with thermal demand peaks, in which the heated water is sent from the heat pump and, if necessary, from the condensing boiler; within the tank, when demand of domestic hot water is lower than production, high temperature fluid from solar collectors flows in a coil to additionally support heating supply. Part of the electricity needed by the heat pump is produced by a $22 \mathrm{kWp} \mathrm{PV} \mathrm{system}\left(163 \mathrm{~m}^{2}\right)$. Both the solar thermal collectors and photovoltaic system are mounted on the tilted roof, on the south-east and south-west oriented pitches.

According to the most common construction rules in Italian buildings, especially for social housing, active cooling and mechanical ventilation systems are not installed in the case study building.

\subsection{Climatic condition}

Italy has a wide variety of climatic conditions; the national building energy codes identifies six classes, based on the heating degree days, calculated in base $20^{\circ} \mathrm{C}$. The classes range from $\mathrm{A}$ (below 600 degree days) to $\mathrm{F}$ (above 3000 degree days). No zoning exists for the cooling season. In order to simplify the analysis, two macro-classes were identified and represented by two large cities in this study:

- Turin, 2617 degree days, representative of climatic zone $\mathrm{E}$ (northern and mountain zones) and F (alpine zone)

- Rome, 1440 degree days, representative of zones from A to D, with milder climatic conditions, typical of central and southern zones.

They were selected being large cities, whose degree days are very close to average degree days of the related climatic zones weighted with the population.

\subsection{Building's adjustments to reference climate conditions}

The characteristics of the real building are adjusted to the minimum NZEB requirements in the reference climatic zones in this section. Changes in building envelope, energy systems and renewable sources are following described. To be noted no changes were made on windows, since different requirements have close to negligible impact on costs. 


\subsubsection{Rome climatic zone}

Envelope components insulation was brought to the standard requirements, as indicated in table 1, hence the structures were modified as follows: the external wall is covered with an $8 \mathrm{~cm}$ EPS thermal coating; the first floor between apartments and ground floor has an XPS thermal coating of $4 \mathrm{~cm}$ and an additional insulating layer of EPS $(4 \mathrm{~cm})$ included in the floor heating system; the rooftop has an XPS thermal coating of $9 \mathrm{~cm}$.

Table 1. Transmittance values of the building envelope of the reference buildings

\begin{tabular}{cccc}
\hline City & U-roof $\left[\mathrm{W} / \mathrm{m}^{2} \mathrm{~K}\right]$ & $\mathrm{U}$-wall $\left[\mathrm{W} / \mathrm{m}^{2} \mathrm{~K}\right]$ & $\mathrm{U}$-first floor $\left[\mathrm{W} / \mathrm{m}^{2} \mathrm{~K}\right]$ \\
\hline Rome & 0.26 & 0.28 & 0.28 \\
\hline Turin & 0.21 & 0.25 & 0.24 \\
\hline
\end{tabular}

The number of solar thermal collectors and PV panels was reduced up to exactly meet the requirements of the Standard [35]: to guarantee the 50\% of DHW production from renewable sources and contemporarily to cover the $50 \%$ of total energy demand (heating, cooling and DHW) with renewable sources. According to this, solar collectors were reduced from $43 \mathrm{~m}^{2}$ to $27 \mathrm{~m}^{2}$ and the PV panels from 163 to $142 \mathrm{~m}^{2}$. This number of PV panels is also the minimum amount to meet the standard of Appendix 3 [36] which requires an installed peak power of $22 \mathrm{Kw}$ for this building. Results of the energy calculation will be shown in paragraph 6.2 to be compared with energy results of the low-cost scenarios.

\subsubsection{Turin climatic zone}

The insulation thickness of the envelope components was brought to the NZEB requirements, as shown in Table 1. The structures were modified as follows: the external wall is a double brick walls with an EPS thermal coating of $13 \mathrm{~cm}$; the first floor between apartments and ground floor has an XPS thermal coating of $7 \mathrm{~cm}$ and an additional insulating layer of EPS $(4 \mathrm{~cm})$ included in the floor heating system; the roof top is insulated with $11 \mathrm{~cm}$ of XPS.

As for the previous case, solar thermal collectors were reduced from 43 to $40 \mathrm{~m}^{2}$ and the PV panels from 163 to $142 \mathrm{~m}^{2}$. The Mechanical Ventilation with Heat recovery (MVHR) system was here included in the reference case, this is still a cutting-edge solution in Italy dwellings but recently often used in very high energy performing buildings in colder climates. It was therefore decided to model the MHVR system in each apartment.

\subsubsection{Adjusted construction costs}

The adjusted construction costs for the two reference buildings are shown in Table 2 and 3 . The costs have been taken from the bill of quantities of the real building. Cost modifications due to variation in the insulation thickness for the two reference buildings have been estimated as unitary variation $\left(€ / \mathrm{m}^{3}\right)$ of the original prices. Cost of the MVHR system used in Turin was not included in the bill of materials of the real building, but was provided by a technical company, which was asked to simulate a real offer to supply a MHVR system for the reference building [40]. For the building located in Rome, overall construction cost is $€$ 3'388' 584 which corresponds to $1 ' 594 € / \mathrm{m}^{2}$. Table 2 shows the costs divided by categories and their percentage on the overall cost. It can be noticed that the heaviest category is Architectural components which accounts for the $46 \%$ of the overall construction costs. Overall construction costs of the building located in Turin is $€ 3^{\prime}, 511^{\prime} 820$ which corresponds to $1^{\prime} 652 € / \mathrm{m}^{2}$. The incidences of each category on the overall cost are similar to ones in Rome. Differences in costs between the two buildings are mainly due to the installation of the MVHR in Turin which causes an increase in the energy systems cost of $40 € / \mathrm{m}^{2}$. More moderate differences (in the order of 5 to $15 € / \mathrm{m}^{2}$ ) are observed for the Architectural components and Renewable plants.

The cost optimal analysis of the proposed scenarios will be based only on the reduction of the "energy related costs": those costs have a direct impact on the building energy performance. In both Table 2 and 3 disaggregated energy related costs for each construction category are highlighted in grey. It can be noted 
that: the structural costs are fixed; up to the $38 \%$ of both architectural and energy systems costs is adjustable; the entire cost of renewable energy systems can be modified. In Rome the $24 \%$ of the total construction costs can be decreased by implementing more energy efficient solutions, which corresponds to $389 € / \mathrm{m}^{2}$; in Turin it is the $27 \%$ which corresponds to $447 € / \mathrm{m}^{2}$.

Table 2. Total and energy related construction costs of reference building in Rome

\begin{tabular}{cccccc}
\hline & Structure & Construction components & $\begin{array}{c}\text { Technical } \\
\text { Systems }\end{array}$ & Renewable sources & Total \\
\hline Costs $[€]$ & $996^{\prime} 624$ & $1^{\prime}, 554^{\prime} 631$ & $782^{\prime} 027$ & $55^{\prime} 302$ & $3^{\prime} 388^{\prime} 584$ \\
\hline Incidence on overall costs [\%] & 29 & 46 & 23 & 2 & 100 \\
\hline Unitary costs $\left[€ / \mathrm{m}^{2}\right]$ & 469 & 731 & 368 & 26 & 1594 \\
\hline Energy related $[€]$ & 0 & $522^{\prime} 783$ & $248^{\prime} 194$ & $55^{\prime} 302$ & $826^{\prime} 279$ \\
\hline $\begin{array}{c}\text { Incidence on category cost } \\
{[\%]}\end{array}$ & 0 & 34 & 32 & 100 & 1 \\
\hline $\begin{array}{c}\text { Unitary energy related costs } \\
{\left[€ / \mathrm{m}^{2}\right]}\end{array}$ & 0 & 246 & 117 & 26 & 389
\end{tabular}

\section{Identification of low-cost solutions}

This section describes the solutions identified to reduce the construction costs of the two reference buildings. Each subsection describes the selected technologies and strategy, highlighting their peculiarities respect to common trends.

\subsection{Building envelope}

Two main variations were identified. The common technique for external wall construction of NZEB in Italy consists of brickworks and ETICS; instead of following the usual approach of variation of insulation levels to reach the most performing solutions, in this paper the approach was to detect alternative construction technologies. In particular, large autoclaved concrete blocks were selected. They are based on natural elements and reach very high insulation and lightweight properties, thanks to a specific production process which creates micro air bubbling inside the material. These blocks come in different size, so that different transmittance values can be obtained within a single construction layer. Thanks to the ad-hoc designed profiles, the blocks can be easily handled and assembled. Compared to the other solutions, this technology reduces complexity, construction time and costs.

The second proposed solution is the mono-block window. Generally, in Italy residential building are equipped with traditional windows which are composed as follows: subframe, placed in the hole of the façade, the shutter box mounted above the window and the windows itself. The most time-consuming phase for windows is the preparation phase, since masonry workers have to create the hole, provide insulation for thermal bridges, wait for wet materials to dry. After that, masonry workers install the subframe and 
specialised workers mount the shutter box and finally the window itself. The mono-block windows are directly placed in the facade hole and then fixed, with consequent savings in time, and material and labour costs for the subframe works.

In both cases the performance indicator (thermal transmittance) keeps the value of the base case, but its cost change. In some Turin scenarios, the so-called super NZEB envelope was tested, where lower transmittances for walls, roof and ground floor were considered. Hence for these super NZEB scenarios the $U$ values [W/ $\left./ \mathrm{m}^{2} \mathrm{~K}\right]$ were adjusted as follows: 0.105 (roof), 0.15 (wall), 0.12 (ground floor). This configuration was tested in combination with alternative energy systems, targeted to an overall cost reduction.

\subsection{Energy systems and renewable energy}

In Italy space heating in NZEB buildings is generally provided by heat pumps coupled with floor heating while DHW is normally supplied by condensing boilers supported by solar thermal collectors.

The implementation of both systems is expansive, therefore one of the proposed strategies is a thermal driven scenario where the condensing boiler is used for both heating and DHW services. The floor heating distribution system is then replaced by aluminium radiators. The use of condensing boilers and radiators allows to save money and reduce construction and maintenance costs: the architectural works for the construction of the floor heating system, the backbone lines of the floor heating system and the storage tank of the heat pump are eliminated. In addition, also maintenance costs of the condensing boilers and radiators is lower, allowing to save money in a life cycle cost (LCC) perspective. On the other side, the amount of renewable sources has to be increased to respect the percentage of renewable energy production required by the Standard.

A second strategy is, conversely, an electricity-driven solution which minimize the use of gas: the air water heat pump is used both for heating and DHW production. According to this, the condensing boiler is used as a backup system for both services. Floor heating is replaced by low temperature aluminium radiators which are more expensive than conventional aluminium radiators but lower expensive than floor heating. In this case the minimum level of energy production from renewable sources are achieved only by means of the PV panels which feed the heat pump, so the expense for solar thermal collectors is avoided.

The third strategy is at the forefront, but it is forbidden in Italy according to the current Standard. It consists in providing space heating with electric radiators in rooms: it allows to eliminate technical system for heating production and most of electricity is provided by the PV panels. This approach does not comply with Italian regulation, since energy from PV panels cannot be counted for the contribute of renewable sources if they directly feed electric systems for heating, DHW or ventilation services. The condensing boiler is only used for DHW production. For respecting the standard requirements, the amount of solar thermal collectors and PV panels is considerably increased: the highest technical expenses in this scenario are basically due the installation of renewable sources. Nevertheless, investment costs of technical systems for heating supply and distribution are avoided.

Another very simple solution to reduce construction costs was to decrease the number of PV panels to the minimum amount needed for self-consumption. This strategy does not comply with national standards, since the minimum peak power of photovoltaic is calculated as a function of the surface area of the building at ground level.

Common to all the strategies is to replace the floor heating with a cheaper solution; due to this, the insulation provided by the floor heating system was always replaced with an additional layer of thermal insulation of EPS $(4 \mathrm{~cm})$ on the floors to respect the transmittance values required by the Standard.

For the colder climate in Turin, in addition to the others, two proposals were tested. Firstly, the combined use of solar thermal collectors for both Heating and DHW in the thermal driven scenarios: solar thermal 
collectors provide pre-heated water for condensing boiler, allowing to reduce the amount of gas needed. It is a cheaper solution, but, on the other side, the benefits of the heat recovery on heating consumption are no more guaranteed.

\subsection{Passive cooling solutions}

Modern buildings may suffer of overheating respect to older ones, since well insulated envelopes obstacle the thermal discharge of the building at night; in fact, active cooling systems are often installed in NZEB in Italy, as documented in the relevant chapter in [41]. This trend also depends on the calculation method used to assess the energy performance of buildings, based on steady-state method, which overestimates the cooling demand and does not allow to assess the potentialities of passive cooling techniques to provide thermal comfort conditions. The objective is a better understanding of the thermal response of NZEBs in the cooling and season and to assess whether proper passive solutions might avoid the installation of active cooling, thus keeping lower costs for design and installation of such systems.

The mitigation of the indoor environment is pursued through two main strategies:

a) Solar protection. The application of external solar shading devices on all the windows with orientation from north-east to north-west passing through south.

b) Night ventilation cooling. The increase of natural ventilation during the night hours, when the ambient temperature drops below the internal ones, creates favourable conditions to lower indoor air and structure temperatures. This objective can be pursued through windows opening, especially with different orientation.

Solutions other than the selected ones exist, however they have higher economic impacts, e.g. phase change materials on envelope elements and installation of heat sinks, thus were not taken into account. On the contrary, solar protection and natural ventilation are typical solution in Mediterranean dwellings, that only recently are replaced by mechanical cooling systems. The assessment of the impact of such solutions was carried out through a numerical analysis, described in section 5.

\section{Calculation}

\subsection{Thermal calculation}

The analysis was carried out according the relevant standard [42] in which the thermal comfort, and consequently the overheating risk, is assessed in buildings without active cooling systems. The concept relays on the principle of the adaptive comfort, in which the subject has not fixed comfort expectations but adapt himself to different conditions depending on internal microclimatic conditions, external weather conditions, clothing and possibility to building features to improve personal comfort.

The standard identifies two categories, which are relevant in residential buildings:

I. High level of expectation and is recommended for spaces occupied by very sensitive and fragile persons with special requirements like handicapped, sick, very young children and elderly persons

II. Normal level of expectation and should be used for new buildings and renovations

The focus is on the second category, which is relevant according to the building typology investigated in this paper; the analysis is however carried out on the first category for completeness, as well.

The relevant metric is the time evolution of the operative temperature, defined as the arithmetic average of air and mean radiant temperatures in a built environment, according to standard. The compliance with the 
standard requires that the number of hours in which the operative temperature exceeds the upper and lower band for the operative temperature is governed by the following equation for respectively category I and II:

$$
\begin{aligned}
& 0.33 \times t_{r m}+18.8-2 \leq t_{o p} \leq 0.33 \times t_{r m}+18.8+2 \\
& 0.33 \times t_{r m}+18.8-3 \leq t_{o p} \leq 0.33 \times t_{r m}+18.8+3
\end{aligned}
$$

Being:

$t_{o p}\left({ }^{\circ} \mathrm{C}\right)$ - hourly operative temperature

$t_{r m}\left({ }^{\circ} \mathrm{C}\right)$ - mean running outdoor air temperature, calculated according to [42].

To reduce the calculation time, the operative temperature was calculated only in the apartments in the portion of the building delimited by red square in figure 1. This portion includes 8 apartments: A1-A3 on the first floor, A4-A6 on the second floor, A7 and A8 on the third floor.

The numerical analysis was carried out with TRNSYS, a well-known and calibrated software, able to model the thermal behaviour of the building in transient state [43]. TRSNYS works with assembled calculation components, named types, each of them with a specific calculation tasks in the framework of the overall thermal and energy performance analysis. The project implemented in this analysis consists of the following components:

- weather data reader, for this project the climatic data of Rome were used, being more severe, and so more conservative, than Turin during the summer season;

- the solar generator which allows to build the solar irradiation dataset;

- additional components used for specific calculation tasks (such as the calculation of the effective sky temperature and of the heat transfer through the ground);

- the building block, which is filled in with all the data building inputs;

- the output results of the calculation, in this case outdoor temperatures in all flats and the outdoor air temperature.

The time resolution for the analysis is one hour, according to the requirements in the relevant standard. The building is in free floating conditions, meaning that no active cooling systems are installed. Simulations were run first increasing the solar shading (from 0 to 0.8 ), next increasing the base $0.3 \mathrm{ACH}$ with additional night ventilation (from 0 to $1.5 \mathrm{ACH}$ ). The calculation was carried out for the base case NZEB configuration and for the configuration with increased insulation levels for the building envelope (super NZEB).

\subsection{Energy calculation}

Energy calculation were performed using EDILCLIMA, version EC700 [44]. The software is based on the national technical specification UNI/TS 1300 series [45], and on the CEN relevant standards with adaptation to the Italian context. A quasi-steady-state method is used for calculation of heating and cooling needs, with monthly heat balance and utilization factors in compliance with relevant national and EU standards. Input data (i.e. climatic condition, user behaviour) can be adapted to assess energy performance in accordance with standard or with real operating conditions. The tool allows to model any type of technical system and building components, both in graphical form and in tabular form. Envelope can be modelled using materials from the library or using the default building envelopes. The software allows calculating thermal transmittance of opaque structures according to the UNI EN ISO 6946 [46]. In this analysis the annual 
energy is computed for the following energy services: space heating, ventilation, domestic hot water production.

In all simulations the internal gains are set to $5 \mathrm{~W} / \mathrm{m}^{2}$ for sensible heat and $2.5 \mathrm{~W} / \mathrm{m}^{2}$ for latent heat, according to Italian standards [45]. In the building according the national building code, an air change rate of $0.3 \mathrm{~h}-1$ is considered. Artificial lighting in residential buildings is not taken into account in the energy performance scheme and certification in Italy.

In Table 4 and 5 the characteristics of the reference buildings and scenarios for the Rome and Turin are shown.

Table 4. Characteristics of the reference buildings and scenarios for Rome

\begin{tabular}{|c|c|c|c|c|c|c|}
\hline & Technology & Reference building & $\begin{array}{l}\text { Scenario } 1 \\
\text { Thermal driven } \\
\text { solution }\end{array}$ & $\begin{array}{l}\text { Scenario } 2 \\
\text { Electricity driven } \\
\text { solution }\end{array}$ & $\begin{array}{l}\text { Scenario } 3 \\
\text { Electricity driven } \\
\text { solution (outlaw) } \\
\end{array}$ & $\begin{array}{l}\text { Scenario } 4 \\
\text { Thermal driven } \\
\text { solution (outlaw) }\end{array}$ \\
\hline & $\begin{array}{r}\text { Solar thermal } \\
\text { collectors }\end{array}$ & 15 modules; $27 \mathrm{~m}^{2}$ & $\begin{array}{l}19 \text { modules; } \\
34 \mathrm{~m}^{2}\end{array}$ & Absent & $\begin{array}{l}18 \text { modules; } \\
33 \mathrm{~m}^{2}\end{array}$ & $\begin{array}{l}19 \text { modules; } \\
34 \mathrm{~m}^{2}\end{array}$ \\
\hline & $P V$ & $\begin{array}{l}89 \text { modules; } \\
142 \mathrm{~m}^{2}\end{array}$ & $\begin{array}{l}89 \text { modules; } \\
142 \mathrm{~m}^{2}\end{array}$ & $\begin{array}{l}89 \text { modules; } \\
142 \mathrm{~m}^{2}\end{array}$ & $\begin{array}{l}100 \text { modules; } \\
163 \mathrm{~m}^{2}\end{array}$ & $\begin{array}{l}6 \text { modules; } \\
9.6 \mathrm{~m}^{2}\end{array}$ \\
\hline & External wall & $\begin{array}{l}\text { two brick walls }(20 \mathrm{Cm}) \\
\text { with an EPS thermal coating } \\
(8 \mathrm{~cm}) \text { covered by plaster }\end{array}$ & \multicolumn{4}{|c|}{ autoclaved concrete bricks $(30 \mathrm{~cm})$ covered by plaster } \\
\hline & Roof & \multicolumn{5}{|c|}{ Masonry tilted roof with an XPS thermal coating of $9 \mathrm{~cm}$ covered by a steel plate mounted on wooden planks. } \\
\hline & $\begin{array}{r}\text { Floor above } \\
\text { apartments }\end{array}$ & $\begin{array}{l}\text { Masonry floor with an XPS } \\
\text { thermal coating of } 4 \mathrm{~cm} \text { and } \\
\text { an EPS layer }(4 \mathrm{~cm}) \\
\text { included in the floor heating } \\
\text { system }\end{array}$ & \multicolumn{4}{|c|}{ Masonry floor with an XPS thermal coating of $8 \mathrm{~cm}$. } \\
\hline & Windows & Traditional windows & \multicolumn{4}{|c|}{ Monoblock windows } \\
\hline \multirow{2}{*}{$\begin{array}{r}\text { Heat } \\
\text { supply }\end{array}$} & Unit & $\begin{array}{l}\text { Heat pump + Condensing } \\
\text { boiler (back up) }\end{array}$ & Condensing boiler & $\begin{array}{l}\text { Heat pump }+ \\
\text { Condensing boiler } \\
\text { (back up) }\end{array}$ & Absent & Condensing boiler \\
\hline & $\begin{array}{l}\text { Heating } \\
\text { System }\end{array}$ & Floor heating & Radiators & $\begin{array}{l}\text { Low-temperature } \\
\text { radiators }\end{array}$ & Electric radiators & Radiators \\
\hline$D H W$ & Unit & Condensing boiler & Condensing boiler & $\begin{array}{l}\text { Heat pump }+ \\
\text { Condensing boiler } \\
\text { (back up) }\end{array}$ & Condensing boiler & Condensing boiler \\
\hline
\end{tabular}

Table 5. Characteristics of the reference buildings and scenarios for Turin

\begin{tabular}{|c|c|c|c|c|c|c|c|}
\hline \multicolumn{2}{|c|}{ Technology } & Reference building & $\begin{array}{l}\text { Scenario } 1 \\
\text { Thermal driven } \\
\text { solution }\end{array}$ & $\begin{array}{l}\text { Scenario } 2 \\
\text { Thermal driven } \\
\text { solution }\end{array}$ & $\begin{array}{l}\text { Scenario } 3 \\
\text { Electricity } \\
\text { driven solution }\end{array}$ & $\begin{array}{l}\text { Scenario } 4 \\
\text { Electricity } \\
\text { driven solution }\end{array}$ & $\begin{array}{l}\text { Scenario 5 } \\
\text { Electricity } \\
\text { driven solution } \\
\text { (outlaw) } \\
\end{array}$ \\
\hline \multicolumn{2}{|c|}{$\begin{array}{r}\text { Solar thermal } \\
\text { collectors }\end{array}$} & 22 modules; $40 \mathrm{~m}^{2}$ & $\begin{array}{l}44 \text { modules; } \\
79 \mathrm{~m}^{2}\end{array}$ & $\begin{array}{l}44 \text { modules; } \\
79 \mathrm{~m}^{2}\end{array}$ & Absent & Absent & $\begin{array}{l}30 \text { modules; } \\
54 \mathrm{~m}^{2}\end{array}$ \\
\hline \multirow{2}{*}{\multicolumn{2}{|c|}{ External wall }} & $\begin{array}{l}89 \text { modules; } \\
142 \mathrm{~m}^{2}\end{array}$ & $\begin{array}{l}89 \text { modules; } \\
142 \mathrm{~m}^{2}\end{array}$ & $\begin{array}{l}89 \text { modules; } \\
142 \mathrm{~m}^{2}\end{array}$ & $\begin{array}{l}89 \text { modules; } \\
142 \mathrm{~m}^{2}\end{array}$ & $\begin{array}{l}89 \text { modules; } \\
142 \mathrm{~m}^{2}\end{array}$ & $\begin{array}{l}100 \text { modules; } \\
163 \mathrm{~m}^{2}\end{array}$ \\
\hline & & $\begin{array}{l}\text { two brick walls }(20 \mathrm{Cm}) \\
\text { with an EPS thermal } \\
\text { coating }(13 \mathrm{~cm}) \text { covered } \\
\text { by plaster }\end{array}$ & $\begin{array}{l}\text { autoclaved } \\
\text { concrete bricks } \\
(36 \mathrm{~cm}) \text { covered } \\
\text { by plaster }\end{array}$ & $\begin{array}{l}\text { super NZEB } \\
\text { autoclaved } \\
\text { concrete bricks } \\
(45 \mathrm{~cm}) \text { covered } \\
\text { by plaster }\end{array}$ & $\begin{array}{l}\text { autoclaved } \\
\text { concrete bricks } \\
(36 \mathrm{~cm}) \text { covered } \\
\text { by plaster }\end{array}$ & $\begin{array}{l}\text { super NZEB } \\
\text { autoclaved } \\
\text { concrete }(45 \\
\mathrm{cm}) \text { covered by } \\
\text { plaster }\end{array}$ & $\begin{array}{l}\text { Super NZEB } \\
\text { autoclaved } \\
\text { concrete }(45 \\
\mathrm{cm}) \text { covered by } \\
\text { plaster }\end{array}$ \\
\hline \multicolumn{2}{|r|}{ Roof } & $\begin{array}{l}\text { Masonry tilted roof with } \\
\text { an XPS thermal coating } \\
\text { of } 11 \mathrm{~cm} \text { covered by a } \\
\text { steel plate mounted on } \\
\text { wooden planks. }\end{array}$ & $\begin{array}{l}\text { As reference } \\
\text { building }\end{array}$ & $\begin{array}{l}\text { super NZEB } \\
\text { Masonry tilted } \\
\text { roof with an } \\
\text { XPS thermal } \\
\text { coating of } 27 \\
\mathrm{~cm}\end{array}$ & $\begin{array}{l}\text { As reference } \\
\text { building }\end{array}$ & $\begin{array}{l}\text { super NZEB } \\
\text { Masonry tilted } \\
\text { roof with an } \\
\text { XPS thermal } \\
\text { coating of } 27 \\
\text { cm }\end{array}$ & $\begin{array}{l}\text { super NZEB } \\
\text { Masonry tilted } \\
\text { roof with an } \\
\text { XPS thermal } \\
\text { coating of } 27 \\
\mathrm{~cm}\end{array}$ \\
\hline \multicolumn{2}{|c|}{$\begin{array}{r}\text { Floor above } \\
\text { apartments }\end{array}$} & $\begin{array}{l}\text { Masonry floor with an } \\
\text { XPS thermal coating of } 7 \\
\mathrm{~cm} \text { and an EPS layer ( } 4 \\
\mathrm{~cm} \text { ) included in the floor } \\
\text { heating system }\end{array}$ & $\begin{array}{l}\text { Masonry floor } \\
\text { with an XPS } \\
\text { thermal coating } \\
\text { of } 11 \mathrm{~cm} .\end{array}$ & $\begin{array}{l}\text { super NZEB } \\
\text { Masonry floor } \\
\text { with an XPS } \\
\text { thermal coating } \\
\text { of } 20 \mathrm{~cm} .\end{array}$ & $\begin{array}{l}\text { Masonry floor } \\
\text { with an XPS } \\
\text { thermal coating } \\
\text { of } 11 \mathrm{~cm} .\end{array}$ & $\begin{array}{l}\text { Super NZEB } \\
\text { Masonry floor } \\
\text { with an XPS } \\
\text { thermal coating } \\
\text { of } 20 \mathrm{~cm} .\end{array}$ & $\begin{array}{l}\text { Super NZEB } \\
\text { Masonry floor } \\
\text { with an XPS } \\
\text { thermal coating } \\
\text { of } 20 \mathrm{~cm} .\end{array}$ \\
\hline \multicolumn{2}{|r|}{ Windows } & Traditional windows & \multicolumn{5}{|c|}{ Monoblock windows } \\
\hline \multicolumn{2}{|c|}{ Ventilation } & MVHR & MVHR & MEV & MVHR & MEV & MVHR \\
\hline $\begin{array}{r}\text { Heat } \\
\text { supply }\end{array}$ & Unit & $\begin{array}{l}\text { Heat pump }+ \text { Condensing } \\
\text { boiler (back up) }\end{array}$ & $\begin{array}{l}\text { Condensing } \\
\text { boiler }\end{array}$ & $\begin{array}{l}\text { Condensing } \\
\text { boiler }\end{array}$ & $\begin{array}{l}\text { Heat pump + } \\
\text { Condensing } \\
\text { boiler (back up) }\end{array}$ & $\begin{array}{l}\text { Heat pump + } \\
\text { Condensing } \\
\text { boiler (back } \\
\text { up) }\end{array}$ & Absent \\
\hline
\end{tabular}


In Rome, transmittances of the external walls and windows are the same as in the base case. The roof and floor above the apartments are the same as the reference building apart from the additional insulation layers which compensates the absence of floor heating in the four scenarios.

In Turin, two of the five scenarios maintain the same transmittance values of the building envelope as in the base case (scenarios 1 and 3), while the other three scenarios have a super NZEB envelope. According to this, scenario 2 has the same characteristics as scenario 1 apart from the lower transmittance values of the envelope and the Mechanical Extract Ventilation (MEV) instead of the MVHR. Similarly, scenario 4 is coupled with scenario 3 . In the thermal driven scenarios 1 and 2 solar collectors provide pre-heating of water for both heating and DHW services.

As aforementioned in paragraph 4.2, it must be noticed that scenarios 3 and 4 in Rome and scenario 5 in Turin are outlaw either because of the installation of electric radiators as heating system, or because of the lower amount of PV panels respect to the Standard requirements.

\subsection{Financial calculation}

Prices of proposed low-cost solutions for the envelope (autoclaved blocks, mono-block window) and for the energy systems which were not included in the bill of quantities of the real building (Mechanical extract ventilation and MVHR) in a first stage were derived from official regional price lists, which provide unitary costs $\left(€ / \mathrm{m}^{2}\right)$ for materials and labour [47]. Lately, it was chosen to ask for costs to real construction companies since it was noticed that price lists generally overpriced values.

For external wall a company which uses both technologies [48] was asked to simulate a real market offer for the reference building, giving disaggregated costs in labour and material of both traditional (brick-wall + thermal coating) and new solution (autoclaved blocks). It was observed that the cost of material of the blocks is $15 \%$ lower than traditional solution; in terms of labour savings results are even more relevant since the impact on the construction time is a man-hours reduction of about $48 \%$. It resulted in a reduction of $16 € / \mathrm{m}^{2}$ in all the scenarios where transmittances of the external walls are the same as in the base case; a reduction of $5 € / \mathrm{m}^{2}$ did occur in the super NZEB scenarios in Turin.

Similarly, disaggregated costs for conventional windows and full mono-block windows were provided by a construction company [49]. In this case it was observed that windows cost in the new solution is higher (about 38\% more than conventional windows) but cost of the subframe is substantially null compared to standard solution. It leads to the overall observation that the full mono-block is cheaper by nearly $20 \%$ with about $60 \%$ time saving in the installation phase. It resulted in a reduction of $40 € / \mathrm{m}^{2}$ compared to the conventional windows.

For the Mechanical Extract ventilation system, as for MVHR, a company simulated a real economic offer to supply the MEV system for the reference building [40].

All the other costs of the building envelope and energy systems in the scenarios have been estimated as unitary variation $\left(€ / \mathrm{m}^{3}\right)$ of the original prices included in the bill of quantities or as price variation due to the different couplings of the installed systems. 
The LCC analysis was developed in terms of incremental and actualized savings compared to the base case on 50 years expected lifetime of the building. According to this, only the "Energy related costs" of the overall construction costs have been considered in accordance to the standard application of the cost-optimal methodology [50]. The economic analysis was carried out based on the requirements of relative European Standard [51] taking into account: costs and lifetime of technical solutions implemented in the building configurations, costs for the used fuels, national economic indicators. The net present value (NPV) was selected as key performance indicator.

The maintenance costs and lifetime of the solutions are shown in Table 6. Most of these values have been taken from the Standard [51] apart from the values related to electric radiators which have been extrapolated from German guidelines VDI 2067 which deals with the calculation of the economic efficiency of building installations.

Table 6. maintenance costs and lifetime of the proposed solutions

\begin{tabular}{|c|c|c|c|}
\hline & Technology & $\begin{array}{l}\text { Life Time } \\
\text { [years] }\end{array}$ & $\begin{array}{c}\text { Maintenance } \\
\text { Costs [\%] }\end{array}$ \\
\hline \multicolumn{2}{|c|}{ Solar thermal collectors } & 20 & 0.5 \\
\hline \multirow{2}{*}{\multicolumn{2}{|c|}{$\begin{array}{r}P V \\
\text { Building envelope }\end{array}$}} & 50 & 0.5 \\
\hline & & 50 & 0.5 \\
\hline \multicolumn{2}{|r|}{ Windows } & 30 & 0.5 \\
\hline \multirow{2}{*}{$M V H R$} & Unit & 15 & 4 \\
\hline & Pipes & 30 & 1 \\
\hline \multirow{2}{*}{$M E V$} & Unit & 20 & 4 \\
\hline & Pipes & 30 & 1 \\
\hline \multirow{2}{*}{ Heat pump } & Unit & 20 & 3 \\
\hline & Pipes & 30 & 1 \\
\hline \multirow{2}{*}{ Condensing boiler } & Unit & 20 & 1.5 \\
\hline & Pipes & 30 & 1 \\
\hline & Floor heating & 50 & 2 \\
\hline \multirow{2}{*}{\multicolumn{2}{|c|}{$\begin{array}{r}\text { Radiators } \\
\text { Electric Radiators }\end{array}$}} & 35 & 1.5 \\
\hline & & 22 & 1 \\
\hline
\end{tabular}

Table 7. National economic indicators for LCC analysis

\begin{tabular}{lc}
\hline Discount rate & $4 \%$ \\
\hline Tax of interest income & $26 \%$ \\
\hline $\begin{array}{l}\text { Inflation of energy } \\
\text { electricity }\end{array}$ & $3.4 \%$ \\
\hline Inflation of energy gas & $2.3 \%$ \\
\hline Inflation of maintenance & $2 \%$ \\
\hline Evolution Price Product & $2 \%$ \\
\hline
\end{tabular}

Table 7 shows the national economic indicators used for the LCC analysis [52]. These data were extrapolated from a preliminary study for the new cost optimal analysis in Italy. Costs for the used fuels are the following: Gas $0.72 € / \mathrm{smc}$; Electricity (bought from the grid) $0.20 € / \mathrm{kWh}$; Electricity (sold to the grid) $0.06 € / \mathrm{kWh}$. Estimation of incomes for selling the surplus of renewable electricity to the grid is based on the Italian procedure of the net metering as prescribed in [53]. The GSE company [54] provides on annual basis the economic contribution $(C S)$ for electricity sold to the grid according to this formula:

$C S=(\min (O E: C E i))+(C U S f \times E S)$

Where: 
- $O E$ is the product between the amount of energy taken from the grid and the national power exchange price

- $C E i$ is the product between the amount of energy sold to the grid and the price zone available on the Electricity Day-Ahead Market

- CUsf is the annual lump-sum contribution for energy exchange

- $E S$ is minimum, on an annual basis, between the amount of electricity put into and taken from the grid

It was chosen to calculate only the second term of the formula for two main reasons: first it was observed that is the heaviest part of the contribute and secondly the prices for estimating $O E$ and $C E i$ are daily variable so it would have been difficult to assess the precise values. Value of CUS $f$ for the year 2017 were taken from the Arera web site, the Regulatory Authority for Energy, Networks and Environment in Italy [55] and it corresponds to the price for electricity sold to the grid.

\section{Results}

\subsection{Passive cooling}

The first simulation runs showed that solar shading alone does not provide adequate thermal comfort with standard $0.3 \mathrm{ACH}$, with discomfort hours always above $20 \%$. The second set showed the improvement of comfort conditions upon the simultaneous application of shading devices and night ventilation cooling strategies. For brevity, results are presented for the best performing configuration, consisting of external solar protection devices with shading factor 0.8 and $1.5 \mathrm{ACH}$ of night ventilation rate.

Figure 3 presents the hourly plot of the operative temperature in three reference apartments, located respectively at first, second and third (upper) floors for a week in July. It can be observed the small amplitude of the operative temperature in the apartments, $3^{\circ} \mathrm{C}$ maximum in the 24 hours, versus variations up $14^{\circ} \mathrm{C}$ of the external air temperature. The figure also shows the higher thermal stress in the attic flats, where the operative temperature raises up to $1^{\circ} \mathrm{C}$ respect to the lower floors.

Under these conditions and taking into account the comfort category 2 of the relevant standard [42], the number of hours in which the operative temperature exceeds the comfort band is in the $0-1.3 \%$ range for the NZEB configuration in the observation period, while it raises to $0-1.9 \%$ range for the super NZEB configuration. In all cases the discomfort hours are by far below than $5 \%$, limit indicated by the relevant standard. To be noted, finally, that the number of hours in the two digits range are calculated for the two flats located in the upper floor, just below the roofs, being negligible in all the other apartments.

An additional test was carried out to check the compliance with category 1 of the relevant standard, to assess if the thermal indoor environment might be significantly deteriorated respect to the requirements for weaker classes of residents. The results are presented in figure 4 and show a significant increase of discomfort hours. The discomfort hours are in the $0-4 \%$ range of the observation period for all the analysed flat but A8, where they reach $10 \%$, for the NZEB configuration, thus above the standard limits. The super NZEB configuration causes an increase of discomfort hours; in three cases (A1, A4, A7) the operative temperatures hours are above the limit in the 5-8\% of the all observation period, while for apartment A8 they reach $14 \%$. 


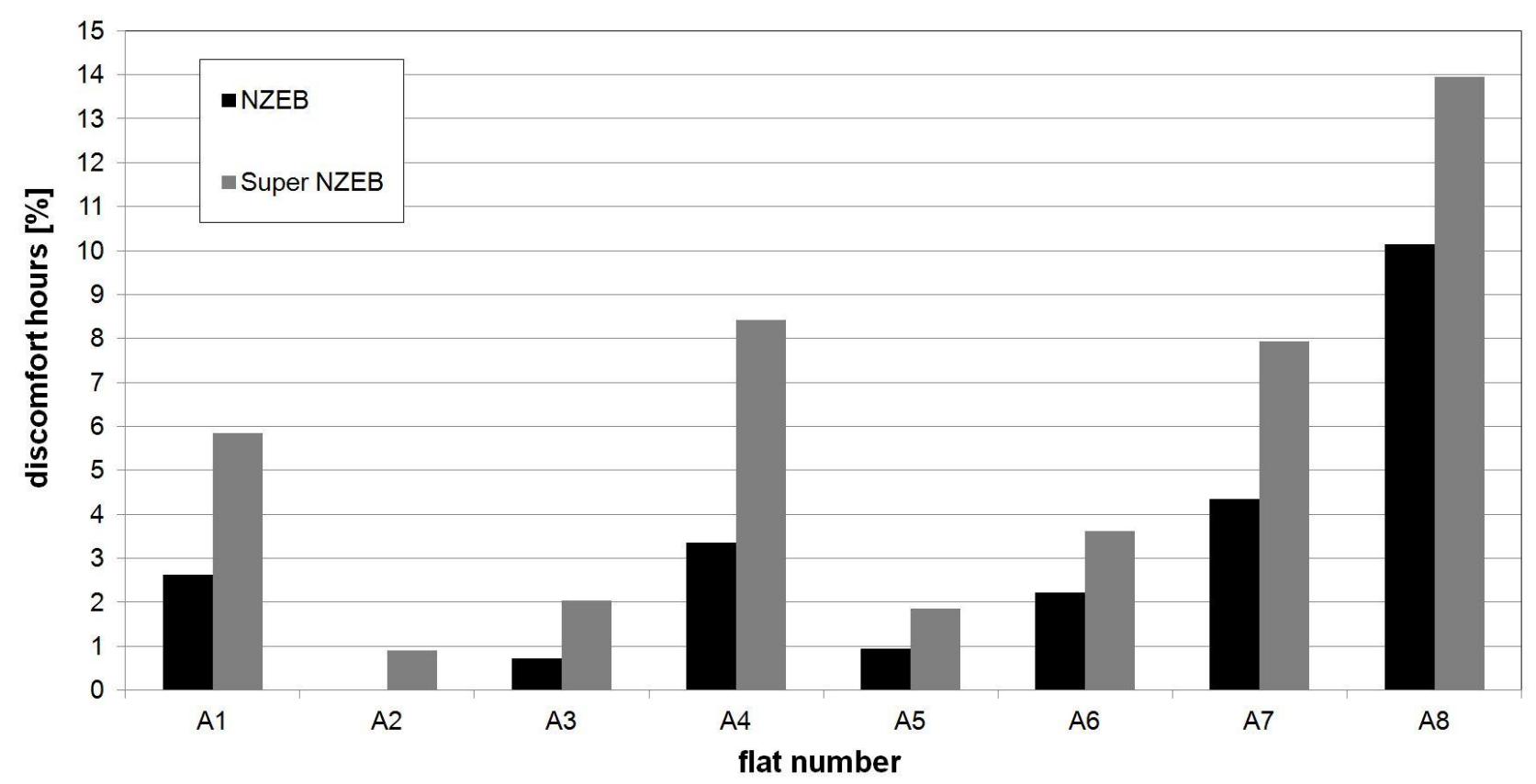

Figure 4. Relative discomfort hours in the investigated portion of the building for NZEB and super NZEB configurations in the June-August period.

The main outcomes of the analysis are:

- Requirements set for solar protection devices can be achieved with conventional textile and technical shading systems. Air exchange rates can also be easily fulfilled with multiple opening of windows, adequate planning of lay-out and facades of the building can ensure even higher rates [56][57][58]. This implies that passive solutions can be adequately planned and installed at no extra costs.

- The passive cooling solutions generally provides acceptable thermal comfort conditions at tested latitudes, according to the category II requirements of the relevant standard; in fact the discomfort hours are always at very low level for category II.

- Higher deviations are calculated for category I, however very low-cost solutions can be implemented. Higher night ventilation rates and improved indoor conditions can be easily achieved by ceiling fans or simple ventilation systems, thus lowering the discomfort hours to acceptable levels. These punctual systems should be installed and switched on only where and when needed. Moreover, they might be fed by the renewable electricity produced at building level, which exceeds 


\subsection{Energy performance}

In all the scenarios simulated with Edilclima, the building obtained the grade A4 which is the highest level of energy performance; infact, although the indicator of primary energy (EP) is different for each scenario, it is always much lower than the EP of the reference building to whom the case study is compared. According to the Italian Standard, in each simulation a reference building is defined, which is the same as the case study building in terms of geometry, orientation, geographic location, energy systems, but it has predetermined thermal and energy characteristics. It allows to calculate to primary energy limit that must be respected by the case study building.

The final energy and primary non-renewable energy $\left(\mathrm{EP}_{\text {nonren }}\right)$ for heating, DHW and Ventilation of Rome and Turin are shown in Figure 5 and 6; Table 8 shows the global primary non-renewable energy $\mathrm{EP}_{\text {nonrengl }}$.

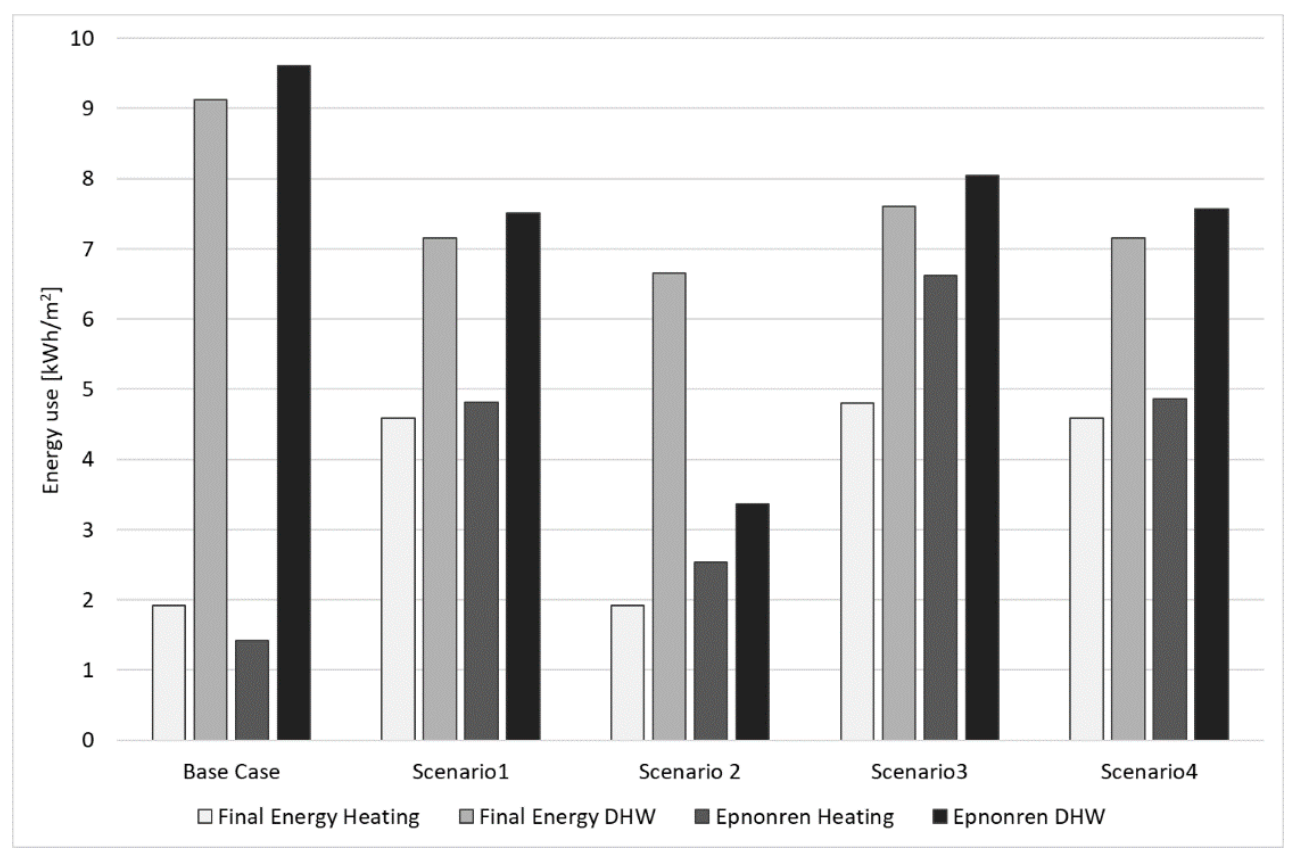

Figure 5. The final energy and primary non-renewable energy $\left(\mathrm{EP}_{\text {nonren }}\right)$ for heating and $\mathrm{DHW}$ in Rome. 
In Rome, the $\mathrm{EP}_{\text {nonrengl }}$ of all the scenarios (sum of Heating and DWH) is higher than base case, except for scenario 2. With a $\mathrm{EP}_{\text {nonrengl }}$ of $5.91 \mathrm{kWh} / \mathrm{m}^{2}$ it is the most energy efficient scenario: the use of the heat pump for both heating and DHW allows to exploit as much as possible the potentiality of both the heat pump and the PV panels.

In the base case scenario, there is a high difference between $\mathrm{EP}_{\text {nonren }}$ of DHW and Heating, being the first high $\left(9.6 \mathrm{kWh} / \mathrm{m}^{2}\right)$ and the second very low $\left(1.42 \mathrm{kWh} / \mathrm{m}^{2}\right)$ : two separate systems are used (heat pump and condensing boiler) and a lower amount of solar thermal collectors is installed. On the contrary, in the other scenarios, the $\mathrm{EP}_{\text {nonren }}$ for heating is always higher compared to the base case thanks to the use of the condensing boiler instead of the heat pump, while a decrease in the $\mathrm{EP}_{\text {nonren }}$ for DHW is always obtained due to increase of solar thermal collectors and/or the optimization of the heat pump.

The worst scenario is number 3. It has the highest $\mathrm{EP}_{\text {nonren }}$ for heating $\left(6.7 \mathrm{kWh} / \mathrm{m}^{2}\right)$, since, when not provided by the PV panels, energy is directly taken from the grid: therefore, firstly much more electricity is absorbed for heating supply compared to amount of electricity needed for the heat pump compressor and secondly the share of non-renewable energy in the electric grid is much higher compared to the renewable part.

Conversely, in Turin all the scenarios present a better energy performance compared to the base case, with globally lower $\mathrm{EP}_{\text {nonren. }}$ ranging between 17.38 and $21.05 \mathrm{kWh} / \mathrm{m}^{2}$.

The best scenario is number 2, where the $\mathrm{EP}_{\text {nonren. }}$ for heating is slightly higher than base case (10.4 vs 9.1 $\mathrm{kWh} / \mathrm{m}^{2}$.) due to the use of condensing boiler, but the $\mathrm{EP}_{\text {nonren }}$ for DHW is much lower $\left(7.0 \mathrm{vs} 11.1 \mathrm{kWh} / \mathrm{m}^{2}\right)$ thanks to the installation of twice as many solar thermal collectors. The $\mathrm{EP}_{\text {nonren }}$ for ventilation is null: the installed MEV requires a lower amount of electricity compared to the MVHR and so, being scenario 2 a thermal driven solution, the highest part of electricity from PV panels can be used for the mechanical ventilation system. 
Results of scenario 1 are coupled with the ones of scenario 2; similarly, also scenarios 3 and 4 . The $\mathrm{EP}_{\text {nonren }}$ in these two couples are aligned: differences among the values range between $1 \%$ for heating and $5 \%$ for DHW. These differences are due to the fact that scenarios 1 and 3 have a standard NZEB envelope and a MVHR, while scenarios 2 and 4 have a super NZEB envelope and a MEV. As a matter of fact, the super NZEB envelope almost does not affect the $\mathrm{EP}_{\text {nonren }}$ for heating but it has a little influence on the $\mathrm{EP}_{\text {nonren }}$ for DHW. In fact, in the couple 1-2, solar thermal collectors provide pre-heats water for both heating and DHW: the lower transmittance values of the envelope in scenario 2 allow to employ the solar collectors more for DHW than for heating, reducing the $\mathrm{EP}_{\text {nonren }}$ up to $4 \%$ compared to scenario 1 . In cases 3 and 4 , DHW and heating are supplied by the heat pump; being scenario 4 a super NZEB, lower energy needs are required so a higher amount of electricity from PV panels can be provided to the heat pump for DHW, reducing the $\mathrm{EP}_{\text {nonren }}$ up to $5 \%$ compared to scenario 3.

In scenario 3 and 5, the $\mathrm{EP}_{\text {nonren }}$ for ventilation is higher than base case, since more electricity from PV panels is absorbed for heating supply compared to the other scenarios.

Table 9. Energy consumption and production in Rome and Turin

\begin{tabular}{|c|c|c|c|c|}
\hline & Scenarios & $\begin{array}{l}\text { Electricity } \\
\text { consumption } \\
{[\mathrm{kWh}]}\end{array}$ & $\begin{array}{l}\text { Electricity } \\
\text { production } \\
{[\mathrm{kWh}]}\end{array}$ & $\begin{array}{c}\text { Gas } \\
\text { consumption } \\
{[\text { Smc }]}\end{array}$ \\
\hline \multirow{5}{*}{ Rome } & Base case & 1601 & 20618 & 2324 \\
\hline & Scenario 1 & 0 & 23060 & 2913 \\
\hline & Scenario 2 & 7149 & 10513 & 98 \\
\hline & Scenario 3 & 8604 & 22934 & 1890 \\
\hline & Scenario 4 & 304 & 363 & 2913 \\
\hline \multirow{6}{*}{ Turin } & Base case & 8490 & 13277 & 3481 \\
\hline & Scenario 1 & 78 & 13676 & 4171 \\
\hline & Scenario 2 & 0 & 16666 & 4110 \\
\hline & Scenario 3 & 18004 & 4086 & 1212 \\
\hline & Scenario 4 & 16340 & 5428 & 1234 \\
\hline & Scenario 5 & 16864 & 14068 & 1876 \\
\hline
\end{tabular}

In table 9 the energy consumption of electricity and gas and the renewable energy production are shown. Both in Rome and Turin, the thermal driven scenarios ( 1 and 4 in Rome and 1 and 2 in Turin) have almost zero electricity consumption and consume only a slightly higher amount of gas compared to the base case (up to $26 \%$ more in Rome) thanks to the greater number of solar thermal collectors installed. Additionally, in the base case in Turin the back-up condensing boiler does often intervene instead of the heat pump for heating supply due to the lower outdoor temperature. It contributes to align the data of gas consumption between the base case and the thermal driven scenarios which only use condensing boiler for space heating.

Conversely, in electricity driven scenario 2 in Rome the use of the heat pump for both heating and DHW make the electricity consumption arise up to $346 \%$ and the gas consumption decreases up to zero; in Turin electricity and gas consumption in electricity-driven scenarios are both high.

\subsection{Economic analysis and $L C C$ results}

Two additional scenarios, called S3b and S5b, have been introduced in the financial analysis for respectively Rome and Turin, as variations of scenarios 3 and 5. In these variants of the scenarios 3 and 5, a lower investment cost for the electric radiators has been proposed. Due to the variability in the market price of these systems, it was chosen to show two representative costs in these range of prices. 
In Table 10 the Net Present Values (NPV) and the energy related construction costs are shown for each scenario; these unitary NPVs $\left(€ / \mathrm{m}^{2}\right)$ are expressed in terms of actualized savings compared to the base case on 50 years expected lifetime of the building.

Table 10. Net Present Values (NPV) and the energy related construction costs in Rome and Turin

\begin{tabular}{|c|c|c|c|}
\hline & Scenarios & $\begin{array}{c}\text { Energy related } \\
\text { construction costs } \\
{\left[€ / \mathrm{m}^{2}\right]}\end{array}$ & $\begin{array}{c}\mathrm{NPV} \\
{\left[€ / \mathrm{m}^{2}\right]}\end{array}$ \\
\hline \multirow{6}{*}{ Rome } & Base case & 389 & - \\
\hline & Scenario 1 & 310 & 133 \\
\hline & Scenario 2 & 321 & 111 \\
\hline & Scenario 3 & 296 & 143 \\
\hline & Scenario 4 & 295 & 150 \\
\hline & Scenario $3 b$ & 287 & 163 \\
\hline \multirow{7}{*}{ Turin } & Base case & 447 & - \\
\hline & Scenario 1 & 384 & 121 \\
\hline & Scenario 2 & 385 & 158 \\
\hline & Scenario 3 & 382 & 77 \\
\hline & Scenario 4 & 383 & 122 \\
\hline & Scenario 5 & 391 & 105 \\
\hline & Scenario $5 b$ & 383 & 121 \\
\hline
\end{tabular}

In graphs 7 and 8 the cash flows of the scenarios over the 50-year life time of the building for the two climate zones are shown. The occurring positive and negative variations in the trends, which make the slope of the line vary and savings increase or decrease rapidly, are due to the one-off replacement of the technical systems. The replacements are also expressed as costs difference between the scenarios and the base cases: when the scenario has lower costs, there are savings and the slope of the line increases, when the scenario has higher replacement costs compared to the base case there are expenses and the slope of the line decreases. 


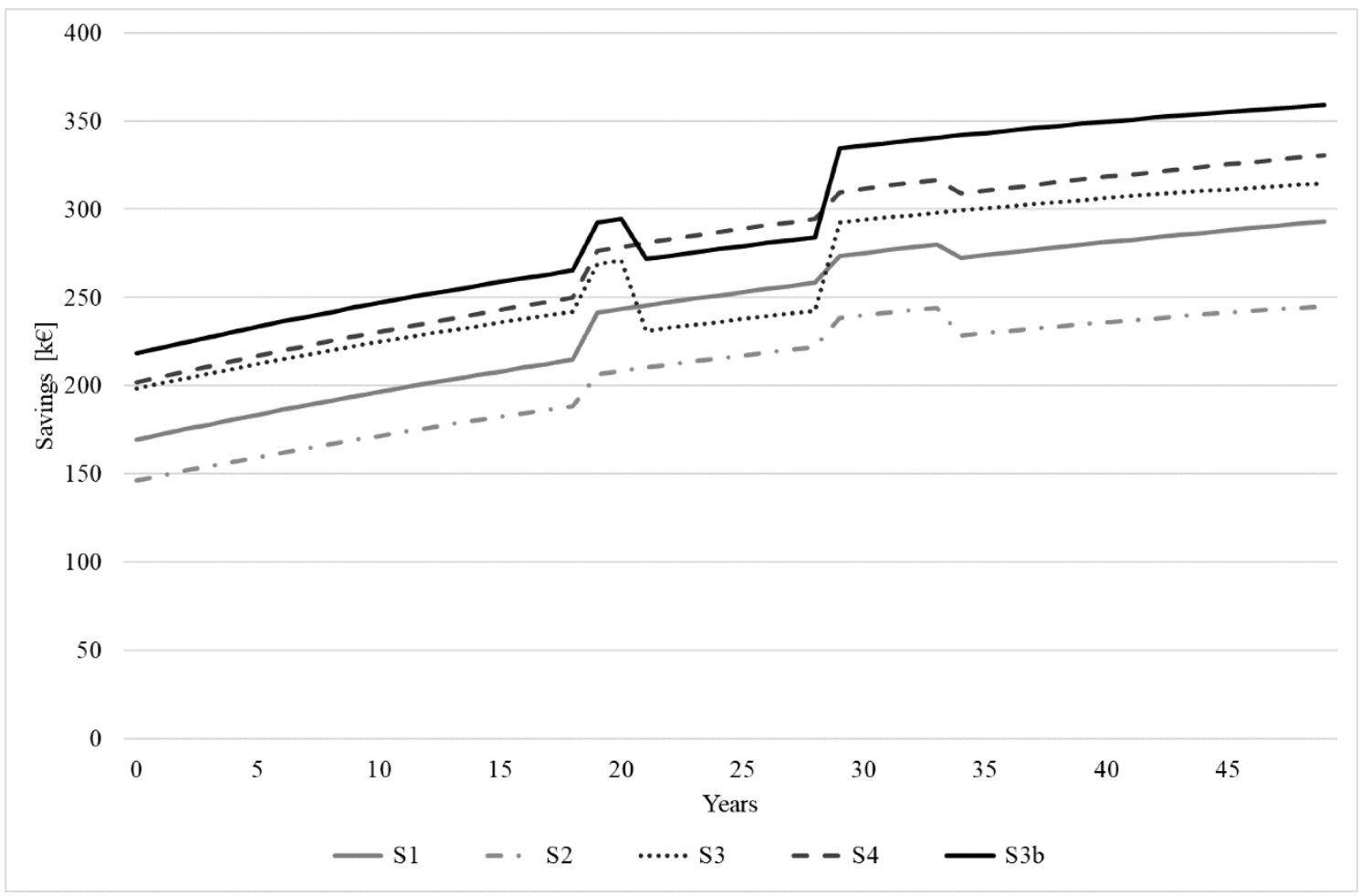

Figure 7. LCC analysis in Rome

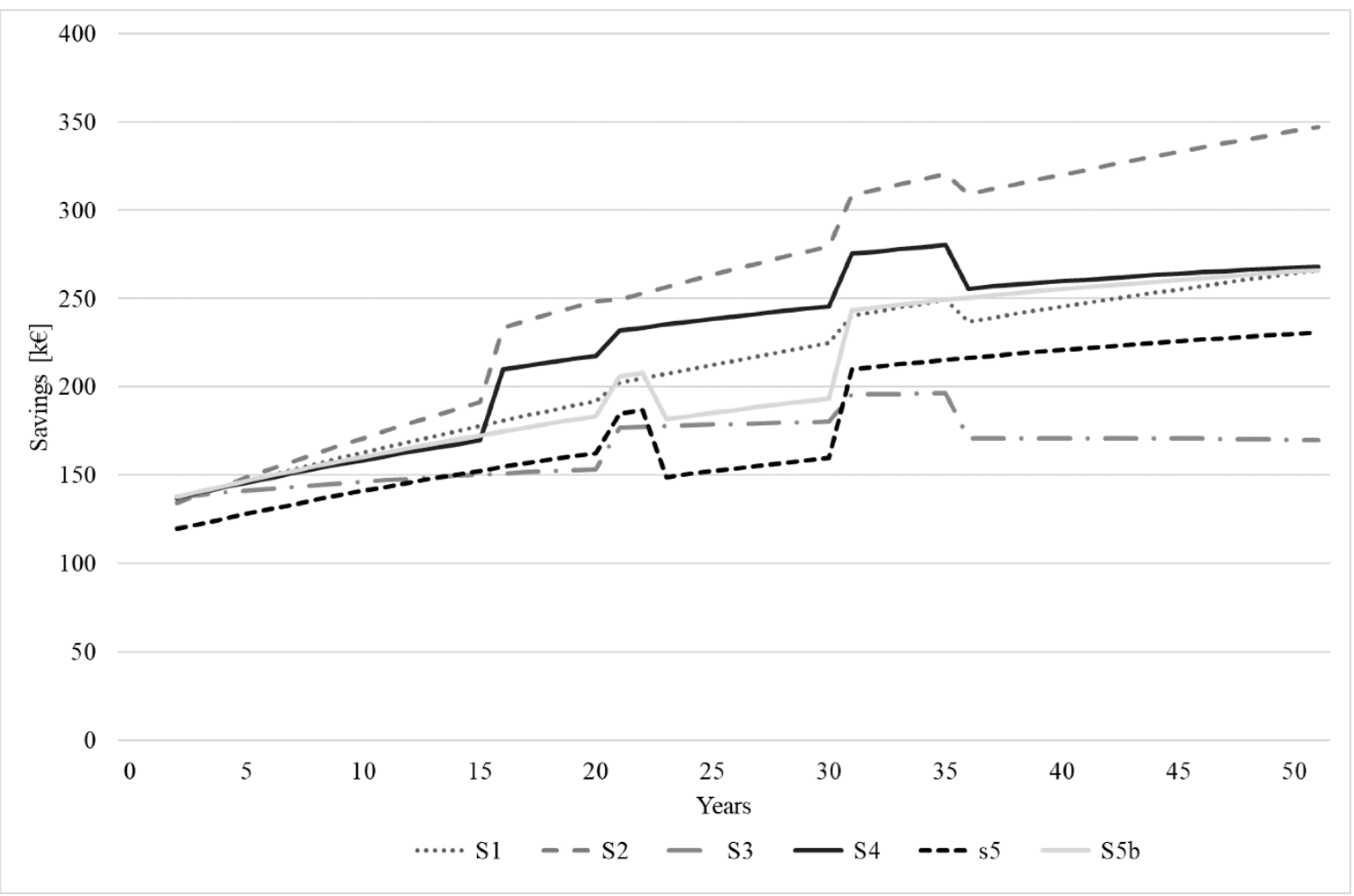

Figure 8. LCC analysis in Turin

It can be noted that all scenarios in the two climate zones allow both reductions in the construction costs and savings in a long-term perspective. In the life cycle cost analysis three types of costs have been considered: maintenance costs of the technical systems and envelope, energy costs, and replacements costs based on the lifetime of each technology. 
In Rome, the development of low-cost technical solutions in the construction phase guarantees up to $26 \%$ reduction of investment costs. All scenarios have lower annual maintenance costs for the envelope compared to the base case; differences among scenarios are mainly registered in terms of variations of maintenance costs for the technical systems and energy costs. The best scenario is $3 \mathrm{~b}$, which shows the lowest initial construction costs $\left(287 € / \mathrm{m}^{2}\right)$ and the highest NPV $\left(163 € / \mathrm{m}^{2}\right)$. The absence of technical system for heating supply allows to considerably reduce maintenance and replacement costs: at the end of the 50 years up to $€$ $329^{\prime} 000$ are saved for maintenance costs of technical system compared to the base case. It compensates for the annual energy expense which is much higher than the base case, achieving a total actualized expense of about $€ 93^{\prime} 000$ more than the base case. High profits can be also achieved with scenarios 4 and 3; the main variation between scenario $3 \mathrm{~b}$ and 4 is due to the difference in savings for systems replacement, which are much higher in scenario $3 \mathrm{~b}$. It has to be observed that these three scenarios are outlaw. Considering only the scenarios compliant with legal standard, the most efficient is number 1.

In Turin, up to $15 \%$ of savings in investment costs were obtained with scenario 3. Construction costs of the five scenarios are very similar to each other reaching a maximum percentage difference of about $2 \%$ between 3 and scenario 5: in fact, when the expense for the envelope are higher (super NZEB) it is balanced by cheaper technical systems (MEV instead of MVHR, absence of solar thermal collectors, elimination of heat supply system); also in this case differences among scenarios are mainly registered in terms of variations of maintenance costs for the technical systems and energy costs.

Scenario 2 is the most efficient from a long-term perspective showing a NPV of $158 € / \mathrm{m}^{2}$ : after 50 years maintenance costs for renewable system and envelope are higher than the base case (actualized expense of respectively $€ 12$ '000 more than the base case), but operational energy costs and maintenance costs for technical systems are much lower (actualized savings of about $€ 398^{\prime} 000$ for maintenance costs and $€$ 106 '000 for energy costs). The replacement of technical system is also less expensive than base case, since the condensing boiler is used instead of the heat pump and the MEV instead of the MVHR.

Scenarios 1, 4 and 5b, despite the differences in trends, show aligned NPV at the end of the 50 years. A great impact on the trend variations among these scenarios is given by the different costs for systems replacement.

The outlaw scenario $5 \mathrm{~b}$ allows the highest savings for maintenance costs of the technical systems but on the other side it entails an increase of costs for PV panels, envelope and energy due to the high amount of electricity taken from the grid as it happens in scenarios 3 and 4. As shown in Table 9, despite the high electricity consumption, the amount of energy sold to the grid is also very high, contrary to cases 3 and 4 where the energy sold to the grid is considerably lower than the bought one. Based on the procedure of net metering, the energy payed to the building owner corresponds to the minimum between the amount of electricity sold and bought from the grid: in this case, being these two values quite aligned and very high, the annual incomes are much more than the other scenarios.

\section{Conclusion}

In this paper solution sets for reducing construction costs of new nearly zero energy multi-family houses were explored in a life cycle perspective. Conversely to the typical methodology of cost-optimal analysis, in this study alternative constructive strategies and unconventional combinations of technical solutions have been proposed, analysing also the efficacy of forefront proposals currently forbidden in Italy according to the relevant Standard. The real case study building, located in the centre of Italy, was standardized and adapted to the minimum NZEB requirements of the two reference climatic zones chosen for the analysis (Rome and Turin). The choice of an existing building allowed to carry out a more realistic evaluation of the cost effectiveness of the proposed variants, thanks to the availability of technical and economic data based on real market instead of on average values. The LCC analysis also allowed to compare all the scenarios in a life cycle perspective, including the annual operational, maintenance and replacements costs based on the lifetime of each technology. 
In a first stage of analysis, since the real building was not provided with a cooling system, a thermal calculation was performed to assess whether the use of passive solutions (solar protection and night ventilation cooling) might avoid the installation of active cooling to prevent summer overheating, thus keeping lower costs for design and installation of such systems. Results demonstrated that low-cost passive strategies can be adequately planned and installed at no extra costs, providing acceptable thermal comfort conditions at tested latitudes: in the three reference apartments, located respectively at first, second and third (upper) floors, results show that the discomfort hours in summer period are by far below than $5 \%$, limit indicated by the relevant standard.

Lately, results of the energy calculation performed on the low-costs scenarios in Rome and Turin demonstrated that all the variants reached the highest grade of energy performance (level A4). Although, it was observed that in all the scenarios in Rome, except for number 2, the global primary non-renewable energy indicators $\left(\mathrm{EP}_{\text {nonrengl }}\right)$ is higher than base case, with a maximum percentage difference of $34 \%$. The most energy efficient is the electricity driven scenario number 2 , where the use of the heat pump for both heating and DHW allows to exploit as much as possible the potentiality of both the heat pump and the PV panels. The $\mathrm{EP}_{\text {nonrengl }}$ is $46 \%$ lower than the base case.

Conversely in Turin, all the scenarios show a lower $\mathrm{EP}_{\text {nonrengl }}$ compared to the base case, with a reduction up to $18 \%$ between base case and the thermal driven scenario 2 . It is also the most efficient: electricity consumption for heating is reduced, the high number of solar collectors allows to minimize thermal consumption for DHW and the installed MEV requires a lower amount of electricity compared to the MVHR of the base case, maximizing the contribute of PV panels.

From the financial perspective, it was demonstrated that, compared to the base case, all the scenarios in the two climate zones allow both reductions in the construction costs, up to $26 \%$ in Rome, and savings over the 50 -year life time of the building, up to $163 € / \mathrm{m}^{2}$ in Rome. Results also show the importance of an accurate evaluation of the maintenance and replacement costs of each technology, since it was observed that these expenses have a key role in the assessment of the most profitable scenario, making the differences among the proposed solution sets.

In Rome, the most economically efficient is scenario $3 b$, having both the lowest investment costs $\left(287 € / \mathrm{m}^{2}\right)$ and the highest NPV $\left(163 € / \mathrm{m}^{2}\right)$. It is a variant of the electricity driven scenario 3 , not compliant with Standard requirements, where the investment costs of the electric radiators are lower than scenario 3 and the absence of technical system for heating supply allows to considerably reduce maintenance and replacement costs.

In Turin, differently from Rome, the most energy efficient scenario, number 2, is also the most profitable: it shows the highest NPV $(158 € / \mathrm{m} 2)$ although it doesn't have also the lowest construction costs. Nevertheless, it can be observed that investment costs of the five scenarios in Turin are very similar reaching a maximum percentage difference of about $2 \%$ between 3 and scenario 5 . These results confirm that differences among the scenarios can be only assessed in a long-term perspective, highlighting the importance of developing LCC analysis on buildings.

Future developments of this research would consider the inclusion of more detailed costs occurring in the building construction process, such as design and planning costs and preliminaries. Preliminaries costs, also called indirect, include expenses not related to the building site, as commercial and administrative costs, which cannot be directly imputed to the construction process itself, but may have a high impact on the entire process. The inclusion of these variables and the evaluation of alternative and unconventional technologies, would improve the cost-optimal analysis of the building, reaching the best compromise between energy and economic efficiency from a global perspective. 


\section{AKNOWLEDGEMENTS}

The CoNZEBs project has received funding from the European Union's Horizon 2020 research and innovation programme under grant agreement no. 754046. The article reflects the authors' view. The Commission is not responsible for any use that may be made of the information it contains.

\section{References}

[1] Horizon 2020 EU Research and Innovation programme. Available at: http://ec.europa.eu/research/participants/portal/desktop/en/funding/reference docs.html

[2] Green Paper, A 2030 framework for climate and energy policies, COM (2013)169 http://ec.europa.eu/energy/consultations/20130702 green paper 2030en.htm

[3] 2050 Energy strategy. Available at: https://ec.europa.eu/energy/en/topics/energy-strategy-andenergy-union/2050-energy-strategy

[4] Eurostat. Final energy consumption by sector. 2016. Available at: http://ec.europa.eu/eurostat/en/web/products-datasets/-/T2020_34

[5] European Parliament and Council: Directive 2010/31/EU of the European Parliament and of the Council of 19 May 2010 on the energy performance of buildings. 2010. Official Journal L 153, 18.6.2010, p. 13-35. Available at http://eur-lex.europa.eu/legalcontent/EN/TXT/?uri=OJ:L:2010:153:TOC.

[6] S. Attia et al. Overview and future challenges of nearly zero energy buildings (nZEB) design in Southern Europe, Energy and Buildings, 2017, vol 155, pp.439-458

[7] J. Schnieders, W. Feist, L. Rongen, Passive Houses for different climate zones, Energy and Buildings, 2015, vol. 105, pp. 71-87.

[8] S. Colcough, O. Kinnane, N. Hewitt, P. Griffiths, Investigation Of nZEB Social Housing built to the Passive House Standard, Energy \& Buildings, 2018, vol 179, pp. 344-359.

[9] S. K. M. Chvatal, H. Corvacho, The impact of increasing the building envelope insulation upon the risk of overheating in summer and an increased energy consumption, Journal of Building Performance Simulation, 2009, vol. 4, pp. 267-282.

[10] A. Pathan, A. Mavrogianni, A. Summerfield, T. Oreszczyn, M. Davies, Monitoring summer indoor overheating in the London housing stock, Energy and Buildings, 2017, vol. 141, pp.361-378.

[11] G. Murano, I. Ballarini, D.Dirutigliano, E.Primo, V. Corrado, The significant imbalance of nZEB energy need for heating and cooling in Italian climatic zones, Energy Procedia, 2017, vol. 126, pp. 258-265.

[12] S. Guillén-Lambea, B. Rodríguez-Soria, J.M. Marín, Comfort settings and energy demand for residential nZEB in warm climates, Applied Energy, 2017, vol. 202, pp 471-486.

[13] F. Ascione, R.F. De Masi, F. de Rossi, S. Ruggiero, G. P. Vanoli, Optimization of building envelope design for nZEBs in Mediterranean climate: Performance analysis of residential case study, Applied Energy, 2016, vol 183, pp. 938-957.

[14] A. Figueiredo, J. Kämpf, R. Vicente, Passive house optimization for Portugal: overheating evaluation and energy performance, Energy and Buildings, 2016, vol. 188, pp. 181-196.

[15] D. D'Agostino, D. Parker, A framework for the cost-optimal design of nearly zero energy buildings (NZEBs) in representative climates across Europe, Energy, 2018, vol. 149, pp. 814-829

[16] W. Wu, H. M. Skye, P. A. Domanski, Selecting HVAC systems to achieve comfortable and costeffective residential net-zero energy buildings, Applied Energy 212 (2018) 577-591.

[17] EU, 244/2012. Commission Delegated Regulation No 244/2012 of 16 January 2012. Supplementing Directive 2010/31/EU of the European Parliament and of the Council on the energy Performance of Buildings by Establishing a Comparative Methodology Framework for Calculating Cost-optimal Levels of Minimum Energy Performance Requirements for Buildings and Building Elements. Official Journal of the European Union.

[18] P.M. Congedo, C. Baglivo, D. D'Agostino, I. Zacà, Cost-optimal design for nearly zero energy office buildings located in warm climates, Energy, 2015, vol. 91, pp. 967-982 
[19]I. Zacà, D. D'Agostino, P.M Congedo, C. Baglivo, Assessment of costoptimality and technical solutions in high performance multi-residential buildings in the Mediterranean area, Energy and Buildings, 2015, vol. 102, pp. 250-265.

[20] D. D'Agostino, L. Mazzarella, What is a Nearly zero energy building? Overview, implementation and comparison of definitions, Journal of Building Engineering, 2019, vol. 21, pp. 200-212

[21] J. Kurnitskia, A. Saarib, T. Kalameesc, M. Vuolled, J. Niemeläd, T. Tarke, Cost optimal and nearly zero (nZEB) energy performance calculations for residential buildings with REHVA definition for nZEB national implementation, Energy and Buildings, 2011, vol. 43, pp. 3279-3288.

[22] E. Pikas, M. Thalfeldt, J. Kurnitski, R. Liias, Extra cost analyses of two apartment buildings for achieving nearly zero and low energy buildings, Energy, 2015, VOL. 84, pp. 623-633

[23] M.I Villa-Arrietaa, A. Sumperb, Economic evaluation of Nearly Zero Energy Cities Economic evaluation of Nearly Zero Energy Cities, Applied Energy 2019, vol. 237, pp. 404-416.

[24] P. Huang, Y. Sun, A clustering based grouping method of nearly zero energy buildings for performance improvements, Applied Energy, 2019, vol. 235, pp. 43-55.

[25] C. Becchio, M. C. Botterob, S. P. Corgnatia, C. Ghiglione, nZEB design: challenging between energy and economic targets, Energy Procedia, 2015, vol. 78, pp. $2070-2075$.

[26] V.M. Barthelmes, C. Becchio, S.P. Corgnati, C. Guala, M. Lequio, Replicability of nZEBs on real estate market in Mediterranean countries

[27] BPIE (Buildings Performance Institute Europe). Implementing the costoptimal methodology in EU countries. Pages 1-82. ISBN 9789491143083. http://bpie.eu/costoptimalmethodology.html

[28] E. Annunziata, M. Frey, F. Rizzi , Towards nearly zero-energy buildings: The state of art of national regulations in Europe, Energy, 2013, vol. 57, pp. 125-133

[29] CA EPBD, Concerted action EPBD: Implementing the energy performance of buildings directive (EPBD). Information of the joint initiative of EU Member States and the European Commission, Available at: http://www.epbd-ca.eu/themes/cost-optimum.

[30] S. Attia, Net Zero Energy Buildings (NZEB), 1st Edition, Butterworth-Heinemann, 2018

[31] Hamdy, M., Siren, K., Attia, S., Impact of financial assumptions on the cost optimality towards nearly zero energy buildings: a case study. Energy and Buildings, 2017, vol. 153, pp. 421- 438.

[32] Buildings Performance Institute Europe (BPIE), Europe's buildings under the microscope: A country-by-country review of the energy performance of buildings.

[33] M. Ferrara, V. Monetti, E. Fabrizio, Cost-Optimal Analysis for Nearly Zero Energy Buildings Design and Optimization: A Critical Review, Energies, 2018, vol. 11, n. 1478.

[34] B. Heymer, Sh. Pless, S. Hackel, 2016. Zero net energy building cost and feasibility. Webinar. Available from: http://www.seventhwave.org/sites/default/files/zero-energywebinar-slides052616.pdf (accessed 20.01.18).

[35] DM 26 giugno 2015: Application of calculation methodologies for energy performance and definition of prescription and minimum requirements of buildings. 2015.

[36] Dlsg 28/2011: Implementation of Directive 2009/28/CE on the promotion of the use of energy from renewable sources and amending and subsequently repealing Directives 2001/77/EC and 2003/30/EC, 2011.

[37] PANZEB: Piano d'Azione Nazionale per incrementare gli edifici ad energia quasi zero, 2016. Available at.:

http://www.sviluppoeconomico.gov.it/images/stories/normativa/all_decreto_interministeriale_19 _giugno_2017_panzeb.pdf

[38] CoNZEBs - Solution sets for the cost reduction of new Nearly Zero-Energy Buildings, EU H2O2O Funded Project, Contract number 754046 (www.conzebs.eu)

[39] V. Corrado, I. Ballarini, S. Paduos, Sviluppo della metodologia comparativa costoptimal secondo Direttiva 2010/31/UE, Ricerca di sistema elettrico, Report RdS/2013/144.

[40]C. Buttà: Personal Communication, Mydatec.

[41] H. Erhorn-Kluttig, H. Erhorn, B. Utesch, K. Wittchen, K. Engelund Thomsen, O. Mørck, O. Baslev-Olsen, M. Jungshoved, M. Zinzi, B. Mattoni, M. Šijanec-Zavrl, D. Varšek, 2018, Overview of Cost Baselines for three Building Levels, Report of CoNZEBs Project, available at www.conzebs.eu. 
[42] EN15251- Indoor environmental input parameters for design and assessment of energy performance of buildings addressing indoor air quality, thermal environment, lighting and acoustics, 2007.

[43] TRNSYS 17. Available online at www.trnsys.com

[44]EDILCLIMA EC700. https://www.edilclima.it/

[45] UNI/TS 11300: Parte 1 - Determinazione del fabbisogno di energia termica dell'edificio per la climatizzazione estiva ed invernale, 2014.

[46] UNI EN ISO 6946:2008: Componenti ed elementi per edilizia - Resistenza termica e trasmittanza termica - Metodo di calcolo,2008.

[47] Prezzi Informativi dell'edilizia, Nuove costruzioni, DEI, Febbraio 2018

[48] Miliani, A.: Personal communication, Xella Italia S.r.I.

[49] Paolini, A.: Personal communication, Giuliani S.C.

[50] J. Kurtnitskij, A. Saari, T. Kalamees, M. Vuolle, J. Niemela, T. Tark, Cost optimal and nearly zero (nZEB) energy performance calculations for residential buildings with REHVA definition for nZEB national implementation. Energy and Buildings, 2011, vol. 11, pp. 3279-3288.

[51]UNI EN 15459-1: Energy Performance of Buildings-Economic evaluation procedure for energy systems in buildings -Part 1, 2018.

[52] Riva, G.: Personal communication, 2017.

[53] Allegato A alla delibera ARG/elt 74/08 - Testo integrato delle modalità e delle condizioni tecnico economiche per lo scambio sul posto - Available at: https://www.arera.it/allegati/docs/08/07408argall2.pdf

[54] GSE Gestore Servizi Energetici. Available at: https://www.gse.it/

[55] Valori del corrispettivo unitario di scambio forfetario per l'anno 2017, 03 aprile 2018. Available at: https://www.arera.it/it/comunicati/18/180403.htm

[56] G.Iwashita, H. Akasaka, The effects of human behavior on natural ventilation rate and indoor air environment in summer- a field study in southern Japan, Energy and Buildings, 1997, vol. 25, pp. 195-205

[57] C. Howard-Reed , L.A. Wallace, W. R. Ott , The Effect of Opening Windows on Air Change Rates in Two Homes, Journal of the Air \& Waste Management Association, 2002, vol. 52:2, pp. 147-159.

[58] P.R. Warren, Ventilation through openings on one wall only, in: International Conference Heat and Mass transfer in Buildings, Dubrovnik, Yugoslavia, 1977. 


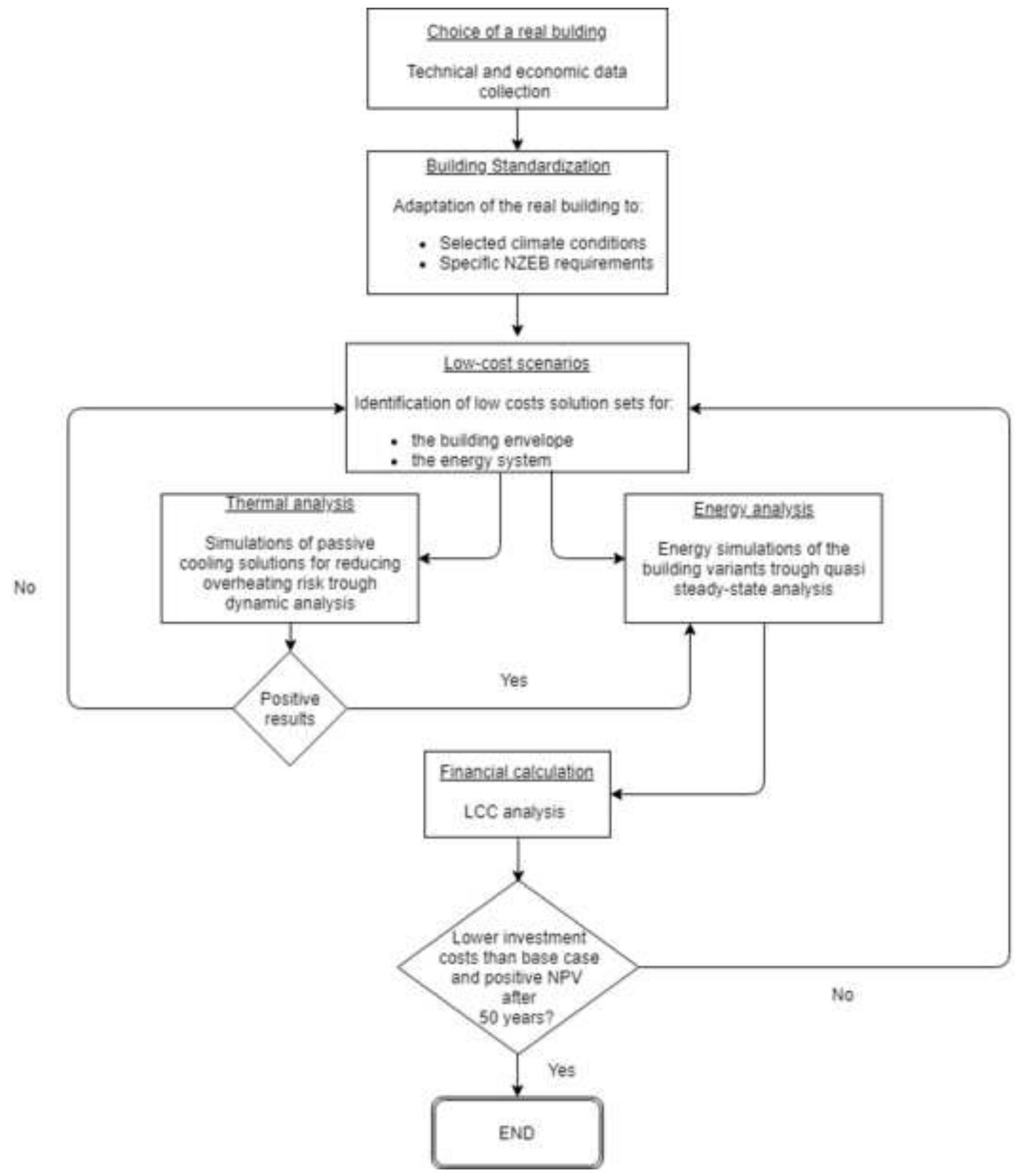


Click here to download high resolution image
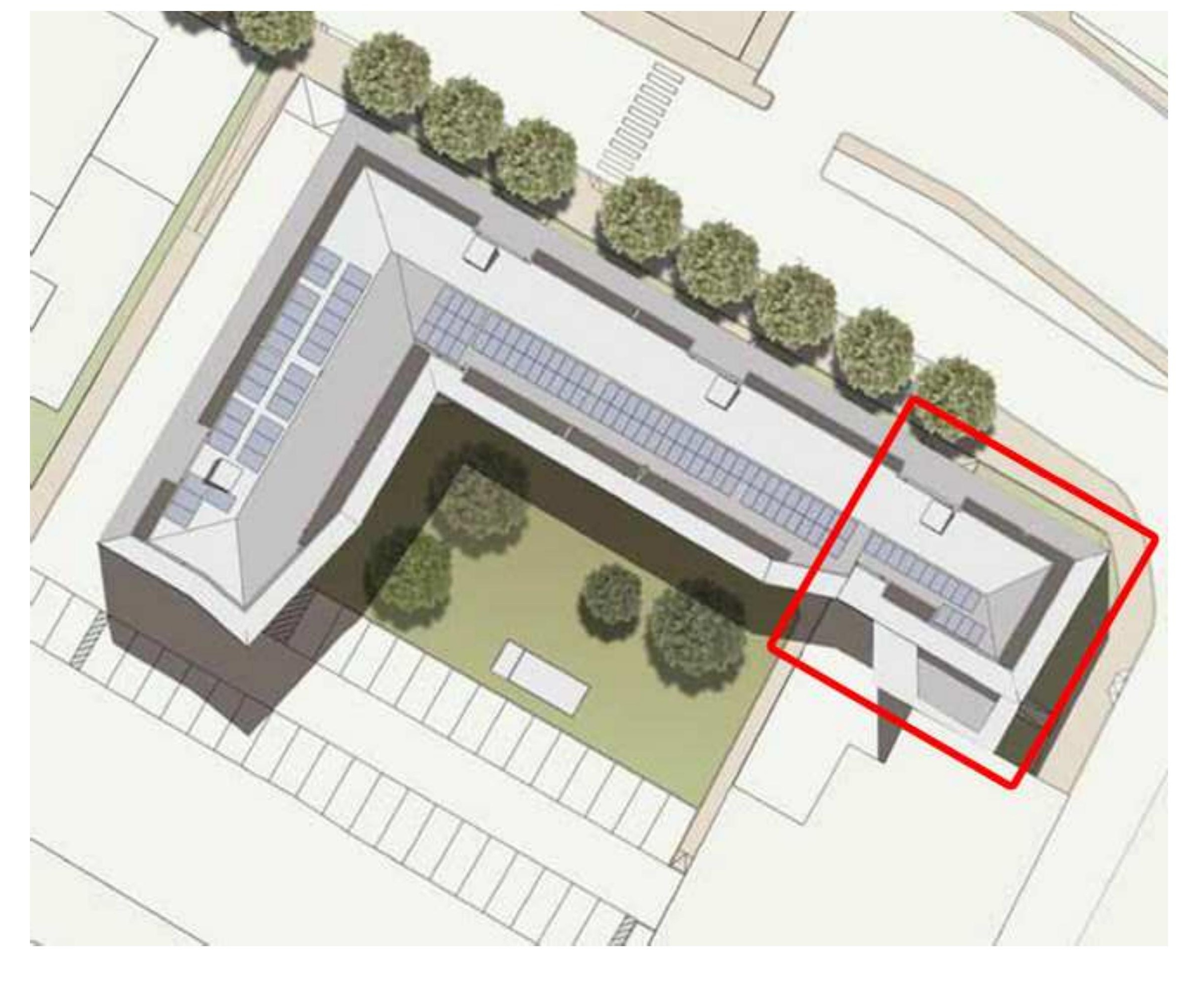

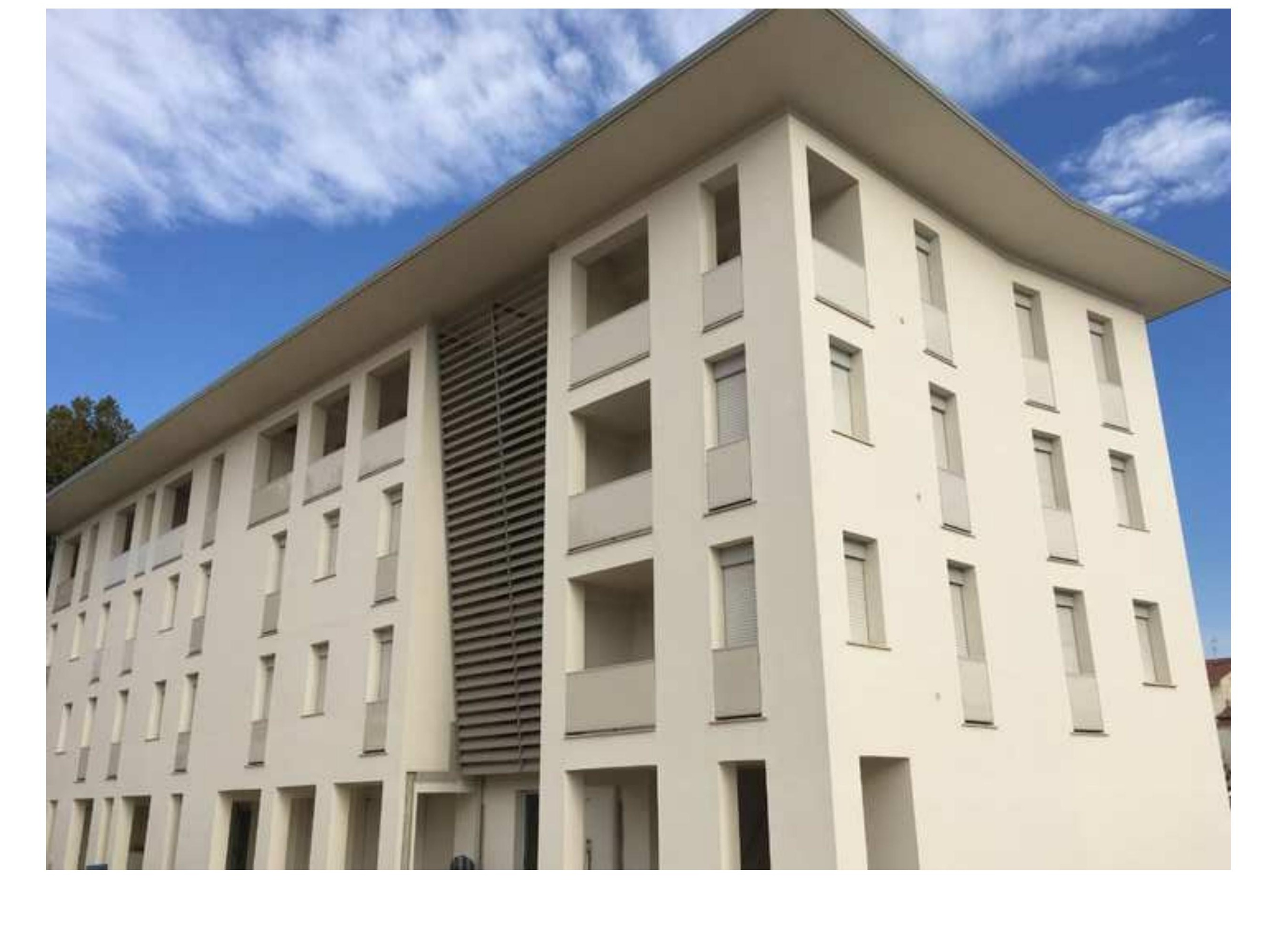


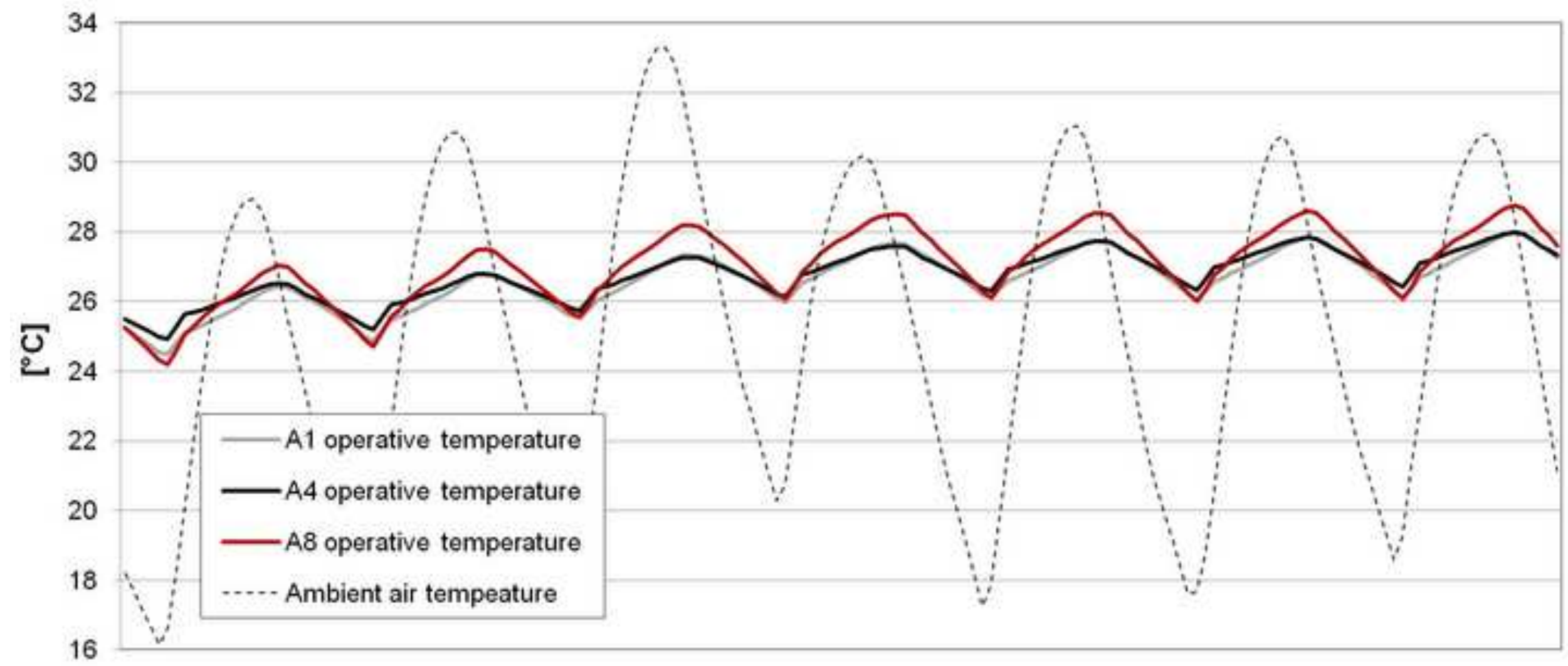

hours $[-]$ 
Click here to download high resolution image
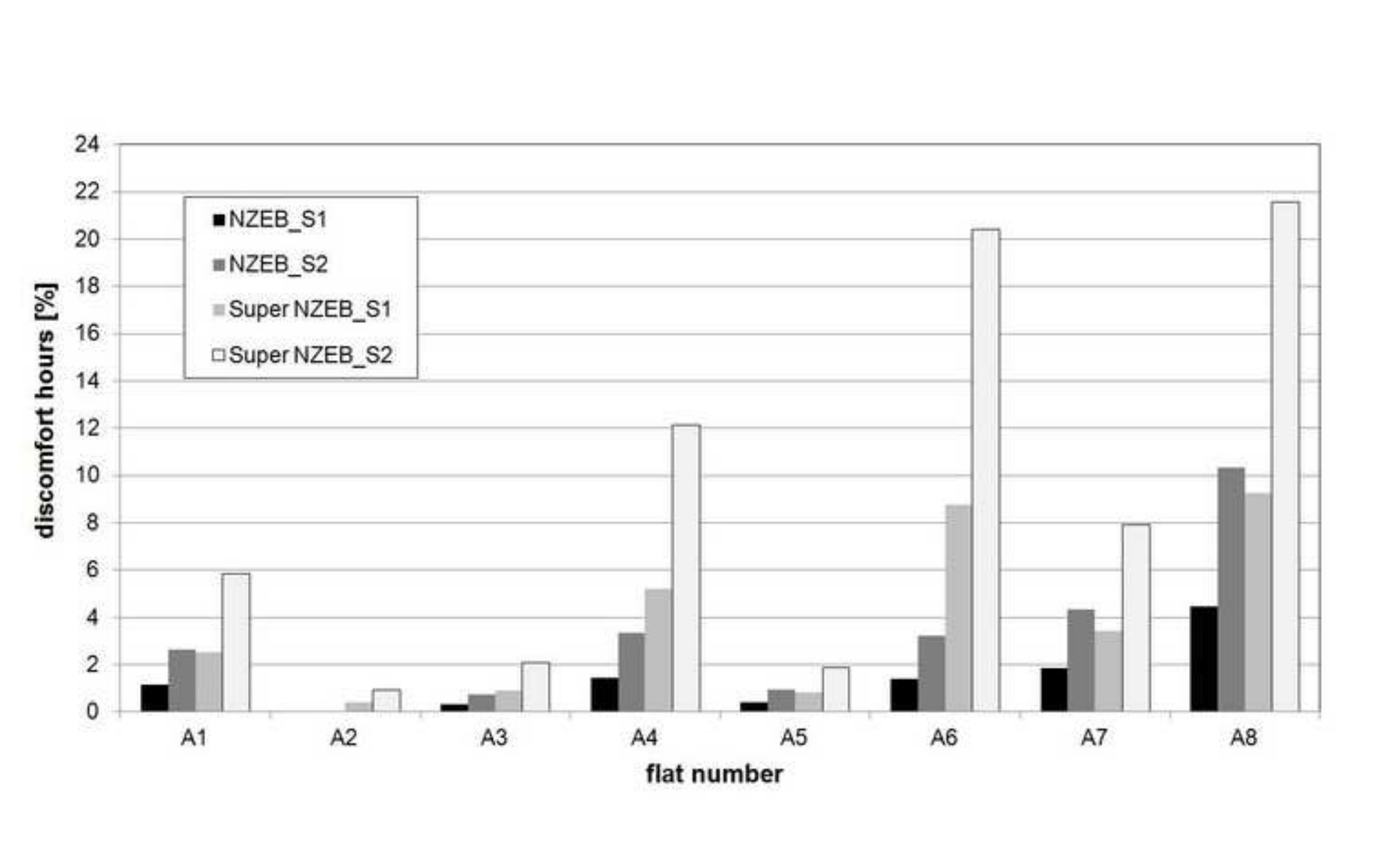

\begin{abstract}
(
\end{abstract}

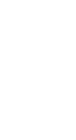

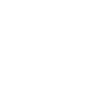

. 


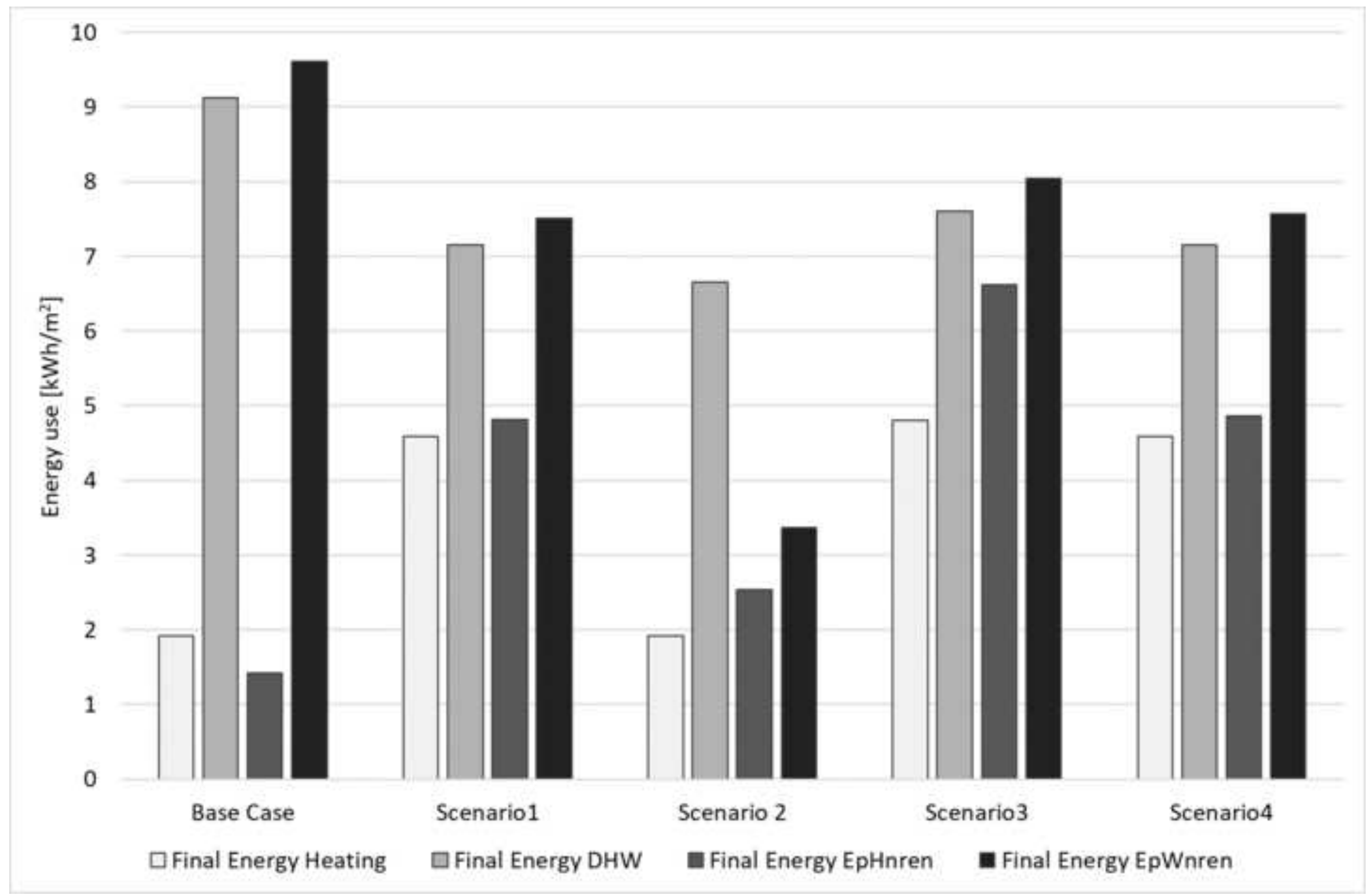




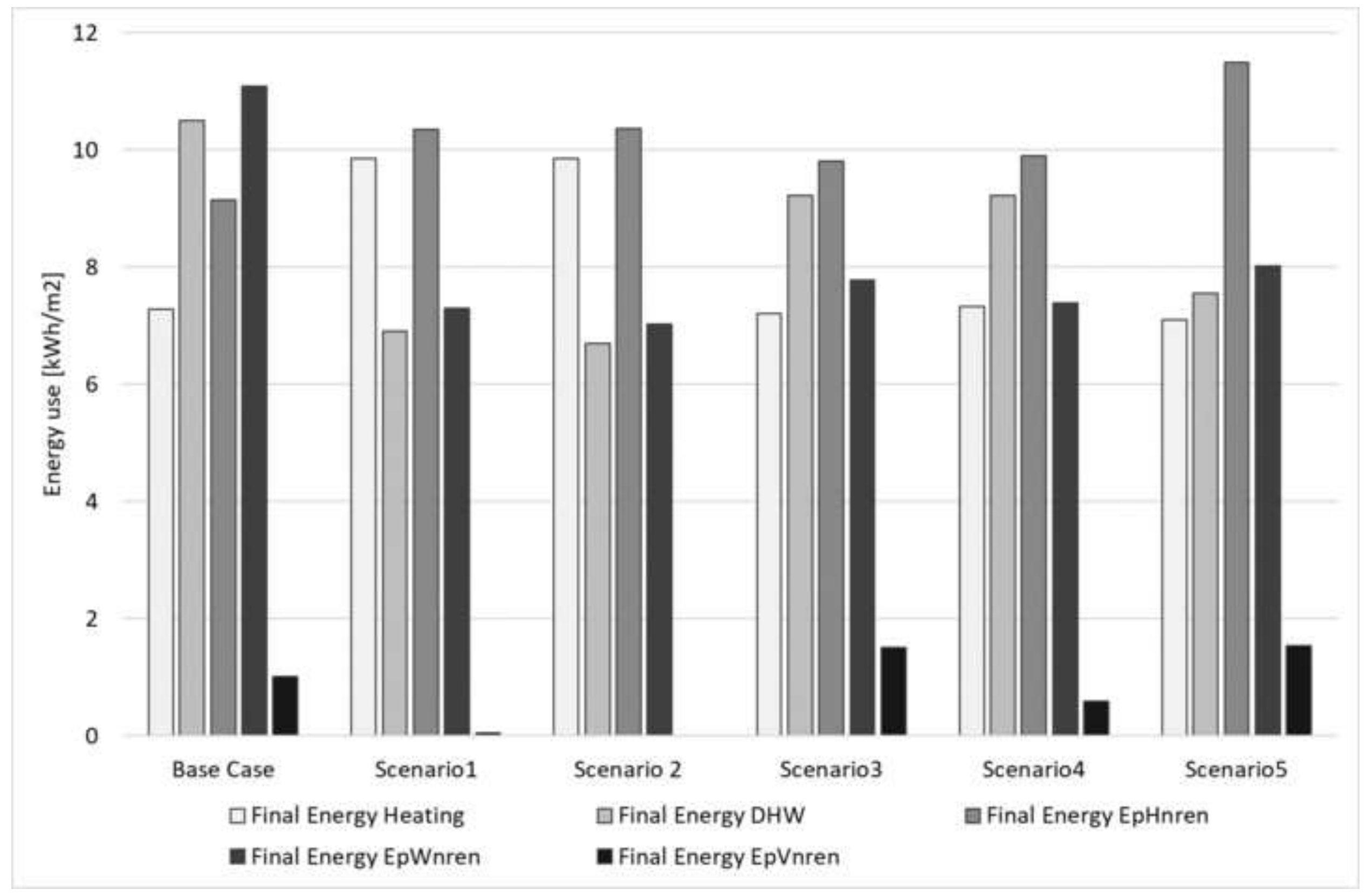


Click here to download high resolution image

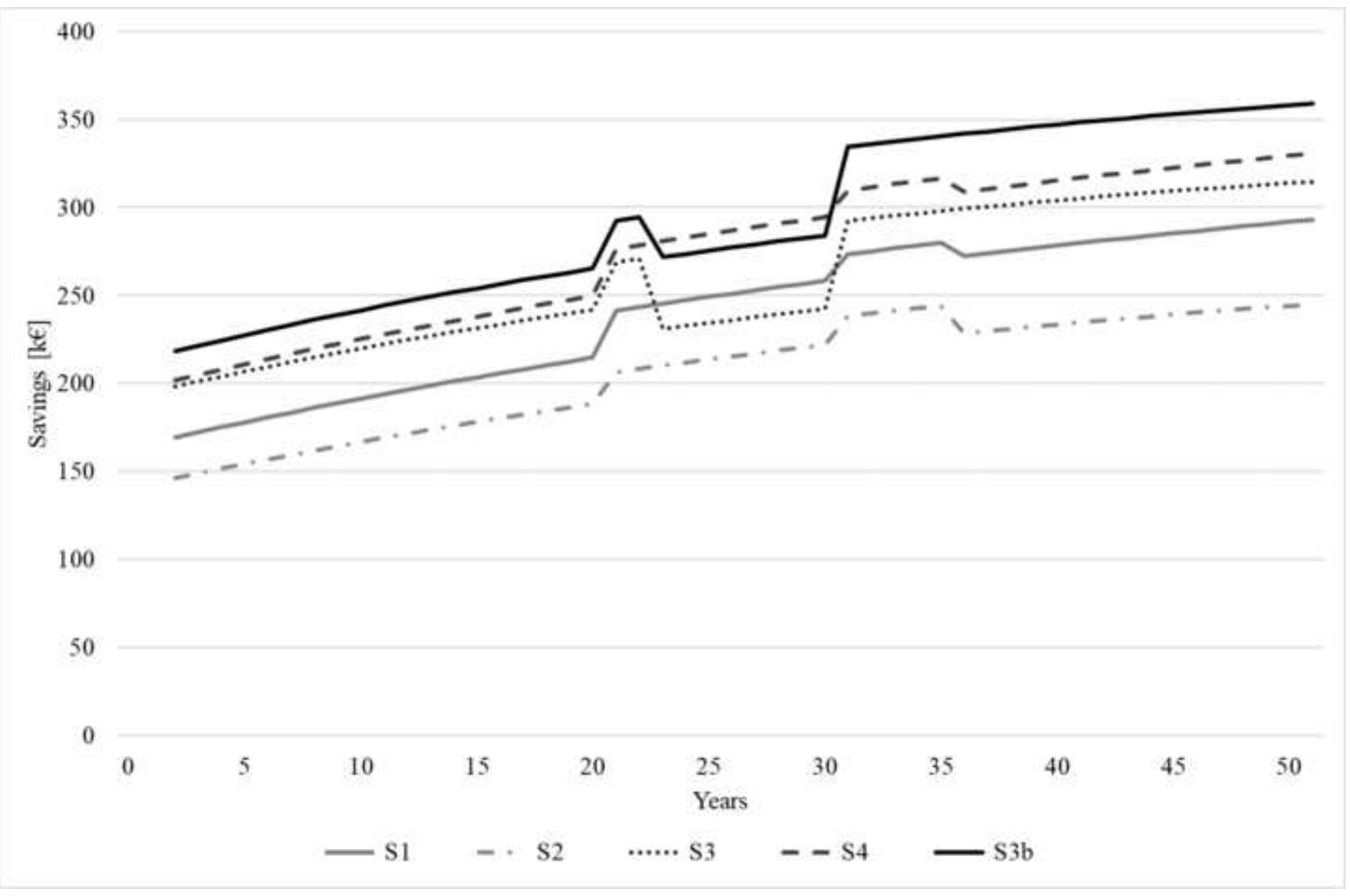

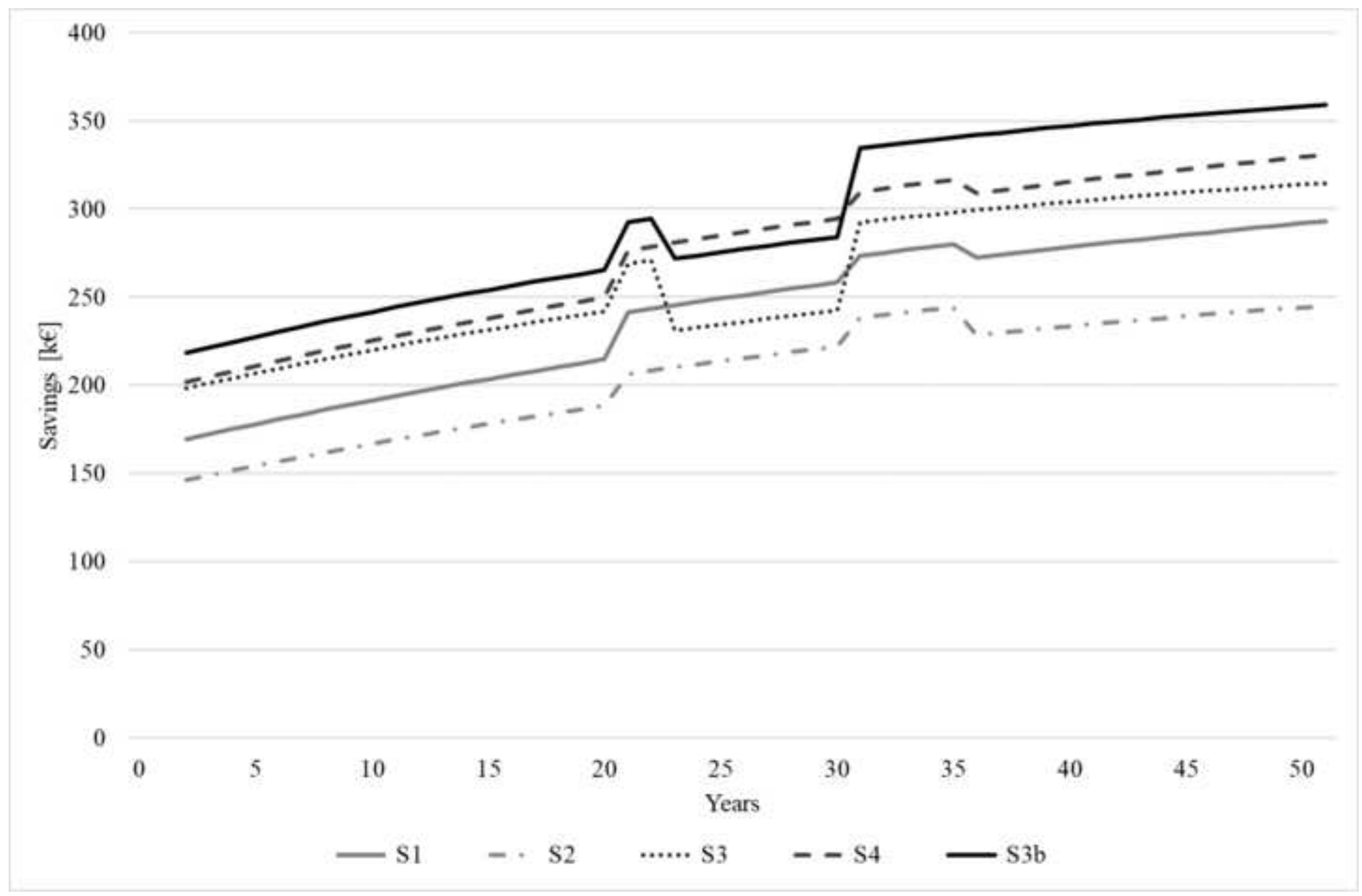


Click here to download high resolution image

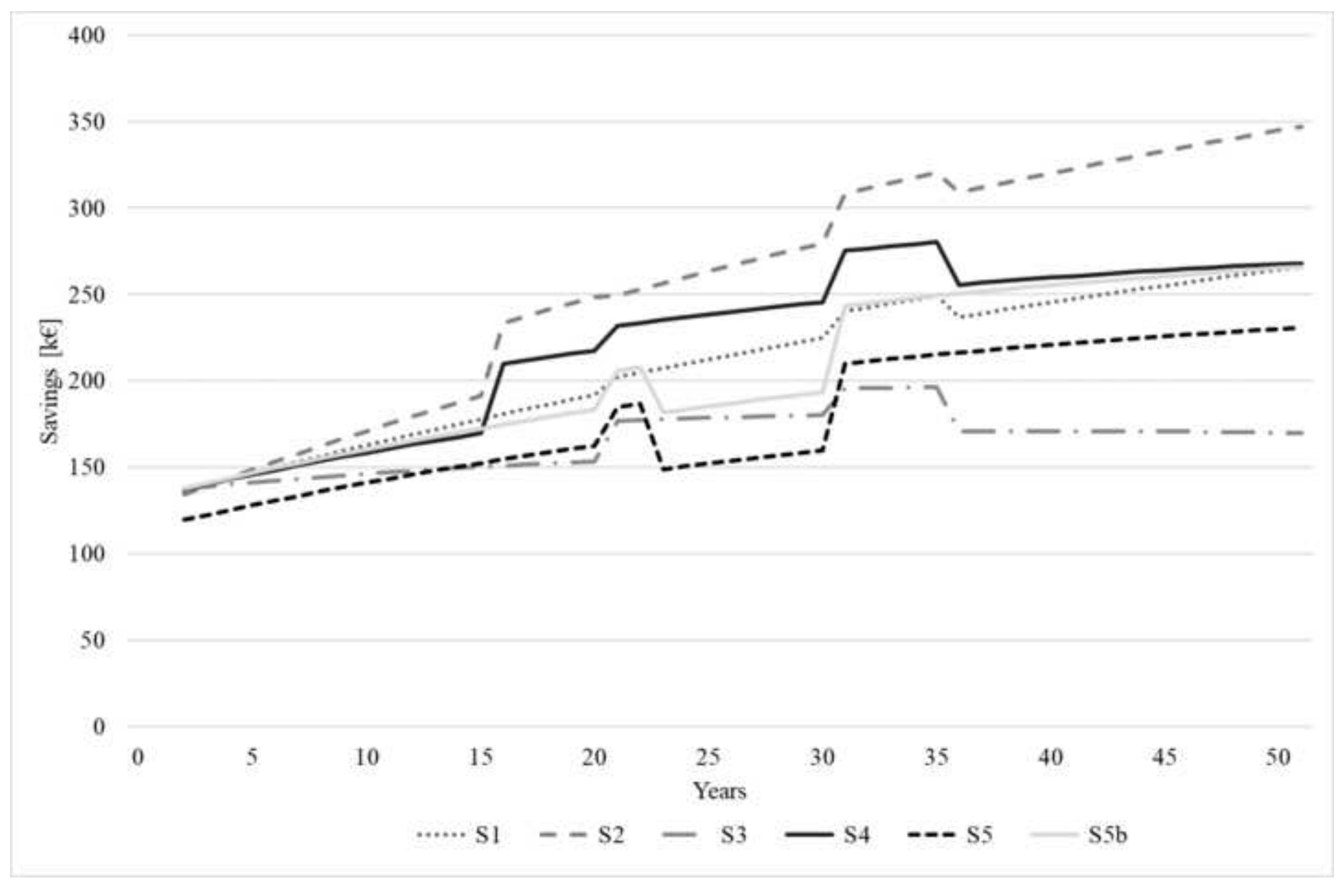

